\title{
I. Nationale Fraktionierung, Konkurrenz, Kooperation: Das Industrieverbandswesen
}

\section{Vorgeschichte, Gründung, Auf- und Ausbau}

Die Entstehungsgeschichte des tschechoslowakischen Industrieverbandswesens hängt mit dem Zerfall des Habsburger Staats und der Geburt der Ersten Republik eng zusammen. War in der Zeit der Monarchie die Industrie der böhmischen Länder im „Verband der Industriellen in Prag und Umgebung“, einer dem „Bund österreichischer Industrieller" angeschlossenen, „supranationalen“ Vereinigung organisiert", so prägten nationale Separierung und eine deutsch-tschechische Doppelung der Organisation zumindest die erste Nachkriegszeit. Ausdifferenzierung neuer Institutionen aus dem Industrieverbandswesen der Monarchie und Ausfällung der nationalen Elemente gingen ineins. Führte dies zu beziehungslos nebeneinander existierenden, komplementären oder gar sich überschneidenden Strukturen?

\section{a) Der Zentralverband der tschechoslowakischen Industriellen (Ústrèni svaz československých primyslniku - ÚSČP)}

Ab 1916 und insbesondere im Zeichen des herannahenden Kriegsendes wuchs in der böhmischen und der mährischen Unternehmerschaft das Bewußtsein der Dringlichkeit von Vorbereitungen für eine eigenständige industrielle Interessenvertretung in einem künftigen tschechoslowakischen Staat. Kristallisationskern dieser Bestrebungen war der mährische Industriellenverein. Von dessen drei Fachgruppen war die wichtigste die der Schuhwirtschaft, geleitet von dem „Schuhkönig “ Tomáśs Bat' a; Sekretär der mährischen Organisation, für deren Aufschwung er maßgeblich verantwortlich zeichnete, war seit 1911 František Hodác. Als im Juli 1917 die Generalversammlung des Verbandes als wichtigstes Ziel für die nähere Zukunft die Gründung einer zentralen Organisation der Wirtschaft in Böhmen und Mähren proklamierte, hatte Hodáč bereits die Verbindung zu einflußreichen Persönlichkeiten des tschechischen Wirtschaftslebens geknüpft. ${ }^{2}$ Am 14. Dezember des gleichen Jahres beratschlagte das Präsidium des mährischen Industriellenvereins über die Anbahnung von Kontakten zur Industrie in Böhmen, wo sich inzwischen, unabhängig von den Entwicklungen in Mähren, ähnliche Bestrebungen gezeigt hatten. ${ }^{3}$

Daß von beiden Seiten diese Fäden gesponnen wurden, hing nicht nur mit der zunehmend konkreter werdenden Perspektive der staatlichen Selbständigkeit zusammen. Ein

1 Stanovy jednoty průmyslníků v Praze a okolí. Odbor Zentralverbandu rakouských průmyslníků, Prag 1903. (Statuten des Verbandes der Industriellen von Prag und Umgebung, Sektion des Bundes österreichischer Industrieller).

2 OB 15 (1933), S. 247-250.

3 OB 15 (1933), S. $248 f$. 
vorgängiger Anlaß war die Kriegswirtschaft gewesen, in der sich die mährische Industrie durch die Modalitäten der von den Wiener Zentralbehörden gesteuerten Rohstoffzuteilung benachteiligt fühlte. Nicht von ungefähr schloß sich die am meisten in Mitleidenschaft gezogene Fachgruppe der Schuhwirtschaft als erstes mit dem Verein der Schuhfabrikanten für Böhmen, Mähren und Schlesien zusammen. ${ }^{4}$ Bis zum Tag des Umsturzes verstand sich die im Entstehen begriffene nationale Organisation in erster Linie als Schutzvereinigung zur Wahrung der eigenen Belange gegenüber Wien. Erst mit der Gründung des tschechoslowakischen Staates trat diese defensive Ausrichtung in den Hintergrund. ${ }^{5}$ Die Entwicklung, die, ausgehend von der mährischen Keimzelle, zügig auf ein die ganze spätere tschechoslowakische Republik umspannendes Gebilde zusteuerte ${ }^{6}$, beschleunigte sich im Frühling und Frühsommer des letzten Kriegsjahres. Anfang Mai 1918 leitete Hodáč die Genehmigung der Statuten und die Vorbereitungen für die erste Vollversammlung in die Wege. ${ }^{7}$ Die Gründungsversammlung des Zentralverbandes der tschechoslowakischen Industriellen fand am 18. Juni 1918 statt. Auf ihr waren vorläufig nur die tschechischen Unternehmer vertreten; man warb allerdings sogleich auf dem gesamten Staatsgebiet der späteren Republik für zügigen und massenhaften Beitritt. ${ }^{8}$

War der Aktionsradius des Zentralverbands anfänglich auch auf Böhmen und Mähren beschränkt - das Verbandsorgan erschien, bezeichnend für die mährischen Wurzeln der Vereinigung, unter der Bezeichnung "Průmyslový věstník“ noch bis Anfang 1919 in Brünn'-, so verstand er sich doch von Anfang an als gesamtstaatliche Organisation, der laut Statuten die Wahrung und Förderung der industriellen Interessen oblag. ${ }^{10}$ Grundsätzlich stand die Mitgliedschaft deshalb nicht nur tschechischen Unternehmern, sondern auch solchen anderer Nationalität bzw. solchen mit andersnationaler Kapitalbeteiligung offen. Folgerichtig umfaßte der Zentralverband bald auch die slowakische Industrie und zählte, aus anderweitig zu erläuternden Gründen, zudem eine stattliche Reihe „deutsch" firmierender Unternehmen zu seinen Mitgliedern. ${ }^{11}$ Die Vollversammlung vom 10. Mai 1919 trug dieser Entwicklung auch formal Rechnung, da eine Aktualisierung der Statuten den Verband nun ausdrücklich zum Repräsentanten der gesamten tschechoslowakischen Industrie erklärte. ${ }^{12}$

${ }^{4}$ OB 15 (1933), S. 248.

5 SÚA, ÚČ́P, Karton 10, Rede Malinskýs, Vollversammlung des Zentralverbands am 10. 5. 1919. Viškovský, Zentralverband, passim.

6 SÚA, ÚSČP, Karton 10, Rede Kováŕiks, Gründungsversammlung des Zentralverbands am 18.6.1918.

7 ANB, ŽB, S VII/i-1-I, Hodáč an Preiss, 8. 5.1919.

8 SÚA, ÚSČP, Karton 24, 0/50/1, Mitteilungsschreiben des Zentralverbands über die Gründung an die Firmen vom 19.6.1918.

9 SỨ, ÚSČP, Karton 10, Protokoll der Sitzung des Präsidialausschusses des Zentralverbands am 18.9. 1918.

10 SÚA, NL Hodáč, Karton 263, Statuten des Zentralverbands (Stanovy ústředního Svazu československých průmyslníků se sídlem v Praze), undatiert.

11 SÚA, ÚSČP, Karton 10, Protokoll der Sitzung des Präsidialausschusses am 18. 9. 1918.

12 SÚA, ÚSČP, Karton 10, Behandlung der Änderungsfrage auf der Vollversammlung am 10.5. 1919. - SÚA, ÚSČP, Karton 21, 0/0/1-0/3/1 (1918-1948), Auszug aus dem Protokoll der Generalversammlung des Zentralverbands am 10. 5. 1919. - Ebenda, Mitteilung Zentralverband an Politische Landesverwaltung vom 3. 11. 1919. - Ebenda, Neue Statuten, undatiert, deutsche Fassung. 
Ungeachtet der proklamierten nationalen Offenheit fühlte sich der Zentralverband allerdings dezidiert der "tschechoslowakischen Identität" der Republik verpflichtet. Aufgabe der Organisation sei es, so Gründungspräsident František Malinský auf der Vollversammlung vom 10. Mai 1919, "nach dreihundert Jahren Knechtschaft" am Aufbau des Nationalstaates mitzuwirken. ${ }^{13}$ Nicht von ungefähr hatte der Nationalausschuß in den Tagen des Umbruchs den Zentralverband als seinen verlängerten Arm mit der Durchführung der Anordnung vom 29. Oktober beauftragt, derzufolge bis auf weiteres alle Betriebe ohne Änderungen weiterzuführen waren. ${ }^{14}$ Loyalität zum Staat bedeutete, zumindest in der Praxis, nicht parteipolitische Neutralität: In den Anfangsjahren der Republik waren die Affinitäten des Zentralverbands zur nationaldemokratischen Partei, in der die industriellen Interessen sich am ehesten aufgehoben wußten, eng. Malinský war einige Monate lang nationaldemokratischer Abgeordneter in der Vorläufigen Nationalversammlung. ${ }^{15}$ Abgeordnete waren auch Jaroslav Preiss und - ab 1929 - Hodáč. Als Forum für zwanglose Begegnungen und Diskussionen diente der Ende 1920 von der Partei eingerichtete „Industrieklub“. ${ }^{16}$

Der Zentralverband hatte sich nicht von der österreichischen Industrieorganisation „losgesagt“, sordern war von dieser ohne abrupten Bruch abgedriftet. Eine Mitgliedschaft böhmischer und mährischer Unternehmen in der Wiener Organisation war zunächst weiterhin statthaft, wenn sie auch bereits vor dem endgültigen Auseinanderbrechen der Monarchie von der Spitze nicht mehr gerne gesehen wurde. Der Beitritt neugegründeter Unternehmen zum österreichischen Verband galt zumindest als überflüssig, und auch von den Altmitgliedern wurde erwartet, daß sie den Zentralverband als ihre Vertretung betrachteten..$^{17}$ Im Oktober 1918 quittierte der Präsidialausschuß die Klagen einer Reihe von Firmen, „Wien“ verlange von den tschechischen Unternehmen hohe Beiträge, ohne entsprechende Leistungen zu erbringen, mit dem Beschluß, man solle sich von nun an mit der Abführung der Beiträge in die alte Hauptstadt nicht mehr sputen und die Gelder zur Disposition des Zentralverbands halten. ${ }^{18}$ Ausdruck der Trennung, andererseits aber auch ein Indiz für die fortbestehenden engen Verflech-

13 SÚA, ÚSČP, Karton 10, Rede Malinskýs, Vollversammlung des Zentralverbands am 10.5. 1919.

14 SÚA, ÚSČP, Karton 24, 0/50/3, Nationalausschuß an Zentralverband, 30.10.1918.

15 Er gab allerdings - die Gründe waren nicht zu eruieren - sein Mandat bereits vor der Mitte des November 1919 wieder auf, was der Präsidialausschuß mit Bedauern zur Kenntnis nahm: Vgl. SÚA, ÚSČP, Karton 21, Korrespondenz Hodáč 0/2/1, Protokoll der Sitzung des Präsidialausschusses am 17.11.1919.

16 Anlaß der Gründung waren die Wirtschaftskrise der Nachkriegszeit und die hierdurch verursachten Probleme der Industrie. Vorsitzender war der spätere Handelsminister Ladislav Novák. Vorgesehen war die Veranstaltung von Expertenvorträgen mit Diskussion; in den Räumen des Národní klub sollte ein wöchentlicher Jour fixe eingerichtet werden. Anläßlich wichtiger politischer Entscheidungen erbat der Klub die Teilnahme Hodáčs. Vgl. das „Vorstellungs- und Einladungsschreiben" des Industrieklubs, undatiert. - SÚA, NL Hodáč, Karton 14, Industrieklub an Hodáč, 14. 12. 1920 und 4.3.1921.

17 SÚA, ÚSČP, Karton 24, 0/50/2, Protokoll der Sitzung des Präsidialausschusses des Zentralverbands am 18. 9.1918.

18 SÚA, ÚSČP, Karton 24, 0/50/2, Auszug aus dem Protokoll der Sitzung des Präsidialausschusses des Zentralverbands am 18.10.1918. 
tungen mit der Wirtschaft Österreichs war im Herbst 1918 der Beschluß zur Errichtung einer Geschäftsstelle in Wien. ${ }^{19}$

Das Sozialprofil der Verbandsführung reflektierte den Kampf des tschechischen Volkes um seine wirtschaftliche Emanzipation im letzten Drittel des 19. Jahrhunderts: Gründungspräsident Malinský und seine Stellvertreter František Kovářík, Hanuš Karlík und Josef Bartoň, sämtlich geboren in den fünfziger oder sechziger Jahren des 19. Jahrhunderts, hatten als Industrielle der ersten Generation den Aufstieg der nationalen Ökonomie der Tschechen miterlebt, wenn nicht gar maßgeblich mitgestaltet. In den leitenden Positionen des Zentralverbandes begegnen, bezeichnend für die in industriegeschichtlicher Perspektive ,junge" und moderne tschechische Wirtschaft, überwiegend Persönlichkeiten mit technisch-akademischer Fachbildung; neben selbständige Einzelunternehmer treten bereits Manager. Nicht von ungefähr rekrutierte sich die Verbandselite vorzugsweise aus den überwiegend tschechischen Wirtschaftszweigen wie der nahrungsmittel- und der metallverarbeitenden Industrie, daneben auch aus dem tschechischen Bankwesen. Das Führungspersonal hatte bereits unter der Monarchie in exponierter Position vielfältige Erfahrungen in der Verbandspolitik oder in den Handelsund Gewerbekammern sammeln können; daß es auch politisch der tschechischen Emanzipationsbewegung nahestand, überrascht nicht.

Dieses Muster findet sich auch bei den Angehörigen des Präsidialausschusses, bei Eugen Škarda, Jan Roskošný, František Hodáč, J. Prokop, Karel Vogl, Jaroslav Preiss, Rudolf Hotowetz, Jan Samek, Bohuslav Mařík und Rudolf Bárta. Hodáč, gut eine Generation jünger als die übrigen Mitglieder des Präsidiums, von Beruf Dozent der Wirtschaftswissenschaften, hatte keine unternehmerische Praxis vorzuweisen, verfügte durch seine Tätigkeit für die mährische Industriellenvereinigung jedoch über reiche Erfahrung im Verbandsmanagement. Nicht zuletzt deshalb wurde er, obwohl noch nicht einmal 35 Jahre alt, in der Gründungsversammlung zum Generalsekretär gewählt. Im Mai 1919 trug man - anläßlich der Verstärkung des Präsidialausschusses - durch die Zuwahl Theodor Liebiegs und des Generaldirektors der Wittkowitzer Werke, Sonnenschein, der Mitgliedschaft auch vieler deutscher bzw. deutsch-jüdischer Unternehmen Rechnung. In Aussicht genommen wurden weitere Kooptationen durch das Präsidium, die der slowakischen Industrie eine angemessene Vertretung sichern sollten. ${ }^{20}$

Von einer Kanzlei aus, die - bezeichnend für den maßgeblichen Einfluß der Živnostenská banka im Zentralverband - zunächst von dieser unterhalten wurde, tetrieb Alois Viškovský, früher Sekretär der Handels- und Gewerbekammer in Königgrätz, den Aufbau der Branchenorganisation. Diese für den Zentralverband charakteristische Gründung „von der Spitze abwärts“ war darauf zurückzuführen, daß unmittelbar nach der Gründung des tschechoslowakischen Staates am Regierungssitz eine Organisation zur Wahrung der industriellen Interessen präsent sein mußte. Zum Zeitpunkt der ersten Besprechungen im Vorfeld der Konstituierung des Verbandes hatten in Böhmen und Mähren nur wenige, verstreute Fach- bzw. örtliche Organisationen des Bundes österreichischer Industrieller existiert, etwa für die Zucker-, die Textil- und die Maschinenindu-

19 SÚA, ÚSČP, Karton 10, Protokoll der Sitzung des Präsidialausschusses des Zentralverbands am 18. 9.1918.

20 SƯA, ÚSČP, Karton 10, Vollversammlung des Zentralverbands am 10.5.1919. - Viškovský, Zentralverband, passim. 
strie, für das graphische Gewerbe und die Bierbrauerei. ${ }^{21}$ Dieser lückenhafte Unterbau wurde nun durch die Errichtung von insgesamt 19 Fachgruppen für alle bedeutenderen Branchen komplettiert. Existierende Fachverbände wie der Verband der Textilindustriellen oder der Maschinenbauer wurden aufgefordert, die Funktion von Fachgruppen zu übernehmen. Wo bisher utraquistische - binationale - Fachorganisationen bestanden hatten, sollten neue, tschechische Verbände gegründet werden, wenn die utraquistische Vereinigung sich ihren Aufgaben nicht gewachsen zeigte oder nicht „unparteiisch“ arbeitete. Verstärkt galt dies dort, wo nur deutsche Vereinigungen existierten. Der Präsidialausschuß einigte sich in der Sitzung vom 18. Oktober 1918 allerdings darauf, daß Funktionen einem utraquistischen Verband anvertraut werden konnten, ,insoweit er im tschechischen Geist geführt werde" - was immer dies konkret bedeuten mochte. ${ }^{22}$

Das Schwergewicht der Verbandsaktivitäten verlagerte sich bald in die Untergliederungen der Fachgruppen, die Sektionen. Anfang 1920 bestanden bereits 77 Sektionen, von denen lediglich 15 schon vor dem Umsturz existiert hatten ${ }^{23}$; Mitte 1921 gab es 105 Sektionen. ${ }^{24}$ Einer auf der Generalversammlung von 1922 verabschiedeten Statutenänderung zufolge beinhaltete bereits die Zugehörigkeit zu einer Fachgruppe automatisch die Mitgliedschaft im Zentralverband. War anfangs die direkte Mitgliedschaft dort die Regel gewesen, so wurden die Unternehmen in der Folgezeit mehr und mehr "mediatisiert ${ }^{\text {“ }}{ }^{25}$ Damit ging eine Verlagerung der Entscheidungsbefugnisse vom Zentralverband in den Zentralausschuß der Delegierten der Fachgruppen und Sektionen einher, der jetzt auch die grundsätzlichen wirtschaftspolitischen Stellungnahmen des Verbandes erarbeitete. ${ }^{26}$ Sitzungen dieses Gremiums fanden im Abstand von ein bis zwei Monaten statt; die Delegierten stimmten auf der Grundlage der Beschlüsse „ihrer“ Generalversammlungen $a b^{27}$

Wichtige Abteilungen der zentralen Organisation wie das handelspolitische oder das Finanzreferat wurden von "Komitees“, bestehend aus Repräsentanten der Orts- bzw. der Fachgruppen, geleitet. Die hierdurch ermöglichte Einbindung mehrerer hundert Mitglieder in die Verbandsarbeit erweiterte die Partizipationschancen des "rank and file" nicht unwesentlich. ${ }^{28}$ Der direkte Verkehr des Zentralverbands mit seinen Mitgliedsfirmen wurde im Zuge dieser Entwicklung eingeschränkt bzw. auf die nachgeordneten Organisationen verlagert, so daß das Präsidium und der Zentralausschuß der Delegierten sich ungeteilt den Grundsatzfragen widmen konnten. ${ }^{29}$ Prinzipiell intervenierte der Zentralverband nur dort, wo die Belange aller involvierten Branchen auf einen

21 Viškovský, Zentralverband, S. 5 f. - Hodáč, Organisationsfragen.

22 SÚA, ÚSČP, Karton 24, O/50/2, Protokoll der Sitzung des Präsidialausschusses am 18.9.1918 und Auszug aus dem Protokoll der Sitzung am 18.10.1918.

23 Viškovský, Zentralverband, S. 7.

24 Rede Hodáčs, Vollversammlung des Zentralverbands am 28. 5. 1921, in: OB 3 (1921), S. 344.

25 Vollversammlung des Zentralverbands am 27. 5. 1922, in: OB 4 (1922), S. 5. - Rede Hodáčs, Vollversammlung des Zentralverbands am 25. 5. 1923, in: OB 5 (1923), S. 357.

26 Sitzung des Präsidialausschusses am 30.3.1920, Protokoll in: OB 2 (1920), S. $188 \mathrm{ff}$.

27 Rede Hodáčs, Vollversammlung des Zentralverbands am 25. 5. 1923, Protokoll in: OB 5 (1923), S. 357.

28 Rede Hodáčs, Vollversammlung des Zentralverbands am 28. 5. 1921, in: OB 3 (1921), S. 348 f.

29 Bericht über die Vollversammlung des Zentralverbands am 7.5.1924, in: OB 6 (1924), S. 196200. 
einheitlichen Nenner zu bringen waren; wo verbandsinterne Differenzen vorlagen, konnten den offiziellen Stellen lediglich die unterschiedlichen Standpunkte vorgetragen werden. ${ }^{30}$

Ungeachtet der Verlagerung von Kompetenzen in den Zentralausschuß der Delegierten blieb der Ausbau der zentralen Exekutive eine wichtige Aufgabe. Schließlich verfügte Anfang 1920 weniger als ein Drittel der Sektionen über ein eigenes Büro; die restlichen ließen ihre Geschäfte durch den Zentralverband besorgen, so daß dessen etwa hundert Angestellte sich durch die Fülle der Aufgaben überfordert sahen. ${ }^{31}$ Die zentralen Problemfelder der Wirtschaftspolitik bearbeiteten spezielle Sektionen bzw. Referate. Das handelspolitische Referat der am 22. Januar 1919 gegründeten Exportsektion, die bald über tausend Mitgliedsfirmen zählte, wirkte in den ersten Nachkriegsjahren im Rahmen der staatlichen Außenhandelskontrolle in der Im- und Exportkommission, der Devisenzentrale sowie im Kompensationsamt mit und beteiligte sich an der Ausarbeitung von Handelsverträgen und eines Programms für die Rohstoffeinfuhr. Das Kreditkomitee akquirierte Rohstoffkredite im Ausland; die Arbeitgeberstelle war für sozialpolitische Fragen zuständig, und das Finanzreferat, das seine Tätigkeit im Sommer 1919 aufgenommen hatte, befaßte sich - angesichts der prononciert fiskalistischen Finanzpolitik des tschechoslowakischen Staates eine besonders wichtige Aufgabe - mit der Beratung der Mitgliedsfirmen in Steuerfragen. ${ }^{32}$

Der als vordringlich angesehene Aufbau der Fachorganisation war im Frühjahr 1920 weitgehend abgeschlossen. Diese war anfänglich durch einen ausgesprochenen Zentralismus charakterisiert. Alle Fachvereine hatten ihren Sitz in Prag; eine Ausnahme stellten nur die Vertretungen einiger lokal konzentrierter Branchen dar, etwa die der Malzproduzenten in Brünn oder die der Porzellanindustrie in Karlsbad. Der lokale und regionale Unterbau des Verbandes befand sich zu diesem Zeitpunkt noch im embryonalen Stadium. Anfang 1920 gab es - meist an den Sitzen der Handels- und Gewerbekammern - erst vierzehn Lokalorganisationen, sieben davon in Böhmen, vier in Mähren und drei in der Slowakei; im Mai 1921 existierten 15 Ortsgruppen. Der in der Folgezeit ins Auge gefaßte Aufbau von Gaugruppen sollte sich an die geplante Verwaltungseinteilung in Gaue anlehnen. In den industriellen Zentren waren zudem Ortssektionen geplant. ${ }^{33}$

Mit dem Ausbau der Organisation ging ein schneller Anstieg der Mitgliederzahlen einher. Waren im März 19192700 und im November des Jahres knapp 4000 Unternehmen im Zentralverband zusammengeschlossen, so betrug die Zahl Anfang 1920 schon annähernd 5600 und Mitte 1921 fast 6300. In kurzer Zeit, so Viškovský nicht ohne Spitze gegen "Wien“, sei es gelungen, eine Vereinigung von einem Umfang zu schaffen, den zu erreichen man in der Monarchie Jahrzehnte gebraucht habe. Erst 1924 war in der Folge der schweren Wirtschaftskrise ein Abgang von etwa 900 Unternehmen zu verzeichnen. Hier handelte es sich zum einen um Konkursfälle, zum anderen um Firmen, die,

30 Sitzung des Zentralausschusses der Delegierten der Fachgruppen und Sektionen beim Zentralverband am 4. 5. 1923, Protokoll in: OB 5 (1923), S. $241 \mathrm{ff}$.

31 SÚA, ÚSČP, Karton 10, Rede Bártas, Vollversammlung des Zentralverbands am 13. 3. 1920.

32 Viškovský, Zentralverband, S. 8.

33 Rede Viškovskýs, Vollversammlung des Zentralverbands am 13.3.1920, in: OB 2 (1920), S. 5. Ders., Zentralverband, S.6. - Rede Hodáčs, Vollversammlung des Zentralverbands am 28. 5. 1921, in: OB 3 (1921), S. 344. 
mutmaßlich aufgrund ihrer bedrängten finanziellen Lage, über längere Zeit hinweg keine Beiträge bezahlt hatten und aus diesem Grunde ausgeschlossen wurden. ${ }^{34}$

Der Zentralverband als "gesamtstaatliche Gründung “ im nationaltschechischen Geist provozierte eine deutsche Gegengründung: den Deutschen Hauptverband der Industrie in der Tschechoslwakei.

\section{b) Der Deutsche Hauptverband der Industrie (DHI)}

Der Deutsche Hauptverband der Industrie in der Tschechoslowakei wurde am 28. Oktober 1918 „erfunden “ ${ }^{35}$ Zwar nahm der Geschäftsführer des Verbandes nordböhmischer Industrieller, Rudolf Fernegg, zusammen mit Theodor Cichorius, dem Präsidenten dieser Vereinigung, vom 27. bis zum 29. Oktober in Wien noch an Besprechungen des österreichischen Industriellenverbandes teil; am Tag des Umsturzes aber verständigten sich Fernegg und Cichorius auf das Projekt einer Zusammenfassung der deutschen Industrie der zukünftigen Tschechoslowakei in einer eigenständigen Organisation. Cichorius, unter anderem auch Vorsitzender des Kriegsverbandes der Baumwollspinner, regte zusätzlich die Gründung eines Baumwollspinnerverbandes an, welcher sich am 4. November 1918 in Reichenberg konstituierte und zur Keimzelle des Allgemeinen Deutschen Textilverbandes wurde.

Läßt sich die Initiative zur Gründung des Hauptverbandes auch in erster Linie durch die letztlich gebieterische Notwendigkeit einer Anpassung der industriellen Organisation an die geänderten politischen Rahmenbedingungen erklären ${ }^{36}$, so fällt doch die erhebliche Verzögerung des eigentlichen Gründungsakts - mehr als ein Jahr nach der Entstehung des Staates und fast eineinhalb Jahre nach der des Zentralverbands - ins Auge. Zwar wurde von "führenden industriellen Kreisen" schon im Februar 1919 auf einer Zusammenkunft in Teplitz-Schönau die Einrichtung einer "Zentralkanzlei“ für die deutsch besiedelten industriellen Regionen der Tschechoslowakei beschlossen ${ }^{37}$, aber erst nach sieben Sitzungen eines „Vorbereitenden Ausschusses“ und vier Delegiertentreffen berief man für den 19. November 1919 die konstituierende Vollversammlung ein. ${ }^{38}$ Angesichts der für die Frühgeschichte des Verbandes bedauerlich dürftigen Quellenlage - Protokolle der vorbereitenden Sitzungen etwa sind nicht aufzufinden - lassen sich über die Hintergründe lediglich Mutmaßungen anstellen. Die ersten Monate des Zuwartens dürfen auf das Konto der fluiden politischen Lage gebucht werden: Gemeint ist damit die Initiative zur Errichtung eines selbständigen oder an das Deutsche Reich bzw. an Deutsch-Österreich angeschlossenen deutschböhmischen Staates. Angesichts

34 SÚA, ÚSČP, Karton 21, Korrespondenz Hodáč 0/2/1, Protokoll der Sitzung des Präsidialausschusses des Zentralverbands am 17.11. 1919. - Rede Malinskýs, Vollversammlung des Zentralverbands am 13. 3. 1920, in: OB 2 (1920), S. 1. - Viškovský, Zentralverband, S. 6 f. - Rede Karlíks, Vollversammlung des Zentralverbands am 28. 5.1921, in: OB 3 (1921), S. 343. - Mitteilung auf der Vollversammlung des Zentralverbands am 7.5.1924, in: OB 6 (1924), S. 199.

35 So die Formulierung in einem Interview Rudolf Ferneggs mit der „Wirtschaft ${ }^{\alpha}$ : „Die Erfindung des Deutschen Hauptverbandes der Industrie", in: WI 20 (1938), S. 3.

36 So laut Bericht des DHI über das Vereinsjahr 1920, Teplitz-Schönau 1921, S. 3.

37 Rede Mühligs, Vollversammlung des DHI am 21. 9. 1929, in: MDHI 10 (1929), S. 763.

38 Bericht des DHI über das Vereinsjahr 1920, Teplitz-Schönau 1921, S. 13. 
solcher Bestrebungen lag - sieht man von der Fernegg-Cichorius-Initiative ab - die Notwendigkeit einer nationalen Industrievereinigung vermutlich nicht sogleich auf der Hand.

In diesem Zusammenhang sind die Optionen in der "Frage Deutschböhmen“, soweit für die Wirtschaft von Belang, zu rekapitulieren: Mitte Oktober 1918 nahm der in Lobositz versammelte Deutsche Volksrat den Beschluß der deutschböhmischen Reichsratsabgeordneten, sich als Vertretung der Deutschen in Böhmen zu konstituieren, zur Kenntnis und formulierte als vorrangiges Ziel die Realisierung des Selbstbestimmungsrechts im Wege des Anschlusses an Deutschland. Am 23. Oktober konstituierte sich eine deutschböhmische Nationalversammlung. ${ }^{39}$ Den Traum von Autonomie machte jedoch die Besetzung der Randgebiete Böhmens durch tschechische Truppen zunichte. Nach der Einnahme von Reichenberg, Komotau und Eger waren am 17. Dezember alle größeren Städte in tschechischer Hand, die von Rudolf Lodgman geführte Regierung hatte sich nach Wien geflüchtet. ${ }^{40}$ Die Stellung der Deutschen werde, so Masaryk Ende 1918, jetzt durch die Existenz der Tschechoslowakei bestimmt. Die Parole „Deutschböhmen bleibt unser" sei durchaus mit demokratischer Selbstverwaltung und der Wahrung der Nationalitätenrechte im vollen Umfang kompatibel, schließe eine Sezession jedoch aus. ${ }^{41}$ Dies war die Realität, umso mehr, als das Deutsche Reich einer Konsolidierung der inneren Verhältnisse beim Nachbarn nichts in den Weg legte - wie es auch in der Folgezeit im Interesse gedeihlicher bilateraler Beziehungen die "deutschböhmische Fra-

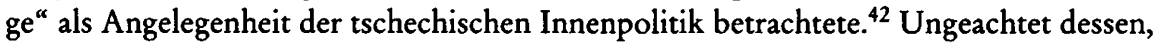
daß Berlin zu dieser Zeit noch nicht zu einer widerspruchsfreien Haltung gegenüber dem neuen Staat gefunden hatte und zwischen voller Anerkennung der Tschechoslowakei, Anerkennung ihrer Selbständigkeit ohne das Grenzland und militärischer Intervention schwankte, belebten sich bereits die wirtschaftlichen Beziehungen. Der deutsche Konsul in Prag, Gebsattel, zählte sogar zu den entschiedensten Anhängern eines Anschlusses der böhmischen Randgebiete an die Tschechoslowakei. ${ }^{43}$

Gebsattel konnte sich hierbei auch auf die deutschböhmische Industriellen berufen, für deren Votum die Furcht vor der überlegenen reichsdeutschen Konkurrenz maßgeblich gewesen sein dürfte. Die Einstellung der deutschböhmischen Wirtschaft zur Frage des "Anschlusses" in den Monaten zwischen dem Vorabend des Umsturzes und dem Ende Deutschböhmens ist wegen der spärlichen, diffusen, oft nur auf Stimmungsberichten außenstehender Beobachter und "Gewährsleute" fußenden Informationen allerdings nicht leicht auf einen Nenner zu bringen. Vermutlich handelte es sich auch nicht um eine Konstante. Hatten im Herbst 1918 deutsche industrielle Kreise zunächst "mit allem Nachdruck und den größten Aufwendungen" die gemäßigten, deutschfreundlichen Strömungen unter den Tschechen unterstützt, sich also vermutlich Chancen auf einen Modus vivendi in einem tschechoslowakischen Staat ausgerechnet, so schwand mit

$39 \mathrm{VZ}$ vom 18. und vom 24.10.1918.

$40 \mathrm{KZ}$ vom 9. 2.1919. - VZ vom 19.12.1918.

$41 \mathrm{VZ}$ vom 23.12. 1918.

42 Aufzeichnung aus dem Auswärtigen Amt, ohne Unterschrift, undatiert, aber vermutlich vom Jahresende 1918, in: ADAP, Serie A, Band 1, Dokument 84, S.133 f. - Gesandtschaft Prag an AA, 25.9.1919, in: Deutsche Gesandtschaftsberichte aus Prag, Teil I, Dokument Nr.71, S. 197-199.

43 Kořalka, Vznik, S. $836 \mathrm{ff}$ - - Leoncini, Questione, S. $133 \mathrm{ff}$. 
dem Herannahen des Umsturzes der Optimismus zunächst: Eine Entschließung der Vereinigten Warnsdorfer Fabrikanten und des Vereins zur Wahrung von Industrieund Handelsinteressen etwa stellte im Vorfeld des 28. Oktober die „Wahrung der nationalen Interessen" allen anderen Belangen voran und forderte Selbständigkeit im Rahmen Österreichs oder, sollte sich dies als unmöglich erweisen, die Hinwendung zu Deutschland..$^{44}$ Ein Anonymus, der aus der Perspektive der Textilindustrie das Für und Wider einer Zugehörigkeit zum Reich erwog, erklärte nun die Befreiung vom "tschechoslowakischen Joche“ zum glühendsten Wunsch aller Deutschen im „besetzten Gebiet"; eine andere publizistische Stimme ${ }^{45}$ warb mit der verlockenden Perspektive des Eintritts in die „deutsche Kulturgemeinschaft". Hinter solchen Floskeln steckte jedoch ein solides ökonomisches Kalkül: In diesem Zusammenhang fielen nämlich zum einen die zunächst fragil erscheinenden Konsolidierungschancen der ČSR ins Gewicht. Was die Rohstoffversorgung anlangte, so hätte der Verbleib bei der Tschechoslowakei zwar den Kohlebezug erleichtert; hinsichtlich vieler anderer Rohmaterialien aber war die deutschböhmische Industrie eher auf das Reich angewiesen. Auf der Absatzseite sprachen gegen die ČSR ihr, gemessen am Industriepotential, zu enger Binnenmarkt und der fehlende direkte Zugang zum Meer. Auf dem reichsdeutschen Markt wäre die böhmische Textilindustrie zwar auf eine höchst leistungsfähige einheimische Konkurrenz gestoßen - längerfristig verhieß aber gerade dieser Umstand mächtige, allfällige Anfangsschwierigkeiten aufwiegende Entwicklungsimpulse. In Betracht zu ziehen war auch, daß die traditionelle Vorzugsstellung auf dem weiträumigen, durch hohe Zollmauern geschützten österreichisch-ungarischen Markt nach dem absehbaren Zerfall der Monarchie ohnehin obsolet erscheinen mußte; im neuen Zollausland der Nachfolgestaaten war unweigerlich mit der reichsdeutschen Konkurrenz zu rechnen.

Auf der anderen Seite sprachen dann allerdings gerade auch ökonomische Argumente für die Eingliederung der böhmischen Randgebiete in die ČSR. Nach dem Umsturz stellte ein "Gewährsmann" der Kreuz-Zeitung in der deutschen Schwerindustrie der Tschechoslowakei deswegen Geneigtheit zu einem „Kompromiß“ mit den Tschechen fest. ${ }^{46}$ Gebsattel konstatierte sogar eine starke protschechoslowakische Stimmung. Auch nach dem Wettersturz, den die Zurückweisung der deutschen Unterhändler in Prag durch Rašíns berühmtes Diktum „Mit Rebellen verhandelt man nicht" bewirkt hatte, beharrte Gebsattel zufolge Ende November nahezu die gesamte deutschböhmische Wirtschaft auf der Zugehörigkeit zur ČSR ${ }^{47}$ - ein Sachverhalt, den Viškovský gegenüber der Vossischen Zeitung auf die treffende Formel brachte, Deutschböhmen sehe sich, allen lärmenden Kundgebungen gegen eine „Einverleibung" zum Trotz, zur Integration in die Tschechoslowakei schlicht deshalb gezwungen, weil seine Industrie ihre Märkte unmöglich opfern könne. ${ }^{48}$ Die Innenseite des böhmischen Hufeisens, so auch das für die amerikanische Delegation bei den Pariser Friedensverhandlungen angefer-

$44 \mathrm{VZ}$ vom 24. 10.1918.

45 AKPR, D 9254/20, Karton 8, Broschüre „Wirtschaftliche Fragen zum Anschlusse Deutschböhmens und des Sudetenlandes an das Deutsche Reich“, o.V., undatiert. - Pribram, Wirtschaftliche Lage, passim.

$46 \mathrm{KZ}$ vom 9. 2. 1919. Wie man sich diesen konkret vorstellte, geht aus dem Artikel nicht hervor.

47 Generalkonsulat Prag, von Gebsattel, an AA, 27.11. 1918, in: ADAP, Serie A, Band 1, Dokument Nr. 44, S. 67-70.

$48 \mathrm{VZ}$ vom 28. 10. 1918. 
tigte Exposé des Diplomaten Kerner, sei als separate ökonomische Einheit nicht überlebensfähig. Die Tschechoslowakei ihrerseits sei auf die Rohstoffvorkommen in den deutsch besiedelten Gebieten, insbesondere auf die Kohle des Brüx-Teplitzer Raums, angewiesen und werde im Falle eines Anschlusses Deutschböhmens an Deutschland mit Unterstützung der Entente zumindest diese Region für sich reklamieren. ${ }^{49}$

Bemängelten interne Kritiker hier auch, Kerner mache sich unbesehen tschechische Argumente für die Einheit Böhmens zu eigen und operiere hinsichtlich der „mangelnden Konkurrenzfähigkeit der böhmischen Wirtschaft" mit unbewiesenen Behauptungen $^{50}$, so waren vermutlich gerade solche Überlegungen die Grundlage für das Resümee der Prager deutschen Gesandtschaft, die führenden Kreise der deutschböhmischen Industrie seien „keineswegs so kompromißfeindlich und unbedingt der Vereinigung mit dem Deutschen Reiche so geneigt ${ }^{\text {" }} .{ }^{51}$ Zwar hatte Friedrich Naumann schon 1915, das Für und Wider eines einheitlichen mitteleuropäischen Wirtschaftsraums erwägend, zu bedenken gegeben, im Rahmen der Monarchie sei die böhmische Industrie der reichsdeutschen im Wettbewerb noch am ehesten gewachsen. Das niedrigere österreichische Lohnniveau bedeute sogar einen Konkurrenzvorteil. Ein Wegfall des Zollschutzes werde die Großindustrie nur geringfügig beeinträchtigen, während sich die ungewohnte Konkurrenzsituation für die Nahbedarfswirtschaft durch eine Steuer- und Tarifsenkung und durch Entbürokratisierung entschärfen lasse. Entwicklungsgefälle seien somit ohne größere Probleme einzuebnen. ${ }^{52}$ Dieser Optimismus hätte a fortiori in die Nachkriegszeit gepaßt: Der österreichische Staat hatte seine Rolle als Hemmfaktor ausgespielt; andererseits mußten nun die prospektiven Absatzprobleme auf dem engen tschechoslowakischen Binnenmarkt als Negativposten auf die Rechnung gesetzt werden. Eugen von Philippovich, Professor der Volkswirtschaftslehre an der Universität Wien, hatte in österreichischen Industrie- und Handelskammerkreisen bereits um die Jahrhundertwende eine prinzipielle Mehrheit für ein Zollbündnis mit dem Reich geortet - eine Übergangsphase mit je nach Branchenbedürfnissen individuell dosierten Schutzzöllen vorausgesetzt. ${ }^{53}$

Trotzdem bestanden die Vorbehalte fort. Die Deutschböhmen erhofften einer Beobachtung der sächsischen Gesandtschaft in Wien Mitte Oktober 1918 zufolge $^{54}$ zwar Reichshilfe gegen eine Okkupation, hegten andererseits aber eine so deutliche Reserve gegen eine Zugehörigkeit zu Deutschland, daß man sie zweckmäßigerweise der Vorkehrungen gegen ökonomische Beeinträchtigungen - angesichts der überaus großen Bedeutung der Wirtschaftsfragen für die deutschböhmischen Führer tunlichst durch eine Grundsatzerklärung - zu versichern habe.

Der tschechische Wille zur Angliederung Deutschböhmens war eindeutig. Masaryks bekannter Brief zur deutschböhmischen Frage vom 21. Januar 1919 konstatierte auf der Grundlage des historischen Staatsrechts und angesichts der nationalen Gemengelage im

49 Exposé Kerners für Coolidge, undat., in: FRUS, Paris Peace Conference, 1919, Band XII, S. 337341.

50 A.C. Coolidge an Commission to Negotiate Peace, 17. 2. 1919, in: FRUS, Paris Peace Conference, 1919, Band XII, S. 334-336.

51 PA, R 73 818, Gesandtschaft Prag an AA, 19.10.1920.

52 Naumann, Mitteleuropa, S. $115 \mathrm{ff} ., 123 \mathrm{f} ., 199 \mathrm{f}$.

53 Von Philippovich, Wirtschafts- und Zollverband, S. 3-5, 44-59.

54 HStA Dresden, Gesandtschaft Berlin, 835, Königlich Sächsische Gesandtschaft Wien an Sächsisches Ministerium des Auswärtigen, 11., 12. und 13.10.1918. 
Grenzgebiet zwar konfligierende Selbstbestimmungsrechte von Deutschen und Tschechen, plädierte aber nicht zuletzt aus ökonomischen Gründen für die Beibehaltung der bisherigen Grenzen zu Deutschland: Der Verlust der hochindustrialisierten Gebiete werde die internationale Position der Tschechoslowakei beeinträchtigen. ${ }^{55}$ Auf der $\mathrm{Pa}$ riser Friedenskonferenz überzeugte Benešs und Kramářs Mémoire III die Großen Vier von der essentiellen Bedeutung Deutschböhmens für die Lebensfähigkeit des neuen Staates: Bereits die Geographie verbiete die Bildung einer autonomen Provinz ebenso wie den Anschluß an Deutsch-Österreich. Gegen die Angliederung an das Deutsche Reich sprächen neben den strategischen und politischen auch wirtschaftliche Gründe: der Rohstoff- und Industriereichtum des deutschen Nord- und Nordwestböhmen sowie seine Anbindung an Prag, wo zahlreiche Unternehmen ihren Sitz hätten. Deutschböhmen importiere Lebensmittel und Arbeitskräfte aus den tschechischen Gebieten und setze seine Produkte dorthin ab, so daß eine Abtrennung die Tschechoslowakei schwer treffen, nicht zuletzt aber auch die deutschen Gebiete ruinieren werde. ${ }^{56}$ Die Deutschen wüßten, abgesehen von gewissen intellektuellen pangermanischen Zirkeln, selbst, daß diese Argumente zwingend seien. ${ }^{57}$

Das Memorandum berief sich auf eine Stellungnahme im „Prager Tagblatt“ vom 3. November 1918, derzufolge maßgebliche Kreise der deutschböhmischen Wirtschaft, eine internationale Garantie der „volklichen Selbständigkeit“ vorausgesetzt, die Zugehörigkeit zur ČSR der zu Deutschland vorzögen. Nun wurde damit zwar - ob absichtlich, sei dahingestellt - der Tenor des zitierten Kommentars im „Prager Tagblatt“ nicht ganz korrekt wiedergegeben, denn dort war nur davon die Rede gewesen, daß die Wirtschaft in einem Verbleib bei der Tschechoslowakei - jenseits aller Gefühlspolitik die einzig realistische Option - „kein so großes Unglück“ sehe. ${ }^{58}$ Selbst wenn die tschechoslo-

55 Šolle, Böhmen, S. $230 f$.

56 Raschhofer (Hrsg.), Denkschriften, S. $89 \mathrm{ff}$.

57 Raschhofer (Hrsg.), Denkschriften, S. 103 ff. - Zitiert wurden in der Denkschrift die Prager deutsche Zeitung "Montagsblatt" vom 4.11.1918 sowie PT vom 30.10.1918; laut PT vom 19. 10. 1919 lag allerdings ein Irrtum vor, da aus dem „Prager Tagblatt“ vom 3.11.1918 zitiert worden war. - Vgl. zur Rezeption auch: Secretary's Notes of a Conversation Held in M. Pichon's Room at the Quai d' Orsay, Paris, am 5. 2. 1919, in: FRUS, Paris Peace Conference, Band III, S. 877-887, v. a. S. 879-881.

58 Die deutschen Abgeordneten kamen erst im Herbst 1920 in den Besitz des Textes; die Bohemia veröffentlichte ihn in mehreren Folgen zwischen dem 10. und dem 19. Oktober 1920. Man habe, so das Prager Tagblatt am 19. Oktober in einem harschen Kommentar zu der verzerrenden Wiedergabe seiner Stellungnahme vom 3. November 1918, sich damals ausdrücklich gegen „das wahre Gefühl“ der bürgerlichen wie der sozialdemokratischen politischen Führer gestellt, die für einen Anschluß an Deutsch-Österreich oder Deutschland plädiert hätten. Das Schicksal Deutschböhmens sei damals bereits entschieden gewesen; zudem habe die Reichsregierung nichts von einem Anschluß wissen wollen. Sogar die von der tschechoslowakischen Regierung ins Auge gefaßte Abtretung einiger kleinerer Grenzgebiete sei von Frankreich, das eine Vergrößerung Deutschlands nicht zulassen wollte, verhindert worden. Von einer Abtretung des für sich genommen nicht lebensfähigen deutschböhmischen Landstumpfs sei nicht die Rede gewesen, weil die Entente die dortigen Kohlenreviere als lebensnotwendig für den neuen Staat erachtet habe: Vgl. PT vom 19. 10. 1920. - Der „Skandal“ um das Mémoire wurde in der dringlichen Interpellation Křepek, Lodgman und Genossen vom 9.11.1920 im Abgeordnetenhaus, betreffend das der Friedenskonferenz im Jahre 1919 überreichte Mémoire III über das Problem der Deutschen in Böhmen, TTZPS, 1. WP, Drucksache 1047, vor das Parlament gebracht (eine gleichlautende Interpellation brachten am gleichen Tage Jelinek, Spiegel und Gen. im Senat ein: Vgl. TTZS, 1. WP, Drucksache 211. Beneš verwahrte sich gegen den Vorwurf der Fälschung mit 
wakische Diplomatie in Paris sich mit einer gewissen Verschlagenheit einer beschönigenden Interpretation des Artikels bedient haben mochte, so war doch auch die distanziertere Version - an deren Authentizität niemand rütteln mochte - noch einmal ein gewichtiger Beleg für eine den Gefühlen vielleicht widerstreitende, jedoch der wirtschaftlichen Vernunft entsprechende Bereitschaft der deutschböhmischen Wirtschaft zur Integration in den tschechoslowakischen Staat.

Die Beziehungen zwischen Tschechen und Deutschen waren Anfang 1919 äußerst gespannt. Das Vorgehen der tschechischen Truppen im Grenzgebiet, gipfelnd am 4. März in blutigen Ausschreitungen, hatte auf der deutschen Seite allenthalben Erbitterung hervorgerufen und lastete als Hypothek auf der gemeinsamen Zukunft. Der tschechoslowakische Staat, so das Brünner deutsche Konsulat im Herbst des Jahres, habe es verstanden, sich in den Deutschen in kürzester Zeit erbitterte Irredentisten heranzuziehen. Lodgman agitierte für eine Bündelung aller nationalen Kräfte im Kampf um das Selbstbestimmungsrecht. ${ }^{59}$ Dies war das nationalpolitische Umfeld der Gründung des Hauptverbandes: Lodgmans Versuch einer Zusammenfassung der deutschen Unternehmen auch der bereits in den Zentralverband eingetretenen - in einer eigenständigen Organisation stellte das Pendant zum Versuch einer Überwindung der Parteienzersplitterung durch eine Einheitsfront auf dem Gebiet der Wirtschaft dar. ${ }^{60}$ Diese Vereinigung sollte einen Schutzwall gegen die „Tschechisierung“ bilden, auf deren Konto die deutsche Seite, abgesehen von den allfälligen realen tschechischen Depossedierungsbestrebungen, auch alle objektiven, $d$. h. durch die Nachkriegskrise, vielleicht auch durch die bürokratischen Hemmschuhe der "gebundenen Wirtschaft" verursachten Beeinträchtigungen ihrer Aktivitäten zu buchen geneigt war. Dem kam entgegen, daß diese beiden Komponenten in vielen Fällen außerordentlich schwer zu trennen waren. Die deutschen Exporte würden durch eine Umorientierung der Prager Außenwirtschaftsbeziehungen auf die Geburtshelfer des Staates, die Westmächte, künstlich abgeschnürt; die Devisenzentrale weise die zum großen Teil durch die Exporte der deutschböhmischen Unternehmen erwirtschafteten Zahlungsmittel vorzugsweise tschechischen Betrieben zum Zweck des Rohstoffeinkaufs zu. Die deutsche Industrie werde durch eine lediglich vorgegaukelte Aussicht auf Rohstoff- und Kohlenzuteilung dem Zentralverband in die Arme getrieben; durch eine unbefriedigende Regelung der Kriegsanleihenfrage suche man ihre $\mathrm{Ka}$ pitalbasis zu schmälern. Diese defensive Sichtweise teilte das Auswärtige Amt, das die Gründung des Hauptverbandes als ein nicht nur in wirtschaftlicher, sondern auch in nationalpolitischer Hinsicht höchst bedeutsames Unterfangen betrachtete und eine - nicht weiter konkretisierte - finanzielle Unterstützung durch deutsche Großbanken erwog. Eine solche scheiterte allerdings am Einspruch des Reichswirtschaftsministeriums, das

der Begründung, der Konferenz habe außer dem Mémoire, einer nicht offiziell unterfertigten bzw. überreichten bloßen „Hilfsschrift", eine riesige Menge veröffentlichter Materialien mit kontroverser Ausrichtung vorgelegen, eine Möglichkeit zur Manipulation habe also nicht bestanden: Vgl. die Antwort des Ministers des Äußern vom 5. 7.1921 auf die Interpellation Křepek und Genossen in: TTZPS, 1. WP, Drucksache 2520 bzw. auf die Interpellation Jelinek und Genossen in: TTZS, 1. WP, Drucksache 758.

59 PA, R 9104, Gesandtschaft Prag an AA, 4. 1.1919. - PA, R 22 576, Deutsche Botschaft Wien an AA, 3.6. 1919. - PA, R 9103, Konsulat Brünn an AA, 19.10.1919.

60 PA, R 9103, Deutsche Botschaft Wien an AA, 24. 10.1919. 
im Interesse korrekter bilateraler Beziehungen die Aktivitäten der deutschböhmischen Industrie als eine innertschechische Angelegenheit eingestuft wissen wollte. ${ }^{61}$

Lag unter diesen Umständen aus dem Blickwinkel der deutschen Wirtschaft in der ČSR die Notwendigkeit eines industriellen Schutzverbandes im Frühjahr 1919 auf der Hand, so verzögerte sich doch der Zusammenschluß aufgrund langwieriger, von Fernegg im Vorfeld der Gründung nur mühsam zu überwindender Eigenbröteleien der existierenden Wirtschaftsvereinigungen. Diese Zerklüftung der Verbandslandschaft war ein Gegenstück zu der notorischen Uneinigkeit der deutschen politischen Szene. Strittig war etwa die Frage des Sitzes der neuen Vereinigung: Wollte der Nordböhmische Industriellenverband diesen nach Reichenberg legen, so bestanden die Vertreter Westböhmens wegen der schlechten Bahnverbindungen dorthin auf Teplitz-Schönau; sie setzten sich schließlich durch. ${ }^{62}$ Unter diesen Umständen rechnete es sich Fernegg schon als Erfolg an, daß - nach dem Interim eines Zusammenschlusses lediglich der böhmischen Industrie - der Hauptverband der gesamten deutschen Wirtschaft in der Tschechoslowakei „bereits“ im November 1919 gegründet werden konnte.

Triebkraft der außerordentlich starken Beteiligung an der konstituierenden Vollversammlung war zu diesem Zeitpunkt allerdings nicht mehr allein die Abwehrhaltung gegen die "Tschechisierung “. Zusammen mit dem Bewußtsein der wirtschaftlichen Macht der Deutschen finde sich, wie der neue Bevollmächtigte des Deutschen Reiches in Prag, Saenger, anmerkte, das Selbstbewußtsein wieder ein, das nach der Gründung eines tschechoslowakischen Naticnalstaates zunächst dem Kleinmut gewichen sei: „Die Herren waren, indem sie ihre Reihen durchliefen, selbst erstaunt, welch hoher Prozentsatz der Produktionsmittel des Landes sich in deutschen Händen befinde; und hinterher war man über das $\mathrm{Maß}$ an Einschüchterung verwundert, dem man so lange anheimgefallen war." Man gedenke, so der Konsens der Gründungsversammlung, die Selbständigkeit gegenüber den tschechischen Verbänden zu wahren; getrennt marschieren und „sich suchen lassen“, hieß nun die Devise. Das „Hinwegdisponieren über die wirtschaftsmächtigste deutsche Gruppe", so Saenger, werde nun nicht mehr toleriert, und dies sei als ein beachtlicher Schritt zur Konsolidierung des Deutschtums generell einzustufen. ${ }^{63}$

Erstreckte sich der Aktionsradius des Hauptverbands auch auf die gesamte tschechoslowakische Republik, so lag der Schwerpunkt seiner Tätigkeit selbstverständlich im deutschen Gebiet. Das Hauptbüro zusammen mit einem Referat für Finanz- und Steuerfragen befand sich in Teplitz-Schönau. ${ }^{64}$ Zusammen mit dem Allgemeinen Deutschen Textilverband (ADTV) unterhielt der DHI außerdem aber eine Geschäftsstelle in der Hauptstadt. 1920 war der Aufbau der Fachorganisation in vollem Gange. ${ }^{65}$ Ähnlich wie im Zentralverband war die Zusammenfassung der bestehenden fragmentarischen Organisationen das erste Ziel. Die in einigen Branchen wie der Chemie, der Textilwirtschaft, der Metall- und der Glasindustrie in der Vorkriegszeit gegründeten deutschen Wirtschaftsvereinigungen gliederten sich nun als Fachgruppen in den DHI ein oder as-

61 BArch-B, RMWi, 2885, AA an RMWi, 6. 9. 1919. - Aktenvermerke Poerschke vom 2.10.1919 und RMWi an AA, 13.10.1919.

62 Interview Ferneggs, in: WI 20 (1938), S. 3.

63 BArch-B, RMWi, 2885, Der Bevollmächtigte Vertreter des Deutschen Reiches an AA, 14.11.1919.

64 Wallner, Organisation, in: MHDI 2 (1921), S. $547 \mathrm{f}$.

65 Bericht des DHI über das Vereinsjahr 1920, S. $5 \mathrm{f}$. 
soziierten sich als „angeschlossene Verbände"66; eine wichtige Zäsur war der im Juni 1922 vollzogene Beitritt des Wirtschaftsverbands der tschechoslowakischen Porzellanindustrie. ${ }^{67}$ Neben die Angliederung existierender Organisationen trat bald die Neuwerbung von Mitgliedern in breiteren industriellen Kreisen. ${ }^{68}$

Theodor Cichorius war 1900 Mitbegründer und seitdem Vorsitzender des Verbandes nordböhmischer Industrieller in Reichenberg gewesen. Diese Vereinigung wurde im September 1920 in den Deutschen Arbeitgeberverband umgewandelt. ${ }^{69}$ Die Arbeitgeberorganisation war vom DHI - ähnlich wie in Deutschland ${ }^{70}$ - organisatorisch getrennt; die Kompetenzen waren nicht klar geschieden. Allerdings arbeiteten beide Vereinigungen sehr eng zusammen. Die Hauptstelle befand sich in Reichenberg; örtliche Arbeitgeberstellen wurden ins Leben gerufen. ${ }^{71}$ Vorsitzender blieb Cichorius. Zur Leitung gehörte von Amts wegen auch der Präsident des DHI; im Präsidium fand sich darüber hinaus eine Reihe prominenter Namen aus der Führungsetage des Hauptverbandes, u. a. Mühlig, Doderer, Goltz, Zebisch und Tugendhat. ${ }^{72}$

Wie der Zentralverband schuf sich auch der DHI in den ersten Jahren seines Bestehens einen regionalen Unterbau. Ein wichtiger Schritt war die Gründung des Gaus Egerland im Oktober 1920. ${ }^{73}$ Die Vollversammlung vom 4. April 1921 beschloß die Errichtung von Kreisstellen zur Bearbeitung allgemeiner Wirtschaftsfragen, die auch als "Exekutive“ der Arbeitgeberorganisation fungierten, wo diese nicht vertreten war. Kreisstellen bestanden bald in Karlsbad, Rumburg, Trautenau, Aussig, Reichenberg und Teplitz. Der Aufbau auf Kreisebene war im November 1921 im wesentlichen abgeschlossen. ${ }^{74}$ Überhaupt war das Organisationsgefüge des DHI rasch durchgebildet: Im Mai 1920, etwa ein halbes Jahr nach der Gründung, existierten neun Orts- und vier Fachgruppen sowie 22 angeschlossene Verbände, Anfang November 1921 bereits acht Kreisstellen und 52 Orts- bzw. 31 Fachgruppen mit 113 Sektionen. ${ }^{75}$ Die angeschlossenen Organisationen widmeten sich in erster Linie der Mitgliederbetreuung; Gutachten in Fragen von grundsätzlichem und allgemeinem Interesse durften sie nicht ohne Einverständnis der Zentrale erstatten. ${ }^{76}$

Die Führung des Hauptverbandes rekrutierte sich aus den vordersten Rängen der Industriellen in den schwerpunktmäßig deutschen Wirtschaftszweigen der Republik. Diese Unternehmer hatten durchweg bereits unter der Habsburger Monarchie prominente Positionen im Wirtschaftsverbandswesen, zum Teil auch in der Politik bekleidet. Gründungspräsident des DHI war der Aussiger Chemieindustrielle Heinrich Schicht.

66 MDHI 1 (1920), S. 1 f. - SÚA, MPOŽ, Karton 316, 2762/20, Rede Schichts auf der Gründungsversammlung des DHI.

67 MDHI 3 (1922), S. 445.

68 Bericht des DHI über das Vereinsjahr 1920, S. $3 \mathrm{f}$.

69 Bericht über die Verbandsgeschichte auf der Jubiläums-Vollversammlung des DHI am 21.9. 1929, in: MDHI 10 (1929), S. 767.

$70 \mathrm{Vgl}$. zu den Verhältnissen in Deutschland: Ullmann, Interessenverbände, S. $135 \mathrm{f}$.

71 Wallner, Organisation, S. 547 f. - Bericht des DHI über das Vereinsjahr 1920, S. 5 f.

72 Vgl. den Bericht über die Vollversammlung des DHI am 4. 4.1921 in Teplitz-Schönau, MDHI 2

(1921), Folge 9, unpag. - MDHI 3 (1922), S. 70. - MDHI 4 (1923), S. 60.

73 MDHI 1 (1920), S. 123.

74 MDHI 2 (1921), S. 116 und S. 189. - Wallner, Organisation, S. 547 f.

75 MDHI 1 (1920), S. 9. - Wallner, Organisation, S. 547 f.

76 Vgl. MDHI 1 (1920), S. 3. 
Unter den fünf Vizepräsidenten befanden sich Joseph Max Mühlig und Cichorius, im erweiterten Führungsgremium, dem Präsidialausschuß, waren Karl Baumgartner, Richard Doderer und der Textilindustrielle Rudolf Teltscher vertreten, der auch im Allgemeinen Deutschen Textilverband eine Schlüsselstellung innehatte. Überhaupt spielte im Vorstand mit Hermann Brass, Willi Ginzkey, Otto Goltz und Theodor Liebieg die Textilwirtschaft die bedeutende Rolle, die ihr in der deutschen Ökonomie der ČSR zukam. ${ }^{77}$ Fanden sich in der Führungsetage des Zentralverbands durchwegs Unternehmer der ersten Generation, so waren im Unterschied hierzu die im vordersten Glied des DHI anzutreffenden Angehörigen der Unternehmerdynastien Schicht, Mühlig und Liebieg ein Indiz für das in wirtschaftsgeschichtlicher Perspektive und gemessen an der tschechischen Ökonomie höhere Alter der deutschen Industrie. Modern anmutend und für den hohen Stand des Bildungswesens in den böhmischen Ländern bezeichnend - war auch hier der hohe Anteil der Unternehmer mit technischer oder kaufmännischer akademischer bzw. Fachschulausbildung. ${ }^{78}$

Die größte und wichtigste der angeschlossenen Organisationen war der Allgemeine Deutsche Textilverband (ADTV), entstanden aus dem Zusammenschluß der mährisch-schlesischen und der böhmisch-deutschen Textilwirtschaft. Die mährische Vereinigung wurde am 26. August 1919 in Olmütz in Anwesenheit der Vertreter der Handels- und Gewerbekammern Troppau und Olmütz, des Verbandes mährischer Industrieller und des nordböhmischen Textilverbandes gegründet. Die Genehmigung der Satzung war im März beim Innenministerium beantragt worden. Bis zu ihrem späten Eintreffen am 28. Juli hatte die Vereinigung ihre Tätigkeit inoffiziell bereits aufgenommen und eine so erfolgreiche Werbung betrieben, daß die Unternehmen zum groBen Teil bereits Mitglieder waren. Die einige Monate früher, am 24. Januar 1919, von den deutschböhmischen Textilindustriellen eingereichten Statuten für einen Verband mit Sitz in Reichenberg wurden Anfang Mai genehmigt.

Die gemeinsamen Interessen und die dichte Vernetzung der Textilwirtschaft führten fast automatisch zur Vereinigung des mährisch-schlesischen Verbands mit seinen etwa 170 und des böhmischen mit seinen 700 Mitgliedern. Angesichts der immensen Exportprobleme der ersten Nachkriegszeit regte Reichenberg zunächst eine Interessengemeinschaft an; von Anfang an bestanden auch enge Beziehungen auf der Fachgruppenebene. Auf der Gründungsversammlung des böhmischen Verbandes traten diesem die Angehörigen des Partnerverbandes als außerordentliche Mitglieder bei; ein gemeinsamer Vollzugsausschuß wurde eingesetzt. Solange die Satzungen des mährisch-schlesischen Verbandes nicht genehmigt waren, dieser somit nicht öffentlich tätig werden konnte, übernahm Reichenberg die Vertretung seiner Interessen und stellte hierfür seine Prager Geschäftsstelle zur Verfügung ${ }^{79}$, die in der Folgezeit ausgebaut und ab 1920 von Josef Kislinger geleitet wurde. ${ }^{80}$ Die Vereinigung wurde im März 1920 vollzogen. Mit der Wahl der Vorstände beider Verbände in die neuen Leitungsgremien war die Konstituie-

77 Vgl. die Liste der Mitglieder der leitenden Gremien in: MDHI 3 (1922), S. 69 f.

78 Die Analysekategorien nach Berghoff/Möller, Aspekte, passim. Feudalisierungstendenzen könnte man im Grundbesitz und im Adelstitel Liebiegs sowie in der Heiratsverbindung seiner Tochter mit dem reichsdeutschen Diplomaten Köster erblicken. Für eine Verallgemeinerung sind solche Indizien selbstverständlich nicht tragfähig.

79 Vollversammlung am 26. 8. 1919, in: MVDTR 1 (1919), S. 15-24.

80 Bericht über die Vorstandssitzung des nordböhmischen Verbandes am 25.11. 1919, auf der der 
rung des Allgemeinen Deutschen Textilverbandes, der zu diesem Zeitpunkt bereits über 1000 Mitglieder zählte, abgeschlossen. ${ }^{81}$ Präsident wurde Theodor Liebieg, unter den Vorstandsmitgliedern begegnen wieder prominente Namen der deutschen Textilwirtschaft wie Ginzkey, Brass, Cichorius, Teltscher und Larisch. ${ }^{82}$

Die Zahl der Mitglieder pendelte sich bis Ende 1922 auf etwas über 1200 ein. In der Folge der Krise, die vor allem viele kleinere Firmen in den Konkurs trieb, sank sie bis zum Frühjahr 1924 auf etwa 1100. Entsprechend der weitgehenden internen Differenzierung der Textilwirtschaft war die Fach- und die Regionalorganisation, deren Aufbau Ende 1922 abgeschlossen wurde, sehr tief gestaffelt: Die Unternehmen waren in 26 Fachgruppen, 73 Fachortsgruppen und fünf allgemeine Ortsgruppen gegliedert. Hochburg des ADTV waren die deutschen Gebiete der Republik; Mitglieder fanden sich aber auch in den überwiegend tschechisch besiedelten Landesteilen und in der Slowakei. ${ }^{83}$ Einen weiteren Schub im Ausbau der Regionalorganisation bedeuteten die ab Oktober 1923 jeweils für ein engeres Verbandsgebiet - zuerst für Jägerndorf, Olmütz und Reichenberg - abgehaltenen Mitgliederversammlungen, die der Aussprache über die Wirtschaftslage dienten ${ }^{84}$ Die Fachorganisation wurde auch zum organisatorischen Unterbau branchenspezifischer Konditionenvereinbarungen nach dem Modell der "Tschechoslowakischen Tuchkonvention“ ${ }^{.85}$

Die Trennlinien in der Organisation der Textilwirtschaft waren, wie anderswo in der Wirtschaft der Republik, mit der Grenze zwischen Deutschen und Tschechen weitgehend deckungsgleich. Das Deutsche war Geschäftssprache des ADTV. Hatte laut Satzung auch jedes Textilunternehmen der ČSR Anspruch auf Mitgliedschaft, so besaß doch der Vorstand, um den deutschen Charakter des Verbands zu wahren, das Recht, Aufnahmeanträge abzulehnen.$^{86}$ Eine Fusion mit dem tschechischen Verband der Textilindustriellen zog der ADTV nicht in Erwägung, aus Furcht, die deutschen Interessen würden in einer solchen übernationalen Organisation nicht ausreichend berücksichtigt. Geleitet von grundsätzlichem Mißtrauen gegen eine tschechisch-chauvinistische Wirtschaftspolitik, faßte die deutsche Textilwirtschaft eine Zusammenarbeit mit dem tschechischen Verband nur von Fall zu Fall ins Auge. ${ }^{87}$ So stand etwa hinter der Gründung eines Gesamtausschusses der Wirkerei- und Strickereiindustrie die Auffassung, „unter Umständen" könne das Zusammengehen einer Branche über die nationalen Grenzen hinweg von Vorteil sein. Auch im 1922 eingerichteten Zentralausschuß der Industrie

Ausbau beschlossen wurde, in: MVDTR 1 (1919), S. 37f. - Zu Kislinger vgl. ebenda 2 (1920), S. 75.

81 MVDTR 2 (1920), S. 87 ff. - MDHI 1 (1920), S. 13.

$82 \mathrm{Zu}$ Personalfragen vgl. den Bericht über die Vollversammlung des ADTV am 3.4.1921, in: MADTV 3 (1921), S. 89. - Vollversammlung am 28.4.1922, in: MADTV 4 (1922), S. 128. - Vorstandssitzung des ADTV am 13.6.1922, in: MADTV 4 (1922), S. 16.

${ }^{83}$ MVDTR 2 (1920), S. 75 f. - Jahresbericht für die Vollversammlung am 3. 4. 1921, in: MADTV 3 (1921), S. 73 f. - Jahresbericht für die Vollversammlung am 29.4.1923, in: MADTV 5 (1923), S. 71 f. - MADTV 6 (1924), S. 53.

84 MADTV 5 (1923), S. 190 und 6 (1924), S. 53.

85 MADTV 6 (1924), S. 53 f. - Vollversammlung am 18. 4. 1924, in: MADTV 7 (1925), S. 90. - Vollversammlung am 14.5.1926, in: MADTV 8 (1926), S. 90.

86 MADTV 2 (1920), S. 88. - Satzungen des ADTV, in: MADTV 2 (1920), S. 109-112. - Sie wurden am 8. Mai 1920 genehmigt: Vgl. Bericht über die Vollversammlung des ADTV am 3.4.1921, in: MADTV 3 (1921), S. 75.

87 Rede Teltschers, Gründungsversammlung des ADTV am 26. 8. 1919, in: MVDTR 1 (1919), S. 22. 
der Tschechoslowakei war der ADTV mit mehreren Mitgliedern seines Vorstands vertreten. ${ }^{88}$ In konzertierter Aktion mit dem tschechischen Verband intervenierte der ADTV in der Auseinandersetzung um die Vermögensabgabe, ohne daß es allerdings zur Institutionalisierung eines "geregelten Zusammenwirkens" gekommen wäre. ${ }^{89}$

Eng war hingegen die Zusammenarbeit mit dem Hauptverband. Arbeitgeberfragen beispielsweise bearbeitete auf der Grundlage eines Abkommens vom Februar 1920 der DHI. ${ }^{90}$ Zusammen mit der Wiener Providentia, der Leipziger Feuerversicherungsanstalt und der Agrar- und Industriebank gründeten im November 1922 DHI und ADTV die Allgemeine Versicherungs AG „Union“, einen Verband für die industrielle Sachschadensversicherung, die den tschechoslowakischen Kundenstamm der Leipziger und der Providentia übernahm und in deren Verwaltungsrat zwei ADTV-Vorstandsmitglieder saßen. ${ }^{91}$ Die Kooperation mit den überwiegend deutschen Handels- und Gewerbekammern Reichenberg, Eger und Troppau, in deren Sprengel die meisten Mitglieder des ADTV ansässig waren, der Kontakt zur Arbeitgeberhauptstelle in Reichenberg und die Beziehungen zum Verein der Wollindustriellen Mährens in Brünn wie zum Verein Reichenberger Messe, in dessen Hauptausschuß der ADTV saß, bezeugen die Vernetzung des Verbandes mit wichtigen Organisationen und Institutionen des deutschen Wirtschaftslebens. ${ }^{92}$ Im Umkreis des Verbandes fanden sich auch Einrichtungen der fachspezifischen Forschung und Lehre wie die vom ADTV betreute Reichenberger Konditionieranstalt, die dieser angegliederte Forschungsstelle für Textilindustrie und der Verein zur Förderung der Arbeitsstelle für Farbkunde in Reichenberg, in deren Gremien der ADTV vertreten war. ${ }^{93}$ Dem Charakter der Textilindustrie als ausgesprochen exportorientierter Branche entsprechend waren die internationalen Verbindungen und Aktivitäten des ADTV vielfältig und intensiv: Der Verband unterhielt enge Beziehungen zur tschechoslowakisch-ungarischen und zur tschechoslowakisch-österreichischen Handelskammer in Prag wie zu den tschechoslowakischen Auslandshandelskammern, insbesondere denen der Donaustaaten. Bedingt durch die vorrangige Orientierung der tschechoslowakischen Ausfuhr in den südosteuropäischen Raum war die Mitgliedschaft in der Mitteleuropäischen Arbeitsgemeinschaft und die Teilnahme an der Mitteleuropäischen Wirtschaftstagung im September 1925 in Wien. Der ADTV war in der Internationalen Handelskammer in Paris und in der Internationalen Föderation der Baumwollspinn- und Webereivereinigungen in Manchester vertreten und beteiligte sich 1924 am Internationalen Handelskammerkongreß in Rom. ${ }^{94}$

Das Zwischenfazit zur Organisationsgeschichte hebt hervor: Der Neuzuschnitt des Industrieverbandswesens ist in den Kontext der Separierung der Nachfolgestaaten vom alten Zentrum einzuordnen. Die Gründung von Nachfolgeorganisationen auf allen

88 Jahresbericht für die Vollversammlung des ADTV am 29. 4. 1923, in: MADTV 5 (1923), S. 71 f. MVDTR 1 (1919), S. $35 \mathrm{f}$.

89 Jahresbericht für die Vollversammlung des ADTV am 3.4. 1921, in: MADTV 3 (1921), S. $74 \mathrm{f}$.

90 Vollversammlung des mährisch-schlesischen Verbandes am 25.3.1920, in: MVDTR 2 (1920),

S.75f. - Jahresbericht für die Vollversammlung des ADTV am 3.4.1921, in: MADTV 3 (1921), S. 74.

91 Vollversammlung des ADTV am 3. 4. 1921, in: MADTV 3 (1921), S. 87-93, hier S. 88-90. - Vor-

standssitzung des ADTV am 13.10. 1922, in: MADTV 4 (1922), S. 285. - MADTV 5 (1923), S. 74.

92 Jahresbericht für die Vollversammlung des ADTV am 3.4.1921, in: MADTV 3 (1921), S. 74.

93 Vollversammlung des ADTV am 14. 5. 1926, in: MADTV 8 (1926), S. 90.

94 MADTV6 (1924), S. 53. - Vollversammlung des ADTV am 14. 5. 1926, in: MADTV 8(1926), S. 90. 
Gebieten des wirtschaftlichen Lebens und darüber hinaus war eine in der Umbruchsphase häufige Erscheinung; hier handelte es sich, ähnlich wie etwa im Fall der Währungstrennung oder der Nostrifizierung der Unternehmen, um den Gesamtvorgang der Konstituierung des neuen Staates und der Grenzziehung auf allen Lebensgebieten. Der Anspruch des Zentralverbands, gesamtstaatlicher Vertreter der industriellen Interessen eines Staates tschechoslowakischer Identität zu sein, führte zu einer deutschen "Gegengründung" - zunächst im defensiven, grundsätzlich aber in einem ähnlich nationalistisch imprägnierten Geist. Auch "nationale Differenzierung" war beileibe kein Einzelfall, sondern in der Interessenorganisation und im Parteienwesen der Republik eher die Regel als die Ausnahme. Ergebnis der Gründungsphase waren nicht beziehungslos nebeneinander existierende, sondern partiell sich überschneidende Strukturen - zwar mit je unterschiedlicher Schwerpunktsetzung, aber durchaus mit Überlappungen der Fach- oder auch der Regionalorganisation: diffuse Ränder als Grundlage zukünftiger Interessenharmonie. 


\title{
2. Der Zentralverband, der Hauptverband und die tschechoslowakische Wirtschaftspolitik (1918-1922)
}

\author{
a) Selbstverständnis, Schauplätze, Handlungsspielräume
}

Hinsichtlich ihres Selbstverständnisses, ihrer Ziele und Handlungsspielräume hatten sich die beiden Industrieorganisationen mit analogen Problemen auseinanderzusetzen: die Stellung zu Staat und Politik, zum parlamentarischen System und zu den Parteien, die Frage von Kooperation oder Verweigerung. Wie war es auf diesen Feldern um die Gemeinsamkeiten bzw. Unterschiede zwischen Zentralverband und Hauptverband bestellt?

Die vorrangige Aufgabe des Zentraiverbands, die Mitwirkung an der gesamtstaatlichen wirtschaftspolitischen Willensbildung, strich eine Statutenänderung vom Mai 1919 noch deutlicher heraus. Die Vereinigung sollte nun nicht mehr lediglich auf Aufforderung durch staatliche Stellen, sondern zusätzlich nach eigenem Gutdünken durch Gutachten und Stellungnahmen auf Gesetzgebung und Verwaltung einwirken. ${ }^{1}$ Verlautbarungen des Zentralverbands benannten, dem von ständischem Gedankengut durchwirkten mitteleuropäischen Zeitgeist der Nachkriegsjahre adäquat, als denkbaren institutionellen Rahmen der Einflußnahme sporadisch zwar auch ein durch die Korporationen von Industrie und Handel beschicktes „Wirtschaftsparlament", eine zweite legislative Körperschaft, der vorzugsweise die Wirtschaftsgesetzgebung überantwortet werden sollte. ${ }^{2}$ Im allgemeinen bewegten sich die führenden Köpfe des Zentralverbands jedoch pragmatisch innerhalb des vom parlamentarisch-demokratischen Institutionengefüge der Ersten Republik vorgezeichneten Horizonts und begriffen in diesem Rahmen ihre Organisation als legitime Pressure Group. Der Staat müsse - so umriß 1921 Hodáč deren Selbstverständnis - mit dem Zentralverband als "Interessent" rechnen, auch wenn im Vorkriegs-Österreich vor diesem Begriff „eine abergläubische Furcht" geherrscht habe, welche sich "vielfach" auf die tschechoslowakischen Behörden übertragen habe. Ungeachtet mannigfacher, Regierung und Verwaltung zugeordneter Beiräte und Kommissionen obliege das Geschäft der Interessenvertretung im wesentlichen einem freien Verein. Als solcher habe sich der Zentralverband konstituiert, ungeachtet dessen, daß in den ersten Jahren der Republik unter den Vorzeichen der „gebundenen Wirtschaft" der Organisationszwang durchsetzbar gewesen wäre. ${ }^{3}$

Angesichts dieser Auffassung vom Zweck des Zentralverbands mutet auf den ersten Blick erstaunlich an, daß die Statuten in der Fassung vom Mai 1918 eine politische Be-

1 SÚA, ÚSČP, Karton 10, Behandlung der Änderungsfrage auf der Vollversammlung des Zentralverbands am 10.5.1919. - SÚA, ÚSČP, Karton 21, 0/0/1-0/3/1 (1918-1948), Auszug aus dem Protokoll der Generalversammlung des Zentralverbands am 10.5.1919. - Ebenda, Mitteilung des Zentralverbands an die Politische Landesverwaltung, 3.11.1919. - Ebenda, Neue Statuten, undatiert, deutsche Fassung. - Vgl. auch die Resolution zur öffentlichen Verwaltung, vorgelegt von Hodáč auf der Vollversammlung des Zentralverbands am 11.5. 1919, in: TA vom 12. 5. 1919.

2 Resolution zur öffentlichen Verwaltung, vorgetragen von Hodáč auf der Vollversammlung am 11. 5. 1919, in: TA vom 12. 5. 1919. - Reden Hodáčs und Malinskýs, Vollversammlung des Zentralverbands am 13.3.1920, in: OB 2 (1920), S. 1-3.

3 Rede Hodáčs, Vollversammlung des Zentralverbands am 28.5.1921, in: OB 3 (1921), S. 346 f. Generalversammlung des Zentralverbands anläßlich des zehnjährigen Verbandsjubiläums, in: OB 10 (1928), S. $309 \mathrm{f}$. 
tätigung ausdrücklich ausgeschlossen hatten. Auch in der Folgezeit, etwa auf der Vollversammlung vom März 1920, betonte Hodác, man beschränke die Kooperation mit der Verwaltung auf „rein fachliche“ Aktivitäten. ${ }^{4}$ Zwar blieb intern diese Linie in den krisenhaften Anfangsjahren der Republik keineswegs unwidersprochen: Auf der Vollversammlung von 1919 etwa quittierte das Plenum einen Diskussionsbeitrag von den Rängen, der das „Politikverbot“ der Satzung attackierte - das Proletariat geriere sich weniger verschämt-abstinent - bezeichnenderweise mit Beifall. ${ }^{5}$ Am selben Ort rief der nationaldemokratische Handelsminister Stranský die Industriellen zu kämpferischer Beeinflussung der öffentlichen Meinung nach dem Vorbild der Arbeiterbewegung auf. ${ }^{6}$ Wenn der Zentralverband de facto auch keineswegs parteipolitische Abstinenz übte und zum Beispiel, als Präsident Malinský 1919 sein Abgeordnetenmandat aufgab, forderte, dieser Sitz müsse einem Industrievertreter vorbehalten werden ${ }^{7}$, so blieb der „unpolitische Charakter" der Industrievertretung trotzdem die „Lebenslüge" der Organisation.

Eine Erklärung des Politikverbots lediglich anhand des aus der österreichisch-ungarischen Monarchie übernommenen tschechoslowakischen Vereinsrechts, das keine „politischen Vereine" kannte, griffe zu kurz. Eine maßgebliche Rolle spielte auch der gegen Linksparteien und Gewerkschaften gemünzte Anspruch auf Verkörperung der ausschließlich an der Sache orientierten wirtschaftlichen Gesamtvernunft. Der Einfluß des Zentralverbands, so im Mai 1923 der Bescheid Hodáčs an die Adresse der Kritiker, denen das Auftreten des Verbandes "nicht radikal genug" erschien, beruhe nicht auf einer in die Millionen gehenden Mitgliedschaft oder auf einem Propagandaapparat, sondern auf seinem moderaten Agieren als Stimme des Sachverstands, jenseits aller politischen Oszillationen. ${ }^{8}$ Im Hinblick auf die Nationalitätenproblematik noch wichtiger ist eine weitere Facette dieses zumindest dem Buchstaben nach apolitischen Selbstverständnisses: Da der Zentralverband sich berufen fühlte, „die Industrie und deren Interessen in die künftige Organisation des čechischen (!) Staates einzugliedern ${ }^{\text {"9 }}$, mußte er sich als eine die Unternehmerschaft der Republik in ihrer Gesamtheit integrierende, somit auch die Nationalitätengrenzen transzendierende Vereinigung verstehen. Dieser Gesichtspunkt bewog Hodáč zu der Forderung, die Aktivitäten des Zentralverbands seien von „Komplikationen durch politische Rücksichten welcher Art immer (!)“ freizuhalten und an "streng wirtschaftlichen Gesichtspunkten" zu orientieren. Mit den hier angesprochenen potentiellen „Störfaktoren" konnte nach Lage der Dinge nur die separate Verbandsgründung der Deutschen gemeint sein. ${ }^{10}$

Auch der Hauptverband begriff sich als Interessenorganisation ${ }^{11}$ - sehr viel prononcierter als der Zentralverband jedoch als (national-) politische. Offizielle Verlautbarun-

4 Rede Hodáčs, Vollversammlung des Zentralverbands am 13.3.1920, in: OB 2 (1920), S. 3.

5 SỨA, ÚSČP, Karton 10, Rede des Unternehmers Kášs, Vollversammlung des Zentralverbands am 10.5. 1919.

6 SÚA, ÚSČP, Karton 10, Rede Stranskýs, Vollversammlung des Zentralverbands am 11. 5. 1919. PT vom 13. 5. 1919.

7 SÚA, ÚSČP, Karton 21, Korrespondenz Hodáč 0/2/1, Protokoll der Sitzung des Präsidialausschusses am 17.11.1919.

8 Rede Hodáčs, Vollversammlung des Zentralverbands am 25.5.1923, in: OB 5 (1923), S. 357 f.

9 Rede Hodáčs, Vollversammlung des Zentralverbands am 25. 5.1923, in: OB 5 (1923), S. 358.

10 Rede Hodáčs, Vollversammlung des Zentralverbands am 13. 3. 1920, in: OB 2 (1920), S. 2.

11 „Verbandsnachrichten“, in: MDHI 2 (1921), S. $221 \mathrm{f}$. 
gen, insbesondere wenn sie an die Adresse der Behörden gerichtet waren, spielten aus taktischen Gründen diesen Umstand in der Regel herunter. So betonte etwa die dem Handelsministerium übersandte "Geburtsanzeige" des DHI die ausschließlich wirtschaftliche Zwecksetzung des Verbandes. ${ }^{12}$ Die Stellungnahme zum wirtschaftspolitischen Programm der deutschen bürgerlichen Parteien vom Frühjahr 1920 strich heraus, der Gründung des Hauptverbandes habe, da Politik nicht Sache des Unternehmers sei, jede "politische oder demonstrative Tendenz" ferngelegen. Hier, en famille, setzte man die Akzente aber durchaus auch anders: Im gleichen Atemzug wurde die verbandliche Formierung nämlich als ein - schwerlich anders denn politisch zu verstehender - „Akt zur Wahrung des deutschen industriellen Besitzstandes" apostrophiert. ${ }^{13}$

Fanden sich im Zentralverband lediglich Spurenelemente einer Auseinandersetzung um die Problematik der korporativen Repräsentation, so wurden im Hauptverband intensivere Überlegungen über die Alternative „Parlament oder ständische Vertretung“ angestellt. ${ }^{14}$ Eine im Herbst 1919 im Milieu der deutschen bürgerlichen Parteien und an der Spitze des Hauptverbandes einsetzende Debatte konfrontierte das Konzept des Wirtschaftsparlaments mit dem Modell der pluralistisch-parlamentarischen Interessenvertretung durch einen freien Verband mit "parlamentarischem Arm “. Die Diskussion intensivierte sich nach den Parlamentswahlen im Frühjahr 1920, die bekanntlich zum ersten Mal deutschen Abgeordneten ins Parlament, der deutschen Wirtschaft dort aber zu keiner zufriedenstellenden Vertretung verholfen hatten. Es sei nicht gelungen, so der Kommentar des prominenten Wirtschaftsjournalisten Franz Bacher, den ökonomischen Sachverstand der Deutschen in der Nationalversammlung zu verankern. ${ }^{15}$ Wilhelm Medinger, prominenter Vertreter der Deutschen Nationalpartei, machte das mangelnde parlamentarische Engagement der Industrie für das System „wirtschaftsloser Professionspolitiker" verantwortlich, das ungehindert eine wirtschaftsfremde Gesetzgebung produzieren könne. ${ }^{16}$ Diese auf lebhaften Widerhall stoßende Diagnose ${ }^{17}$ steigerte Mühlig ${ }^{18}$ zu grundsätzlicher Skepsis gegenüber dem Parlamentarismus, welcher der sozialen und - unter den speziellen tschechoslowakischen Bedingungen - der nationalen "Hetze" eine Plattform biete und sachorientierte Problemlösungen blockiere. Nur ein Wirtschaftsparlament auf der Grundlage eines berufsständischen Schlüssels hielt Mühlig für imstande, ohne "Popularitätshascherei“ auszukommen; „nicht völlig unbegründet“ sei die Hoffnung, eine solche Körperschaft könne in der Tschechoslowakei auch eine Versöhnung der Nationalitäten bewirken.

12 SÚA, MPOŽ, Karton 316, 2762/20, Hauptverband der deutschböhmischen Industrie an Handelsministerium, 18.11.1919.

13 PA, R 89 745, Äußerung des DHI zum wirtschaftspolitischen Programm der deutschen bürgerlichen Parteien, undatiert, dem Sachzusammenhang nach aber aus dem Frühjahr 1920. Einem auf dem Papier angebrachten handschriftlichen Vermerk zufolge dürfte das Papier von Kislinger stammen.

14 Vgl. zu den Grundzügen der Lehre von der „berufsständischen Ordnung“ bei Spann, Spengler u. a. die Skizze von Hock, Antikapitalismus, S. $35 \mathrm{f}$. und $65 \mathrm{ff}$.

15 Bacher, Senatswahlen, S. 1.

16 Medinger, Vertretung der Industrie. - Die selbe Diagnose galt bezüglich der deutschen Technik: Die Technischen Hochschulen von Prag und Brünn hatten keinen Sachwalter im Parlament: Vgl. Bach, Vertretung.

17 So die Einschätzung bei Wolfrum, Industrie, S. 347-349.

18 Mühlig, Vertretung. 
Sicherlich manifestierte sich in Mühligs Stellungnahme auch eine gute Portion Zeitgeist - die reichsdeutsche Industrie etwa setzte vorzugsweise auf korporatistische Mechanismen. ${ }^{19}$ Abgesehen hiervon nährten aber auch die erschwerten Arbeitsbedingungen der deutschen Abgeordneten in der Nationalversammlung die Ablehnung: Selbständige Anträge, so eine die allenthalben lautgewordene Kritik bündelnde Interpellation Křepeks und Lodgmans vom Oktober 1920, verhedderten sich im Initiativausschuß, Abänderungs- und Zusatzanträge würden niedergestimmt. Offene parlamentarische Auseinandersetzungen würden durch Absprachen zwischen den Koalitionsparteien hinter den Kulissen ersetzt; unter der im Herbst des Jahres installierten, von der alltschechischen Koalition unterstützten Beamtenregierung Černý hätten sich die Zustände noch verschlimmert. ${ }^{20}$

Auch die Gründungsversammlung des DHI hatte das ständische Konzept diskutiert, war jedoch aus der nüchternen Erwägung heraus, die Zuständigkeit für die Wirtschaftspolitik werde augenscheinlich bei der Nationalversammlung verbleiben, zu seiner $\mathrm{Ab}$ lehnung gelangt. ${ }^{21}$ Im Vorfeld der Gründung des Hauptverbandes hatten industrielle Kreise sogar eine die Arbeiterschaft einbeziehende gesamtständische Organisation erwogen. ${ }^{22}$ Allerdings war man dann auch hier realistisch genug für die Einsicht, daß dieses Konzept am Klassengegensatz scheitern müsse. ${ }^{23}$ Aufs Ganze gesehen dominierte in der Foigezeit im Hauptverband ein Vernunftparlamentarismus, der mit der Sympathie für die gängigen kritischen Topoi - „Mittelmäßigkeit“ des Berufspolitikertums, „Parteiendespotismus" - durchaus kompatibel war, trotz einer als "abstoßend“ apostrophierten Situation die Überwindung antiparlamentarischer Wallungen aber für opportun erachtete. ${ }^{24}$ Viele Unternehmer - so Doderer, der sich 1921 in den „Mitteilungen “ des Hauptverbandes sicherlich nicht nur als Privatmann so unverblümt äußerte - glaubten an die Chimäre einer Trennung von Wirtschaft und Politik und seien erst spät, angesichts der sich verschärfenden Wirtschaftskrise und der steigenden Flut des tschechischen Chauvinismus, dabei zu erwachen. Aufgabe der deutschen Parteien sei die Sicherung der ökonomischen Lebensgrundlagen der Deutschen; hieraus ergebe sich andererseits auch das Ansinnen an die Unternehmer, ihre Stimme in den Parteien und in der Öffentlichkeit geltend zu machen. ${ }^{25}$

Aus diesem Grund war der Hauptverband sowohl hinter den Kulissen ${ }^{26}$ wie auch auf

19 Der Anteil der Industriellen an den Reichstagsabgeordneten hatte in Deutschland schon in den beiden Jahrzehnten vor dem Ersten Weltkrieg signifikant abgenommen; ähnlich waren die Entwicklungstrends in England und Frankreich. Verantwortlich waren zum einen die mit wachsender Komplexität der Betriebsleitung abnehmende Verfügbarkeit der Unternehmer für die Parlamentsarbeit und das Anwachsen der sozialistischen Stimmen; zum anderen sah man indirekte Einflußnahme als aussichtsreicher an. Theodor Eschenburg warnte die Industrie Anfang der zwanziger Jahre vor den verderblichen Folgen politischer Abstinenz: Vgl. Best, Politische Modernisierung, S. 63 ff. - Cassis, Wirtschaftselite, S. 28 ff. - Eschenburg, Kaiserreich, S. 183.

20 Dringende Interpellation Křepek, Lodgman und Genossen vom 27. 10. 1920, 1. WP, Drucksache Nr. 643.

21 WI 1 (1919), S. 1.

22 BArch-B, RMWi, 2885, Mitteilung AA an RMWi vom 6.9.1919.

23 Doderer, Industrie.

24 Lecher, Industrie.

25 Doderer, Industrie.

$26 \mathrm{Zu}$ den subkutanen Vernetzungen zwischen Hauptverband und Parteien lassen sich, wie nicht anders zu erwarten, den Quellen nur sporadische, fragmentarische Hinweise entnehmen. Ein In- 
der Bühne der Politik präsent. Er stand im bürgerlichen Lager, ohne dort unter den deutschen Parteien über einen ausgesprochenen Wunschpartner zu verfügen. Auf dem Reichenberger Industriellentag im August 1921 etwa wurden mit den Senator(-innen) Hartl und Herzig, mit Ledebur und Medinger sowohl die Vertreter der Deutschen Nationalpartei wie auch die der Christlich-Sozialen begrüßt. ${ }^{27}$ Auf den Vollversammlungen des Hauptverbands waren Vertreter des bürgerlichen Aktivismus unterschiedlicher Schattierung anwesend. ${ }^{28}$ Die Beziehungen zu Lodgman hingegen, der im Herbst 1919 die treibende Kraft hinter der Sammlung der industriellen Interessen gewesen war, entwickelten sich nicht unproblematisch: Der Hauptverband, so im Frühjahr 1921 eine Mitteilung Kislingers an den Reichsverband der deutschen Industrie, sei eine Interessenorganisation und als solche nicht irredentistisch. Er fordere Autonomie für die Wirtschaft, wolle aber im Staat mitarbeiten und stehe folglich nicht auf dem Boden von Lodgmans Anschauungen. ${ }^{29}$

In diesen Kontext gehören auch die Beziehungen des DHI zur Deutschpolitischen Arbeitsstelle, welche die Aktivitäten der im Deutschen Parlamentarischen Verband zusammengeschlossenen deutschen bürgerlichen Abgeordneten der Nationalversammlung koordinierte. ${ }^{30} \mathrm{Da}$ die Arbeitsstelle nicht durch die Parteien finanziert wurde, sondern durch einen Zirkel von Sponsoren, deren Beiträge jedoch die Kosten nicht deckten,

diz für die Verbindungen zwischen Wirtschaft und Politik sind die hie und da begegnenden Finanzhilfen (Mechanismen "regulärer" Parteienfinanzierung waren aus den Quellen nicht zu ermitteln). So trug sich etwa der Christlich-Soziale Mayr-Harting mit dem Gedanken, für die Gründung einer Zeitschrift im Dienste der christlich-sozialen Idee Liebieg, Ginzkey und andere Industrielle um eine - recht beträchtliche - Subvention von 100000 Kronen anzugehen: Vgl. AKPR, T 12/25, Karton 134, C 2, Aktenvermerk Śámal vom 23.11.1923. - In der Dreieckskonstellation von DHI, deutschen Parteien und tschechischer Politik konnten später, zur Zeit der deutschen Regierungsbeteiligung, beiden Partnern Gefälligkeiten erwiesen werden. So gab etwa "ein hervorragender böhmischer Industrieller“ (es handelte sich um Kislinger) Sámal das Versprechen, man werde bei der Besetzung von Verwaltungsratssitzen im Frühjahr 1932 an Mayr-Harting denken: Vgl. AKPR, T 12/25, Karton 135, C V, Aktenvermerk Sámal vom 17. 2.1932 und Mitteilung Sámal an Mayr-Harting, 20.2.1932.

27 Industriellentag am 15.8.1921 in Reichenberg, in: MDHI 2 (1921), S. 381-398.

28 Z. B. Vollversammlung vom 4. 2. 1922, in: MDHI 3 (1922), S. 5 ff. - Auch hier war die Lage der im Reich vergleichbar, wo der RdI zu DDP, DVP, Zentrum und DNVP Beziehungen unterhielt: Vgl. Ullmann, Interessenverbände, S. 139.

29 PA, II b, Wirtschaft 10, Tschechoslowakei, Band 1, Mitteilung des AA/Zweigstelle München an AA vom 7. 4. 1921 über die Stellungnahme Kislingers. Allerdings ist in Rechnung zu stellen, daß der RdI damals im Interesse guter Beziehungen zwischen Deutschland und der ČSR nur mit dem Zentralverband verkehrte und zum DHI Distanz hielt, weswegen diesem daran gelegen sein mußte, den RdI von seiner Einstellung zur Republik zu überzeugen. Im November 1921 ließ Kislinger aber auch gegenüber Kanzler Sámal durchblicken, die deutschen Industriellen lehnten die einseitige Politik Lodgmans ab: Vgl. AKPR, T 12/25, Karton 134, C 1, Aktenvermerk Sámal vom 13.11. 1921. Hier bestand allerdings ein massives Interesse, die Burg von der Loyalität des DHI zu überzeugen, denn das Gespräch diente der Vorbereitung der Audienz deutscher Industrieller bei Masaryk. - Immerhin fällt auf, daß erst 1924 Lodgman wieder als Gast auf einer Vollversammlung des DHI begrüßt wurde: Vgl. Vollversammlung des DHI am 15.3.1924, in: MDHI 5 (1924), S. 209. - Insgesamt gesehen sind die Quellen für eine differenziertere Analyse der Beziehungen bedauerlicherweise zu dürttig.

30 Die Deutschpolitische Arbeitsstelle war im Herbst 1919 nach dem Vorbild der vor dem Krieg von dem Textilindustriellen Hermann Brass gegründeten deutschnationalen Geschäftsstelle, einer Verbindungsstelle zwischen den deutschen Reichsratsmitgliedern unterschiedlicher Parteien aus Böhmen, Mähren und Schlesien, ins Leben gerufen worden. Im Kontext der ersten Wahlen 
bereisten Spendenwerber systematisch das deutsche Gebiet und ersuchten „nach vertraulicher Unterrichtung " die Industriellen um Zuwendungen. ${ }^{31}$ Als juristische und volkswirtschaftliche Beiräte des "Sudetendeutschen Minderheitenausschusses", der die Deutschen der Tschechoslowakei gegenüber dem Völkerbund vertrat und sich hierbei der Kanzlei der Deutschpolitischen Arbeitsstelle bediente, fungierten der prominente Wirtschaftsanwalt Franz Wien-Claudi und, mit Schicht, Doderer, Brass und Kislinger, die Crème von DHI und ADTV. ${ }^{32}$ Die zum Zeitpunkt der Gründung des Minderheitenausschusses bereits aufgelaufenen Schulden in Höhe von mehreren hunderttausend Kronen konnten durch Spenden „einzelner wirtschaftlicher Organisationen" zum großen Teil abgebaut werden. ${ }^{33}$

Im Frühjahr 1920 berief die Deutschpolitische Arbeitsstelle eine Versammlung aller deutschen Wirtschaftsverbände ein. ${ }^{34}$ Der Zeitpunkt war nicht zufällig: Schließlich existierte, wie sogar Lodgman zugab, in Gestalt des Parlaments seit kurzem eine Bühne, auf der die Forderungen der deutschen Wirtschaft der Öffentlichkeit verdolmetscht werden konnten; mit gesammelten Kräften könne man zudem dem Druck auf Eintritt in die tschechischen Verbände besser widerstehen. ${ }^{35}$ Die Konferenz brachte ein umfangreiches Bündel deutscher Gravamina zur Sprache ${ }^{36}$ : unzureichende Exportförderung und schleppenden Abschluß von Handelsverträgen, Benachteiligung der deutschen Ausfuhr

zur Nationalversammlung gewann sie im Frühjahr 1920 als Organ zur logistischen Unterstützung der deutschen bürgerlichen Parlamentarier - die Sozialdemokraten waren nicht vertreten - und zur Wahrnehmung deutscher Interessen gegenüber den Behörden Konturen. Sie fungierte als Arbeitskanzlei verschiedener parlamentarischer Ausschüsse und des „Sudetendeutschen Minderheitenausschusses“, in dessen Auftrag sie Beschwerden der Deutschen an den Völkerbund abfaßte; sie verstand sich also als Motor und Clearingstelle der politischen, wirtschaftlichen und kulturellen „Schutzarbeit“. Die Leitung oblag dem Vorstand und dem zur Hälfte aus Parteienvertretern, zur anderen Hälfte aus prominenten Persönlichkeiten der deutschen bürgerlichen Öffentlichkeit zusammengesetzten Hauptausschuß. Erster Vorsitzender war zunächst Lodgman, dann Ledebur-Wicheln, als zweiter Vorsitzender amtierte - ein Element der Kontinuität zur Vorkriegszeit - Brass. Hauptamtlicher Leiter des Büros war von Frühjahr 1920 bis 1926 Gustav Peters.

31 Die jährlichen Mindestauslagen sollen nie weniger als 300000 Kronen betragen haben. In der zweiten Hälfte der zwanziger Jahre reduzierte sich das Aufkommen durch „sinkende Moral“, Steuerdruck und die Industriekrise, weswegen man sich zur Deckung der Finanzierungslücken jetzt an das Reich wandte: Vgl. PA, RA 73 831, „Selbstauskunft“ der Deutschpolitischen Arbeitsstelle, von dieser am 18.2.1927 an Auswärtiges Amt übersandt. - Über die globale Beteiligung der deutschen Wirtschaft an der Finanzierung hinaus war hinsichtlich der Höhe des Engagements einzelner Industrieller nichts in Erfahrung zu bringen.

32 Der Ausschuß unter dem Vorsitz Ledebur-Wichelns bestand aus den Vertretern der sechs deutschen bürgerlichen Parteien, d.h. der Christlich-Sozialen, der Deutschen Nationalpartei, der Deutschen Nationalsozialistischen Partei, der Deutschen Gewerbepartei, der Deutschdemokratischen Freiheitspartei und des Bundes der Landwirte. Vertreten war außerdem - durch Medinger - die Deutsche Völkerbundliga: Vgl. „Selbstauskunft“ der DPA, wie vorhergehende Anmerkung.

33 PA, R 30500, K II, Ledebur-Wicheln an AA, 23.7. 1927. Über die beteiligten Organisationen war nichts Näheres in Erfahrung zu bringen.

34 Jahresbericht der Deutschpolitischen Arbeitsstelle über das Jahr 1920, S. 9 f.

35 SÚA, SdP, dod., Karton 24, Verhandlungsschrift über die Tagung der wirtschaftlichen Verbände mit den neugewählten deutschen nationalen Abgeordneten und Senatoren, herausgegeben von der Deutschpolitischen Arbeitsstelle. Hier auch die übrigen im folgenden referierten Beiträge.

36 Das Referat über Finanzfragen hielt Franz Bacher, zu den speziellen Wünschen der Industrie äußerte sich, als leitender Beamter des DHI, Dr. Siegl, Medinger referierte über die Bodenreform, 
durch die Im- und Exportsyndikate und die Devisenzentrale, Hintansetzung der deutschen gegenüber den tschechischen Banken und deren Expansion in die deutsche Wirtschaft hinein, Bürokratisierung, einen immensen Steuer- und Abgabendruck, die Kriegsanleihenfrage, mangelnde Konsultation der deutschen Verbände bei Gesetzesvorhaben, Benachteiligung bei der Vergabe von Staatsaufträgen sowie „sozialpolitische Experimente" wie Sozialisierung, Gewinnbeteiligung und die Gründung von Betriebsräten. Angesichts der durch die „Eroberungsgelüste“ des "tschechischen Chauvinismus" erlittenen Terrainverluste forderte der Geschäftsführer der Arbeitsstelle, Peters, eine eigenständige, Klassen- und Schichten überspannende deutsche Nationalökonomie. Die Deutschen seien, wie der Versammlungsleiter, Handelskammersekretär Freißler, ausführte, seit jeher autoritätsgläubig und erwarteten Hilfe von Regierung und Parlament, vielleicht auch von der Entente oder vom Völkerbund, sie übersähen jedoch, daß ihnen "gerade in diesem Staate gar nichts anderes helfen kann, als ihre eigene Kraft".

Der von Peters angestimmte, von anderen Rednern aufgenommene Ruf nach „Selbstwehr, Selbsthilfe, Selbstverwaltung" implizierte - jedenfalls auf den ersten Blick - eine ethnische Grenzziehung quer durch die Wirtschaft, mit dem ersten Schritt einer Katastrierung des deutschen Besitzstands; gefordert wurden die Vereinheitlichung und Straffung der Wirtschaftsverbände und die Stärkung des deutschen Bank-, Genossenschaftsund Gewerkschaftswesens, die Markierung der Scheidelinie zu den jeweiligen tschechischen Pendants und die Fokussierung der Geschäftsbeziehungen nach dem tschechischen Vorbild des „svůj ke svému“ - der Parole "Jeder zu den Seinen“, die vor 1918 der Schlachtruf der tschechischen Emanzipationsbewegung gewesen war: Die deutsche Industrie sollte das deutsche Gewerbe und die deutschen Genossenschaften beliefern; Aufgabe des deutsche Bankwesen sei es, die hierfür erforderlichen Kredite bereitzustellen. Klangen solche Verlautbarungen prima facie auch nach einer Wiederauflage der sezessionistischen Anwandlungen vom Herbst 1918, so beinhaltete dieser Katalog doch keineswegs die Absage an die Mitarbeit im Staat. Vielmehr sollten in den zentralen Sektionen des Handels- bzw. des Arbeitsministeriums deutsche Beamte als Vertrauensleute der deutschen Wirtschaft plaziert werden - eine Forderung, deren Realisierung die Regierungsbeteiligung der deutschen Parteien geradezu voraussetzte. Die verantwortungsvolle Aufgabe, zu entscheiden, wann der Zeitpunkt hierfür gekommen sei, wurde den deutschen Parlamentariern zugewiesen.

Die Konferenz endete - ganz in der Konsequenz dieser letzlich wirtschaftsaktivistischen Einstellung - mit dem von Peters angeregten Beschluß zur Errichtung einer „Deutschen Wirtschaftsstelle“. Der Deutschpolitischen Arbeitsstelle sollte unter diesem Namen eine Wirtschaftsabteilung angegliedert werden, die enge Kontakte mit den deutschen Parlamentariern zu halten, alle aus deutscher Sicht wichtigen Probleme der Wirtschaftspolitik zu bearbeiten und so für eine optimale Abstimmung der „beiden Abwehrfronten" Wirtschaft und Politik zu sorgen hatte. Dem mit der Durchführung dieses Beschlusses betrauten Komitee gehörte als Vertreter der Industrie Kislinger an. ${ }^{37}$ Die in der Folgezeit für den Ausbau der deutschen Wirtschaftsorganisation zuständige wirtschaftspolitische Reichsstelle besaß einen Beirat, bestehend aus Vertretern aller wirt-

der Direktor der Deutschen Agrar- und Industriebank, Ulbrich, über das Bankwesen, Landesrat Kubelka über Gewerbe und Handel.

37 Verhandlungsschrift über die Tagung. - Jahresbericht der Deutschpolitischen Arbeitsstelle über das Jahr 1920, S. 9 f. 
schaftlichen Interessengruppen sowie aus je zwei Vertretern der fünf nationalen Parteien. Im Exekutivausschuß der Reichsstelle saß als Vertreter der Industrie wiederum Kislinger, das Büro, finanziert von den großen Wirtschaftsverbänden, leitete ab Anfang Oktober 1920 Karl Janovsky, der Generalsekretär des DHI. ${ }^{38}$

Richtungsweisende Initiativen vom Kaliber der Maikonferenz gingen in den folgenden Monaten und Jahren von der Deutschpolitischen Arbeitsstelle allerdings bezeichnenderweise nicht mehr aus. Ihre Aktivitäten erschöpften sich im Alltagsgeschäft der Informationssammlung und -aufbereitung ${ }^{39}$ und in Einzelfallinterventionen bei den $\mathrm{Be}$ hörden. ${ }^{40}$ Auch die wirtschaftspolitische Reichsstelle wirkte im Einklang mit ihrem Gründungszweck in der Folgezeit weniger als impulsgebende denn als koordinierende und die Außenbeziehungen der deutschen Wirtschaft pflegende Einrichtung, in welcher Eigenschaft sie auch Fäden zu offiziellen Stellen im Reich knüpfte ${ }^{41}$ und die Öffentlichkeitsarbeit pflegte. $^{42}$

Das vorläufige Fazit hat auf den - gemessen am Zentralverband - „mühsameren Parlamentarismus" des Hauptverbands und seine stärkere Affinität zum ständischen Gedankengut abzuheben. Die Ursache ist vermutlich weniger darin zu suchen, daß auf tschechischer Seite die „besseren Demokraten“ zu finden waren. Entscheidend war die weniger günstige Position der Deutschen in der politischen Landschaft der frühen Republik. Vorherrschend waren, wie die Maitagung 1920 demonstriert, zunächst die Tendenzen zum Rückzug ins „deutsche Milieu“. Dies implizierte allerdings nicht den Abbruch aller Brücken; der Hauptverband bemühte sich, ebenso wie der Zentralverband, von Anfang an in der Konstellation zwischen Parteien, Parlament, Regierung und Bürokratie um Ansprechpartner.

38 Jahresbericht der Deutschpolitischen Arbeitsstelle über das Jahr 1920, S. $9 \mathrm{f}$.

39 Die Arbeitsstelle verfügte über eine aus 28 tschechischen und 105 deutschen Periodika gespeiste Zeitungsausschnittsammlung, die allen Benutzern aus Politik, Wirtschaft oder Kultur zur Verfü-gung stand: Vgl. Jahresbericht der Deutschpolitischen Arbeitsstelle über das Jahr 1920, S. $11 \mathrm{f}$.

$40 \mathrm{Im}$ zweiten Halbjahr 1920 sprach die Arbeitsstelle vierundsiebzigmal in Angelegenheiten der deutschen Industrie bei der Verwaltung vor. Wirtschaftsangelegenheiten waren damit der zweithäufigste Interventionsgrund überhaupt: Vgl. Jahresbericht der Deutschpolitischen Arbeitsstelle über das Jahr 1920, S. $14 \mathrm{f}$.

41 Anfang 1921 kündigte Janovsky im Auswärtigen Amt einen Besuch von Peters an, anläßlich dessen interessierte Mitarbeiter über die einschlägigen Fragen informiert werden sollten: PA, R 118 331, Janovsky an AA, 14.1.1921.

42 Janovsky etwa publizierte 1921 eine Gegendarstellung zu Jan Koloušeks Schrift „La Situation économique et financière de la République tchécoslovaque vers la Fin de l'Année 1920“, einer amtlichen, im Auftrag des tschechoslowakischen Außenministeriums und im Rahmen seiner Auslandspropaganda verfaßten Studie. In der Kritik an dieser Schrift verwahrte sich Janovsky gegen die Leugnung des Charakters der typisch deutschen Industrien in Böhmen, indem man die Deutschen dort einfach zu Tschechen erkläre: Vgl. die Stellungnahme Janovskys im Auftrag der deutschen Parlamentarier der Tschechoslowakei, herausgegeben im Auftrag des Deutschen Parlamentarischen Verbandes von der Deutschpolitischen Arbeitsstelle, Prag o.J. (1921). 


\section{b) Bundesgenossen, Konkurrenten, Ansprechpartner}

"In der Tschechoslowakei“, so Bachers Diagnose 1919, „hat sich auch in wirtschaftlichen Dingen ein Obrigkeitsregime herausgebildet, das in starrer Anlehnung an streng bureaukratische Systeme über Existenzfragen ganzer Untertanengruppen entscheidet,

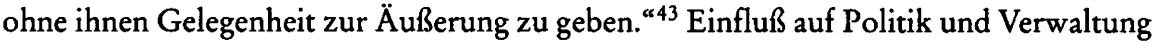
zu gewinnen war unter diesen Vorzeichen für den Zentralverband nicht weniger als für den Hauptverband ein vorrangiges Problem.

Klagte man deutscherseits auch über Zurücksetzung aufgrund tschechischer Ressentiments, so verzerrte doch die nationalitätenpolitische Brille die Wahrnehmung, denn Unmut über die mangelnde Einbindung in den wirtschaftspolitischen Entscheidungsprozeß wurde auch im Zentralverband laut: Die revolutionäre Nationalversammlung habe, so eine Resolution vom November 1919, die Konsultation der Industrie bei der Behandlung einer Reihe wichtiger sozial- und finanzpolitischer Vorlagen unterlassen. ${ }^{44}$ Ähnliche Monita begleiteten die Verbandsaktivitäten in den folgenden Jahren. Nach dem Abtritt des Kabinetts Kramář betrieb die bis September 1920 amtierende Regierung Tusar, die im Kern auf der Kooperation der tschechischen Agrarpartei mit den Sozialdemokraten beruhte, eine Politik, welche mit der Kohlensteuer und hohen indirekten Abgaben, Gebühren und Frachttarifen die Belastbarkeit der Wirtschaft auf die Probe stellte. ${ }^{45}$ Der nationaldemokratische Handelsminister Stranský äußerte sich im Mai 1920 entschuldigend gegenüber seiner industriellen Klientel, sie dürfe von dieser Koalition keine Hilfe erwarten. ${ }^{46} \mathrm{Zu}$ den Barrieren, die aus der parteipolitischen Konstellation resultierten, kam die von Bacher monierte, seit den Zeiten der Monarchie lebendig gebliebene Tradition administrativer Wirtschaftsreglementierung sowie eine Präponderanz wirtschaftsfremder Juristen in der Verwaltung. ${ }^{47}$

Parteipolitische Konstellation und Bürokratismus engten also den Spielraum nicht nur der deutschen, sondern auch der tschechischen Industriellen ein. Die Position des „nationalen Sonderbundes" DHI war allerdings prekärer als die des Zentralverbands. Der Hauptverband hatte sich beim Handelsministerium als eine den „Besonderheiten der Randgebiete des Staates“ Rechnung tragende Organisation vorgestellit ${ }^{48}$; diese Absetzung gegen die Industrie der innerböhmischen Gebiete hatte wenig mit Wirtschaftsgeographie und viel mit Nationalitätenpolitik zu tun. Hier wie in verschiedenen anderen Verlautbarungen der Folgezeit ${ }^{49}$ wurde der deutsche "Sonderweg" mit den Erfahrungen

43 Bacher, Hauptverband.

44 Resolution, Vollversammlung des Zentralverbands am 4.11.1919, in: OB 1 (1919), S. $14 \mathrm{f}$.

45 Bacher, Abtretende Regierung, S. 227.

46 SÚA, ÚSČP, Karton 10, Rede Stranskýs, Vollversammlung des Zentralverbands am 11.5. 1920.

47 Wandruszka/Urbanitsch (Hrsg.), Habsburgermonarchie, S. 59.

48 SÚA, MPOŽ, Karton 316, 2762/20, Hauptverband der deutschböhmischen Industrie an Handelsministerium, 18.11.1919.

49 SÚA, MPOŽ, Karton 316, 2762/20, Hauptverband der deutschböhmischen Industrie an Handelsministerium, 18.11.1919. - Rede Schichts, Gründungsversammlung des DHI, in: MDHI 1 (1920), S. 4. - Bericht des DHI über das Vereinsjahr 1920, S. 4 f. - PA, R 89 745, Äußerung des DHI zum Wirtschaftspolitischen Programm der deutschen bürgerlichen Parteien, undatiert, dem Sachzusammenhang nach aus dem Frühjahr 1920. Einem auf dem Exposé angebrachten handschriftlichen Vermerk zufolge dürfte das Papier von Kislinger stammen. - Die Motive für die eigenständige Verbandsgründung legt ausführlich dar die Interpellation von Medinger, Kostka, Lehnert und Gen. vom 2. 12. 1920, TTZPS, 1. WP, Drucksache Nr. 949. - Kislinger, Organi- 
der Vorkriegszeit gerechtfertigt, in der die Wiener Verbandszentralen die Belange der böhmischen Peripherie ungenügend berücksichtigt hätten. Hinzu komme das Bedürfnis, in deutscher Sprache zu kommunizieren; daß die Verhandlungssprache des Zentralverbands das Tschechische sei und alle Protokolle ausschließlich in dieser Sprache angefertigt würden, verhindere ein Zusammengehen. Ungeachtet dessen bekundete der DHI seine Bereitwilligkeit, ,in loyaler Weise an dem Wiederaufbaue des wirtschaftlichen Lebens in der Republik mitzuarbeiten“. Dem Mißverständnis einer Identifizierung mit Lodgmans Position sollte auf jeden Fall vorgebeugt werden.

Nun herrschte im Hauptverband durchaus Klarheit darüber, daß die Spaltung und Doppelung der industriellen Interessenvertretung ihre Durchsetzungskraft beeinträchtigte. ${ }^{50} \mathrm{Z}$ war verfügte der Zentralverband - anders als der DHI, der sich nur von Fall zu Fall auf Kontakte zu Ministerialreferenten stützen konnte - über einen direkteren Draht zur Politik. Auch der tschechische Verband aber sei, auf sich gestellt, als Lobby zu schwach. Eine Kooperation der beiden Vereinigungen unter Wahrung ihrer Selbständigkeit lehnte der DHI keineswegs ab. Ihm schwebte ein gemeinsamer, in allen zentralen Fragen einheitliche Stellungnahmen erarbeitender Ausschuß vor. Zur Einrichtung eines solchen Gremiums habe man schon im Herbst 1919 Bereitwilligkeit bekundet; man sei aber zurückgewiesen worden, da nicht überall "der ernste Wille hierzu“ vorhanden gewesen sei. Das Widerstreben des DHI gegen eine Fusion war somit, wie in Verbandskreisen, in den bürgerlichen Parteien und in der deutschen Wirtschaftspresse immer wieder zu hören oder zu lesen war, „nicht immer der Ausdruck separatistischer Bestrebungen oder eitler Eigenbrödelei (!) ${ }^{\times 51}$, sondern resultierte aus der Befürchtung, der Zentralverband wolle den DHI „aufsaugen" und einen Konkurrenten aus dem Wege räumen. Alle tatsächlich oder vermeintlich in diese Richtung weisenden Indizien registrierte der Hauptverband seismographisch: Mitte 1920 etwa faßte der Reichsverband der deutschen Industrie angesichts des bevorstehenden Abschlusses der Handelsvertragsverhandlungen zwischen der Tschechoslowakei und dem Deutschen Reich die Errichtung einer Expositur der reichsdeutschen Wirtschaft in Prag ins Auge. Schon daß in deren Leitung ein tschechischer Sekretär eintreten sollte, rief in "nationalen Kreisen Deutschböhmens" Befremden hervor, welches sicherlich von Überempfindlichkeit zeugte, nachdem sogar der diplomatische Vertreter des Reiches dem Vorhaben bescheinigte, es sei sinnvoll. ${ }^{52}$ Als dann aber die im September 1920 gegründete Außenstelle ausschließlich mit dem Zentralverband zusammenarbeitete und den DHI ignorierte, war dies auch nach Auffassung des Auswärtigen Amtes in Berlin geeignet, die Stellung des tschechischen Verbandes auf Kosten des DHI zu festigen und die Regierung in Prag in ihrer distanzierten Haltung gegenüber dem Hauptverband zu bestärken. ${ }^{53}$ Im Mai

sation. - PA, R 73 825, Vorstand der deutschen Paßstelle Reichenberg, von Strahl, Zusammenfassender Bericht über die Lage der Sudetendeutschen, undatiert, von der Gesandtschaft Prag am 31.3.1925 an AA übersandt. - PA, II b, Wirtschaft 10, Tschechoslowakei, Band 1, AA/Zweigstelle München an AA, 7. 4.1921.

$50 \mathrm{Vgl}$. die Stellungnahmen in der vorhergehenden Fußnote.

51 So die Formulierung Kislingers, in: Ders., Organisation.

52 BArch-B, RMWi, 2885, Gesandtschaft Prag an AA, 15.6.1920.

53 Die Stelle entfaltete ohnehin keine besonders fruchtbringenden Aktivitäten, weil sie nicht ausreichend informiert war und zuwenig Kontakte knüpfte: Vgl. PA, II b, Wirtschaft 10, Tschechoslowakei, Band 1, AA/Zweigstelle München an AA, 7.4.1921 und Gesandtschaft Prag an AA, 29.7.1921. 
1921, als Verhandlungen über eine deutsche Regierungsbeteiligung sich festgefahren hatten und der Deutsche Parlamentarische Verband vorübergehend wieder auf den Konfrontationskurs Lodgmans einschwenkte ${ }^{54}$, polemisierte die Deutschpolitische Arbeitsstelle, die Tschechen wollten, um das wirtschaftliche und finanzielle Übergewicht der Deutschen nicht allzu offensichtlich werden zu lassen und um sich die deutsche Finanzkraft dienstbar zu machen, die Deutschen im Verbandswesen wie im Parlament in einen „Syndikalismus“ hineinzwingen. Hodáč und seinen Genossen, die die Deutschen als „die Geduldeten und Beschenkten“ ansähen, spuke „der Siegertraum noch im Kop$\mathrm{fe}$ ". 55

Im gegebenen Rahmen einer nationalen Sektionierung des Industrieverbandswesens wurde nun tatsächlich der Anspruch des Zentralverbands, als Repräsentant der Industrie des Gesamtstaates an erster Stelle gehört zu werden, von allen tschechischen Kabinetten ungeachtet ihrer parteipolitischen Zusammensetzung anerkannt. Die prinzipiell ablehnende Haltung gegenüber den Deutschen, so im Dezember 1920 eine Interpellation Medingers, werde notdürftig mit dem Argument bemäntelt, Regierung und Verwaltung seien aus technisch-organisatorischen Gründen nur mit einem Adressaten zu verkehren in der Lage. Dies widerspreche dem Grundsatz der Rechtsgleichheit - abgesehen davon, daß der Zentralverband bei weitem nicht die gesamte Wirtschaft der Tschechoslowakei unter seinem Dache vereine. Die Regierung müsse auch keineswegs mit einer Vielzahl von Verbänden verhandeln, sondern lediglich mit dem vom DHI projektierten gemeinsamen Ausschuß der beiden nationalen Großorganisationen, von denen die deutsche die potentesten Steuerzahler des Staates in ihren Reihen versammle. ${ }^{56}$ Allerdings implizierte die Vorrangstellung des Zentralverbands nicht die Ächtung und Entrechtung der Deutschen. Auf der Vollversammlung des Zentralverbands vom Mai 1919 hatte Malinský der Hoffnung auf kollegiale Zusammenarbeit im Gesamtinteresse der Industrie Ausdruck gegeben. ${ }^{57}$ Masaryk hatte schon vorher auf einer Audienz für die Vertreter des Zentralverbands deren Absichtserklärung, die „industrielle Wiedergeburt“ in Eintracht mit den Deutschen anzustreben, mit Befriedigung quittiert und sie als Beispiel für das gesamte öffentliche und private Leben hingestellt. ${ }^{58}$ Bedauerlicherweise, so Viškovský, zerschlügen die Deutschen „aus nationalen Gründen“ die „einheitliche Front“. Nach dem Abklingen der nationalen Leidenschaften werde die nordböhmische Industrie hoffentlich zum Zentralverband, der bereits an die 1500 deutsche Mitglieder vertrete, finden. Die deutsche Industrie, seit alters an eine Vorzugsstellung gewöhnt, müsse sich, auch wenn dies schwerfalle, den neuen Rahmenbedingungen anbequemen und in der Einheitsorganisation die „Erziehung des tschechoslowakischen Staatsbürgers zur nationalen Verträglichkeit “ fördern. ${ }^{59} \mathrm{Daß}$ verschiedene industrielle Organisationen ihren Sitz in der Hauptstadt genommen hätten, sei schlicht zweckmäßig und habe, entge-

54 PA, R 73 804, Gesandtschaft Prag an AA, 19.4.1921. - VZ vom 4. 8. 1921.

55 SÚA, SdP, Karton 66, Rundschreiben der Deutschpolitischen Arbeitsstelle Prag vom 30. 5. 1921.

56 Interpellation Medinger, Kostka, Lehnert und Genossen vom 2. 12. 1920, TTZPS, 1. WP, Drucksache Nr. 949.

57 SÚA, ÚSČP, Karton 10, Rede Malinskýs, Vollversammlung des Zentralverbands am 10.5.1919.

58 SÚA, ÚSČP, Karton 10, Bericht Malinskýs über die Audienz - deren exaktes Datum nicht zu ermitteln war - auf der Vollversammlung des Zentralverbands am 10.5.1919. - Wiedergabe der Ansprache Masaryks in TA vom 11.5.1919.

59 Viškovský, Zentralverband, S. 5 f., Zitat S. 6. - Vgl. auch die Rede Viškovskýs, Vollversammlung des Zentralverbands am 13.3.1920, in: OB 2 (1920), S. 4. 
gen den Vorwürfen des DHI, mit „Zentralisierung" unter tschechisch-nationalen Vorzeichen nichts zu tun. Die Deutschen nähmen ihrerseits unter der Parole der Dezentralisierung eire Zerfaserung der Kräfte, eine Verdoppelung der Apparate, der Anstrengungen und der Ausgaben in Kauf. ${ }^{60}$ Auf seinem Alleinvertretungsanspruch beharrte der Zentralverband nicht zuletzt deshalb, weil die Deutschen dort in den leitenden Gremien vertreten waren, eine zusätzliche Konsultation des DHI durch die Behörden somit ein deutsches Übergewicht zur Folge gehabt hätte. ${ }^{61}$ Die Regierung, so im Juli 1921 Handelsminister Hotowetz' Antwort an Medinger, habe nichts gegen nationale Vereinigungen einzuwenden, erkenne eine Pflicht zu deren Konsultation aber nicht an und werde deshalb, wo sie Gutachten in gesamtindustriellen Fragen benötige, sich weiterhin an den gesamtnationalen Verband halten. Es gehe um „streng wirtschaftliche Fragen“, welche „in keiner Weise grundsätzlich mit nationalen Fragen zusammenhängen, denn in wirtschaftlichen Angelegenheiten gibt es keine grundsätzlichen Differenzen vom nationalen Standpunkte und die Interessen und Bedürfnisse der Industrie als solche sind und werden stets die gleichen sein, ob es sich um einen Industriellen čechischer (!), deutscher oder was immer für eine Nationalität handelt ${ }^{\text {“ }}{ }^{62}$

Andererseits hatte Handelsminister Stranský bereits auf der Vollversammlung des Zentralverbands vom 10. Mai 1919 bei den deutschen Industriellen die allerschlimmsten Befürchtungen erweckt. Die unbezweifelbare Überlegenheit der deutschen Industrie über die tschechische sei das Ergebnis einseitiger Förderung durch die österreichische Wirtschaftspolitik; nirgendwo, so Stranský unter lautem Beifall, sei die tschechische Nation über ein ganzes Jahrhundert hinweg schwerer geschädigt worden als auf dem $\mathrm{Ge}-$ biet der Industrie. Das derzeitige Gefälle sei, wenn auch nicht durch die Unterdrückung der deutschen Wirtschaft, so doch durch eine mit den Grundsätzen des Rechtsstaats zu vereinbarende, vorerst bevorzugte Förderung der tschechischen Industrie einzuebnen, welche ein echte Konkurrenz überhaupt erst ermöglichendes ebenbürtiges Entwicklungsniveau herbeiführen werde. ${ }^{63}$

Hatte Stranský damit auch keiner gezielten Benachteiligung der deutschen Wirtschaft das Wort geredet, so boten seine Ausführungen doch Anlaß zum Mißverständnis. Der Minister habe sich für eine einseitige Begünstigung der Tschechen und die zielgerichtete Schädigung der Deutschen stark gemacht: So sedimentierte sich die Erinnerung an den Auftritt in einer nach Auffassung der deutschen Gesandtschaft „recht anerkennenswerte(n) Darstellung des Nationalitätenkampfes ${ }^{\text {“ }}{ }^{64}$ Nun beinhaltete die Ankündigung, erst wenn die Deutschen sich als loyale Staatsbürger bewährt hätten, müsse man sich wieder zur Förderung ihrer Industrie verpflichtet fühlen, tatsächlich die pauschale Unterstellung politischer Unzuverlässigkeit, womit sich ein Schuß nationalpolitischen Ressenti-

60 Klumpár, Organisation. - K.R. („von einem Großindustriellen“), Fehlende Einigkeit.

61 SÚA, MPOŽ, Karton 316, 2762/20, Exposé des Zentralverbands zu der Interpellation Medinger, von Hodáč am 26.12.1920 an das MPOŽ übersandt.

62 Antwort Hotowetz' vom 18.7.1921, TTZPS, 1. WP, Drucksache 2954. - Vgl. auch Rede Hotowetz', Vollversammlung des Zentralverbands am 28.5.1921, in: OB 3 (1921), S. 341.

63 SÚA, ÚSČP, Karton 10, Rede Stranskýs auf der Vollversammlung des Zentralverbands am 11.5.1919. - Vgl. auch PT vom 13.5.1919.

64 Vorstand der deutschen Paßstelle Reichenberg, von Strahl, Zusammenfassender Bericht über die Lage der Sudetendeutschen, undatiert, von der Gesandtschaft Prag mit dem zitierten Kommentar am 31.3. 1925 an das Auswärtige Amt übersandt. Das Exposé sei für die Orientierung jüngerer Beamter geeignet: Vgl. PA, R 73 825, Gesandtschaft Prag an AA, 31. 3. 1925. 
ments in Stranskýs an sich nicht unplausiblen Gedankengang mischte. Der Minister - so etwa der Kommentar des "Prager Tagblatts" - versuche, als "Wiedergutmachung“ zu bemänteln, was bei Licht besehen nur Ausnutzung der tschechischen Machtstellung sei. Stranskýs Herr im Haus-Standpunkt sei eine fixe Idee mit schädlichen Konsequenzen: Würden die deutschen Industriellen öffentlich stigmatisiert, so ermuntere dies nicht gerade zu unternehmerischen Aktivitäten ${ }^{65}$ Mag durchaus auch Ressentiment im Spiel gewesen sein, so waren andererseits die Deutschen an ihrer Randständigkeit nicht unschuldig: Als Folge ihrer anfänglichen Opposition gegen den Staat, so ein kundiger reichsdeutscher Beobachter, sei die Neuorganisation des Verbandswesens als tschechisches Internum gehandhabt worden; angesichts der auf der Hand liegenden Vorteile der Mitgliedschaft im tschechischen Verband hätten die deutschen Wirtschaftsvereinigungen nicht alle potentiellen Kandidaten an sich ziehen können. ${ }^{66}$

In diesem Kontext beklagte der Hauptverband dann auch eine Unterrepräsentation der Deutschen in Beiräten und bei Enqueten. Fordernder als in dem diplomatisch geglätteten Einführungsschreiben an das Handelsministerium war die Resolution der Gründungsversammlung, welche Loyalität an Partizipation band und unverzüglich die Aufnahme deutscher Vertreter in die zahlreichen Expertenkommissionen der gebundenen Wirtschaft anmahnte. ${ }^{67}$ Angesichts der elementaren Wichtigkeit der Kohlenversorgung stand beispielsweise eine Mitarbeit im Kohlenausschuß an, welche der häufig beklagten willkürlichen Verteilung der Vorräte ein Ende setzten sollte. ${ }^{68}$ Anspruch erhob der DHI auch auf Sitz und Stimme in der Kommission für Übergangswirtschaft ${ }^{69}$, wo bereits seit dem Dezember 1918 der Zentralverband vertreten war. ${ }^{70} \mathrm{Zwar}$ waren bis Ende Januar 1920 auch Erklärungen des Präsidenten der Republik und der wichtigsten Ministerien über ihre Bereitschaft zur Konsultation des DHI eingegangen ${ }^{71}$; diese jedoch wurden keineswegs immer eingelöst. Hatte der Hauptverband bis zum Frühjahr 1920 auch in einigen Gremien wie dem Wirtschaftsbeirat und der Kommission für AuBenhandel seine Vertrauensleute plaziert ${ }^{72}$, so sah er sich dort doch schlecht vertreten und in seiner Arbeit behindert - abgesehen davon nehme die Regierung die Aktivitäten dieser Kollegien ohnehin kaum zur Kenntnis. ${ }^{73} \mathrm{Daß}$ die Verhandlungssprache ausschließlich das Tschechische war, bot weiteren Anlaß zu Zwistigkeiten. Beides zusammengenommen veranlaßte im Oktober 1920 den Auszug des Hauptverbands aus dem Wirtschaftsbeirat. ${ }^{74}$ Habe man auch, so das Fazit des DHI für dieses Jahr, zu allen wich-

65 PT vom 13.5.1919.

66 Arens, Einflußsphäre, S. $163 \mathrm{f}$.

67 SÚA, MPOŽ, Karton 316, 2762/20, Entschließung der Gründungsversammlung des DHI am 9.11. 1919.

68 BArch-B, RMWi, 2885, Der Bevollmächtigte Vertreter des Deutschen Reiches an AA, 14.11. 1919.

69 SÚA, MPOŽ, Karton 316, 2762/20, Hauptverband der deutschböhmischen Industrie an Handelsministerium, 27.11.1919.

70 Artikel 2 der Verordnung des MPOŽ vom 2.12.1918, Sb. z. a n. Nr. 59.

71 SÚA, MPOŽ, Karton 316, 2762/20, Hauptverband der deutschböhmischen Industrie an MPOŽ, 12. 1. 1920. - Interpellation Medinger, Kostka, Lehnert und Genossen vom 2. 12. 1920, TTZPS, 1. WP, Drucksache Nr. 949.

72 MDHI 1 (1920), S. 2.

73 So die Kritik in der Rede Teltschers auf dem Industriellentag am 15.8.1921 in Reichenberg: Vgl. den Bericht in: MDHI 2 (1921), S. $394 \mathrm{f}$.

${ }^{74}$ MDHI 3 (1922), S. 48. - Auch die deutschen Sozialdemokraten zogen ihre Vertreter bald zurück, 
tigen Gesetzgebungsprojekten Stellung genommen, so lehnten doch maßgebliche Regierungsstellen die Heranziehung der Deutschen nach wie vor grundsätzlich ab. ${ }^{75}$ Auf dem Reichenberger Industriellentag im August 1921 fiel Teltschers Bilanz ${ }^{76}$ vernichtend aus: Die Sprachenproblematik mache alle Partizipationsrechte illusorisch. Im Wirtschafts-, im Gewerbe-, im Eisenbahn- und im Zollbeirat bewirke die Geschäftsordnung eine "dramatische Zurückdrängung des Deutschtums mit allen Mitteln des Terrors“. Die Tschechen, so Janovsky dann 1922, seien nie zu Beziehungen von gleich zu gleich bereit gewesen, sondern hätten sich nur ein demokratisches Aushängeschild besorgt. „Hatte die Regierung tatsächlich die Absicht, auf dem Umwege über den mehr neutralen Boden der wirtschaftlichen Beiräte die schweren nationalen Gegensätze zwischen den Deutschen und den Tschechen zu überbrücken, so muß diese als verfehlt be-

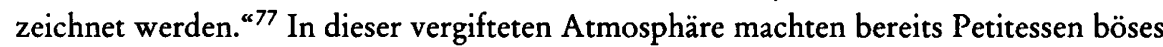
Blut. So hatte man zum Reichenberger Industriellentag von 1920, wo immerhin die Erörterung der lebenswichtigen Frage der gebundenen Wirtschaft auf der Tagesordnung stand, auch die Vertreter des Handelsministeriums und des Amtes für Außenhandel ${ }^{78}$ gebeten. Daß beide auf die Einladung nicht reagierten und nur Minister Hotowetz sich - nachträglich - entschuldigte, wurde als Affront empfunden. ${ }^{79}$ Erst auf dem Industriellentag in Reichenberg am 15. August 1921, fast drei Jahre nach der Gründung des Staates und fast zwei Jahre nach der des Hauptverbandes, konnte Präsident Schicht einen Sektionsrat als Repräsentanten des Handelsministeriums begrüßen. ${ }^{80}$

Für die ungenügende Berücksichtigung des Hauptverbands in der Politik waren, abgesehen von nicht hinwegzudisputierenden tschechischen Ressentiments, aber auch obrigkeitsstaatliche Strukturdefizite des politischen Systems verantwortlich. Dies illustriert der Fall des Wirtschaftsbeirats. Zum Vorsitzenden dieses Gremiums, das Regierung und Verwaltung durch Gutachten und Anträge unterstützte, hatte am 11. März 1920 das Handelsministerium den Industriellen Léon Bondy ernannt. Den Vizevorsitz teilten sich ein Deutscher, ein Mährer und ein Slowake. Manko des Beirats war seine Staatsnähe, die sich in der Bestellung der Mitglieder - aus den Reihen der Arbeitgeber, der Arbeitnehmer bzw. Konsumenten, aus Landwirtschaft und Industrie - durch Ernennung anstatt Wahl ausdrückte, so daß die Wirtschaft zögerte, dieses Gremium als ihre berufene Vertretung anzuerkennen. ${ }^{81} 1922$ suchten Reorganisationspläne des Han-

weil der Vorsitzende Verhandlungen in deutscher Sprache ablehnte: Vgl. PA, R 73 884, Gesandtschaft Prag an AA, 19.10.1920.

$75 \mathrm{Um}$ welche Stellen es sich handelte, wurde nicht gesagt: Vgl. Bericht des DHI über das Vereinsjahr 1920, S. 3 f.

76 Rede Teltschers, Industriellentag am 15. 8. 1921 in Reichenberg, in: MDHI 2 (1921), S. 394 f.

77 Janovsky, Drei Jahre, S. 10.

78 Das Amt für Außenhandel war eine dem Ministerium nachgeordnete Behörde, die ab dem 1. September 1920 in der Nachfolge der Außenhandelskommission die staatliche Außenhandelsregulierung wahrnehmen sollte: Vgl. BArch-B, RMWi, 2886, Gesandtschaft Prag an AA, 23.8. 1920 .

79 MDHI 1 (1920), S. 53.

80 Zumindest aber hatte sich Ministerpräsident Černý ausdrücklich entschuldigt: Vgl. den Bericht über den Industriellentag am 15. 8.1921 in Reichenberg, in: MDHI 2 (1921), S. $381 \mathrm{f}$.

81 Vgl. die Verordnung vom 5. 11. 1919, sb. z. a n. Nr. 632. - ONH 25 (1920), S. 228 f. - AMZV, Sektion IV, Karton 743, Informationen über den PSOH, zusammengestellt in dessen Sekretariat, am 10. 3. 1931 von MPOŽ an MZV übersandt. 
delsministeriums die Ernennung der Mitglieder zumindest an die Nominierung durch die Verbände zu knüpfen; hier forderte der DHI dann das Recht der Anhörung und der Gesetzesinitiative. ${ }^{82}$

Als im Herbst 1921 der Hauptverband sein Verhältnis zur Regierung zu verbessern suchte, geriet dieses Unternehmen zum traumatischen Schlüsselerlebnis, welches die unterschiedlichen Auffassungen über das industrielle Verbandswesen wieder in aller Deutlichkeit offenbarte. Im September war das Beamtenkabinett Černý von der Regierung Beneš - getragen vom Fünferbündnis der tschechischen Parteien, der Pětka - abgelöst worden. Beneš hielt man am ehesten für geeignet, einen tschechisch-deutschen Ausgleich herbeizuführen. Auch die Deutschen sahen ihn als Gemäßigten an; keiner der in der Nationalitätenfrage exponierten Politiker war in seinem Kabinett vertreten. ${ }^{83} \mathrm{Im}$ Vorfeld der Regierungsbildung wurden bezeichnenderweise sogar die Einrichtung eines Minoritätenministeriums bzw. einer Abteilung für Minderheitenfragen beim Präsidium des Ministerrats erwogen. ${ }^{84}$ Abgesehen von Lodgman, der mit entschlossenem Auftreten Konzessionen herbeizuzwingen suchte ${ }^{85}$, neigten die deutschen Parteien zu einer "Realpolitik der kleinen gegenseitigen Zugeständnisse“. Das Deutsche Reich hielt Distanz. ${ }^{86}$

Die diplomatische Initiative der DHI-Spitze ${ }^{87}$ schien deshalb unter einem günstigen Stern zu stehen. Kislinger fühlte bei Kanzler Śámal wegen einer Audienz für den Sprecher der deutschen Industriellen, Ginzkey, bei Beneš vor und ließ bei dieser Gelegenheit die Distanz zu Lodgman durchblicken. ${ }^{88}$ Medinger lotete Masaryks Bereitschaft, Lie-

82 Ebenda. - Erst 1931 übertrugen neue Statuten den zentralen Interessenverbänden das Recht zur Nominierung von zwei Fünfteln der Angehörigen des Beirates. Von den insgesamt 150 Mitgliedern und 150 Ersatzleuten waren dies je 60 in der Sektion der Arbeitnehmer bzw. der Arbeitgeber. Von letzteren rekrutierte der Zentralverband - auch im Namen des DHI, mit dem er seit 1928 in einem Dachverband zusammenarbeitete -25 , fünf davon aus den nahrungsmittelverarbeitenden Branchen, vier aus dem Berg- und Hüttenwesen und 14 aus den übrigen Industrien, zwei waren Vertreter der industriellen Zentralorganisationen. Hinzu kamen acht Bankenvertreter, 15 Landwirte, neun Vertreter des Gewerberats und drei der Kammern. Aufgrund eines fixen Nationalitätenschlüssels befanden sich unter den 60 Unternehmervertretern 47 Tschechen und 13 Deutsche, in der Gruppe der Industriellen belief sich der Anteil der Deutschen auf 8 von 25. Der Vorwurf der Unterrepräsentation war nicht gerechtfertigt, mißt man die Vertretung der Deutschen an ihrem Anteil an der Bevölkerung der ČSR. Allerdings entsprach die Beteiligung der Deutschen sicherlich nicht ihrem wirtschaftlichen Gewicht, insbesondere in der Industrie. Vgl. Europäischer Nationalitätenkongreß (Hrsg.), Nationalitäten, S. 244 f. - AMZV Sektion IV, Karton 743, Information über den PSOH, aus dessen Sekretariat, am 10.3.1931 von MPOŽ an MZV übersandt.

83 ÖStA, BAA, Gesandtschaft Prag, Z1.566/P, Österreichische Gesandtschaft Prag an BAA, 27.9.1921.

84 Dies ein Vorschlag Mayr-Hartings. Als Leiter sollte ein höherer deutscher Beamter berufen werden: Vgl. AKPR, T 12/25, Teil I, Karton 134, Aktenvermerk Sámal vom 15.9.1921.

85 Auf einer Rede in Trautenau am 15. November: Vgl. PA, R 73 820, Grenznachricht für den Reichskommissar für die Überwachung der öffentlichen Ordnung vom 28. 10.1921.

86 ÖStA, BAA, Gesandtschaft Prag, Z1. 625/Pol, Karton 1, Lageanalyse der Österreichischen Gesandtschaft Prag, Gesandtschaft an BAA, 19.10.1921. - PA, R 73 772, Gesandtschaft Prag an AA, 18.11.1921.

87 Eine erste Anspielung hierauf findet sich in der Morgennummer der Bohemia vom 12. November 1921 .

88 AKPR, T 12/25, Karton 134, C 1, Aktenvermerk Śámal vom 13.11.1921. 
bieg zu empfangen, aus. ${ }^{89}$ Ende November jedoch endete ein Empfang Liebiegs, Schichts und Teltschers bei Handelsminister Novák im Desaster..$^{90}$ Die Unterredung, deren Ton „ein außerordentlich gereizter und aggressiver" 91 war, gipfelte in Nováks Vorwurf, die deutschen Industriellen hätten mit dem Deutschen Reich geliebäugelt und in Mark spekuliert ${ }^{92}$, sie hätten, um die Inflation anzuheizen, die Löhne hochgetrieben und könnten als Hochverräter weder Schutz noch Hilfe gewärtigen. $\mathrm{Da}$ Schicht und Teltscher "die Antwort nicht schuldig blieben“, wurde die Debatte abgebrochen.$^{93} \mathrm{Zu}$ diesem unerfreulichen Ausgang trug nicht unwesentlich bei, daß der Hauptverband wieder das Konzept zweier separater, nur von Fall zu Fall kooperierender Industrievereinigungen verfochten hatte, während der Minister bekundete, keine deutsche und auch keine tschechische, sondern nur eine tschechoslowakische Industrie zu kennen und alle Klagen, der Hauptverband werde zurückgesetzt, schroff zurückwies. ${ }^{94}$ In der Folge konnte Friedrich Weil in der "Wirtschaft" ${ }^{95}$ die Furcht vor "Aufsaugung" handfest mit Verweis auf diesen Eklat begründen ${ }^{96}$, und die Deutschpolitische Arbeitsstelle erklärte nach diesem Klimasturz alle Versuche, die Regierung der Loyalität des Hauptverbandes zu versichern, für sinnlos. ${ }^{97}$ Schon vor dieser Verhärtung der Fronten hatte oft als Quisling gegolten, wer sich auf Mitarbeit im Zentralverband einließ. Deutsche Mit-

89 AKPR, T 12/25, Karton 134, C 1, Śámal an Voves, 12.11.1921, und Aktenvermerk Sámal vom 13.11.1921.

90 Die Vertreter des DHI, so Friedrich Weil, seien bei Novák regelrecht untergegangen: Vgl. Weil, Kritik, S. $511 \mathrm{f}$.

91 Sámal vermerkte die Äußerung Medingers, Novák habe sich außerordentlich echauffiert; der Minister habe sich benommen „wie ein Portier in einem kleinen Gasthaus“: Vgl. AKPR, T 12/25, Teil I, Karton 134, Aktenvermerk Śámal vom 5.12.1921.

92 Der Vorwurf der "Markspekulation“ verstummte in der gesamten Zeit der Ersten Republik nicht. Eine maßgebliche Rolle spielte er noch 1935 in der „Industriefriedhof-Kontroverse“ über die Hintergründe der Wirtschaftskrise in den deutschen Gebieten und den Schuldanteil der als deutsch firmierenden Unternehmer an dieser; aus diesem Kontext stammt auch die bündigste Zusammenfassung der Vorwürfe in zwei Artikeln der „Börse“. Hier wurden als langfristige Ursache für die Auszehrung der deutschen Unternehmen - die sie dann zu einer leichten Beute der Krise machte - die Markanlagen bei reichsdeutschen Banken verantwortlich gemacht, welche die deutschen Industriellen in den frühen zwanziger Jahren mangels Vertrauen in die Währung des neuen Staates und vor dem Hintergrund ihrer generellen Illoyalität diesem gegenüber getätigt hätten. Die Entwertung dieser Guthaben durch die deutsche Inflation sei die eigentliche Ursache für die Kapitalschwäche der deutschen Industrie: Vgl. BÖ vom 31.10. und vom 14.11.1935. NO 6 (1935), S. 126. - Zu den Gegenargumenten des Hauptverbandes vgl. MDHI 16 (1935), S. $394 \mathrm{f}$.

93 ÖStA, BAA, Gesandtschaft Prag, Z 1.714/Pol, Karton 11, Österreichischer Geschäftsträger in Prag an Österreichisches BAA, 4. 12.1921.

94 AKPR, T 12/25, Teil I, Karton 134, Aktenvermerk Śámal vom 5. 12.1921. - Als Novák auf der Generalversammlung der slowakischen Industrie 1925 auch alle Unterschiede zwischen tschechischer und slowakischer Industrie leugnete, kommentierte dies die „Wirtschaft “ schnippisch, der Minister habe vielleicht selbst gespürt, „daß sich die Unterschiede in der ganzen Struktur zwischen den historischen Ländern und der Slowakei nicht mit einer ministeriellen Enunziation aus der Welt schaffen lassen“. Die slowakische Wirtschaft habe nämlich viele Sonderprobleme: Vgl. WI 6 (1925), S. $956 f$.

95 Das wichtigste deutsche wirtschaftliche Periodikum der ČSR. Zwischen ihm und dem Hauptverband gab es keine organisatorische Verbindung; das Blatt verstand sich jedoch als kritischkonstruktives Sprachrohr der deutschen Wirtschaft in der Tschechoslowakei.

96 WI 3 (1922), S. 571.

97 SÚA, SdP, Karton 66, Rundschreiben der Deutschpolitischen Arbeitsstelle Prag vom 30. 5. 1921. 
gliedschaften dort datierten oft aus der Zeit vor der Gründung des DHI, und die betreffenden Unternehmer hatten keine Möglichkeit des Austritts gesehen, weil in der gebundenen Wirtschaft der ersten Nachkriegsjahre der Zentralverband vielfach in die Ronstoffverteilung eingeschaltet war und etwa die Abschneidung vom Kohlebezug sich für die überwiegend deutsche Porzellan- und Glasindustrie fatal ausgewirkt hätte. ${ }^{98} \mathrm{Un}$ geachtet solcher Vernunftgründe brandmarkte der Deutsche Parlamentarische Verband 1921 den deutsch-jüdischen Witkowitzer Werksdirektor Sonnenschein, im Zentralverband Vertreter der deutschen Schwerindustrie, als „Deutschen a.D., der das Volkstum nach der Höhe der möglichen Dividenden einschätzt. So weit ist das Deutschtum noch nicht gesunken, als dass es sich die Mentalität des Herrn Direktors (!) Sonnenschein beilegt. " ${ }^{\text {"9 }}$ Schon die Tagung der deutschen wirtschaftlichen Verbände vom Mai 1920 hatte „das noch immer bestehende Schwanken der wirtschaftlich Tätigen zwischen nationalen und internationalen Verbänden" als Mangel an klarer Linie gerügt, welcher einem Vordringen der Tschechen Vorschub leiste. ${ }^{100}$ Als Musterbeispiel für diejenigen, die ihr Schäfchen durch Anbiederung an die Tschechen ins Trockene zu bringen suchten, galt einer „dem DHI nahestehenden“ Persönlichkeit Liebieg, der Präsident des Allgemeinen Deutschen Textilverbandes, zugleich aber auch Präsidialmitglied des Zentralverbands, der sich auf einem Bankett am Rande der Prager Messe gezeigt habe, obwohl die deutsche Reichenberger Messe von der Regierung boykottiert werde. ${ }^{101}$ Nun konnte Liebieg sich rechtfertigen, er sei ins Präsidium des Zentralverbands eingetreten, um dort für gut Wetter zu sorgen, nachdem das Innenministerium sich auch nach Monaten noch nicht zu einer Genehmigung der Satzungen des ADTV herbeigelassen und Minister Stranský Liebiegs Eintritt als Prüfstein dafür gewertet habe, daß es sich bei den deutschen Wirtschaftsverbänden nicht um nationale Kampfvereinigungen handle. ${ }^{102}$ Auf der Tagung warb auch Teltscher um Verständnis für die „Abtrünnigen“, die aus Verantwortung für Unternehmen und Belegschaft die ihnen zugeworfenen „Rettungsseile“ ergreifen müßten. ${ }^{103}$ Daß Firmen mit Betriebsstätten im deutschen und im tschechischen Gebiet oft beiden Verbänden angehörten, führte Bacher auf ein charakteristisches Bestreben der deutschen Industriellen zurück, auf zwei Stühlen gleichzeitig sitzen zu wollen, schwächte den Vorwurf der Rückgratlosigkeit aber unverzüglich ab: Der Berufung in das Präsidum des Zentralverbands hätten manche Folge leisten müssen, „wenn sie nicht die Gefahr schwerer Benachteiligungen wegen eines ihnen übel ausgelegten Refus auf sich nehmen wollten". ${ }^{104}$

Ungeachtet dessen, daß im Hauptverband mancherorts die nationale Karte gespielt wurde, trieben weitgehend parallele, ja identische Probleme und Interessen zur Zusammenarbeit. Dies zeigt der folgende Blick auf die Forderungen und Aktivitäten beider Vereinigungen.

98 Interpellation Medinger, Kostka, Lehnert und Genossen vom 2. 12. 1920, TTZPS, 1. WP, Drucksache Nr. 949.

99 Ebenda.

100 Verhandlungsschrift über die Tagung, wie Fußnote 35.

101 Stellungnahme einer „dem DHI nahestehenden Persönlichkeit“, veröffentlicht in: WI 3 (1921), S. $353 \mathrm{f}$., mit einem grundsätzlich zustimmenden Kommentar Weils.

102 Er habe im Zentralverband auch kaum je an Sitzungen teilgenommen. „Gegendarstellung “ Liebiegs, in: WI 3 (1921), S. $376 \mathrm{f}$.

103 Verhandlungsschrift über die Tagung, wie Fußnote 35.

104 So in der Rückschau Bacher, Zusammenschluß, S. 1135. 


\section{c) Forderungen und Aktivitäten}

Nicht nur die Nationalitätenpolitik, auch das Nachkriegschaos in Wirtschaft und Verwaltung, Währungsprobleme und Versorgungsschwierigkeiten, nicht zuletzt auch die scharfen sozialen Konflikte waren Schubkräfte für die Formierung der deutschen Industrie im Hauptverband gewesen. ${ }^{105}$ Charakteristisch war jedoch die Neigung, alle Beeinträchtigungen des Wirtschaftslebens auf das Konto des tschechischen Chauvinismus zu buchen, so daß die Unterscheidung zwischen den zweifellos vorhandenen „Tschechisierungstendenzen“ und „objektiven“ Problemlagen aus dem Blick geriet. 1920 sei, so Teltscher, das Jahr nationaler und politischer Kämpfe sowie wirtschaftlicher Experimente gewesen, „welche letzten Endes aber auch nur dem Versuch entsprangen, den wirtschaftlichen Aufbau als Waffe im sozialen und nationalen Kampfe zu benützen! " ${ }^{106}$ Eine ähnlich diffuse Diagnose lieferte Medinger: Die Krise werde sich so lange verschärfen, bis man einsehe, daß Industriepolitik nicht von nationalpolitischen Gesichtspunkten aus betrieben werden dürfe. ${ }^{107} \mathrm{Zu}$ ihrem dritten Geburtstag stellte Janovsky der Republik das Zeugnis aus, sie habe mit subtilen administrativen Methoden in der Politik wie in der Wirtschaft, vor allem durch ihre Handelspolitik zu Lasten der exportorientierten deutschen Industrie Bürger erster und zweiter Klasse geschaffen. ${ }^{108}$ Wo der DHI seine Forderungen an die Politik herantrug, zeigte sich allerdings, daß die Klagen des Zentralverbands sich von den seinen höchstens in Nuancen unterschieden. Identisch war das Hauptziel: Die Sicherung der industriellen Interessen in einer als feindlich empfundenen, von der fortbestehenden $Z$ wangswirtschaft und einer gestärkten Arbeiterbewegung geprägten Umwelt. Dies ist im einzelnen anhand der wichtigsten Politikfelder nachzuweisen: Die "soziale Frage“, der Problemkomplex der "gebundenen Wirtschaft", Außenhandels- und Währungspolitik, Steuern und Staatsfinanzen.

Die soziale Frage spielte bereits in der Gründungsversammlung des Hauptverbandes eine Rolle, auf der eine Resolution gegen die Einführung von Betriebsräten verabschiedet worden war ${ }^{109}$; der unter dem Druck der Linksparteien ausgearbeitete Entwurf eines Betriebsrätegesetzes sah immerhin wesentlich schärfere Eingriffe in die Unternehmerautonomie als etwa in Deutschland oder Deutsch-Österreich vor. ${ }^{110}$ Die im gleichen Atemzug geäußerten offiziell-rituellen Bekundungen des Hauptverbandes, sich dem "sozialen Fortschritt" nicht entgegenstemmen zu wollen, dürften lediglich als taktisch motivierte Konzessionen zu werten sein, denn die Gründungsversammlung hatte zwar "vernünftige sozialpolitische Maßnahmen“ befürwortet, ineins damit jedoch Rücksichtnahme auf die Krise gefordert und gleichzeitig der vorläufigen Nationalversammlung das Recht abgesprochen, weitreichende wirtschaftspolitische Gesetze zu verabschieden, weil dort die Deutschen nicht vertreten waren. ${ }^{111} \mathrm{Daß}$ sich hier soziale

105 SÚA, MPOŽ, Karton 316, 2762/20, Rede Schichts, Gründungsversammlung des DHI.

106 Teltscher, Diktatur, S. 472.

107 Medinger, Industriekrise.

108 Janovsky, Drei Jahre, S. 1-3.

109 SÚA, MPOŽ, Karton 316, 2762/20, Entschließung des DHI, gefaßt auf der Gründungsversammlung am 9.11.1919.

110 Dies bemängelte Janovsky: Vgl. Janovsky, Drei Jahre, S. $12 \mathrm{f}$.

111 Resolution auf der Gründungsversammlung, wie vorletzte Anmerkung. 
Dickfelligkeit das nationale und demokratische Mäntelchen umzuhängen versuchte, legt die Kritik des diplomatischen Vertreters des Reiches nahe, der dem Hauptverband bescheinigte, seine Kritik richte sich "mit blinder Heftigkeit gegen jede, selbst gegen die bescheidenste, Form einer Arbeiterkontrolle des Unternehmertums“. Das hier zum Ausdruck gelangende Ideal sei „die unproduktive Sehnsucht nach den früheren Verhältnissen zwischen Kapital und Arbeit". ${ }^{112}$

Dringlich war auch die Problematik der „Kriegswirtschaft im Frieden“. Die Mechanismen der bürokratischen Wirtschaftslenkung waren schließlich nicht sofort mit dem Ende des Krieges abgebaut worden; ob behördliche Regulierung ein adäquates - insbesondere auch national- und sozialpolitisch neutrales - Instrument zur Verwaltung des Mangels und zur Bewältigung des Übergangs zur Friedenswirtschaft sei, war kontrovers. In längerfristiger Perspektive schloß sich hieran die umfassendere Frage nach dem Grundcharakter der künftigen Wirtschaftsordnung an. Daß die "gebundene Wirtschaft" des neuen Staates mit zu vielen - und zu vielen neuen - Beamten bürokratische Deformationen zuhauf sowie Ungerechtigkeiten in nationalpolitischer und Begünstigungen in sozialpolitischer Hinsicht produzierte, war nicht zu leugnen. In der Ernährungswirtschaft beispielsweise hatte die Ablieferungspflicht passive Resistenz der Bauern zur Folge gehabt; der Verteilungsapparat war so zerrüttet, daß im Mai 1920 das System, das in erster Linie der organisierten Arbeiterschaft billigen Lebensmittelbezug sicherte, zusammengebrochen war. Abgesehen von den Funktionsmängeln der Nahrungsmittelbewirtschaftung war dem Hauptverband als besonders unsympathisch ins Auge gestochen, daß dieses System ein politisches Zugeständnis an den kombinierten Klassen- und nationalen Gegner, die tschechische Sozialdemokratie, darstelle. ${ }^{113}$ Laut Staatsvoranschlag für das Jahr 1921 bewirtschafteten zwölf Kommissionen die wichtigsten landwirtschaftlichen bzw. industriellen Güter; außerdem existierten 16 Aus- bzw. Einfuhrsyndikate ${ }^{114}$, welche sämtlich, zumindest nach Auffassung der deutschen Wirtschaft, deutsche Lizenzund Zuteilungsansuchen ungünstiger beurteilten als tschechische und zudem der Stellenbeschaffung für nationalpolitisch zuverlässige Tschechen dienten. Ein besonderes Ärgernis war die Kohlebewirtschaftung; die Kritik zielte aber auch gegen die für die deutschen Außenhandelsbeziehungen lebenswichtige Devisenzuteilung. 1920 wurde deshalb die Dezentralisierung der Außenhandelskommission, eine Durchforstung der Bewilligungsbürokratie, der Zoll- und der Devisenvorschriften gefordert. Ein Schlüsseltrauma war der Baumwollskandal des Jahres 1920. Auf der Grundlage einer Staatsgarantie hatten deutsche Textilunternehmen größere Rohstoffeinkäufe im Ausland getätigt; nach dem unvermuteten Rückzug des Staates aus dem Geschäft hatte die Baumwollbranche, zu 85 Prozent deutsch, die Verluste allein zu tragen. ${ }^{115}$

Die Grundsatzdebatte des Hauptverbandes auf dem Industriellentag in Reichenberg am 16. August 1920 drehte sich deshalb nicht zufällig um die gebundene Wirtschaft. Das

112 BArch-B, RMWi, 2885, Der Bevollmächtigte Vertreter des Deutschen Reiches an AA, 14.12.1919.

113 Dies legen die Ausführungen bei Janovsky, Drei Jahre, S. 13f. nahe.

114 So gab es etwa die Spiritus-, die Zucker-, Brau-, Leder-, Leinen, Malz-, Papier- und die Kunstdüngerkommission. Syndikate existierten u.a. für Metall, Tafelglas, Hohlglas, Stein, Holz, Baumwolle: Vgl. Janovsky, Drei Jahre, S. 14-16.

115 Dies die wichtigsten Punkte in Janovskys „Sündenregister“: Vgl. die Bilanz der ersten drei Jahre tschechoslowakischer Wirtschaftspolitik in Janovsky, Drei Jahre, S. 14-16. - Die Forderungen zur Handelspolitik zusammengefaßt im Bericht des DHI über das Vereinsjahr 1920, S. 7. 
Generalthema hatte Medinger schon einige Monate vorher in einem programmatischen Artikel des Prager Tagblatts anklingen lassen, der die Ursache der Krise in den überzogenen Staatseingriffen lokalisierte und den Glauben an die Allmacht des Staates durch das Vertrauen auf die Privatwirtschaft ersetzt sehen wollte. ${ }^{116}$ In Reichenberg präsentierten sich die Standpunkte differenzierter: War auf der einen Seite auch die Meinung zu hören, man solle sich der "gezwungenen Wirtschaft" am besten sofort entledigen, da Zentralen und Syndikate den egoistischen Interessen einer Oligarchie von Usurpatoren staatlicher Hoheitsrechte Vorschub leisteten, so erklang daneben doch auch die Warnung vor einer überhasteten, anders als graduellen Abschaffung der Bindungen, welche angesichts des Zwangs zur Verteilung knapper Güter, zur optimalen Verwendung spärlicher Rohstoffe und zur Regulierung der Ausfuhr keineswegs mit dem Ende des Krieges obsolet geworden seien. Die Diskussion legte differenzierte Branchenbedürfnisse offen: Plädierte etwa die Textilindustrie in toto gegen die gebundene Wirtschaft, so wollten speziell das Flachs- und das Leinengewerbe, beide stark auf Rohstoffimporte angewiesen, die Importkontrollen vorerst noch aufrechterhalten wissen, während die Wollindustrie wiederum gegen eine sofortige Abschaffung der Bindungen nichts einzuwenden hatte. Konsensfähig war deshalb lediglich ein generelles Plädoyer für die Wirtschaftsfreiheit, unter dem Vorbehalt der Bedürfnisse einzelner Wirtschaftszweige. ${ }^{117}$

Der in der deutschen Kritik an der Wirtschaftsbürokratie des öfteren lautwerdende Vorwurf der "nationalpolitischen Schlagseite“ ist sicherlich nicht rundweg abzustreiten und bedürfte zumindest der eingehenden Prüfung. Die Behauptung, die bürokratische Wirtschaftslenkung sei als „Tschechisierungsinstrument“ mißbraucht worden, erscheint jedoch in einem milderen Licht, weil auch im Zentralverband Unzufriedenheit über die Nichtberücksichtigung des "wirkliche(n) Bedarf(s)“, über Desorganisation und Korruption lautwurde. ${ }^{118}$ Kritisierte ein Redner auf dem Industriellentag in Reichenberg am 15. August 1921, der ${ }_{n}$ Sturmlauf“ der Gesetzgebung führe zu administrativem Chaos ${ }^{119}$, so herrschten auch nach Auffassung des Zentralverbands in viel zu vielen Ressorts Konfusion und Kompetenzwirrwarr anstelle von Rechtssicherheit und Stabilität. ${ }^{120}$ Die Industrie - dies war deshalb auch die Forderung der Vollversammlung des Zentralverbands im Mai 1919 - nehme keine staatliche Protektion in Anspruch, sondern wünsche lediglich Ruhe und eine Stabilisierung der Rahmenbedingungen des Wirtschaftens durch Politik und Verwaltung; an die Stelle der tendenziell krisenverschärfenden Bürokratisierung der Wirtschaft müsse die Wiedererweckung des Unternehmergeistes treten. ${ }^{121}$ Auf der Hauptversammlung 1920 kritisierte der handelspolitische Referent des

116 PT vom 27. 3.1921.

117 Referate und Protokoll der Diskussion auf dem Industriellentag in Reichenberg am 16. 8. 1920, Bericht in: MDHI 1 (1920), S. 54 ff. (=Sondernummer anläßlich des Industriellentages).

118 SÚA, ÚSČP, Karton 10, Rede Hodáčs, Vollversammlung des Zentralverbands am 10.5. 1919. Rede Malinskýs, Vollversammlung des Zentralverbands am 4.11.1919, in: OB 1 (1919), S. 15.

119 „Im Finanzministerium blitzt manchmal eine Idee auf, die nicht 1000 Hände, sondern 10000 Hände zur Durchführung notwendig hat. Es ist aber Tatsache, daß diese Kräfte nicht zur Verfügung stehen, und infolgedessen ist das Chaos fertig": Vgl. Rede des Oberfinanzrats Pobitschka, Industriellentag am 15.8.1921 in Reichenberg, in: MDHI 2 (1921), S. 395 f., Zitat S. 395.

120 Rede Hodáčs, Vollversammlung des Zentralverbands am 13.3.1920, in: OB 2 (1920), S. 2. - Rede Hodáčs, Vollversammlung des Zentralverbands am 28. 5. 1921, in: OB 3 (1921), S. 344. Das hier genannte Beispiel waren die Eisenbahntarife.

121 Bericht über die Vollversammlung des Zentralverbands am 9. 5. 1919, in: TA vom 10.5. 1919. - 
Verbandes, Stangler, insbesondere die zu Reibereien zwischen den Branchen führende Verselbständigung der Interessen der Syndikate, und Hodáč verstieg sich bei diesem Anlaß sogar zu der Behauptung, die Sozialisierungsforderungen der Arbeiterschaft seien weniger bedrängend als die Behinderung der Unternehmer durch die Bürokratie. ${ }^{122}$ Eine Zurückdämmung der Staatseingriffe auf das unbedingt erforderliche Mindestmaß war deshalb im Herbst 1921 auch in einem umfangreichen Katalog von Forderungen des Zentralverbands an die Regierung Beneš enthalten. ${ }^{123}$ Hinsichtlich der Notwendigkeit der Deregulierung war bis in die einzelnen Branchen hinein der Konsens also durch die Sache motiviert und damit übernational. Die tschechischen Woll- und Baumwollindustriellen beispielsweise plädierten ebenso wie die deutschen Vertreter der Branche für freie Rohstoffeinkaufsmöglichkeiten anstelle behördlicher Zuteilung und Devisenbewirtschaftung. ${ }^{124}$ Von daher lag die Forderung nach einer generellen Beendigung der Crux des staatlich regulierten Ein- und Ausfuhrhandels nahe. ${ }^{125}$

Eine eingehendere Analyse der Bedingungen, Motive, Abläufe und Konsequenzen der tschechoslowakischen Außenhandelspolitik in den ersten Nachkriegsjahren ist an dieser Stelle nicht angebracht; herauszuarbeiten sind lediglich die Gemeinsamkeiten und Unterschiede der handelspolitischen Vorstellungen und Forderungen von Zentralverband und DHI. Generell war die tschechoslowakische Volkswirtschaft stark exportorientiert: Die ČSR hatte ein Viertel der Bevölkerung der Donaumonarchie, jedoch an die 80 Prozent, in einigen Branchen sogar bis zu 90 Prozent ihres Industriepotentials geerbt. ${ }^{126}$ Folge der beschränkten Aufnahmefähigkeit des Binnenmarkts war, daß im Durchschnitt aller Branchen 30 bis 40 Prozent der Industrieproduktion - in der Metallindustrie über 50, in der Textil- und der Glasindustrie deutlich über 70 Prozent - ausgeführt werden mußten. ${ }^{127}$ Die aus der Aufteilung des Habsburgerreichs nach politischen Gesichtspunkten resultierenden Disproportionen waren die Ursache dafür, daß die ČSR sich mit ihrer industriellen Produktion, die vor 1918 zu 60 Prozent innerhalb der Monarchie abgesetzt worden war, zum großen Teil auf die Ausfuhr verwiesen sah. ${ }^{128}$ Exportfragen waren, pointiert gesagt, für die tschechoslowakische Wirtschaft Lebensfragen. Galt dies auch in erster Linie für die deutschböhmische Wirtschaft, so war doch auch im Zentralverband von Anbeginn das Bewußtsein lebendig, daß der Strukturwan-

Ähnlich der Zentralverband auf der Audienz bei Masaryk: Vgl. SÚA, ÚSČP, Karton 10, Bericht Malinskýs über die Audienz - Datum unbekannt - auf der Vollversammlung des Zentralverbands am 10.5.1919. - Prokop auf der Vollversammlung des Zentralverbands am 11.5.1919, ebenda. - Rede Karlíks, Vollversammlung des Zentralverbands am 28.5.1921, in: OB 3 (1921), S. $341 \mathrm{ff}$.

122 Rede des handelspolitischen Referenten des Zentralverbands, Stangler, Vollversammlung des Zentralverbands am 13.3.1920, in: OB 2 (1920), S. 10. - Rede Hodáčs, Vollversammlung des Zentralverbands am 13.3.1920, in: OB 2 (1920), S. 2.

123 OB 3 (1921), S. $529 \mathrm{f}$.

124 SÚA, ÚSČP, Karton 1, Rede des Direktors Pytlik, Vollversammlung des Zentralverbands am 10.5. 1919.

125 Rede Hodáčs, Vollversammlung des Zentralverbands am 13.3.1920, in: OB 2 (1920), S. 2.

126 Olšovský, Světový obchod, S. 127. - PA, IIb, Wirtschaft 6, Tschechoslowakei, Band 1, Bericht der Gesandtschaft Prag vom 7.1.1927.

127 Teichova, Wirtschaftsgeschichte, S. 21. - Olšovský, Světový obchod, S. 119, 124 und 127.

128 PA, IIb, Wirtschaft 6, Tschechoslowakei, Band 1, Bericht der Gesandtschaft Prag vom 7. 1. 1927. - Vgl. auch Boyer, Deutsches Reich, S. 554 ff. 
del von einer binnenmarkt- zu einer ausfuhrorientierten Wirtschaft ein existentielles Problem darstellte. ${ }^{129}$

In der ordnungspolitischen Frage des zukünftigen Außenhandelsregimes teilte der Zentralverband die Auffassung des Hauptverbandes, das Außenhandelsregime der gebundenen Wirtschaft - Bewilligungssystem und Kontingentierung - sei ehestmöglich abzulösen. Im Juli 1919 bereits konstatierte Hodáč mit Befriedigung, auch im Handelsministerium säßen Anhänger einer stufenweisen Freigabe des Handels, die für bestimmte Warengruppen bereits die Erteilung genereller Aus- bzw. Einfuhrbewilligungen anstatt Einzellizenzen ins Auge faßten. ${ }^{130}$ Die Aus- und Einfuhrverbote galten nun als das größte Handelshemmnis ${ }^{131}$; Anlaß zu Kritik boten darüber hinaus Autokratie und Programmlosigkeit der Devisenzentrale. ${ }^{132}$

In der Frage „Freihandel oder Zollschutz?“ fielen im Haupt- wie im Zentralverband die Planspiele nach Maßgabe der jeweiligen währungspolitischen Rahmenbedingungen aus; sie orientierten sich im allgemeinen aber am Konzept des Erziehungszolls. 1920 sah Preiss für neue Industrien einen eventuellen Nutzen des Zollschutzes, während die etablierten Wirtschaftszweige, vor allem in der Textilindustrie und der Metallverarbeitung, den Wind der internationalen Konkurrenz benötigten. ${ }^{133}$ Ähnlich freihändlerischen Geist atmeten die Warnungen des DHI vor Schutzzöllen: Sie schüfen eine Treibhausatmosphäre, leisteten der Klüngelwirtschaft Vorschub und vergifteten die internationalen Beziehungen. ${ }^{134} \mathrm{Die}$ im erwähnten Forderungskatalog des Zentralverbands für die Regierung Beneš vom Herbst 1921 enthaltene Freigabe des Außenhandels setzte allerdings die Fertigstellung des neuen Zolltarifs voraus, die unter der abgetretenen Regierung Černý in Kooperation mit der Industrie erst in die Wege geleitet worden war. ${ }^{135}$

Um die Jahreswende 1921/22 allerdings wurden in der Folge der Deflation der tschechoslowakischen Krone die Stellungnahmen aus der Industrie zu dem Vorschlag der internationalen Konferenz von Portorose, die mitteleuropäischen Staaten sollten ab Juli 1922 mit gewissen Vorbehalten den Außenhandel freigeben, zurückhaltender. Zur Conditio sine qua non erklärte der Zentralverband die Regelung des Zolltarifs; dieser sei, weil von den Parteien zum Politikum gemacht, im Parlament steckengeblieben, wodurch die Handelsvertragsverhandlungen blockiert würden. Hodáč notierte Befürchtungen einzelner Industriegruppen, angesichts der Entwertung der Währung in den Nachbarstaaten werde die Freigabe des Handels zu einer Überflutung der Tschechoslowakei mit Importgütern führen ${ }^{136}$; eine Regelung der internationalen Finanzbeziehun-

129 So die Ausführungen auf der Vollversammlung des Zentralverbands am 9. 5. 1919: Vgl. den Bericht in der TA vom 10.5.1919.

130 Sitzung des Hauptausschusses der Fachgruppen und Sektionen des Zentralverbands an 21.7.1919, Bericht in: OB 1 (1919), S. 1-3.

131 Vollversammlung des Zentralverbands am 21.9.1920, in: OB 2 (1920), S. 4-7.

132 Rede des handelspolitischen Referenten des Zentralverbands, Štangler, Vollversammlung des Zentralverbands am 13.3.1920, in: OB 2 (1920), S. 10.

133 SÚA, ÚSČP, Karton 10, Jaroslav Preiss, Vollversammlung des Zentralverbands am 11.5. 1920.

134 Zenker, Freihandel.

135 OB 3 (1921), S. $529 f$.

136 Hintergrund waren der hohe Außenwert der Krone und die Preisstabilität in der ČSR, während in den Nachbarländern Inflation herrschte; deren Währungen verloren gegenüber der tschechoslowakischen an Wert. Nun senkte die Inflation den Binnenwert der Währung aber schneller als den Außenwert, wodurch sich eine „Export-Prämie“ für die Nachbarn ergab: Die Tsche- 
gen müsse deshalb das außenhandelspolitische Regime ergänzen. ${ }^{137}$ Ebendiese Position reflektierte ein in den „Mitteilungen“ des Hauptverbandes abgedruckter Vortrag Medingers am 28. März vor dem Forum der Gesellschaft österreichischer Volkswirte in Wien ${ }^{138}$, wo Medinger eine scharfe Attacke gegen das Verbotssystem, gegen ${ }_{n}$ Zollplakkereien" und „Passunwesen" ritt, allerdings auch dem schrankenlosen Freihandel eine Absage erteilte: Eine Zollunion der Donaustaaten, wie sie 1919 für die böhmische Industrie durchaus noch im Bereich des Denkbaren gelegen habe, sei durch die Währungstrennung unmöglich geworden, da sie eine Währungsunion, also eine gemeinsame Finanzpolitik und tendenziell die politische Integration überhaupt vorausgesetzt hätte. In der gegebenen Situation mache der Sturz der österreichischen Krone Zollschutz für die tschechoslowakische Wirtschaft aber unabdingbar.

Ein Politikum ersten Ranges war die geographische Ausrichtung des tschechoslowakischen Außenhandels; diese Problematik war entstanden im Zuge der politisch induzierten Bestrebungen, die Im- und Exportbeziehungen des neuen Staates vom Donauraum und vom deutschen Reich, den herkömmlichen Hauptabsatzgebieten, auf den Westen umzuorientieren. Eine solche Umleitung der Handelsströme war angesichts der Zollgrenzen, die in der Folge des Zerfalls der Monarchie zwischen den Nachfolgestaaten aufgerichtet worden waren, zum guten Teil zwangsläufig; sie war darüber hinaus, als Versuch einer Parallelisierung der ökonomischen Bindungen und der politischen Loyalitäten der Tschechoslowakei, durchaus auch politisch gewollt. Nahm in den Augen der deutschen Industriellen der tschechoslowakische Staat damit zumindest billigend in Kauf, daß ihr Export durch die Absperrung von den angestammten Märkten in seiner Substanz getroffen wurde, so betrachtete doch auch die im Zentralverband organisierte Exportwirtschaft diese Experimente mit Mißbilligung.

Der Blick nach Westen war nun allerdings keineswegs eine Konstante der Prager Handelspolitik. Redete im Mai 1919 der bevollmächtigte Minister Schuster, der dann bald die Handelsvertragsverhandlungen mit Deutschland führte sollte, der Westorientierung das Wort, so hob er im gleichen Atemzug doch auch die Bedeutung des Handels mit dem Reich und den Nachfolgestaaten hervor. ${ }^{139}$ Auch Heidler, der Handelsminister der Regierung Tusar, die im Herbst 1919 das prononciert deutschfeindliche Kabinett Kramár̆ beerbte, befürwortete den Ausgleich und die Verständigung mit den Deutschen und eine kooperative Lösung der Sachfragen unter Beteiligung aller staatsloyalen Kräfte. Die Folgerung aus dieser Richtschnur der Heidlerschen Politik war, daß die nordböhmische, überwiegend deutsche Exportindustrie als Devisenbringer besonders gehegt werden müsse. ${ }^{140}$ Anfang 1920 war, wie der Vertreter des Reiches in Prag notierte, bei

choslowakei mußte sich deshalb, wie alle Länder mit wertvoller Währung, durch Zölle gegen dieses "Valutadumping" schützen.

137 Rede Hodáčs, Sitzung des Zentralausschusses der Delegierten der Fachgruppen und Sektionen beim Zentralverband am 15.12. 1921, in: OB 3 (1921), S. 666.

138 MDHI 3 (1922), S. 214-218. - Medingers Position untermauerten weitere Veröffentlichungen wie etwa Josef Gruntzels - Professor an der Handelshochschule in Wien - Mitteleuropäische Handelspolitik. - Ders., Freihandel.

139 Interview mit Schuster in den NáL vom 4.5.1919. - Als positives Signal kommentiert in: BArch-B, Handel 5, Tschechoslowakei, Band 1, Deutsches Konsulat Prag an AA, 14. 5. 1919.

140 Interview mit Heidler im PT vom 14. 8. 1919. 
den führenden tschechischen Politikern die Ernüchterung gegenüber der Politik der Westbindung bereits allgemein. ${ }^{141}$

Die sich kreuzenden, oft widersprüchlichen und verworrenen Linien der Regierungspolitik im Detail weiterzuverfolgen, ist hier nicht der Ort. Entscheidend ist in unserem Zusammenhang, daß, bei aller Inkonsequenz und Halbherzigkeit der Politik der Westorientierung, der Hauptverband doch wieder und wieder Anlaß hatte, den Finger auf die Beeinträchtigung des Exports zu legen, den der schleppende Abschluß der Handelsverträge mit den alten Absatzräumen, dem Reich und den Nachfolgestaaten, nach sich zog. Man habe, so sein Resümee für das Jahr 1920, von Anfang an „auf die schweren Schäden der Gefühlspolitik“ hingewiesen, die den Handel mit Deutschland und Deutschösterreich vernachlässige und so für die Industriekrise mit verantwortlich zeichne. ${ }^{142} \mathrm{Die}$ zu Zeiten der Monarchie angeblich künstlich gezüchtete Abhängigkeit von Deutschland durch eine Umorientierung nach dem Balkan und nach Rußland aufheben zu wollen, war für Janovsky ein sinnloses Anrennen gegen elementare ökonomische und wirtschaftsgeographische Gegebenheiten. ${ }^{143}$ Janovskys Generalabrechnung mit den ersten Jahren der tschechoslowakischen Wirtschaftspolitik stellte zwar die prekäre Lage des Welthandels in Rechnung, erhob aber doch den Vorwurf, man habe versucht, das eherne Faktum zu ignorieren, daß der neue Staat „in die mitteleuropäische Haut eingenäht“ $\operatorname{sei}^{1{ }^{144}}$, in der neben den Nachfolgestaaten auch das Reich lebe. Eine vom $\mathrm{Haß}$ gegen Deutsche und Ungarn ideologisch aufgeladene Handelspolitik habe alle Eingaben und alle parlamentarischen Interventionen des Hauptverbandes zu Makulatur gemacht; Männer ohne nationale Vorurteile gälten auf tschechischer Seite als "weiße Raben ". ${ }^{145}$ 1923 forderte Janovsky dann angesichts der allenthalben spürbaren Einschnürung, ja Rückbildung der Wirtschaftsbeziehungen zu den Nachfolgestaaten und der Autarkieund Hochzollbestrebungen im Neu-Ausland, zumindest gegenüber Österreich müßten alle verfügbaren handelspolitischen Instrumente genutzt werden. So sah Artikel 222 des Vertrags von St. Germain die Möglichkeit der Gewährung besonderer zolltarifärer Vorteile zusätzlich zur Meistbegünstigung für einen Zeitraum bis zu fünf Jahren vor, was insbesondere der - weitgehend deutschen - Porzellan- und der Textilindustrie Entlastung verschafft hätte. ${ }^{146}$ Nicht nur die Handels-, sondern die Wirtschaftsbeziehungen zu Deutschland und zu Österreich in toto waren ja, so Medinger, weitaus intensiver als die zur Kleinen Entente oder gar zu Frankreich - „und daher sind auch die politischen Engagements mit diesen Staaten nur Liaisons vergleichbar. Eine dauerhafte politische Ehe kann nur mit Deutschland und Österreich geschlossen werden, dessen Wirtschaftsund damit auch dessen Kulturkreise die Tschechoslowakei zugehörig bleibt. Die Erkenntnis dieser unabänderlichen Tatsache wächst im tschechischen Lager und wird den Kurs immer mehr aus dem französischen Kielwasser herauszwingen." Die Außenpolitik müsse „alle Künsteleien und alle Voreingenommenheiten lassen und zu einer me-

141 BArch-B, RMWi, 2885, Der Bevollmächtigte Vertreter des Deutschen Reiches an AA, 2.1.1920.

142 Bericht des DHI über das Vereinsjahr 1920, S. 6 f.

143 Janovsky, Prag-Paris?

144 Janovsky, Wirtschaftskrise, S. 9.

145 Janovsky, Drei Jahre, S. 3-9. - Ders., Wirtschaftskrise, hier zur Handelspolitik passim. Das Manuskript wurde im Juni 1921 abgeschlossen.

146 Janovsky, Beziehungen. 
chanischen Funktion des Güterverkehres werden“. Hätten die Deutschen im Lande in der tschechoslowakischen Politik bereits ab 1918 Mitspracherechte besessen, wäre die unsinnige Politik einer Fortsetzung des Weltkrieges mit ökonomischen Mitteln nicht betrieben worden. Gemeint waren damit neben der Handels- auch die Verkehrs- und die Bankenpolitik mit der Abschaffung der Effektenfreizügigkeit und der Zurückhaltung der Dividenden sowie die Nostrifikation. Die meisten Firmen hatten nach wie vor Niederlassungen in Wien, deutschböhmische Industrielle besaßen umfangreiche Posten österreichischer Werte, so daß, aufs Ganze gesehen, die Interessenverflechtung der Österreicher mit den Deutschböhmen sehr viel enger als die mit den Tschechen war. ${ }^{147}$

Bei der von Preiss in einer programmatischen Rede auf der Vollversammlung des Zentralverbands im Mai 1920 vorgetragenen Forderung nach Lösung des neuen Staates aus der Botmäßigkeit Wiens und Berlins durch die Umorientierung des Handels nach Westen ${ }^{148}$ dürfte es sich eher um eine politisch-taktisch motivierte Loyalitätsbekundung gehandelt haben. Hierfür spricht, daß die Fachsektionen des Zentralverbands Ende 1919 allergrößtes Interesse an der Aufrechterhaltung der Handelsbeziehungen mit Deutschösterreich bekundet hatten ${ }^{149}$; der handelspolitische Referent des Zentralverbandes forderte im März 1920 ein Exportprogramm für die „natürlichen“ Absatzgebiete der tschechoslowakischen Wirtschaft sowie den Ausbau des Handelsvertragssystems durch zumindest provisorische Verträge und die Vervollständigung des Netzes der Auslandsvertretungen. ${ }^{150}$ Die Vollversammlung im September erörterte den aktuellen Gedanken einer Reorganisation des Donauraums. ${ }^{151}$

Die deutschböhmische Wirtschaft befürwortete dringend die Verhandlungen, die dann am 29. Juni 1920 zum Abschluß eines vorläufigen Handelsabkommens mit dem Reich führten, und drängte in der Folgezeit - gegen eine seitens der „Westler" befürchtete Verschleppung - immer wieder auf die baldige Ratifizierung dieses Übereinkommens. ${ }^{152}$ Bezeichnend für die innige Verklammerung der reichsdeutschen mit der deutschböhmischen Wirtschaft war die Verstimmung im Hauptverband darüber, daß der tschechoslowakische Bevollmächtigte Schuster anläßlich der Verhandlungen mit dem Reich die Wünsche der deutschböhmischen Textilindustriellen nicht gebührend berücksichtigt und sich im Vorfeld einseitig mit Hilfe des Zentralverbands unterrichtet habe. Auf der Anklagebank saß hier allerdings auch das Reich, denn bei privaten Besuchen in Berlin hatte man den Repräsentanten der deutschböhmischen Textilwirtschaft bedeutet, Verhandlungen mit nicht autorisierten Verbänden aus dem Nachbarland, auch den deutsch firmierenden, seien nicht angängig. Den Vorwurf, das nationale Interesse sei

147 Bericht über den Vortrag Medingers vor der Gesellschaft österreichischer Volkswirte in Wien am 28.3.1922, in: MDHI 3 (1922), S. 214-218.

148 SÚA, ÚČC, Karton 10, Jaroslav Preiss, Vollversammlung des Zentralverbands am 11. 5. 1920.

149 Sitzung der Delegierten der Fachsektionen des Zentralverbands am 15. 12. 1919, Bericht im PT vom 16.12.1919.

150 Rede des handelspolitischen Referenten des Zentralverbands, Stangler, Vollversammlung des Zentralverbands am 13.3.1920, in: OB 2 (1920), S. 10.

151 Vollversammlung des Zentralverbands am 21.9.1920, in: OB 2 (1920), S. 4-7.

152 Vgl. etwa die parlamentarische Interpellation der Senatoren Spiegel und Mayr-Harting, warum der Vertrag dem Parlament noch nicht vorgelegt worden sei: PA, R 73 897, Gesandtschaft Prag an AA, 14. 12. 1920. - 1921 monierte Teltscher, die Ratifizierung des Vertrages mit dem Reich werde verzögert, mit Österreich verhandle man im Geist des Siegerhochmuts: Vgl. Teltscher, Diktatur. 
vernachlässigt worden, kommentierte der diplomatische Vertreter des Reichs in Prag, Saenger, kühl, es sei „nicht Sache der reichsdeutschen Amtsstellen..., wenn sie mit Vertretern der tschechoslowakischen Regierung über wirtschaftliche Dinge zu verhandeln haben, Unterscheidungen nach nationalpolitischen Gesichtspunkten vorzunehmen“. Die deutschen Industriellen müßten sich bei der Regierung des Staates, „dem sie nun einmal angehörten“, Gehör verschaffen. ${ }^{153}$ Mehr Berechtigung billigte Saenger hingegen der Verstimmung zu, die in Reichenberger Industriekreisen entstanden war, weil in der offiziellen tschechoslowakischen Verhandlungsdelegation für Berlin kein deutsches Mitglied vertreten war: Der Ausschluß der Deutschen sei nationalpolitisch verwerflich, undemokratisch und angesichts der großen deutschen Wirtschaftskraft auch unklug. Der Reichsregierung Vorwürfe zu machen, weil sie dies hingenommen habe, sei nun allerdings auch hier „über die Massen kindlich“, denn es handle sich ein weiteres Mal um die innere Angelegenheit eines souveränen Staates; der DHI müsse jetzt, nach dem $\mathrm{Zu}-$ sammentritt des Parlaments, selbst Mittel und Wege finden, sich durchzusetzen. ${ }^{154} \mathrm{Daß}$ in deutschen politischen und wirtschaftlichen Kreisen in dieser Beziehung traumtänzerische Vorstellungen herrschten, daß der diplomatische Comment und das völkerrechtliche Gebot der Nichteinmischung Fremdworte waren, illustriert das Anfang 1921 vorgebrachte Ansinnen des „Hilfsvereins für Deutschböhmen und die Sudetendeutschen“, zu zukünftigen Handelsvertragsverhandlungen die deutschen Abgeordneten im Prager Parlament heranzuziehen; wenn die Regierung sich weigere, sollten die reichsdeutschen Vertreter mit den Parlamentariern allein verhandeln. Deutschen könne nur durch Deutsche geholfen werden - ohne eine solche "wirtschaftliche Rücksichtnahme der deutschen Regierungsstellen“ würden die Deutschen im Lande in ihrem „Existenzkampf“ zusammenbrechen. ${ }^{155}$

Daß beide Verbände ungestörten Wirtschaftsbeziehungen zum Reich immensen Wert beimaßen, erwies sich insbesondere in der Testfrage, ob es für die Tschechoslowakei ratsam sei, den 1921 von Frankreich initiierten Sanktionen gegen das Reich durch die Erhebung eines fünfzigprozentigen Aufschlags auf deutsche Exporte nach der ČSR und im Transit nach dem europäischen Südosten Flankenschutz zu geben. Nach Auffassung der Deutschpolitischen Arbeitsstelle hatte die deutsche Wirtschaft in der Tschechoslowakei von eventuellen reichsdeutschen Retorsionsmaßnahmen schwerste Beeinträchtigungen zu gewärtigen ${ }^{156}$ - ein Standpunkt, den der Zentralverband mit dem DHI teilte: Die Abhängigkeit der tschechoslowakischen Wirtschaft von der schlesischen Steinkohle, von einer Vielzahl sonstiger Roh- und Hilfsstoffe, von Maschinen- und von Nahrungsmittelimporten aus dem Reich bzw. via Transit über die deutschen Nordseehäfen werde, so ein ausführliches Exposé Janovskys zu dieser Frage, die tschechoslowakischen Eisenbahnen, die bodenständige Industrie, den ganzen Staat „sofort in tödliche Verlegenheit" bringen. Der Absatz der böhmischen Braunkohlengruben und der deutschböhmischen Ausfuhrindustrien auf dem reichsdeutschen Markt sowie der Transithandel der ČSR würden blockiert. In summa werde sich die tschechoslowakische Volkswirtschaft

153 BArch-B, RMWi, 2885, Der Bevollmächtigte Vertreter des Deutschen Reiches an AA, 2.1.1920.

154 BArch-B, RMWi, 2885, Der Bevollmächtigte Vertreter des Deutschen Reiches an AA, 15.6. 1920.

155 PA, R 73 819, Hilfsverein für Deutschböhmen und die Sudetendeutschen an AA.

156 SÚA, SdP, Karton 66, Rundschreiben der Deutschpolitischen Arbeitsstelle vom 7.3.1921. 
„mit eigenen Händen das Grab schaufeln“ ${ }^{157}$ Der Hauptverband hatte diesem Fazit Janovskys lediglich eine akribische Untersuchung der zu erwartenden branchenspezifischen Konsequenzen eines Wirtschaftskrieges mit dem Reich hinzuzufügen. ${ }^{158}$

Konnte Janovsky, der in dieser Lebensfrage des Staates völlig richtig einen Interessengegensatz zwischen „diplomatischen Gesichtspunkten und sachlicher Wirtschaftspolitik" diagnostizierte, hinsichtlich der desaströsen Auswirkungen einer Teilnahme der ČSR an den Sanktionen auch einen Grundkonsens zwischen den Wirtschaftsfachleuten ungeachtet ihrer Nationalität konstatieren, so unterschieden sich die deutsche und die tschechische Einstellung doch in einer Facette: Verliehen in den Augen der Deutschen die ökonomischen Argumente der ablehnenden Haltung nämlich lediglich zusätzliches Gewicht, so hielten die Tschechen aus politischen Gründen immerhin noch nach einem Mittelweg zwischen Paris und Berlin Ausschau. Einen solchen finden zu wollen war für Janovsky eine Illusion, da "Gedeih und Verderb dieses Staatswesens" an das Schicksal der beiden deutschen Nachbarstaaten gebunden seien. ${ }^{159} \mathrm{Daß}$ nicht nur die deutsche, sondern auch die tschechische Industrie, ja der ganze Staat Nachteile zu befürchten hatten, war dann letztlich aber auch auf tschechischer Seite ausschlaggebend, wo sich die Industrie, die Fachreferenten aus dem Handels- und Finanzministerium und selbst Handelsminister Hotowetz gegen die Sanktionen aussprachen. Gleichzeitig zeichnete sich aber auch der Unwillen der Parteien ab, vor der Wählerschaft für den Ruin des Landes verantwortlich zu zeichnen. ${ }^{160}$ Die Probe aufs Exempel unterblieb wegen der Annahme des Entente-Ultimatums durch Deutschland am 10. Mai 1921.

Die Anfang des gleichen Jahres in Kraft getretene Regelung der Handelsbeziehungen mit Frankreich, die dem französischen Export nicht nur die Meistbegünstigung bei den tschechoslowakischen Einfuhrzöllen, sondern darüber hinaus großzügige Importkontingente einräumte, brachte breite Kreise im Zentralverband gegen Hotowetz so sehr auf, daß der Minister sich veranlaßt sah, in Privatbriefen an die prominentesten tschechischen Industriellen seine lauteren Absichten zu beteuern. ${ }^{161}$ Auch in Janovskys Augen

157 SÚA, ÚSČC, Karton 5, Exposé Karl Janovskys, Die Teilnahme Tschechiens an den wirtschaftlichen Sanktionen gegenüber Deutschland, undatiert.

158 Folgen hätten die Sanktionen für den Im- und den Export gehabt. Die Textilindustrie beispielsweise war zwar auf das Reich weniger als Exportland angewiesen, dafür aber stammten an die 70 Prozent aller Textilmaschinen aus dem Reich; groß war die Abhängigkeit der Textilbranche auch bei Farben und Chemikalien. Auf alliierte Zulieferer auszuweichen wäre problematisch gewesen, denn die Verbindungen waren nicht eingespielt, die Warenqualität war im allgemeinen schlechter, und die Beschaffung der nötigen Devisen nicht einfach. In der Chemie war man auf deutsche Maschinen, Roh- und Hilfsstoffe, auf den Export nach und den Transit durch Deutschland angewiesen. Die Einstellung der deutschen Kohlelieferungen hätte die Stillegung großer Teile der schlesischen und nordböhmischen Industrie nach sich gezogen. Ähnliche Abhängigkeiten existierten mutatis mutandis in anderen Wirtschaftszweigen mit starker deutscher Beteiligung, wie der Porzellan-, Glas, Email-, Papier-, Leder-, Mühlen-, Holz-, Musikinstrumenten- und Spielwarenindustrie sowie in der Lebensmittelverarbeitung: Vgl. SÚA, ÚSČP, Karton 5, DHI/Zentrale Teplitz-Schönau an DHI/Geschäftsstelle Prag, 2. 5. 1921. - ADTV an Kislinger, 3. 5.1921.

159 Janovsky, Teilnahme Tschechiens, wie vorletzte Fußnote.

160 ÖStA, BAA, Gesandtschaft Prag, Karton 11, Österreichische Gesandtschaft an das BAA, 6.4.1921.

161 Die gewöhnlich gut unterrichtete österreichische Gesandtschaft hatte von solchen Briefen erfahren: Vgl. ÖStA, Gesandtschaft Prag, Zl. 694/P, Karton 10, Österreichische Gesandtschaft Prag an BAA, 27.11.1920. 
war der Vertrag eine einseitige, für die ČSR nachteilige, offensichtlich politisch motivierte Konzession, die nicht von ungefähr auf dem Verordnungsweg anstatt durch das ordentliche parlamentarische Procedere Geltungskraft erlangt habe. ${ }^{162}$ Die deutschböhmische Wirtschaft habe sich seinerzeit vom "westlichen regierungsseitigen Umstellungsbolschewismus überrumpeln" lassen; sie werde sich einem zweiten derartigen Experiment aber auf alle Fälle widersetzen. ${ }^{163}$ Mißtrauisch beäugte man im Hauptverband 1921 deshalb auch die Pläne, nach der Aufhebung des Amtes für Außenhandel die Zuständigkeit für den Export und die Handelsvertragspolitik dem Außenministerium anzugliedern, da man befürchtete, im Schlepptau der Außenpolitik einem verstärkten Druck in Richtung Westbindung ausgesetzt zu sein. ${ }^{164}$

Neben der Handelspolitik war für die gesamte Industrie in den ersten Jahren der Republik der Steuerdruck, der die Produktion verteuerte und damit die Konkurrenzfähigkeit auf den Exportmärkten beeinträchtigte, ein gravierendes Problem: Nach einer Berechnung des Zentralverbands stieg die Steuerbelastung pro Kopf von 245 Kronen (1919) auf nicht weniger als 900 Kronen (1921). ${ }^{165}$ Auf der Vollversammlung des Zentralverbands im September 1920 konnte darauf verwiesen werden, daß die Regiering selbst im Wirtschaftsbeirat die stark fiskalistisch orientierte Steuergesetzgebung als Krisenursache bezeichnet hatte. ${ }^{166}$ Spätestens die weltweite Nachkriegs-Absatzflaute, die bis Mitte 1921 die Lage der Exportindustrie verschlechterte, machte die Reduzierung der Produktionskosten und damit auch der Steuern zum brennendsten Problem, dessen Lösung nicht zuletzt eine größere Sparsamkeit der öffentlichen Haushalte voraussetzte $^{167}$; diese legte der Zentralverband sogleich der neuen Regierung Beneš ans Herz. ${ }^{168}$ Nur einige Wochen früher hatte auch der Hauptverband eine größere Rücksichtnahme der Finanzverwaltung bei der Eintreibung der Steuern, eine Reduzierung unproduktiver Staatsausgaben, die Vereinheitlichung des Steuersystems und eine längerfristige staatliche Finanzplanung gefordert, da die Gefräßigkeit des Staates die Unternehmen in Schulden treibe und die Investitionen verhindere, die zur Erneuerung des im Krieg verschlissenen Kapitalstocks erforderlich seien. ${ }^{169}$

An einem Strang zogen beide Verbände auch hinsichtlich der Kritik an den staatlichen Zwangsanleihen und den Sonderabgaben zur Deckung des öffentlichen Finanzbedarfs: Die Industrie, so Preiss im Mai 1919, erkenne die Notwendigkeit der finanziellen Sanierung des Staates und damit der Vermögensabgabe an, dürfe finanziell aber nicht ausblu-

162 Und zwar durch die Verordnung Nr.177 vom 14.1.1921, auf der Grundlage des Gesetzes Nr. 637 vom 25.11.1919, das die Regierung ermächtigte, die 1919 und 1920 abgeschlossenen Handelsverträge provisorisch in Kraft zu setzen.

163 Janovsky, Prag-Paris?

164 MDHI 2 (1921), S. $468 \mathrm{f}$.

165 Rede Hodáčs, Vollversammlung des Zentralverbands am 27.5. 1922, in: OB 4 (1922), S. 1-8.

166 Vollversammlung des Zentralverbands am 21.9. 1920, in: OB 2 (1920), S. 4-7.

167 Rede Karlíks, Vollversammlung des Zentralverbands am 28. 5. 1921, in: OB 3 (1921), S. 341 ff. -

Der Zentralverband, so Hodáč, habe immer die Antiinflationspolitik der Regierung unterstützt, denn Inflation gehe letztlich immer auf Kosten der Industrie. Die Grenzen der Belastung seien erreicht: Vgl. ebenda, S. 345.

168 OB 3 (1921), S. 529 f.

169 Resolution, einstimmig angenommen auf dem Industriellentag in Reichenberg am 15. 8. 1921, in: MDHI 2 (1921), S. $397 \mathrm{f}$. 
ten. ${ }^{170} \mathrm{Nahm}$ der Finanzreferent des Zentralverbands die Höhe der Vermögensabgabe, die Zahlungsmodalitäten und die Arkanpraktiken bei der Ausarbeitung der Durchführungsvorschriften mehrmals kritisch unter die Lupe ${ }^{171}$, so erhob der Hauptverband Anfang 1921 vor allem Einspruch gegen die Pläne zu einer Zwangsanleihe zur Beschaffung der Mittel für den Ausbau des Telefon- und des Eisenbahnnetzes. ${ }^{172}$ Nachdem ungeachtet mehrerer Denkschriften des Hauptverbandes an die Adresse von Regierung und Parlament und gegen die Stimmen der deutschen Abgeordneten am 18. März das Gesetz über die sogenannte Investitionsverkehrsanleihe verabschiedet worden war, protestierte das DHI-Präsidium gegen die Modalitäten der Bemessung der Zwangsabgabe ohne Rücksicht auf die Belastbarkeit der Wirtschaft. Allerdings gelang es nicht, die vorgesehene Höhe der Zeichnung zu reduzieren und eine größere Transparenz bei der Planung der zu finanzierenden Projekte auf dem Wege über eine obligatorische Begutachtung seitens der wirtschaftlichen Körperschaften durchzusetzen. ${ }^{173}$ Die deutschen Wirtschaftsverbände und die Kammern erzielten auch in der Folgezeit über den Deutschen Parlamentarischen Verband nur unbefriedigende Zugeständnisse, etwa eine Streckung der Zeichnungsfristen. ${ }^{174}$ Hauptverband und Zentralverband stimmten auch in dieser Frage überein, wie eine - der Vorsprache beider Organisationen im Eisenbahnministerium am 25. Juli vorgeschaltete - Unterredung erwies. Auch in konzertierter Aktion konnten die beiden Verbände der Regierung allerdings nur ungenügende Konzessionen abringen ${ }^{175}$; wie auf einer Besprechung aller Industrieverbände mit den Kammern eine Woche später in Prag deutlich wurde, waren die meisten Eingaben nicht einmal beantwortet worden. ${ }^{176}$

Geradezu tumultuös war Anfang 1921 die Reaktion der deutschen Wirtschaft auf die Pläne der Regierung Černý, rückwirkend die Gewinne aus dem Export einer Reihe von Gütern wie Papier, Glas, Porzellan und Emailwaren, Holz, Malz, Hopfen und Kohlen mit einem Satz von nicht weniger als 50 Prozent zu besteuern. Auch diese Maßnahme, welche die Ende 1919 auslaufende Kriegssteuer ersetzen sollte, war aus dem fiskalistischen Geist geboren, der die tschechoslowakische Finanzverwaltung regierte. Ziel war die Erfassung der zum Teil tatsächlich sehr hohen Gewinnsätze im Außenhandel von 25 bis zu 135 Prozent. ${ }^{177}$ Die "Bohemia “ lehnte einen verdeckten Ausfuhrzoll als Charakteristikum des Merkantilsystems ab ${ }^{178}$; im „Prager Tagblatt ${ }^{\alpha}$ kritisierte der Glasindustrielle Heinrich Goldberg das Projekt als Kind der durch den Kronenabsturz hervorgerufenen kurzlebigen, inzwischen bereits nachlassenden Hausse der tschechoslo-

170 SÚA, ÚSČP, Karton 10, Preiss, Vollversammlung des Zentralverbands am 11. 5. 1919.

171 Reden des Finanzreferenten des Zentralverbands, Wagner, Vollversammlungen am 4.11.1919 und am 13.3.1920, in: OB 1 (1919), S. 15 und 2 (1920), S. 5-7.

172 MDHI 2 (1921), S. 129.

173 MDHI 2 (1921), S. 172f. und S. 210-213.

174 MDHI 2 (1921), S. $243 \mathrm{f}$.

175 MDHI 2 (1921), S. 320f. - OB 3 (1921), S. 401-403.

176 MDHI 2 (1921), S. 337.

$177 \mathrm{Da}$ andererseits der gleiche Mechanismus die Rohstoffimporte verteuerte, galt die Steuer nur für Exportgüter, zu deren Produktion keine importierten Rohstoffe erforderlich waren. Der Exportgewinn war definiert als Differenz zwischen dem ausländischen und dem inländischen Verkaufspreis; 20 Prozent davon blieben - als Exportanreiz - auf jeden Fall unversteuert. Erfaßt wurden überhaupt nur Exportgewinne von mehr als 50000 Kronen im Jahr.

178 BO vom 2. 2. und vom 4. 2.1921. 
wakischen Ausfuhrwirtschaft, welche sich auf den Auslandsmärkten inzwischen wieder scharfer Konkurrenz bei abflauender Nachfrage zu erwehren habe. Auf die nationalpolitischen Implikationen legte Goldberg den Finger mit dem Hinweis, die Abgabe treffe nur die Exportgewinne und hier nur bestimmte Branchen. Die geforderten Zahlungen addierten sich zur Vermögensabgabe und höhlten die durch das Debakel der Kriegsanleihen ohnehin geschwächte Kapitalbasis der Betriebe weiter aus. ${ }^{179}$ Hatte der Hauptverband schon im November 1920 gegen eine erste Version der Steuerpläne Protest erhoben ${ }^{180}$, so wurden scharfe Reaktionen in der Folge insbesondere aus der mehrheitlich deutschen, zu über 90 Prozent auf die Ausfuhr angewiesenen Porzellanindustrie laut ${ }^{181}$; in Reichenberg drohten die Exportindustriellen mit der Schließung ihrer Betriebe. ${ }^{182}$ Auch im Zentralverband waren die Ausfuhrinteressen hinreichend stark für eine Intervention. Goldberg wußte sich deshalb in dieser Frage mit den industrienahen „Národní listy" einig ${ }^{183}$, und die für den 4. Februar in der Prager Handelskammerzentrale einberufene gemeinsame Krisensitzung von Zentralverband und Handelskammern - welche beide, stilgerecht, von dem Vorhaben der Regierung wieder einmal nicht informiert worden waren - stellte für eine Vorsprache bei Ministerpräsident Černý ein Komitee zusammen. ${ }^{184}$

Bezeichnenderweise war es allein der erbittert ausgefochtene Konflikt um die Ein!ösung der österreichisch-ungarischen Kriegsanleihen durch den tschechoslowakischen Staat, in der der Zentralverband sich zurückhielt und dem DHI die Federführung überließ. Die Kriegsanleihen waren überwiegend von der ehedem staatstragenden deutschen Wirtschaft gezeichnet worden, während der K.u.k.-Patriotismus der tschechischen Unternehmer sich aus begreiflichen Gründen in Grenzen gehalten hatte. Da ein beträchtlicher Teil des deutschen Kapitals in diesen Papieren angelegt war, hätte ihre Nichteinlösung ein finanzielles Desaster ersten Ranges bedeutet. Daß der neue Staat es zunächst rundweg ablehnte, für die Erblasten der Monarchie geradezustehen, mutet einerseits verständlich an, war andererseits aber unklug, weil er dadurch $Z$ weifeln an seiner Seriosität und damit seiner Kreditwürdigkeit in der Zukunft Vorschub leistete. Bei den existierenden engen Verflechtungen innerhalb der Grenzen der Republik hätte die finanzielle Unterhöhlung der deutschen Wirtschaft aber natürlich auch die tschechische Seite in Mitleidenschaft gezogen. Die gewundenen, mit komplizierten finanztechnischen Details gepflasterten Wege zu der - erst nach mehreren Jahren erzielten - Kompromißlösung einer Umwandlung der Kriegsanleihe in tschechoslowakische Staatsanleihen sind hier weniger von Belang als die Tatsache, daß der Hauptverband von Anbeginn in vorderster Front im Kampf um die Einlösung stand und durch massenhaft besuchte Informations- und Agitationsveranstaltungen Druck auf die Regierung auszuüben suchte. ${ }^{185}$ Auch der Zentralverband hatte sich bis Mitte 1920 bereits mehrmals

179 Goldberg, Konjunktursteuer. - Vgl. auch den kritischen Kommentar in der BO vom 8. 2. 1921.

180 PT vom 27.11. 1920.

181 Bericht über eine Protestversammlung in Karlsbad im PT vom 5.2.1921.

182 PT vom 9.2.1921.

183 So der explizite Hinweis in dem zitierten Artikel Goldbergs, Konjunktursteuer.

184 PT vom 5. 2. 1921.

185 Am 25. Juni 1920 fand eine erste vom DHI einberufene große Versammlung in Reichenberg statt. Es folgten die Tagung aller Kriegsanleiheschutzverbände in Prag am 11. Juli des gleichen Jahres, eine Versammlung des Hauptverbandes am 17. Juli in Karlsbad und eine Tagung in Teplitz am 18. Oktober. Der DHI hatte einen eigenen Kriegsanleiheausschuß eingerichtet: Vgl. 
mit der Frage befaßt und beschlossen, im Gesamtinteresse der Industrie Anträge zur Ausgestaltung der Durchführungsverordnung zum Kriegsanleihengesetz zu stellen. Allerdings waren es, wie der "Observer“ anmerkte, doch in erster Linie die Deutschen, die laut klagten - „bei den tschechischen Interessenten galt es nicht als bon ton, sich zu beschweren". Immer rätselhaft werde bleiben, warum die Industriellen die Sache ruhig hingenommen hätten und kaum ein Verband „Vorstellungen“ $z u$ erheben wage. ${ }^{186}$

Obwohl es dem Zentralverband übel angerechnet wurde, daß er in dieser Lebensfrage der deutschen Industrie Distanz hielt, obwohl aus diesem Umstand sogar ein gewichtiges Argument gegen eine Kooperation geschmiedet wurde ${ }^{187}$, reichte aufs Ganze gesehen die Harmonie der Interessen doch so weit, daß eine engere, auch institutionalisierte Zusammenarbeit förmlich prädestiniert schien. Schon der Wahlkampf des Frühjahrs 1920 hatte die Bruchlinien im deutschen Lager aufgezeigt, gleichzeitig aber die Nationalitätengrenze überspannende Kraftfelder erahnen lassen. Monierte die Prager diplomatische Vertretung des Reiches auch die Zerstrittenheit und die mangelnde nationale Solidarität der deutschen Parteien sowie einen im notorischen deutschen Provinzialismus wurzelnden „Luxus der 'Meinungen'“, so bescheinigte sie der „nörgelnde(n) und alles privatim schrankenlos bekrittelnde(n) deutschböhmische(n) Oberschicht" doch Einigkeit im Kampf gegen den Sozialismus. In privaten Werbebriefen werde sogar auf die Gemeinsamkeiten zwischen deutschen und tschechischen Industriellen hingewiesen. ${ }^{188}$ Ebenfalls 1920 hatte sich in der "Wirtschaft" Bacher mit unverkennbar beifälligem Unterton über die „leidenschaftslosen“ deutsch-tschechischen Verhandlungen nach den Vorgängen in Deutschböhmen geäußert und angesichts der ungeheuren Wirtschaftsprobleme für eine Zusammenfassung aller Kräfte votiert. ${ }^{189}$ Ein „Spiel geheimer bürgerlicher Sympathien inbezug auf Dinge der Wirtschafts- und Gesellschaftsstruktur" registrierte die Prager Gesandtschaft Mitte 1920: Als Lodgman, in richtiger Witterung subkutaner Zustimmung bei den tschechischen Bürgerlichen, im Namen des Deutschen Parlamentarischen Verbandes die Notwendigkeit einer Revision des gesamten "progressiven“" wirtschafts- und sozialpolitischen Gesetzgebungswerkes der Vorläufigen Nationalversammlung proklamierte, weil in dieser die Deutschen nicht vertreten gewesen seien, konnte die nationaldemokratische Presse nur deshalb ihre Zustimmung nicht deutlicher als zwischen den Zeilen zum Ausdruck bringen, weil der virulente tschechische Chauvinismus ein lautes Bekenntnis zur sozialpolitischen Solidarität mit den Bürgerlichen auf deutscher Seite verbot. ${ }^{190}$

Die Phase der „Parallelaktionen“ und der Abstimmung ad hoc endete um die Jahreswende 1921/22. Die Zäsur setzte der erwähnte neuerliche Krisenschub, verursacht im wesentlichen von außenwirtschaftlichen Faktoren: Hatte der erste Finanzminister der Republik, Rašín, die Hebung des Außenkurses der Krone zur ersten Priorität seiner Politik gemacht, so hatte sich Engliš, sein Nachfolger in der Beamtenregierung Černý, in

MDHI 1 (1920), S. 25 f., 31 f. und S. 123. - Bericht des DHI über das Vereinsjahr 1920, S. 8. BArch-B, RMWi, 20 256, Gesandtschaft Prag an AA, 19.10.1920. - BO vom 19. und vom 20.10.1920.

186 "Argus“, Kriegsanleihe.

187 PA, IIb, Wirtschaft 10, Tschechoslowakei, Band 1, AA/Zweigstelle München an AA, 7. 4. 1921.

188 PA, R 73 803, Der Geschäftsträger des Deutschen Reiches an AA, 24. 3. 1920.

189 Bacher, Verhandlungen.

190 PA, R 73 803, Gesandtschaft Prag an AA, 8. 6. 1920. 
der richtigen Erkenntnis, daß der steigende Außenwert der tschechoslowakischen Währung zwar Lebensmittel- und Rohstoffimporte verbilligte, die Exporte aber an Konkurrenzfähigkeit verloren, auf den Kompromiß einer Stabilisierung des Kurses zurückgezogen. ${ }^{191}$ Anfang 1922 stieg dieser wieder rapide an - ein, wie der deutsche Gesandte vermerkte, Zeichen des "lebhaften Vertrauens“ zu dem jungen Staat, „auf das man hier nicht wenig stolz ist ${ }^{\prime \prime}{ }^{192}$ Die Ursache lag in dem beträchtlichen Handelsbilanzaktivum der Jahre 1920 und 1921; hinzu kam als psychologischer Faktor die internationale Währungsspekulation. ${ }^{193}$

Eine Hochhaltung des Kronenkurses war, wie Teltscher vor dem Allgemeinen Deutschen Textilverband Ende April 1922 ausführte, auch in den Augen der deutschen Industriellen an sich verdienstvoll, weil sie via Verbilligung der Importe zur Senkung des inländischen Preisniveaus beitrug. Allerdings wuchs damit auch wieder die Gefahr, daß die Industrie auf den Auslandsmärkten an Boden verlor; eine kompensierend wirkende Senkung der gefährlich hohen Produktionskosten, zu denen Steuern und Löhne nicht unwesentlich beitrugen, wurde zwar weiterhin gefordert, war aber nach wie vor nicht in Sicht. ${ }^{194}$ Die Krise schlug Wellen bis ins Parlament ${ }^{195}$, wo sie zum Anlaß nationalpolitisch eingefärbter Polemiken wurde: Die Regierung, so der Senator der Deutschen Nationalpartei, Oberleithner, stehe den Forderungen der Industrie und hier in erster Linie der deutschen Exportwirtschaft mit grenzenloser Gleichgültigkeit gegenüber, ja das Finanzministerium habe bei der wahnwitzigen Erhöhung des Kronenkurses die Hände im Spiel. Man sei im Grunde sogar froh darüber, „die deutsche Industrie an ihrem Lebensnerv treffen" und den Abbau der "Überindustrialisierung " - des industriellen Übergewichts der Deutschen also - bequem bewerkstelligen zu können. Auch Oberleithner plädierte prinzipiell für einen allmählich steigenden Kronenkurs; dieser dürfe jedoch die Exportindustrie nicht erdrosseln und müsse deshalb Hand in Hand mit der Reduzierung der Produktionskosten und der fiskalischen Belastungen gehen. ${ }^{196}$

Nun barg die Rede von einem "tschechischen Komplott" wieder einmal höchstens die halbe Wahrheit: Auch aus den Reihen der tschechischen Industriellen war nämlich zu hören, die Regierung weigere sich, aus der Kursentwicklung Folgerungen für das überdimensionierte Budget zu ziehen. ${ }^{197}$ Abgesehen von der absoluten Höhe des Kronenkurses kritisierte Hodáč insbesondere die permanenten, die Exportwirtschaft verunsichernden, weil stabile Kalkulationsgrundlagen zerrüttenden Schwankungen. Folge

191 Bacher, Neue Regierung.

192 In Wien fungierte die Krone sogar als inoffizielles Zahlungsmittel, etwa für Dienstbotenlöhne: Vgl. PA, R 8955, Gesandtschaft Prag an AA, 25. 1. 1922.

193 So die Erklärung Hodáčs, Sitzung der Delegierten der Fachgruppen und Sektionen beim Zentralverband am 24.1.1922, in: OB 4 (1922), S. 65 f.

194 Vortrag Teltschers auf der Vollversammlung des ADTV am 4. 1922, abgedruckt unter dem Titel „Wirtschaftskrise und Steuerdruck“ im PT vom 4. 5. 1922. - Vgl. zum Gesamtkomplex auch die kritische Stellungnahme von Karl Janovsky, Produktionsgrundlage.

$195 \mathrm{Vgl}$. etwa die dringliche Interpellation der Abgeordneten Schälzky, Böhr, Budig und Genossen (alle Deutsche Christlich-Soziale Volkspartei) vom 28.3.1922, TTZPS, 1. WP, Drucksache Nr. 345.

196 Rede Oberleithners im Senat am 8. 2. 1922, TZS, 1. WP, S. 962 ff. - Oberleithner war Mitglied der Deutschen Christlich-Sozialen Volkspartei, dann der Deutschen Nationalpartei und Führer der nationalen Bewegung in Nordmähren. Im Senat saß er von 1920 bis 1929 als Wirtschaftsfachmann der DNP: Vgl. Balling, Von Reval bis Bukarest, Band 1, S. $429 \mathrm{f}$.

197 PA, R 74 034, Gesandtschaft Prag an AA, 11. 5. 1922. 
dieser Rahmenbedingungen sei nicht nur eine mit steigender Arbeitslosigkeit verbundene Rationalisierungswelle, sondern auch eine wachsende Zahl von Konkursen. ${ }^{198}$ Hodáčs Verlautbarungen zeigen plastisch, wie diese Entwicklung bis in den Frühsommer 1922 hinein immer weitere Kreise zog; einzelne Branchen setzten in wilden Kämpfen Lohnsenkungen von bis zu 30 Prozent durch. ${ }^{199}$

Schon bevor die Krise mit voller Wucht einsetzte, hatten die Verbände sich weiter einander angenähert. Generaldirektor Sonnenschein, der deutsche Vertreter im Zentralverband, konstatierte als Vorboten der Verständigung bereits Mitte 1921 eine intensivere Mitarbeit der Deutschen im Zentralverband und dessen verstärkte Kooperation mit dem DHI. ${ }^{200}$ Die neue Herausforderung dürfte dann aber den Durchbruch in den Gesprächen über eine Institutionalisierung der Kooperation bewirkt haben. Die im November 1921 angebahnten Verhandlungen ${ }^{201}$ waren so heikel, daß sie an die ersten tastenden Verständnisversuche auf parlamentarischer Ebene im Frühjahr 1920, nach dem Konflikt um Deutschböhmen, erinnerten. ${ }^{202}$ Im Rahmen informeller Kontaktgespräche mit der Burg im Vorfeld der Bildung der Regierung Beneš ließ Kislinger durchblicken, die deutschen Industriellen trügen schwer an Lodgman, einem Theoretiker, der keine Rücksicht auf die Bedürfnisse der Wirtschaft kenne. Kislinger bekannte sich als Freund einer "Einheitsfront" der Industrie und trat darüber hinaus für eine politische Annäherung von Deutschen und Tschechen auf allen Ebenen ein. ${ }^{203}$ Auf der anderen Seite signalisierte auch der Zentralverband Konzessionsbereitschaft: Er insistierte nicht mehr auf seinem „Alleinvertretungsanspruch“; von den Vorbehalten gegen die Separatexistenz des DHI war nicht mehr die Rede - günstige Auspizien, unter denen es dem Hauptverband gelang, seine Forderung nach einem paritätisch besetzten Spitzengremium im Verein mit strikten Minderheitenschutzrechten ohne wesentliche Abstriche durchzusetzen. ${ }^{204}$

Das trotz allem erst am 4. März 1922, „nach monatelangen schweren Bemühungen“, unterzeichnete Arbeitsübereinkommen ${ }^{205}$ sah die Einrichtung eines „Reichskomitees der Industrie der tschechoslowakischen Republik" vor (die Bezeichnung "tschechoslowakische Industrie " hatte man absichtlich vermieden), welches sich aus 18 Delegierten des DHI und 25 des Zentralverbands - drei von ihnen deutscher Nationalität - zusammensetzte. Mit dem Nationalitätenschlüssel von 21:22 war die Parität fast erreicht. Daß Abstimmungen eine Dreiviertelmehrheit erforderten und auf Verlangen nicht nur die Anwesenden, sondern die schriftlichen Voten aller Mitglieder des Zentralausschusses einzubeziehen waren, sollte eine Majorisierung unter nationalen Vorzeichen verhin-

198 Rede Hodáčs, Sitzung des Zentralausschusses der Delegierten der Fachgruppen und Sektionen beim Zentralverband am 24. 1. und am 14.3.1922, in: OB 4 (1922), S. 65 f. und S. $158 \mathrm{f}$.

199 Rede Hodáčs, Sitzung des Zentralausschusses der Delegierten der Fachgruppen und Sektionen beim Zentralverband am 25.4. und am 19.6.1922, in: OB 4 (1922), S. 224 und S. 327 f. - Rede Hodáčs, Vollversammlung des Zentralverbands am 27.5. 1922, in: OB 4 (1922), S. 1-8.

200 Rede Sonnenscheins, Vollversammlung des Zentralverbands am 28.5.1921, in: OB 3 (1921), S. 342.

201 BArch-B, RMWi, 2888, Gesandtschaft Prag an AA, 19. 3. 1922.

202 Bacher, Verhandlungen.

203 AKPR, T 12/25, Karton 134, C 1, Aktenvermerk Sámal vom 13. 9. 1921.

204 Skizze der Verhandlungspositionen in: BArch-B, RMWi, 2888, Gesandtschaft Prag an AA, 19.3.1922.

205 AKPR, T 12/25, Karton 134, C 2, Kislinger an Šámal, 4. 3. 1922. 
dern. Scheiterte eine Einigung, so wurde das Minderheitenvotum Regierung und Öffentlichkeit zusammen mit dem Mehrheitsvotum des Ausschusses präsentiert. Das Präsidium, die Repräsentation des Ausschusses nach außen, war alternierend mit Angehörigen der beiden Nationalitäten besetzt: Präsident war Mařík, der 1920 Malinský als Vorsitzender des Zentralverbands abgelöst hatte. Als erster Vizepräsident amtierte Schicht; auf den nächstfolgenden Plätzen fanden sich Hodáč, Kislinger und Preiss. In die Geschäftsführung teilten sich Hodáč und Kislinger. Für das zur Behandlung dringlicher Angelegenheiten eingerichtete Vollzugskomitee, das um vier bzw. sechs Mitglieder erweiterte Präsidium, galt sogar das Einstimmigkeitsprinzip. Der Grundsatz der Gleichberechtigung fand auch in der doppelsprachigen Abwicklung des Geschäftsverkehr seinen Ausdruck. Jedes Ausschußmitglied hatte das Recht, seine Sprache zu benutzen; auf Wunsch wurde übersetzt. Abgesehen von dem gemeinsamen Spitzengremium blieben der bisherige Aufbau der beiden Verbände und ihre organisatorische Unabhängigkeit voneinander unberührt; die Abwerbung von Mitgliedern des Partners war per Besitzschutzklausel ausdrücklich verboten. ${ }^{206}$

Die Vereinbarung zur Errichtung des Zentralausschusses habe, so Hodác in seinem Rechenschaftsbericht auf der Generalversammlung des Zentralverbands am 27. Mai, "mit gutem Gewissen“ getroffen werden können, weil das Arrangement zweier Fachorganisationen aller politischer Implikationen entbehre. ${ }^{207}$ Coram publico spielte auch Kislinger die politische Bedeutung des Aktes herunter und nahm für die Industrie sogar „das bescheidene Verdienst in Anspruch..., hier eine Tat zur Entpolitisierung der Wirtschaft gesetzt zu haben “ ${ }^{208}$ Realitätsgerechter war allerdings die Einschätzung der-die Vorgänge aufmerksam verfolgenden - deutschen Gesandtschaft, das Abkommen, ein "Triumph" des Hauptverbandes, beinhalte "das bedeutsame Moment, daß damit die hiesige deutsche Wirtschaftskraft endgültig und offen in den Dienst der Konsolidierung dieses Staates sich gestellt hat ${ }^{\text {“ }}{ }^{209}$ Hinter den Kulissen äußerte sich auch Kislinger sehr viel unverblümter: Die Vereinbarung sei für das deutsche Bürgertum zunächst einmal eine pragmatische Lösung, darüber hinaus aber auch ein „Markstein“ in den deutschtschechischen Beziehungen und das „Bekenntnis eines gleichen Zieles“ der eng miteinander verflochtenen beiden Völker. ${ }^{210}$

Beweggrund für die auf beiden Seiten offensichtlich angestrebte „unpolitische Verpackung " der Übereinkunft waren zweifellos die - kontrapunktisch zu den Wirtschaftsbeziehungen - gerade zu dieser Zeit besonders virulenten nationalitätenpolitischen Konflikte. Mitte Februar 1922, im unmittelbaren Vorfeld der Übereinkunft, beurteilte die deutsche Gesandtschaft die Lage als labil; seit dem Kulminationspunkt der Ausschreitungen des Herbstes $1920^{211}$ habe sich das "Deutschtum" zwar wieder an die

206 BArch-B, RMWi, 2888, Gesandtschaft Prag an AA, 31. 3. 1922. - Kislinger, Organisation. - Bericht über die konstituierende Sitzung des Zentralausschusses der Industrie in der tschechoslowakischen Republik, in: MDHI 3 (1922), S. 410, 413 - Vgl. auch den ausführlichen Bericht in BO vom 21.6.1922.

207 Rede Hodáčs, Vollversammlung des Zentralverbands am 27.5. 1922, in: OB 4 (1922), S. 5.

208 Kislinger, Organisation.

209 BArch-B, RMWi, 2888, Gesandtschaft Prag an AA, 31. 3. 1922.

210 AKPR, T 12/25, Karton 134, C 2, Kislinger an Śámal, 4. 3.1922.

211 Gemeint waren hier die Übergriffe eines verhetzten chauvinistischen Mobs gegen Deutsche im November 1920. 
Oberfläche wagen können; der tschechische Chauvinismus habe aber „einen sehr leisen Schlaf" und halte die Regierung in Abhängigkeit. Böses Blut habe bei den Extremisten beispielsweise die Zusage der Rückgabe des Ständetheaters durch die Nationalversammlung gemacht. ${ }^{212}$ Die nationaldemokratische Partei instrumentalisiere diese Stimmung, und die nationaldemokratische Presse, allen voran die „Národní listy“, sähe in der tschechischen Minderheit in den deutschen Gebieten unter Hinweis auf ihre „Unterdrükkung " Unzufriedenheit. ${ }^{213}$ Die Verhandlungen über einen Regierungseintritt der Deutschen im Juni verhakten sich dann an den deutschen Minimalforderungen in der Schulund in der Sprachenfrage. ${ }^{214}$ Der Sommer brachte mit weiteren „Tschechisierungsvorstößen" in der Angelegenheit der Grenzwaldenteignung, der Verstaatlichung der Teplitz-Aussiger Bahn und der Schließung deutscher Schulen eine weitere Aufladung der Stimmung mit sich, die sich in Pressepolemiken, aber auch in Zusammenstößen und Prügeleien manifestierte. ${ }^{215}$

Vor diesem Hintergrund waren Kislingers dem Leiter der Kanzlei des Präsidenten, Š́mal gegenüber vertraulich geäußerte Sorgen hinsichtlich der möglichen politischen Folgen des Abkommens und sein Bedürfnis, zunächst bei den deutschen Parlamentariern um Unterstützung zu werben, verständlich. Angesichts eines Mangels an wirklichen Konzessionen der Tschechen in den für die Deutschen zentralen politischen und kulturellen Fragen werde auch den aktivistischen Abgeordneten die Zustimmung schwerfallen; man werde sich vorwerfen lassen müssen, ein wichtiges Kompensationsobjekt vorzeitig aus der Hand gegeben zu haben. Die Regierung, so Kislingers Vorschlag, solle zumindest einige kleinere Zugeständnisse, etwa bei der Besetzung höherer Beamtenstellen in verschiedenen Ministerien, machen - sonst halte der Aktivismus nicht durch. ${ }^{216}$ Angesichts einer im DHI selbst vorhandenen starken Opposition gegen die "wirtschaftsaktivistische" Linie war Kislingers eigene Stellung an der Schaltstelle zwischen Hauptverband und politischem Aktivismus heikel. ${ }^{217}$

Trotz der grundsätzlichen Bereitschaft zur Zusammenarbeit war das Verhältnis zwischen Zentralverband und DHI in den auf die Übereinkunft folgenden Monaten nicht von den Trübungen frei, die ein zuweilen kleinlich anmutendes Gerangel der Verbände um Terraingewinne mit sich brachte. Im Vorfeld einer von Kislinger zusammen mit Samál in die Wege geleiteten Audienz der Industrie bei Masaryk ${ }^{218}$ beispielsweise fand

212 Dieses in deutschem Besitz befindliche Prager Theater war im Zuge der Ausschreitungen besetzt worden.

213 PA, R 73 820, Gesandtschaft Prag an AA, 18. 2. 1922. - PA, R 73 821, Gesandtschaft Prag an AA, 7.4. 1922.

214 Deutsche Abgeordnetenkreise hätten, wie Kanzler Šámal notierte, sogar gerne einen Ministerpräsidenten Kramár̆ gesehen, damit dessen doktrinärer Nationalismus durch die Praxis ad absurdum geführt werde: Vgl. AKPR, T 12/25, 2. Teil, Karton 134, Aktenvermerk Sámal vom 20.6. 1922.

215 PA, R 73 821, Gesandtschaft Prag an AA, 11. 7.1922.

216 AKPR, T 12/25, Karton 134, C 2, Kislinger an Śámal, 4. 3. 1922.

217 So Kislinger gegenüber Sámal: Vgl. AKPR, T 182/22, Karton 84, Aktenvermerk Sámal vom 29.3.1922. Angesichts des Fehlens unabhängiger Quellen bleibt allerdings unklar, wieviel von dieser „Opposition“ auf Selbststilisierung Kislingers zurückzuführen ist.

218 Sámal hatte Kislinger Mitte März seiner Unterstützung beim Bemühen um einen Ausgleich versichert, einen Brief Kislingers an Masaryk und Beneš weitergeleitet und dessen Vorschläge befürwortet: Vgl. AKPR, T 12/25, Karton 134, C 2, Sámal an Kislinger, 13.3.1922. 
ein langwieriges Tauziehen um die Zusammensetzung der Delegation statt, in dem Hodáč sich als Intrigant hervortat. ${ }^{219}$ Zumindest untergründig-atmosphärisch dürfte auch von Belang gewesen sein, daß Exponenten beider Lager alte Rechnungen gegeneinander offenstehen hatten: Kislinger beispielsweise, unter der Monarchie Agent der Prager Polizei und als solcher seinerzeit verantwortlich für Preiss' steckbriefliche Verfolgung, wurde in Gesellschaft von diesem geschnitten. ${ }^{220}$ Überhaupt erschwerte die weitgehende Segmentierung in nationalkulturelle Milieus eine "flankierende" deutschtschechische Annäherung im zwanglosen gesellschaftlichen Verkehr. Mayr-Harting, Exponent des Aktivismus, der über das fast völlige Fehlen eines gemeinsamen Forums Klage führte, benannte als Ausnahme von der Regel eine gelungene Abendgesellschaft Kislingers im Dezember 1922 mit Exponenten des deutschen wie des tschechischen wirtschaftlichen und politischen Lebens. ${ }^{221}$

Warum trotz der „furchtbar kritischen Lage der Industrie“, die ja der Anlaß für das Zusammenrücken gewesen war $^{222}$, der Ausschuß zu seiner konstituierenden Sitzung erst erstaunlich spät, nämlich am 20. Juni 1922, zusammentrat ${ }^{223}$, ist aus den Quellen nicht ersichtlich. Die auf dieser ersten Zusammenkunft erarbeitete Krisenanalyse und ein Forderungskatalog wurden - aus der Einsicht heraus, daß die Industrie, um den ihrer Sachkompetenz entsprechenden Einfluß zu erringen, über ihre bisherigen allgemeinen Forderungen hinaus Auswege aus der Krise aufzeigen müsse - auf einer weiteren Sitzung am 25. August ${ }^{224}$ detailliert. Grundsätzlich forderte der Ausschuß eine Handelsund Finanzpolitik nach präzisen Richtlinien und in enger Abstimmung mit der Wirtschaft. Hier sollte sich der Staat auf die Setzung der Rahmenbedingungen beschränken und von weitergehenden Interventionen Abstand nehmen. Als zentrale Crux wurden ein weiteres Mal die überhöhten, die internationale Konkurrenzfähigkeit der Tschechoslowakei beeinträchtigenden und die Handelsbilanz verschlechternden Produktionskosten benannt. Die Wurzel dieses Übels ortete die Analyse nach wie vor im Lohnniveau und in den überhöhten Staatsausgaben; gefordert wurden die Herabsetzung der Steuern und die Milderung von Sonderbelastungen wie der Vermögensabgabe, die Senkung der Bahn- und Posttarife, äußerste Sparsamkeit der öffentlichen Finanzwirtschaft, die Einschränkung der Ausgaben der Selbstverwaltungskörper und eine Sanierung der

219 Geladen werden sollten sieben Industrielle, einer davon ein Deutscher. Erst nach langen Verhandlungen einigte man sich auf ein Verhältnis von zwei zu fünf. Hodáč berief sich in dieser Auseinandersetzung den Deutschen gegenüber immer wieder darauf, daß er den Vorschlägen der Präsidentenkanzlei zu folgen habe. Tatsächlich aber - dies stellte Sámal klar - folgte die Kanzlei den Vorgaben des Zentralverbands: Vgl. AKPR, T 182/22, Karton 84, Aktenvermerk Š́mal vom 29.3.1922.

220 AKPR, T 12/25, Karton 134, C 2, Aktenvermerk Śámal vom 3. 7. 1922.

221 AKPR, T 12/25, Karton 134, C 2, Aktenvermerke Śámal vom 21. und vom 29. 12. 1922. Auf der Abendgesellschaft am 21. Dezember 1922 waren neben den Exponenten des deutschen Aktivismus - Mayr-Harting, Kafka, Ledebur-Wicheln und Spina - von tschechischer Seite die Tochter des Präsidenten, Alice Masaryková, Hodáč und der frühere Staatssekretär im Handelsministerium, Schuster, anwesend.

222 BArch-B, RMWi, 2888, Gesandtschaft Prag an AA, 31.3.1922.

223 Konstituierende Sitzung des Zentralausschusses der Industrie in der tschechoslowakischen Republik, in: MDHI 3 (1922), S. 407-413 und OB 4 (1922), S. 328-332. - SÚA, NL Hodáč 216, Redemanuskript Schichts für die konstituierende Sitzung, undatiert.

224 Sitzung des Zentralausschusses vom 25. 8. 1920, in: OB 4 (1922), S. 451-453. 
defizitären Staatsbetriebe. Notfalls sollte das Parlament durch eine Pauschalkürzung des Etats dem Ressortegoismus der Ministerien, welcher der Ausuferung der Ausgaben Vorschub leiste, einen Riegel vorschieben.

Standen für den Zentralverband die binnen-, vor allem die finanzwirtschaftlichen Maßnahmen gegen die Malaise an der Spitze des Forderungskatalogs, so sah Schicht als Sprecher der stärker exportorientierten deutschen Wirtschaft die Krise nicht in erster Linie durch das Bündel monetärer Faktoren, sondern grundsätzlicher, nämlich durch den "Geburtsfehler" des tschechoslowakischen Staates: das strukturelle Übergewicht der von der Monarchie „ererbten“ überdimensionierten Exportindustrie verursacht. Den Verlust der angestammten Absatzgebiete hätten alle kompensatorischen Maßnahmen bislang nicht wettmachen können. Diese deutsch-tschechischen Differenzen waren allerdings nicht tiefgreifend; im Grunde wurden hier nur die Akzente unterschiedlich gesetzt. Auch die Vertreter des Zentralverbands verschlossen die Augen ja keineswegs vor den Gefahren des steigenden Kronenkurses; die generell prekäre außenwirtschaftliche Lage der Tschechoslowakei war auch ihnen bewußt. Ihre Forderung nach einer deflationären, die Produktionskosten, insbesondere die Löhne senkenden Wirtschaftspolitik war umgekehrt natürlich auch nach dem Geschmack der deutschen Unternehmer, weil sie geeignet war, die Exportchancen zu verbessern. So waren die handelspolitischen Forderungen - wenn die Deutschen ihre Wichtigkeit auch ganz besonders betonten auch nicht zwischen den nationalen Fraktionen umstritten; Kontroversen im Detail rührten eher von den unterschiedlichen Interessen der Rohstoffe importierenden und der Fertigwaren exportierenden Branchen her. In der Frage der „Dosierung“ von Freihandel bzw. Zollschutz zog der Ausschuß sich deshalb auf den Formelkompromiß zurück, die Zölle dürften den Export nicht hemmen und müßten in erster Linie die Interessen der bodenständigen Wirtschaftszweige mit "natürlichen Daseinsbedingungen“" schützen.

$\mathrm{Daß}$, wie Schicht einige Jahre später im Rückblick resümierte, der Zentralausschuß die ihm zugedachte Geltung nicht erlangen und „nur eine bruchstückweise Tätigkeit“ entfalten konnte ${ }^{225}$, hatte seine Ursache nicht in national- oder wirtschaftspolitischen Differenzen zwischen den beiden Verbänden, sondern vermutlich eher in den limitierten Möglichkeiten, eine industriefreundliche Politik durchzusetzen. Unisono war bereits auf der ersten Sitzung des Ausschusses wieder die Klage über das mangelnde Verständnis für die Belange der Industrie in allen politischen Lagern zu hören gewesen; die am 25. August an die Adresse der Regierung gerichtete Resolution mahnte bereits mit deutlicher Ungeduld die Realisierung der wieder und wieder, bislang immer ohne Erfolg vorgebrachten Vorschläge an. Eine letzte Sitzung des Ausschusses am 11. Oktober diente lediglich dazu, die praktisch unveränderte Liste der Forderungen der neuen Regierung Švehla zu unterbreiten - in diese Regierung war mit Rašín als Finanzminister aber wieder der hartnäckigste Verfechter einer Politik des hohen Kronenkurses eingetreten. Daß die Organe beider Verbände ${ }^{226}$ der Oktoberzusammenkunft nur mehr eine kurze Notiz widmeten, dürfte als Indiz dafür zu werten sein, daß auf beiden Seiten Resignation hinsichtlich der Möglichkeiten einer konzertierten Aktion eingetreten war. 
Zentralverband und Hauptverband agierten also bereits in den Anfangsjahren der Republik als Interessenvertretungen in einem Geschirr - ein angesichts des immensen Problemdrucks eigentlich nicht sonderlich überraschender Befund. Der umfassende Vertretungsanspruch des Zentralverbands und die Sonderbündelei des Hauptverbands, die Segmentierung in nationale Milieus, die virulenten allgemein-nationalpolitischen Spannungen, der allenthalben, stärker noch auf der deutschen - als der defensiven - Seite gereizt hervorgekehrte nationale point d'honneur - all dies zusammengenommen hatte zur Folge, daß das Zusammengehen vorerst sotto voce erfolgte und sich nicht institutionell verfestigte. Blieb der Zentralausschuß auch eine ephemere Erscheinung, so stellte er doch ein zukunftsweisendes Experiment dar: Über die kurzfristige, besonders gravierende Krisensituation der frühen zwanziger Jahre hinaus erhielt sich eine Disposition zur Zusammenarbeit, weil die Problemlage - die Stellung der Industrie im und zum Staat - im Prinzip stabil war. Die zweite Hälfte der zwanziger Jahre ist hierfür die Probe aufs Exempel. 


\section{Der Beitritt des Hauptverbands zum Zentralverband (1928)}

Nach der Überwindung der Nachkriegsanomalien - 1924 war das Jahr der Stabilisierung - schürzt sich der Knoten der Zusammenarbeit erst wieder in der zweiten Hälfte des Jahrzehnts. Die Gründung einer Gesamtvereinigung der tschechoslowakischen Industrie sei, wie das Organ des Zentralverbands 1928 formulierte, „ein Gebot der Zeit, eine ganz elementare und durch die Verhältnisse hervorgerufene Bewegung", mit dem Ziel, „die Organisation weiter zu vereinfachen und alle Zweifel an der Notwendigkeit einer einheitlichen Vertretung der gemeinsamen Interessen zu beseitigen ". ${ }^{1}$ Ein kraftvoller Lobbyismus der Industrie, das System der „korporativen Erledigung von Fragen", wurde im Zentralverband auch nach dem Abflauen der Nachkriegskrise keineswegs als überholt angesehen. Nicht von der Hand zu weisen war die Einschätzung, der säkulare Entwicklungstrend gehe überhaupt in Richtung korporatistischer Arrangements und kollektiver Verhandlungsmechanismen; für solche verfügte auch die Arbeiterbewegung über schlagkräftige Organisationen. Besonders dringlich erschien eine gesamtindustrielle Interessenvertretung angesichts der grundlegenden innenpolitischen Konstellation, des Umstands also, daß die Regierung im wesentlichen auf dem Verbund von agrarischen Interessen und Sozialdemokraten basierte. ${ }^{2}$

Die Wirtschaftspolitik wurde vom Gegensatz zwischen Industrie und Landwirtschaft dominiert. $\mathrm{Da}$ trotz günstiger Konjunktur die industriellen Kapazitäten nicht ausgelastet waren, stellte aus der Sicht der Industrie die Steigerung des Exports und der Ausbau des Handelsvertragssystems die erste Priorität der Wirtschaftspolitik dar. Die Lobby der Landwirtschaft hingegen votierte für agrarische Schutzzölle. Diese steigerten zwar die landwirtschaftlichen Einkommen und die Konsumkraft der Bauernschaft; der Agrarprotektionismus verteuerte jedoch die Lebenshaltung der Arbeiterschaft und trieb durch den Druck auf die Löhne die Kosten der industriellen Produktion nach oben, was sich in verminderter Konkurrenzfähigkeit des Exports und einer Verschlechterung der Zahlungsbilanz niederschlug. Die Zollnovelle von 1926, Indiz für die ungleiche Kräfteverteilung, drohte die Industrie in die Rolle des Aschenbrödels abzudrängen. In der Folgezeit setzten sich die Kämpfe vor und hinter den Kulissen fort. 1927 forderte der Nationaldemokrat Novák in der Nationalversammlung, nachdem die Industrie in der Frage des Zolltarifs zahlreiche Opfer gebracht habe, müßten sich die anderen Interessengruppen zu vergleichbaren Zugeständnissen bereitfinden. ${ }^{3}$ Im Dezember 1928 mahnte Kislinger anläßlich der Arbeiten an einem neuen Zolltarif eine klare Orientierung der Handelspolitik auf der Basis eines vorgängigen Ausgleichs agrarischer und industrieller Belange an. ${ }^{4}$ Preiss hatte bereits Kontakte zur Agrarpartei geknüpft und einen gemeinsamen Ausschusses von Industrie und Landwirtschaft als Forum von Ausgleichsverhandlungen angebahnt. ${ }^{5}$

1 „Nachwort zu den Jubiläumsfeierlichkeiten“, in: OB 10 (1928), S. 327.

2 OB 6 (1924) S. 285.

3 Rede Nováks im Abgeordnetenhaus am 30.11.1927, in: OB 9 (1927), S. 633.

4 Interview Kislingers mit der "Wirtschaft ", im Rahmen einer Rundfrage der Zeitschrift bzgl. der dringendsten wirtschaftlichen Probleme der Tschechoslowakei gegen Ende 1928, in: WI 10 (1928), S. $1518 \mathrm{f}$.

5 AKPR, T 182/22, Karton 84, Preiss an Sámal, 16. 7. 1928. 
Der kardinale Streitpunkt waren die Handelsbeziehungen zu den Staaten des europäischen Südostens. Da der Agrarprotektionismus der ČSR die landwirtschaftlichen Einfuhren aus diesen Ländern hemmte, war potentiellen Abnehmern tschechoslowakischer Industrieprodukte die Möglichkeit beschnitten, die für den Einkauf in der ČSR erforderlichen Devisen zu erwirtschaften. Außerdem leistete der Ausschluß tschechoslowakischer Fertigwarenexporte von den Märkten im Osten und Südosten dort dem Aufbau autochthoner Industrien Vorschub. Solche Autarkietendenzen waren geeignet, auch auf längere Sicht den Spielraum der tschechoslowakischen Ausfuhr zu beschneiden. Janovskys hierauf gemünztes Verdikt, nach dem Zerfall der Monarchie habe man nicht im erforderlichen Maße auf den "mitteleuropäischen Zusammenhang " geachtet $^{6}$, teilte der Zentralverband. Redete dort auch niemand einer völligen Schleifung der Zollmauern das Wort, so bekundete man im Geiste der Genfer Weltwirtschaftskonferenz doch, die Tschechoslowakei könne kein Interesse an einer Erhöhung des Zollschutzes haben, weil man als exportierender Staat danach trachten müsse, „daß unsere Waren auf den internationalen Märkten mit den soweit als möglich geringsten Hindernissen zusammentreffen"?

Die Forderungen beider Industriellenverbände zur Steuer- und Finanzpolitik waren ebenso wie die zur Handelspolitik weitgehend identisch. Die unruhigen ersten Jahre der Republik hatten sich durch eine - aus Unternehmersicht - verschwenderische staatliche Ausgabenwirtschaft ausgezeichnet. Von der nach den Wahlen von 1925 gebildeten bürgerlichen Regierung erhoffte sich der Zentralverband nicht zuletzt im Interesse der Währungsstabilität eine Reduzierung der Staatsausgaben und ein rationelleres Finanzgebaren. Hiervon wie von der Inkraftsetzung der bereits vorbereiteten Steuerreform erwartete man sich eine Senkung der fiskalischen Lasten und verbesserte Rahmenbedingungen für den Export. ${ }^{8}$ Versuche, Finanzminister Engliš aus dem Amt zu drängen, stießen im November 1928 auf scharfe Kritik der Industrie, weil Engliš bemüht gewesen war, die Staatsfinanzen auf eine gesunde Basis zu stellen und seine Politik an klaren, der Industrie eine solide Kalkulationsgrundlage gewährleistenden Vorgaben zu orientieren. Die von der Agrarpartei lancierte Subventionierung der Zuckerindustrie, die Ansprüche der Sozialversicherung und die Anforderungen aus dem Verteidigungsministerium hingegen waren als Bedrohung des von Engliš verteidigten Budgetgleichgewichts einzustufen.

Dies also war der Hintergrund, vor dem die Schlagkraft der industriellen Interessenvertretung zunehmend als unzureichend empfunden wurde: Das Gewicht der Organisation, so Preiss vor der Vollversammlung des Zentralverbands am 19. Juni 1928, müsse wachsen, damit die Industrie, im Parlament bislang kaum vertreten, besser gehört werde. ${ }^{9}$ Schließlich - so das Resümee des „Observer“ anläßlich des zehnjährigen Staatsjubiläums im Herbst des gleichen Jahres - war das vom Zentralverband 1922 aufgestellte

6 Antwort Janovskys in einer Umfrage der Hospodářský rozhled von 1928 zu den größten wirtschaftspolitischen Problemen der ersten zehn Jahre der Republik. Befragt wurden u.a. Bacher und Weil, die beiden Wirtschaftsredakteure der Bohemia und Herausgeber der Wirtschaft, Hejda, der Wirtschaftsredakteur der Lidové Noviny und Pimper, der Chefredakteur der Národní listy: Vgl. HR vom 26. 10. 1928.

7 OB 9 (1927), S. 637.

8 OB 7 (1925), S. 533 f. und 605. - Ebenso in einer Audienz des Zentralverbands bei Finanzminister Engliš am 15. 1. 1926. Vgl. den Bericht in: OB 8 (1926), S. $29 \mathrm{f}$.

9 Rede Preiss', Vollversammlung des Zentralverbands am 19.6.1928, in: OB 10 (1928), S. 319. 
Programm einer Konsolidierung der Wirtschaft bislang nur teilweise durchgeführt worden. ${ }^{10}$ Auch die Zehnjahresbilanz prominenter deutscher und tschechischer Wirtschaftsjournalisten brandmarkte als größten Fehler der Wirtschaftspolitik im abgelaufenen Dezennium die unzureichende Berücksichtigung der industriellen Interessen im Kräftespiel der Politik. ${ }^{11}$ In diesem Zusammenhang wurde die "Politisierung der Wirtschaft" zu einem zentral wichtigen Gegenstand der öffentlichen Diskussion: Der einflußreiche Wirtschaftsjournalist Antonín Pimper monierte die Ausrichtung der Gesetzgebung an den Belangen von Parteiklientelen, welche dringende Vorhaben durch ein schneckenhaftes, sich wieder und wieder in Intrigen verhakendes Procedere blockierten. ${ }^{12}$ Handelte es sich in Hejdas Augen bei der Rede von der "Politisierung" auch in erster Linie um eine Kampfparole, geeignet, Konkurrenten als „unsachlich“ ${ }^{2 u}$ „entlarven", so barg doch auch in seinen Augen das Stereotyp einen wahren Kern: Es denunzierte die gängigen Mauscheleien im Dienste partikularer Interessen, für die die Blokkade der Handelsverträge durch die Agrarlobby das Paradebeispiel darstellte. ${ }^{13}$

Ein zentraler Aspekt der von Preiss gerügten Distanz der Industrie zum Parlament war die Wirtschaftsferne der bürgerlichen Parteiprogramme. Umgekehrt betätigten sich nur wenige Praktiker der Wirtschaft in der Parteipolitik; in der Nationalversammlung fand sich unter mehreren hundert Abgeordneten und Senatoren kein einziger Industrieller. Als industrienah waren am ehesten noch die Nationaldemokraten einzustufen, deren parlamentarische Vertretung Ende der zwanziger Jahre allerdings bereits zur quantité négligeable verkümmert war. ${ }^{14}$ Die Industrie hatte es „bisher höchstens zu erfolglosen Denkschriften an die Ministerien gebracht ${ }^{\text {"15; }}$; vor diesem Hintergrund klang die Forderung nach einer Durchsetzung der Kabinette mit erfahrenen und weitblickenden Fachleuten plausibel. ${ }^{16} \mathrm{Da}$ der Parlamentarismus keine ausreichende Repräsentation industrieller Interessen gewährleisten konnte, erscholl der Ruf nach ständischen, die Stimme der Wirtschaft angemessen zur Geltung bringenden Vertretungs-körperschaften wieder lauter ${ }^{17}$; Fachleute beider Nationalitäten forderten die Berücksichtigung nicht nur der Zahl, sondern auch des Gewichts der Wählerstimmen. ${ }^{18}$

10 „Nachwort zu den Jubiläumsfeierlichkeiten“, in: OB 10 (1928), S. $327 \mathrm{f}$.

11 Dies im Rahmen der Umfrage des Hospodářský rozhled unter prominenten Persönlichkeiten der tschechoslowakischen Wirtschaft: Vgl. HR vom 26. 10.1928.

12 Pimper, Občanská koalice.

13 Hejda, Wirtschaftspolitik, S. 1419f. - Kislinger bezeichnete die Entpolitisierung der Wirtschaft als dringendes, jedoch unlösbares Problem und forderte deshalb zumindest eine "wirtschaftliche Einstellung der Politik“: Vgl. das Interview Kislingers mit der "Wirtschaft“, im Rahmen der Rundfrage bzgl. der dringendsten wirtschaftlichen Probleme der Tschechoslowakei Ende 1928, in: WI 10 (1928), S. $1518 \mathrm{f}$.

14 Zum Beispiel war es den Parteien nicht möglich, einen fähigen Finanzminister aus ihren Reihen zu finden. In den Budgetdebatten traf Engliš, ein parteiloser Experte, höchstens bei den Sozialdemokraten auf ernstzunehmende Gegner. Den 1928 wieder einmal ins Amt gekommenen nationaldemokratischen Wirtschaftsminister Novák tat Hejda verächtlich als guten „Operettenlibrettisten “ - das war er im Hauptberuf tatsächlich - ab: Vgl. Hejda, Hospodářské programy, S. $713 \mathrm{f}$. und S. 804-806.

15 Weil, („F.W.“), Verzicht, S. 883 f.

16 Bacher, Idiosynkrasie, S. 931.

17 O.V., „Agrarischer Zug“.

18 HR vom 1. 11. 1928. - Eine divergierende Position nahm Hejda ein: Auch er konstatierte zwar eine Krise des Parlaments, sah den Ausweg aber nicht in einer Ständevertretung, sondern in der 
Einem Zusammenrücken kam des weiteren die generelle Entspannung der Beziehungen zwischen Tschechen und Deutschen entgegen, deren innenpolitisches Signum die Mitarbeit der deutschen Aktivisten in der Regierung darstellte. War der Eintritt des Bundes der Landwirte und der Deutschen Christlich-Sozialen ins Kabinett des Bürgerblocks im Juli 1926 zunächst auch nur taktisch, nämlich durch die Suche nach einer Regierungsmehrheit, motiviert ${ }^{19}$, so betrachteten doch weite Kreise der tschechischen Öffentlichkeit, nicht zuletzt auch Masaryk und Beneš, die Mitarbeit der Deutschen auch als prinzipiell unerläßlich für die Konsolidierung des Staates. ${ }^{20}$ Ein Anwalt der Kooperation zwischen den Verbänden trat dann mit der Gründung der Deutschen Arbeitsund Wirtschaftsgemeinschaft (DAWG), einer industrienahen, aktivistischen Partei, auf den Plan. Für die Entstehung dieser Gruppierung waren die Defizite der aktivistischen Politik im Kabinett veranwortlich: Legte die Regierungsbeteiligung der Deutschen den „Tschechisierungsbestrebungen“ der Behörden auch gewisse Zügel an, so galten die Minister Spina und Mayr-Harting, weil vorrangig auf Machterhaltung bedacht, doch als überaus nachgiebig. ${ }^{21}$ Die Stresemann im Juli 1927 von „sudetendeutschen Besuchern" zugetragene Schelte, die deutschen Minister „verrieten“ ihre Konnationalen und ließen die "Tschechisierung" ohne Anstalten zur Gegenwehr zu, wies die Prager Gesandtschaft zwar als abwegig zurück, hielt den Vorwurf einer „schwächlichen Haltung “ jedoch für nicht ganz unberechtigt. ${ }^{22}$ Für die zweite Hälfte des Jahres 1927 konstatierte dann aber auch die Gesandtschaft „schrankenlose Bereitwilligkeit“. Die Christlich-Sozialen ergingen sich in zahnlosen Vorstößen, während der Bund der Landwirte sich mit der kleinen Münze des Erfolgs von Einzelfallinterventionen begnügte. ${ }^{23}$

Diese mißliche Lage eröffnete der Agitation der deutschen Opposition - der Deutschnationalen Partei (DNP), der Deutschdemokratischen Freiheitspartei (DDFP) und der Deutschen Nationalsozialistischen Arbeiterpartei (DNSAP) - ein weites Feld. ${ }^{24}$ $\mathrm{Da}$ diese sich aber in steriler Kritikasterei erschöpfte, bekundete der weniger intransigente Flügel der DNP unter Hilfestellung industrieller Kreise Bereitschaft zur Mitarbeit in der Regierung; anders als die Aktivisten machte er diese allerdings von der vorgängi-

sachorientierten Arbeit der Ausschüsse unter Heranziehung von Experten: Vgl. Hejda, Wirtschaftspolitik, S. $1419 f$.

19 Die Frage der Regierungsbeteiligung war, wie Beneš auf einem Bankett zu Ehren der Auslandspresse wenig später ausführte, weniger eine nationale denn eine Klassenangelegenheit gewesen. Vgl. PA, R 73 778, Gesandtschaft Prag an AA, 23.2.1927.

20 PA, R 73 778, Aufzeichung AA/Röpke vom März 1927 (ohne Tag). In ADAP, Serie B, Band 4, Dokument 212, S. 456-458 fälschlicherweise als "undatierte Aufzeichung ohne Unterschrift" verzeichnet.

21 "Wie die artigen Kinder zu Weihnachten haben sie den Wunschzettel übergeben und harren nun der Bescheerung (!). " Diese Haltung sei überhaupt charakteristisch für die Sudetendeutschen, die verkennten, daß man von den Tschechen nur in zähem Kampf Zugeständnisse erreichen könne. Dabei sei die Lage gar nicht so ungünstig, denn die tschechischen Partner seien, um die unter schweren Geburtswehen zustandegekommene Koalition nicht zu gefährden, für Konzessionen durchaus zu haben: Vgl. PA, R 73 831, Gesandtschaft Prag an AA, 20. 2. 1927.

22 Telegramm Stresemanns an Gesandtschaft Prag, 5.7.1927, in: ADAP, Serie B, Band 6, S. 21, Dokument Nr. 9, Anmerkung 1. - Gesandtschaftsrat von Heeren (Prag) an AA, 6. 7. 1927, in: ADAP, Serie B, Band 6, Dokument Nr. 9, S. $21 \mathrm{f}$.

23 PA, R 73 832, Gesandtschaft Prag an AA, 6.12.1927.

24 Dies behauptete zumindest ein der österreichischen Gesandtschaft zugetragenes Ondit: Vgl. ÖStA, BAA, Gesandtschaft Prag, Zl.31/Pol., Österreichische Gesandtschaft Prag an BAA, 24. 2. 1927. 
gen Erfüllung grundsätzlicher Forderungen abhängig. ${ }^{25}$ Die Hoffnung dieser „Neoaktivisten“ war der Nixdorfer Rechtsanwalt und Unternehmer Alfred Rosche, der 1927 als Parlamentsneuling in der Budgetdebatte durch Sachkenntnis und Standvermögen unter Verzicht auf Polemik beeindruckte und sogleich im Anschluß an die Debatte zum DNP-Klubobmann (Fraktionsvorsitzenden) gewählt wurde. ${ }^{26}$ Rosche, so die „Wirtschaft", sei kein weltfremder Idealist, er sei Schlagworten und Ressentiments abgeneigt und habe sich die Unterordnung der Politik unter die Wirtschaft zum Ziel gesetzt. ${ }^{27}$ Die Prager Gesandtschaft bescheinigte ihm, er habe „eine volkswirtschaftlich fundierte, sachliche Einstellung zur Frage der Zusammenarbeit mit den Tschechen " gefunden. ${ }^{28}$

Nachdem der Gegensatz zwischen Aktivisten und Negativisten noch schärfer geworden war ${ }^{29}$, drängte die DNP Mitte 1928 Rosche aus der Partei. Zu den Dissidenten gegen den "Phrasennegativismus" ${ }^{30}$, die der Abweichler nun unter dem Banner der DAWG sammelte, stießen die Deutschdemokraten und die Deutsche Gewerbepartei (DGWP). Die DAWG, die im Spektrum der deutschen Parteien die „nationalliberale Lücke“ füllte, war keine Massenorganisation, sondern eine lose Bündelung von Intelligenz und Unternehmerschaft, die die deutschen bürgerlichen Wirtschaftsstände nach dem Vorbild der Landwirtschaft, aber in Frontstellung gegen diese zusammenzufassen beabsichtigte. Sie strebte eine Verständigung sowohl innerhalb des deutschen Lagers als auch mit den Tschechen an, welche die deutsche Stellung in Wirtschaft und Kultur sichern sollte. Sie votierte für konstruktive Mitarbeit, gedachte aber auch, durch Druck auf die Regierungsparteien tschechische Konzessionen zu erzielen. ${ }^{31}$ Bald war in deutschen Wirtschaftskreisen Rosche als potentieller Wirtschaftsminister im Gespräch. ${ }^{32}$

Einem Zusammengehen leistete auf der anderen Seite die wachsende Distanz des Zentralverbands zur Nationaldemokratie Vorschub. Die anfänglich recht enge Beziehung - Handelsminister Novák beispielsweise war aus dem Zentralverband hervorgegangen und blieb ihm immer verbunden -, hatte sich schon nach der Wahlniederlage von 1925 gelockert. ${ }^{33}$ Der Parteikongreß im April 1929 sollte dann plastisch die Ideenlosigkeit und Auszehrung einer in nationalistischen Phrasen schwelgenden, in den

25 Wortführer dieser Bewegung waren Horpynka (DNP), Jung (DNSAP) und Hanreich (BdL); ihr standen die „Bohemia“ und die „Sudetendeutsche Tageszeitung“ nahe: Vgl. PA, R 73 808, Gesandtschaft Prag an AA, 12. 7.1927. - ÖStA, BAA, Gesandtschaft Prag, Zl. 107/Pol., Österreichische Gesandtschaft Prag an BAA, 11.8.1927.

26 PA, R 73 832, Gesandtschaft Prag an AA, 6.12. 1927.

27 WI 10 (1928), S. 650. - Weil, („F. W.“), Verzicht, S. 883.

28 PA, R 73 833, Gesandtschaft Prag an AA, 7.8.1928.

29 PA, R 73 779, AA/Aktenvermerk Bräuer vom 13.1.1928 über eine Unterredung mit dem DNVP-Abgeordneten Lindeiner-Wildau im Anschluß an dessen Pragreise.

30 Den Gegensatz zwischen Rosche und dem „DNP-mainstream ${ }^{\star}$ kommentierte der Wirtschaftsjournalist Friedrich Weil folgendermaßen: „Meinte es Doktor Rosche also ehrlich mit seinen Absichten, so konnte er länger einem Abgeordnetenklub, der sich aus Pensionisten, Wasserwerksdirektoren, Mittelschulprofessoren zusammensetzt, nicht angehören. Er mußte gehen. Nie wird in dieser Gesellschaft das Verständnis dafür wach werden, daß zum Politikmachen auch gewisse wirtschaftliche Voraussetzungen gehören, wenn man auf einen grünen Zweig kommen will“: Vgl. Weil, („F. W.“), Verzicht, S. 883.

31 PA, R 73 833, Gesandtschaft Prag an AA, 7. 8. 1928. - WI 10 (1928), S. 990. - Heger, Zusammenschluß, S. $616 \mathrm{f}$.

32 Dies insinuierte 1928 Weil, obwohl sich Rosche bei der Vollversammlung des DHI 1927 als nicht dem Hauptverband zugehörig bezeichnet hatte: Vgl. Weil, („F.W.“), Verzicht, S. $883 \mathrm{f}$.

33 P̌̌ 2 (1925), S. 781 f. - OB 7 (1925), S. 577 f. 
Schützengräben gegen Österreich und die Deutschen verschanzten Partei dartun, deren Parlamentsmandate sich in zehn Jahren fast halbiert hatten und die sich mit der Teilhabe an der national gemischten Regierung unverkennbar schwertat. ${ }^{34} \mathrm{Daß}$, wie dies auf der Vollversammlung von 1928 einmal mehr feierlich kundgetan wurde, der Zentralverband im Zuge des Abdriftens von den Nationaldemokraten "unpolitisch" geworden $\operatorname{sei}^{35}$, war zwar eine Schönung der Tatsachen, zumal der reuige Sünder das „Konkubinat" erst nach enttäuschenden Erfahrungen gelöst hatte. ${ }^{36} \mathrm{Daß}$ Anfang der dreißiger Jahre der Zentralverband - durch das Bindeglied Hodáč - sowohl den Nationaldemokraten wie auch der Agrarpartei nahestand ${ }^{37}$, konnte sich nach dem Beitritt der Deutschen, von denen viele politisch anderweitig verankert waren, aber nur noch "gedämpft" auswirken. ${ }^{38}$

Zum Hintergrund der Annäherung zwischen Hauptverband und Zentralverband gehört nicht zuletzt die Entspannung der tschechoslowakischen Beziehungen zum Deutschen Reich. ${ }^{39}$ Benešs im November 1926 im Abgeordnetenhaus vorgetragenes außenpolitisches Exposé, Presseäußerungen Masaryks und seine Neujahrsbotschaft für 1927 deuteten diese an. Die „Národní listy“, Stimme der Nationaldemokraten, konstatierten am 2. Februar 1927 eine bereits seit zwei Jahren anhaltende günstige Entwicklung der Beziehungen, in der wirtschaftliche Erwägungen gegenüber altem Groll die Oberhand gewonnen hätten. ${ }^{40}$ Sogar Kramár, obgleich im Ruf des eingefleischten Deutschenhassers stehend, betonte am 11. Februar vor dem Außenausschuß des Abgeordnetenhauses die Bedeutung eines freundschaftlichen Verhältnisses. ${ }^{41} \mathrm{Daß}$ bei Benešs Besuch in Berlin im Mai 1928 deutscherseits die Idee eines Regionalpakts mit deutsch-tschechoslowakischem Nukleus ventiliert wurde ${ }^{42}$, betrachteten einflußreiche, außenhandelspolitisch eher auf eine "deutsche Kombination" als auf eine Donaugruppierung setzende tschechische Wirtschaftsführer mit Wohlgefallen. ${ }^{43}$ Benešs Entourage stufte die korrekten Beziehungen jetzt zu herzlichen herauf; dies war nicht zuletzt Signal an eine allfällige deutsche Irredenta, sie habe vom Reich nichts zu erwarten. ${ }^{44}$ Auch die „Wirtschaftsdiplomatie" verzeichnete eine Klimaverbesserung: Nach nur kurzem Zögern nahm der Reichsverband der deutschen Industrie auf Anraten der Prager Gesandtschaft die Einladung zur Zehnjahresfeier des Zentralverbands am 18. Juni 1928 an. ${ }^{45}$

34 PA, R 73 809, Gesandtschaft Prag an AA, 16.4.1929.

35 Bericht über die Generalversammlung anläßlich des zehnjährigen Jubiläums des Zentralverbands, in: OB 10 (1928), S. 310.

36 So der Hinweis im HR vom 21.6.1928.

37 PŘ 9 (1932), S. 612-615.

38 So die plausible These bei Hejda, Mraky.

39 Hintergründe waren: die Verbesserung der deutsch-französischen Beziehungen in der Folge von Locarno, das Desinteresse der Kleinen Entente an der Tschechoslowakei und die Unmöglichkeit einer engeren Verbindung mit Polen, die zusammengenommen die ČSR international zu isolieren drohten: Vgl. PA, R 73 778, Aktenvermerk AA/Röpke vom März 1927 (ohne Tag). In ADAP, Serie B, Band 4, Dokument 212, S. 456-458 fälschlicherweise als „undatierte Aufzeichnung ohne Unterschrift" wiedergegeben. - Krüger, Beneš, S. $321 \mathrm{f}$.

40 PA, R 73 778, Gesandtschaft Prag an AA, 2. 2.1927.

41 PA, R 73 778, Gesandtschaft Prag an AA, 13. bzw. 15. 2.1927.

42 Krüger, Beneš, S. $321 \mathrm{f}$.

43 PT vom 13.5. 1928.

44 Der Gesandte in Prag, Koch, an den Staatssekretär des AA, von Schubert, 3. 6. 1928, in: ADAP, Serie B, Band 9, Dokument 60, S. 123-127.

45 Für die Teilnahme sprachen die schwebenden Handelsvertragsverhandlungen und der Wunsch, eine Stellungnahme zu den aktuellen Differenzen zwischen Hauptverband und Zentralverband 
Die in den Gründerjahren unverkennbare nationale Imprägnierung der Industrieverbände hatte sich in diesem Umfeld und angesichts der wachsenden Macht der agrarischen Interessen bereits abgeschliffen und der "Doppelgleisigkeit" mehr und mehr den Boden entzogen. ${ }^{46} 1927$ betonte der Zentralverband, man habe von Anbeginn die Zusammenarbeit aller Nationalitäten des Staates in Sachfragen befürwortet. ${ }^{47}$ Eine säuberliche Grenzziehung zwischen Unternehmern deutscher bzw. tschechischer Nationalität war ja, wie erinnerlich, ohnehin Fiktion. Die meisten wichtigen deutschen Unternehmen waren auch Mitglieder des Zentralverbands; große Teile der deutschen Industrie in Innerböhmen, im Revier von Mährisch-Ostrau und in der Slowakei waren sogar ausschließlich dort organisiert. ${ }^{48}$ Insbesondere die nordmährisch-schlesische Industrie hatte sich bald an den Zentralverband angenähert; ihr Vorsitzender, der Wittkowitzer Generaldirektor Sonnenschein, gab auf der Zehnjahresfeier des Zentralverbands der Meinung Ausdruck, daß „verständige und anständige Menschen durch natürliche, wirtschaftliche sowie nationale Unterschiede und auch der politischen Zugehörigkeit und Programmansichten einer nützlichen Zusammenarbeit sich nicht fernhalten sollen “ ${ }^{49}$ Sogar die deutsche Gesandtschaft, die den Zusammenschluß zunächst mit unverkennbarem Mißtrauen hinsichtlich der Lauterkeit der tschechischen Motive kommentierte, bequemte sich nach dem Vollzug zu dem Fazit, die ursprünglich sinnvolle Arbeitsteilung zwischen den Verbänden - der DHI in erster Linie als Vertreter der verarbeitenden Industrie, der Zentralverband für Schwerindustrie, Chemie und landwirtschaftliche Industrien - sei obsolet gewesen. ${ }^{50}$

Abgesehen von der Großwetterlage wirkten auch die besonderen Belange der beiden Verbände als Impulse für ein Zusammengehen. Nach dem Auf- und Ausbau der Fachorganisation strebte der Zentralverband die Komplettierung seines regionalen Unterbaus an. Am 15. Mai 1926 verabschiedete der Zentralausschuß Richtlinien für die Gründung von Ortsgruppen. ${ }^{51}$ Der Zeitpunkt war nicht zufällig: Die Möglichkeiten der Einflußnahme der Verbände in den Landesvertretungen und in der Sozialversicherung wurden nun erweitert: Bis zu einem Drittel der Mitglieder dieser Selbstverwaltungskörperschaften konnten von der Regierung ernannt werden. Für Präsenz war jetzt Sorge zu tragen. ${ }^{52}$ In Nordböhmen, im Einzugsbereich des Hauptverbands, war der Unterbau des Zentralverbands besonders unvollständig; die Verhältnisse dort durch den Aufbau einer Konkurrenzorganisation zu komplizieren hielt man nicht für opportun, alternative Option war das Zusammengehen mit dem DHI. ${ }^{33}$

in den Einigungsverhandlungen zu vermeiden: Vgl. PA, II b, Wirtschaft 10, Tschechoslowakei, Band 2, AA/Windel, Telegramm an Gesandtschaft Prag vom 23. 5. 1928. - Antwort der Gesandtschaft vom 25. 5. 1928. - Handschriftlicher Vermerk aus dem Amt zu dem Vorgang, undatiert.

46 Der deutsche Volkswirt vom 21.9.1928.

47 Erklärung des Präsidiums auf der Vollversammlung des Zentralverbands am 21. 4. 1927, in: OB 9 (1927), S. 241.

48 HR vom 14. 6. 1928.

49 RedeSonnenscheins, Vollversammlung des Zentralverbands am 18.6.1928, in: OB 10(1928), S. 313.

50 PA, IIb, Wirtschaft 10, Tschechoslowakei, Band 2, Gesandtschaft Prag an AA, 10. 10. 1928.

51 Berichte über die Sitzungen des Zentralausschusses der Delegierten der Fachgruppen und Sektionen am 24.2. und am 15.5.1926, mit den Details der vorgesehenen Regelungen, in: OB 8 (1926), S. $118 \mathrm{f}$. und S. $273 \mathrm{f}$.

52 SÚA, ÚSČP, Karton 11, Rede Hodáčs, Vollversammlung des Zentralverbands am 21.4.1927.

53 Erklärung des Präsidiums des Zentralverbands auf der Vollversammlung am 21.4.1927, in: OB 9 (1927), S. 241. 
Die deutsche Seite hingegen hatte die Erfahrung gemacht, daß der Hauptverband im Einzelfall zwar einiges für seine Klientel durchzusetzen imstande war, die Vereinigung als solche hingegen nach wie vor auf Barrieren stieß. Dies hing mit der Abneigung der Regierung gegen eine Zusammenarbeit mit mehr als einer Organisation zusammen ${ }^{54}$; daß zusätzlich das nationalpolitische Ressentiment eine Rolle gespielt hat, ist nicht von der Hand zu weisen. Nicht von ungefähr häuften sich Hinweise aus dem Dunstkreis der Regierung, man befürworte im Interesse besserer Kommunikation einen Zusammenschluß. Daß 1928 auf dem Brünner Kaufmannstag Handelsminister Novák seine - den deutschen Industriellen seit dem Fiasko der Audienz von $1922 \mathrm{im} \mathrm{Ohr} \mathrm{klingende}$ - Äußerung, er kennne keine deutsche und keine tschechische, sondern nur eine tschechoslowakische Industrie, wiederholte, wurde weniger als Bekenntnis zur Unparteilichkeit denn als ein - an Deutlichkeit nichts zu wünschen übriglassender - Appell an den Hauptverband aufgefaßt, „lieber heute als morgen endgültig unter die alleinseligmachende Schürze des Svaz (des Zentralverbands, C.B.) zu kriechen “. ${ }^{55}$ Nicht zuletzt war das Bestreben des Zentralverbands wirksam, Regierung und Öffentlichkeit anläßlich des Staatsjubiläums auch in organisatorischer Hinsicht eine Erfolgsbilanz vorweisen zu können. ${ }^{56}$

Ab etwa der Mitte des Jahrzehnts wurden die nach dem Scheitern des ersten Anlaufs gerissenen Fäden wieder geflochten. Ende 1926 kam es im Anschluß an eine Sitzung des Zentralverbands über Probleme der Steuerreform, an der auch die Vertreter des Hauptverbandes teilnahmen, zu einer "Diskussion über die Schwerfälligkeit der bisherigen Organisation", welche in den Beschluß mündete, den Zentralausschuß zu reaktivieren und zu einer Konferenz über diese Fragen einzuberufen. ${ }^{57}$ Diese Zusammenkunft, auf der die Gründung eines Einheitsverbands beschlossen wurde, fand am 21. Dezember 1926 statt. $^{58}$ In der Folgezeit agierten die Verbände im Tagesgeschäft verschiedentlich informell als „Seilschaften“, unterstützten sich wechselseitig in Fragen der Präsenz in Gremien der Wirtschaftsverwaltung und repräsentierten dort die industriellen Interessen konzertiert oder nach vorab abgesprochener Aufteilung. ${ }^{59}$ Ende Februar 1928 etwa

54 Rede Schichts, Ausschußsitzung des DHI am 18. 9.1928, in: MDHI 9 (1928), S. $833 \mathrm{f}$.

55 WI 10 (1928), S. 746 und S. 989.

56 WI 10 (1928), S. 746.

57 SÚA, NL Hodáč, Karton 28, Mappe A/I-G, Kuno Grohmann an Hodáč, 13.12. 1926. - Hodač an Grohmann, 16.12.1926.

58 SÚA, NL Hodáč, Karton 28, Mappe A/I-H, Hodáč an den deutschen Industriellen Otto Hamburger, 21.12.1926.

59 Dem DHI-Mitarbeiter Kotrba hatte Hodáč anläßlich der ersten Sitzung des vorbereitenden Ausschusses für die Sozialversicherung versprochen, er wolle sich dafür einsetzen, daß Kotrba zumindest als Ersatzmann in dieses Gremium berufen werde. Der Leiter der Arbeitgeberhauptstelle des Hauptverbandes, Fernegg, quittierte dies mit der Ankündigung, zu „Gegendiensten“ sei man selbstverständlich gerne bereit: Vgl. SÚA, NL Hodáč, Karton 28, Mappe A/I-A, Arbeitgeberhauptstelle des DHI an Hodáč, 19.2.1926. - Als im Dezember 1926 die neuen Mitglieder des Wirtschaftsbeirates ernannt wurden, fungierten als Gesamtvertreter der Industrie Hodáč und Kislinger; Ersatzleute waren Mixa vom Zentralverband und Schicht vom DHI: Vgl. OB 8 (1926), S. 626. - SÚA, NL Hodáč, Karton 38, B/1927, Hodáč an Benda, 12. 1. 1927. - Ergebnis der Verhandlungen über die Entsendung deutscher Vertreter zur Genfer Weltwirtschaftskonferenz war die Zusage einer "deutschen Stelle" in der Reihe der industriellen Experten: Vgl. SÚA, Hodáč, Karton 38, A/I-D, DHI/Kislinger an Hodáč, 25. 2. 1927. - Auf der Sitzung der Zentrale der Handels- und Gewerbekammern in Prag zu wirtschaftspolitischen Tagesfragen am 9.Mai 1928 waren mit Hodáč und Kislinger sowohl die Repräsentanten des Zentralverbands wie auch die 
legte eine gemeinsame Abordnung dem Handelsminister die Gründe für die Ablehnung von Zwangsorganisationen der Industrie dar. ${ }^{60}$

Deutlich war das Bemühen, die Aktivitäten im Anschluß an das Dezembertreffen von 1926 aus dem Dunstkreis der Nationalitätenproblematik herauszuhalten und auf der Sachebene zu positionieren: Die Verhandlungen etikettierte der Zentralverband als Ringen um „organisatorische, keineswegs ... nationale oder politische Fragen“ ${ }^{61}{ }^{61}$ Lagen im Frühjahr 1927 über die Klarlegung der Standpunkte hinausreichende Ergebnisse auch noch nicht vor, so hatte sich doch beidseitig die Überzeugung von der Zweckmäßigkeit der einheitlichen Spitzenorganisation gefestigt. ${ }^{62}$ Ungeachtet dessen wirkte ein gewisses, von Furcht vor Vereinnahmung gespeistes Mißtrauen im Hauptverband als retardierendes Moment; die Verhandlungen zogen sich über anderthalb Jahre hin. Eine starke Meinungsströmung widerstrebte im DHI überhaupt der Einschmelzung der beiden Verbände in eine übernationale Einheitsorganisation. Hätte dieses Verfahren, formal gesehen, auch die Gleichberechtigung der Verhandlungspartner unterstrichen, so wäre damit faktisch doch ein Schlußstrich unter die Eigenständigkeit der Deutschen gezogen worden; man befürchtete eine Atomisierung ihrer Kraft. ${ }^{63}$ Sogar Kislinger, der die Einheit als unabdingbar ansah und sich gegen die Auffassung verwahrte, der Zusammenschluß bedeute eine Gefährdung der deutschen Industrie, beäugte Hodáč mit Argwohn, da dieser sich nicht immer von sachlichen, sondern von „stark politischen und nationalistischen Erwägungen" leiten lasse. ${ }^{64}$ Vermutlich aufgrund solcher Vorbehalte hüllte sich die Führung des Hauptverbands gegenüber dem eigenen „rank and file“ vorzugsweise in Schweigen über die von Preiss und Schicht geführten Verhandlungen. ${ }^{65}$

Aus der Perspektive der deutschen Gesandtschaft war der Motor der Einheitsbestrebungen das Bemühen der den Zentralverband dominierenden Živnostenská banka, die Opposition der im Hauptverband versammelten verarbeitenden Industrie gegen die von der Bank beherrschte Großchemie zu brechen. Aus verteidigungspolitischen Gründen unterstütze der Staat dies mittels der notorischen Pressionen, also durch harsche Steuerforderungen und penible Betriebsrevisionen, unfreundliche Modalitäten bei der Vergabe öffentlicher Aufträge und die Ignorierung deutscher Belange bei Handelsvertragsverhandlungen. Ursprünglich als deutsch figurierende Großunternehmen der Chemie wie der inzwischen von der Živnostenská banka kontrollierte Aussiger Verein für chemische und metallurgische Produktion, der seit jeher Mitglied beider Verbände gewesen war, figurierten in dieser Sicht wieder einmal als "Verräter". ${ }^{66}$ Nun war der Zentralverband unzweifelhaft eine "Sekretärs-Organisation", deren Exekutive nach den

des DHI vertreten: Vgl. SÚA, MPOŽ, Karton 568, 21 959/24, Protokoll der ersten gemeinsamen Sitzung der Kammerzentrale und des Zentralverbands am 9.5.1928.

60 MDHI 9 (1928), S. 201.

61 Erklärung des Präsidiums des Zentralverbands auf der Generalversammlung am 21. 4. 1927, in: OB 9 (1927), S. 241.

62 Rede Schichts, Vollversammlung des DHI am 14. 5. 1927, in: MDHI 8 (1927), S. 408.

63 Gesandtschaft Prag an AA, 10. 10. 1928, in: PA, IIb, Wirtschaft 10, Tschechoslowakei, Band 2.

64 ÖStA, BAA, HP 14, 1927/171 254 (einliegend in 1928/162 299), Österreichische Gesandtschaft Prag an Bundeskanzleramt/ Auswärtige Angelegenheiten, 29.10. 1927. - Von Gruppierungen im Hauptverband, die sich gegen eine Fusion wehrten, war auch in der "Wirtschaft" die Rede, ohne daß diese dort konkreter benannt worden wären: Vgl. WI 10 (1928), S. 989.

65 WI 9 (1927), S. 437.

66 Gesandtschaft Prag an AA, 10. 10.1928, in: PA, Ilb, Wirtschaft 10, Tschechoslowakei, Band 2. 
Anweisungen einiger „starker Männer“, im wesentlichen der führenden Persönlichkeiten des Großbankentrios Živnostenská banka, Böhmische Escompte-Bank und Böhmische Union-Bank mit den von diesen kontrollierten umfänglichen Industriekonzernen im Schlepptau, gesteuert wurde; die restlichen Mitglieder waren mehr oder weniger Satelliten und Trabanten. „Zehn Jahre Zentralverband“ - so brachte der „Hospodářský rozhled“ dieses Faktum auf eine einprägsame Formel - waren in der Essenz „zehn Jahre Živnostenská banka“. Daß der Zentralverband seit den Anfangsjahren der Republik konsequent am Grundsatz der Unternehmerfreiheit und damit der freiwilligen Verbandsmitgliedschaft festgehalten hatte ${ }^{67}$, war weniger auf liberale Prinzipientreue zurückzuführen: Das Plädoyer der Verbandsoligarchie für die freie Organisation war ein Plädoyer für die Aufrechterhaltung des Einflusses dieser Clique; in einer Pflichtorganisation wäre man ohne "Minderheitenschutz" kaum ausgekommen. ${ }^{68}$

Dies hieß allerdings nicht, daß Preiss, bekannt für seine Geschmeidigkeit, berühmt als Virtuose des Kompromisses, im Zentralverband einseitige Interessenpolitik betrieben hätte - und falls doch, dann schwerlich im nationaltschechischen Geist. ${ }^{69}$ Das Prius war die Bank. Zwar apostrophierte er 1926 in einer „Grundsatzerklärung" für Kanzler Sámal seine Überzeugung als ebenso demokratisch wie nationalbewußt und bekundete, hinsichtlich der "Nationalisierung" der Volkswirtschaft gebe es viel zu tun ${ }^{70}$; im gleichen Atemzug aber hieß es, wirtschaftliche Betätigung, vor allem die eines bedeutenden Finanzinstituts wie des seinen vertrage sich nicht mit einseitigem Engagement. ${ }^{71} \mathrm{Als}$ Preiss 1930 zum Präsidenten des Zentralverbands gewählt wurde, würdigte Hodáč sein Engagement für die nationale Sache; ohne seine nationalen Überzeugungen zu verleugnen, verstehe er es jedoch auch, sich fachlich mit den deutschen Industriellen zu vereinbaren. ${ }^{72}$

Die mit dem Hauptverband getroffene, von diesem am 18. September 1928 gebilligte Abmachung löste diese Laudatio-Floskeln ein. Der Hauptverband blieb als Organisation erhalten, trat allerdings in corpore dem Zentralverband bei und war dort im Präsidialausschuß, in allen Arbeitsausschüssen und bei allen Delegierungen in Repräsentativorgane vertreten. ${ }^{73} \mathrm{Im}$ Interesse des Minderheitenschutzes stand eine Reihe wichtiger Festlegungen: War der Präsident des Verbandes auch in jedem Falle ein Tscheche, so stellte der DHI von den insgesamt elf Vizepräsidenten zwei; erster Stellvertreter war in jedem Fall ein Deutscher. Das mit einfacher Stimmenmehrheit für die Dauer von drei

67 Rede Hodáčs, Bericht über die Generalversammlung anläßlich des zehnjährigen Verbandsjubiläums, in: OB 10 (1928), S. 309 f. - Ergänzt aus den Wortprotokollen, in: SÚA, ÚSČP, Karton 11.

68 So das Argument im HR vom 21.6.1928.

${ }^{69}$ HR vom 21.6.1928.

70 Seine Tätigkeit an der Spitze der Bank stellte Preiss ebenso in nationalpolitische Perspektive. Die Formulierung der Grundsätze seiner Bankenpolitik stammt aus einem Gespräch mit Beran am 21. Juli 1933: „Ich legte ihm dar, daß wir einzig der Sache des tschechischen Volkes dienen, und daß wir unser Ziel dadurch erreichen wollen, daß wir eine große, gesunde, starke tschechische Bank schaffen wollen, und daß wir mit der Hilfe dieser Bank dazu beitragen wollen, daß in diesem Staat wir, die Tschechen, die wirtschaftlichen Angelegenheiten beherrschen, wie das die Grundlage unserer gesamten Zukunft ist“: Vgl. ANB, ŽB, S VII/i-1-I, 989, Preiss an Tille, 21.7.1933.

71 ANB, ŽB, S VII/i-1-I, 912, Preiss an Šámal, 15. 9. 1926.

72 Hodáč, Preiss, S. 552.

73 Bericht über die Ausschußsitzung des DHI am 18. 9. 1928, in: MDHI 9 (1928), S. 833 f. - PT vom 19.9.1928. 
Jahren gewählte Präsidium des Zentralverbands, das sich schon bis dahin aus drei Deutschen und sechs Tschechen zusammengesetzt hatte, umfaßte nun fünf Deutsche und sieben Tschechen. Jedes Jahr trat ein Drittel der Mitglieder aufgrund von Losentscheid aus und wurde neu bestimmt. Der Präsidialausschuß, vordem aus 18 Tschechen und zehn Deutschen bestehend, wurde auf 52 Mitglieder erweitert; 22 von ihnen waren deutscher Nationalität, zwölf von diesen stellte der DHI. Eine aus deutscher Sicht gravierende Schwäche dieser Quotenregelung war allerdings, daß der DHI lediglich über das Recht zur Präsentation von Kandidaten verfügte, aus denen der Zentralverband die ihm genehmen auszuwählen berechtigt war. Von zwei Delegierten, die der Gesamtverband in Körperschaften, Beratungsgremien u.ä. abordnete, war einer Deutscher. ${ }^{74}$ Zwischen den Verbänden herrschte Organisationsruhe: Der Mitgliederstand durfte auf beiden Seiten nicht angefochten werden, bei Ausscheiden eines Unternehmens aus einer der Organisationen war die Aufnahme in die andere nicht statthaft. ${ }^{75}$ Der Zentralverband übernahm den Verkehr mit den gesamtstaatlichen Fachverbänden, wo solche bestanden; die unter dem Dach des DHI angesiedelten territorialen Organisationen hingegen wurden in allen einschlägigen Fragen vom Zentralverband auf dem "Dienstweg" über den Hauptverband konsultiert. Grundsätzlich verkehrte der Zentralverband also nicht direkt mit den dem DHI angeschlossenen Verbänden und Fachgruppen. Beide Organisationen einigten sich aber auf die Perspektive einer Kooperation bzw. des Zusammenschlusses auch der nationalen Fachverbände. Daß die Gründung neuer Fachvereinigungen der Genehmigung des Präsidialausschusses bedurfte, implizierte ein nicht unwesentliches Zugeständnis des Hauptverbandes, da dieser in erster Linie auf territorialer Grundlage aufgebaut war und nur zwei Fachverbände - für Textil und für Metall besaß, während der Zentralverband im wesentlichen auf dem Fachverbandsprinzip beruhte. Der DHI wurde nun aus dem direkten Verkehr mit den Fachverbänden ausgeschaltet. ${ }^{76}$

Eine Bereitschaft zu praktikablen Übereinkünften ${ }^{77}$ illustrierte die Vereinbarung in der Sprachenfrage. Zwar handelte es sich hier um eher symbolisches Terrain, auf dem den Männern harter Münze am ehesten ein zwangloser Wille zur weitreichenden Verständigung unterstellt werden darf. Immerhin aber waren Sprachenfragen in anderen Sphären des deutsch-tschechischen Zusammenlebens heiß umstritten. In den gemeinsamen Beratungen stand jedem Teilnehmer die Benutzung seiner Sprache frei. Im Bedarfsfalle wurde übersetzt. Wurden offizielle Protokolle auch auf Tschechisch ausgefertigt, so war zur Orientierung der deutschen Mitglieder doch eine deutsche Version beigefügt. Präsidialerklärungen waren in der Regel zweisprachig. Mit der Staatsverwaltung sollte in tschechischer Sprache korrespondiert werden; allerdings wurden auch hier alle Schreiben den deutschen Mitgliedern in Übersetzung zugänglich gemacht. ${ }^{78}$

74 AKPR, T 182/22, Karton 84, Exposé Preiss' für Š́mal, übersandt am 20.6. 1928. - SÚA, ÚSČP 21, 0/0/1-0/3/1, 1918-1948, Statuten des Zentralverbandes der tschechoslowakischen Industriellen mit dem Sitze in Prag, o.O., undatiert. - PA, IIb, Wirtschaft 10, Tschechoslowakei, Band 2, Gesandtschaft Prag an AA, 10. 10.1928. - Bacher, Zusammenschluß, S. $1135 \mathrm{f}$.

75 Bacher, Zusammenschluß, S. 1136.

76 Ebenda.

77 Ebenda.

78 AKPR, T 182/22, Karton 84, Exposé Preiss' für Śámal, übersandt am 20.6.1928. 
Nicht zu Unrecht stufte Hodáč die Einigung - die Rede von einem tschechischen Sieg über die Deutschen wurde vermieden - als wichtigstes Ereignis der Verbandsgeschichte im Jahre 1928 ein. ${ }^{79}$ Der Zusammenschluß, der eigentlich nur mehr die bestehenden mannigfachen Verbindungen mit Brief und Siegel versah, bewegte sich auf der auch in anderen Bereichen von Wirtschaft und Gesellschaft zu beobachtenden Linie der Konzentration und Vereinheitlichung des Verbandswesens ${ }^{80}$; nach dem Zusammengehen von Landwirtschaft und Gewerkschaften war eine weitere Etappe in der inneren Entwicklung der Republik abgeschlossen ${ }^{81}$ - eine Konsolidierung und Rationalisierung der „bürgerlichen Selbstverwaltung “82, die ein rasches und konzertiertes Vorgehen von Fall zu Fall ermöglichte. ${ }^{83}$ Den wohl wichtigsten Ertrag erblickte Hodáč in der verbesserten Möglichkeit des Ausgleichs divergierender Brancheninteressen im Schoße des nunmehrigen Gesamtverbands. Wichtig war die Existenz eines solchen Forums insbesondere für Kartellverhandlungen; schon die Branchenorganisationen waren ja seit jeher auch das Gerüst, ja der Katalysator von Kartellvereinbarungen gewesen ${ }^{84}$ Grundsätzlich war es den im Zentralverband organisierten Branchen verwehrt, ihre Forderungen vor einer solchen verbandsinternen Abklärung in die Öffentlichkeit zu tragen bzw. mit ihnen an die Verwaltung heranzutreten. Der Interessenausgleich zwischen kartellierten Industrien bzw. zwischen diesen und ihren Lieferanten bzw. Abnehmern war vielmehr durch intern-informelle Einigung oder durch einen formellen verbandlichen Schiedsspruch - nach dem Muster einer Regelung des Reichsverbands der deutschen Industrie - vorzunehmen. Solche Verhandlungen hatte es 1927 in einigen Fällen gegeben, ihre Zahl nahm ständig zu; Paradebeispiel war der 1925 in einer paritätisch besetzten Kommission erreichte Ausgleich zwischen der Chemie und fünf Abnehmerverbänden. ${ }^{85}$

79 „Niemand von uns...verzichtet dadurch auf seine nationalen Ideale." Das tschechische Volk strebe, im „edlen Wettbewerbe“ mit den übrigen Bürgern des Staates, die Entfaltung seiner nationalen Kultur an: Vgl. Rede Hodáčs, Vollversammlung des Zentralverbands am 22.5. 1929, in: OB 11 (1929), S. $223 \mathrm{f}$. - Ausführliche Version in: SÚA, ÚSČP, Karton 11, Wortprotokoll der Rede vom 22.5. 1929.

80 Handelsminister Novák führte in seiner Rede vor der Vollversammlung des Zentralverbands am 22. Mai 1929 als Parallelen den Wirtschaftsbeirat und das Nationalkomitee für wissenschaftliche Organisation an. Wesentliche Fortschritte mache auch die Bildung einer Zentralorganisation des Handels. Vgl. Rede Nováks auf der Vollversammlung des Zentralverbands am 22. 5.1929, in: OB 11 (1929), S. 228.

81 Kommentare des HR vom 14.6.1928 und des PT vom 19.9.1928. - Bacher, Zusammenschluß, S. $1135 \mathrm{f}$.

$82 \mathrm{Zu}$ der Notwendigkeit der Kooperation gerade angesichts der handelspolitischen Tagesprobleme vgl. die Rede Hodáčs, Vollversammlung des DHI anläßlich des zehnjährigen Verbandsjubiläums, in: MDHI 10 (1929), S.759. - Rede Hodáčs, Vollversammlung des Zentralverbands am 22. 5. 1929, in: OB 11 (1929), S. 223 f. - Teilweise ergänzt anhand des Wortprotokolls in: SÚA, ÚSČP, Karton 11.

83 Vgl. die Rede des Nachfolgers Hodáčs, Mixa, Vollversammlung des DHI am 8.4.1933, in: MDHI 14 (1933), S. 177 f.

84 Bereits 1924 hatte etwa der Allgemeine Deutsche Textilverband proklamiert, jetzt, nach der Vollendung der "Binnenorganisation", als zweite Stufe den Aufbau von Konditionenkartellen in Angriff nehmen zu wollen: Vgl. den Bericht über die Vollversammlung des ADTV am 18. 4. 1924, in: MADTV 7 (1925), S. 90 . - Zur Geschichte der seit 1922 bestehenden tschechoslowakischen Tuchkonvention, der Kleiderstoffkonvention und verschiedener anderer Branchenkonventionen vgl. MADTV 6 (1924), S.53f. und den Bericht über die Vollversammlung des ADTV am 14. 5. 1926, in: MADTV 8 (1926), S. 90.

85 Rede Hodáčs, Bericht über die Generalversammlung anläßlich des zehnjährigen Verbandsjubi- 
Auch bei Streitigkeiten in Zolltariffragen ${ }^{86}$ verbesserte die Einbindung des DHI die Chancen einer Konzertierung. Daß das Zusammengehen die Handlungsfähigkeit insbesondere in Arbeitgeberfragen und gegenüber der Landwirtschaft erhöhte, wurde auf Seiten der Kontrahenten deutlich gesehen: Unter der Parole „Lernen wir vom Klassengegner“ maß der "Sozialdemokrat“ der Fusion als „Beitrag zur Naturgeschichte der deutschen Kapitalistenklasse" - verblüffend nur für die, „welche glauben, nicht Mammon, sondern die Nation sei der höchste Gott der Kapitalsbesitzer" - höchste Bedeutung bei, da sie die Arbeiterschaft mit dem „geschlossenen Heerlager ihrer Klassengegner“ konfrontiere. ${ }^{87}$ „Venkov „und „Deutsche Landpost“ machten für die tschechische Agrarpartei und den deutschen Bund der Landwirte auf die gewachsene Macht des Kontrahenten aufmerksam. ${ }^{88}$ Die Dringlichkeit eines handelspolitischen Interessenabgleichs mit diesem wuchs angesichts der neuerlich bevorstehenden Handelsvertragsverhandlungen mit dem Reich. ${ }^{89}$

Auch die Spitze des Hauptverbandes betrachtete mit Blick auf die verbesserten Aktionsmöglichkeiten das Ende der „Hypertrophie“ der Organisation mit Genugtuung. „Wenn nur rein wirtschaftliche Grundsätze zur Leitschnur dienen“, so Kislingers Kommentar, sei es einfacher, „gewisse Normen der Zusammenarbeit praktisch durchzuführen als theoretisch durchzusetzen" ${ }^{90}$ Schicht habe - dies blieb die vorherrschende Auffassung im Hauptverband - erkannt, daß der Zweck des DHI erst dann erfüllt sei, wenn er gebührenden Einfluß bei den staatlichen Stellen erlangt habe; man könne feststellen, "daß keiner der beiden Teile den Zusammenschluß bedauert". 91

Schichts Resümee, das Resultat bedeute einen tragfähigen Kompromiß ${ }^{92}$, machten sich andere Kommentatoren allerdings nur eingeschränkt zu eigen: In der „Wirtschaft“ würdigte Bacher zwar die Vorteile der Geschlossenheit; er sah die wichtigsten Industrien der Republik jetzt aber unter der Botmäßigkeit des Zentralverbands, der sich in den Verhandlungen klar als der Seniorpartner erwiesen habe, den Präsidenten stelle und im Gegensatz zum DHI seine Präsidialmitglieder in eigener Regie benenne. Immerhin konzedierte Bacher, die reale Kräfteverteilung werde sich erst in der Praxis herausbilden; dort werde die Gemeinsamkeit der Interessen wohl so sehr dominieren, daß Entgegenkommen sich als „die rentabelste Methode“ erweisen werde. Zumindest habe man den zwei Jahre lang umstrittenen Blockgedanken durchgesetzt; daß der Zentralverband an Mitglieder des DHI keine Auskünfte erteilen und sie nicht vor Behörden vertreten

läums, in: Observer 10 (1928), S. 309 f. - Ergänzt aus den Wortprotokollen, in: SÚA, ÚSČP, Karton 11.

86 Der wohl wichtigste Fall war die 1927 erreichte Abmachung über Preise und Zölle zwischen der chemischen Industrie und ihren Abnehmern.

87 Sozialdemokrat vom 28.11. 1928. - Ähnlich der Tenor in der kommunistischen Rudé pravo vom 13.12. 1928.

88 Venkov vom 20. 9. 1928. - Die Deutsche Landpost vom 21.9.1928 gab diese Meldung kommentarlos wieder und betonte nur die Passagen vom "stärkeren Gegner".

89 In diesem Kontext verortete auch die deutsche Gesandtschaft die industriellen Zusammenschlußbestrebungen: Vgl. Gesandtschaft Prag an AA, 10.10.1928, in: PA, IIb, Wirtschaft 10, Tschechoslowakei, Band 2.

90 Rede Kislingers, Vollversammlung des Zentralverbands am 22. 5. 1929, in: OB 11 (1929), S. $224 \mathrm{f}$.

91 Laudatio Hochstetters auf den abtretenden DHI-Präsidenten Schicht, Vollversammlung des DHI am 9. 4. 1932, in: MDHI 13 (1932), S. 185.

92 PT vom 19.9.1928 und Rede Schichts, Ausschußsitzung des DHI am 18.9.1928, in: MDHI 9 (1928), S. $833 \mathrm{f}$. 
dürfe, impliziere eine Anerkennung der Eigenständigkeit des DHI. ${ }^{93}$ Weniger optimistisch als Bacher waren Stimmen aus dem Hauptverband selbst, insbesondere aus der Textilindustrie in Warnsdorf, Rumburk und Brünn, die eine zu große Nachgiebigkeit der Deutschen monierten. ${ }^{94}$ Die tschechisch-deutsche Zusammenarbeit, so Teltscher als Exponent dieser Kreise, sei wünschenswert und möglich, allerdings nur auf der Grundlage völliger Gleichberechtigung. ${ }^{95}$ Auch von reichsdeutscher Seite war unverhohlene Kritik zu hören: Daß der Zusammenschluß ausgerechnet während der Amtszeit deutscher Minister durchgeführt worden sei, wertete man dort als bedenkliches Zeichen von Schwäche. ${ }^{96}$ Die deutsche Gesandtschaft sprach sogar von einem „erzwungenen" Anschluß an den Verband der tschechischen Wirtschaft, welche nach ihrem Umfang und ihrem Entwicklungsgrad zu urteilen eigentlich verurteilt sei, die zweite Geige zu spielen. Das „Triumphgeschrei“ der nationaltschechischen Blätter sei ein Indiz für die schweren Einbußen, die die Deutschen, trotz Wahrung aller äußeren Formen, durch diesen "nur als neuen Gewaltakt " zu charakterisierenden Vorgang erlitten habe. ${ }^{97}$

Konsequente Parität, insbesondere die alternierende Besetzung des Präsidentenstuhls, wäre für den Zentralverband nun allerdings tatsächlich ein unannehmbares, weil die reale Machtverteilung - mehr die in der Politik als in der Wirtschaft - außer Acht lassendes Ansinnen gewesen; wohl aus diesem Grunde hatten es die Realpolitiker Schicht und Liebieg in den Verhandlungen auch gar nicht vorgetragen. Viele deutsche Industrielle, so Preiss, dächten noch in der Vorkriegstradition und könnten sich nicht mit dem Faktum abfinden, daß im Zuge der Machtverschiebung in den großen Aktiengesellschaften die führenden Positionen den Tschechen zukämen. ${ }^{98}$ Der Zentralverband, so sekundierte die national gestimmte reichsdeutsche Presse, habe im Zuge der Nationalisierungsbestrebungen von jeher die deutschen Industriellen, von denen viele ohnehin bereits von tschechischem Kapital abhängig seien, „ins tschechischnationale Schlepptau nehmen" und sie "dem Prager Diktat gefügig ... machen" wollen. ${ }^{99}$

Das Zusammengehen der industriellen Vereinigungen Ende der zwanziger Jahre war - so das Fazit - keine isolierte Erscheinung, sondern Teil eines republikweiten Schubs der Aggregierung wirtschaftlicher und sozialer Interessen, häufig über die - damals sich ohnehin einebnenden - Gräben zwischen Deutschen und Tschechen hinweg. Verglichen mit den Konzertierungsbemühungen der deutschen Wirtschaft, wie sie etwa in der Maikonferenz 1920 deutlich geworden waren, hatte sich die Einbindung des Hauptverbands

93 Dies zeigte sich auch an der Gestaltung des Etats: Der DHI führte 165000 Kronen pro Jahr an den Zentralverband ab. Angesichts des Gesamtvolumens - der DHI budgetierte zu der damaligen Zeit mit zwei, der Zentralverband mit drei Millionen Kronen pro Jahr - war es offensichtlich, daß nur ein relativ kleiner Teil der Agenda des Hauptverbandes an den Zentralverband überging: Vgl. Bacher, Zusammenschluß, S. $1135 \mathrm{f}$.

94 AKPR, T 182/22, Karton 84, Exposé Preiss' für Śámal, übersandt am 20.6. 1928.

95 Teltscher, Wirtschaft, S. $491 \mathrm{f}$.

96 Arens, Einflußsphäre, S. 164.

97 Gesandtschaft Prag an AA, 10. 10. 1928, in: PA, IIb, Wirtschaft 10, Tschechoslowakei, Band 2. Eine von der Zentralstelle für den wirtschaftlichen Auslandsnachrichtendienst an die reichsdeutschen Ministerien bzw. Spitzenverbände der Wirtschaft versandte Kopie des Berichts kennzeichnete die politisch brisanten Passagen ausdrücklich als „streng vertraulich“: Vgl. Zentralstelle für den wirtschaftlichen Auslandsnachrichtendienst an RMWi u.a., 24.10.1928, in: BArch-B, RMWi, 2895/3.

98 AKPR, T 182/22, Karton 84, Exposé Preiss' für Śámal, übersandt am 20.6. 1928.

99 Zittauer Nachrichten und Anzeiger vom 25.9.1928. 
in das „deutsche Milieu“ signifikant verringert. In den Vordergrund trat nun die Notwendigkeit des Ausgleichs von Brancheninteressen. Ob die im „Ehevertrag“ vorgenommene Verteilung von Rechten und Pflichten dem relativen Gewicht der Deutschen gerecht wurde, ist schwer zu sagen; möglicherweise ist sie, wie von manchen zeitgenössischen Kritikern behauptet, als Indiz ihrer Juniorpartnerschaft zu werten. Immerhin aber war den Deutschen nicht ein Status minderen Rechts zugewiesen worden; die vor allem in der Frühzeit der Republik als Schreckensperspektive an die Wand gemalte "Aufsaugung" hatte nicht stattgefunden. Die Übereinkunft beruhte auf einem für das Proporzdenken der Erste Republik charakteristischen Quotenmodell: Die Belange beider Seiten waren durch einen stabilen "nationalen Schlüssel“ garantiert. 


\section{Kooperation während der Weltwirtschaftskrise (1929-1932)}

Bachers Prognose bewahrheitete sich: Trotz der kritischen Stimmen und begünstigt durch die politische Großwetterlage - die Zeichen standen im Zuge der deutschen Regierungsbeteiligung weiterhin auf Entspannung - erwies sich das Bündnis als tragfähig. Wie die der Burg nahestehende „Př́tomnost" zu Recht ausführte, hatte das Auseinanderbrechen der Koalition 1929 mit einem sich vertiefenden deutsch-tschechischen Gegensatz nichts zu tun - schon gar nicht mit Konflikten auf dem Terrain der Wirtschaft. ${ }^{1}$ Die nach den Wahlen von Udržal im Dezember des Jahres geschmiedete, wieder im Kern aus den Sozialdemokraten, der tschechischen Agrarpartei und dem Bund der Landwirte bestehende Koalition verzeichnete nicht zufällig die vier Abgeordneten der DAWG, der dem Hauptverband am nächsten stehenden parlamentarischen Gruppierung, als Hospitanten. ${ }^{2}$ Auf der anderen Seite demonstrierte der Zentralverband von Fall zu Fall durch kleine Handreichungen die Bereitschaft, das Räderwerk der aktivistischen Politik zu schmieren. ${ }^{3}$

Als atmosphärisches Indiz können die reibungslosen, ja fast herzlichen Beziehungen der Verbandsspitzen zueinander gewertet werden. Dies galt etwa für den Verkehr zwischen Schicht und Preiss. ${ }^{4}$ Sind solche gemischt geschäftlich-persönlichen Beziehungen im allgemeinen auch eher als „Diplomaticum “ denn als „Herzensangelegenheit" einzustufen, so war die unabdingbare Grundlage, Gleichklang der Interessen, in diesem Fall doch zweifellos gegeben. Gegenseitige Unterstützung war etwa in Personalfragen zu beobachten: Mitte 1929 drängte Preiss den Hauptverband, sich um die Besetzung des vakanten Mandats eines Vizepräsidenten des tschechoslowakischen Nationalkomitees der internationalen Handelskammer - Präsident des Komitees war Preiss - zu kümmern. Daß Medinger als Kandidat der Deutschen von der Mehrheit in diesem Gremium nicht akzeptiert worden war ${ }^{5}$, quittierte Schicht mit Unverständnis, bekundete im gleichen Atemzug jedoch, durch persönliche Empfindlichkeiten die Kooperation nicht be-

1 Př 6 (1929), S. $610 f$.

2 PA, R 73 810, Gesandtschaft Prag an AA, 5. 12. 1929.

3 Anfang 1929 etwa deutete Mayr-Harting bei Kanzler Śámal an, der zum intransigenten Flügel der Christlich-Sozialen gehörende Abgeordnete Luschka mache der aktivistischen Linie große Schwierigkeiten; mit einem bequemen finanziellen Polster könne ihm ein Rückzug aus der Politik schmackhaft gemacht werden. Preiss, von Šámal zu Rate gezogen, schlug die Plazierung Luschkas im Verwaltungsrat einer Spiritusbrennerei vor. Der Ausgang der Angelegenheit ist aus den Akten nicht ersichtlich; der Vorgang demonstriert aber die grundsätzliche Einstellung der führenden Persönlichkeiten im Zentralverband: Vgl. ANB, ZB, S VII/i-1-I, 912, Sámal an Preiss, 25. 1. 1929. - Preiss an Sámal, 4. 3. und 8.3.1929.

4 Schicht lud Preiss z. B. mehrere Male nach Aussig ein: Vgl. ANB, ŽB, S VII/i-1-I, 802, Schicht an Preiss, 21. 6. 1930.- Preiss an Schicht, 24. 2. 1936.- 1936 sprach Schicht von ,angenehmen Beziehungen“: Vgl. ANB, ŽB, S VII/i-1-I, 802, Schicht an Preiss, 17.1.1936.

5 Die Gründe sind unklar. Eventuell könnte eine Rolle gespielt haben, daß Medingers Auslandspropaganda zugunsten der deutschen Minderheit ihn in national denkenden tschechischen Kreisen zur persona non grata gestempelt hatte. Die österreichische Prager Gesandtschaft berichtete Mitte März, Preiss habe Medinger aus diesem Grunde in Gesellschaft geradezu eine Szene gemacht: Vgl. ÖStA, BAA, Gesandtschaft Prag, Zl.39/Pol., Österreichische Gesandtschaft Prag an BAA, 14.3.1929. 
einträchtigen zu wollen. Preiss, dem seinerseits an einer Kampfkandidatur nicht gelegen war, schlug Schicht bzw. Mühlig vor, das Mandat anzunehmen. ${ }^{6}$ Damit ist nicht gesagt, daß nicht manche Freundlichkeiten durch die erwähnte Vormacht des tschechischen Kapitals bedingt waren. Die reibungslosen Beziehungen zwischen Preiss und Liebieg ${ }^{7}$ etwa waren nicht zuletzt auf Liebiegs finanzielle Abhängigkeit von seinen tschechischen Gläubigerbanken zurückzuführen. Die Wirtschaftskrise hatte die Beschäftigung in Liebiegs Textilunternehmen stark schrumpfen, ihre Verluste hingegen stark ansteigen lassen, so daß die Gläubigerinstitute, an der Spitze die Živnostenská banka, die Kontrollen verschärten und eine Senkung der Kosten forderten. ${ }^{8}$ Im Mai 1933, als Liebiegs Baumwollbetriebe bereits seit längerem stillagen und die Wollbetriebe in eine ungewisse $\mathrm{Zu}$ kunft sahen, mußten Liebiegs Bevollmächtigte bei einem Schuldenstand von 196 Millionen Kronen wegen Nachlässen bei den Steuerrückständen mit dem Finanzministerium verhandeln. Die Gesellschafter des Unternehmens verfügten, nachdem sie ihre gesamten privaten Mittel eingebracht hatten, über kein nennenswertes Vermögen mehr. Angesichts dieser Zwangslage betrieben die Gläubigerbanken unter Führung der Živnostenská banka den Umbau der Wollbetriebe in eine Aktiengesellschaft, deren Grundkapital in Höhe von 48 Milionen Kronen zur Hälfte Theodor und Gisbert Liebieg zeichnen sollten; der Liebiegsche Aktienbesitz wurde für die Bankschulden verpfändet. Im Gegenzug waren die Banken bereit, den größten Teil der Zinslast für 1932 zu streichen, 24 Millionen Kronen von ihren Forderungen in Aktienkapital umzuwandeln und die Restschuld von 168 Millionen Kronen vergleichsweise niedrig, zu vier Prozent, zu verzinsen. Weitere Bareinschüsse lehnten die Banken ab. Da die einzige Alternative zu diesem Umbau des Konzerns die Liquidierung gewesen wäre, bestand angesichts drohender Massenarbeitslosigkeit in dem ohnehin notleidenden Reichenberg, der Gefahr für die öffentliche Ordnung und der Aussicht auf eine immense Belastung der öffentlichen Kassen durch Steuereinbußen und Arbeitslosenunterstützung an dieser Lösung auch ein nicht geringes öffentliches Interesse. ${ }^{9}$ Trotz dieser Rettungsaktion war Liebieg jedoch bis in die späten dreißiger Jahre in Bedrängnis und somit auf Kredit bei der Živnostenská banka angewiesen. ${ }^{10}$

Klimatische Eintrübungen wie in der "Telegramm-Affäre" vom März 1930, verursacht durch das Vorpreschen nationalistischer Heißsporne, waren die Ausnahme. An-

6 ANB, ŽB, S VII/i-1-I, 802, Preiss an Schicht 24.6.1929. - Schicht an Preiss, 27.6.1929 und 2.7.1929.

71929 dankte Liebieg Preiss für die „liebenswürdige Einladung“: Vgl. ANB, ŽB, S VII/i-1-I, 491, Liebieg an Preiss, 27. 2. 1929. - 1932 gratulierte Liebieg Preiss persönlich zu seiner Rede vor der Vollversammlung des Zentralverbands, die die wirtschaftliche Situation nin objektiver und klarer Weise beleuchtet" habe, und gab der Hoffnung Ausdruck, die Rede werde bei den Regierungsstellen „den so dringend notwendigen Antrieb zur Besserung bringen“: Vgl. ANB, ŽB, S VII/i-1-I, 491, Liebieg an Preiss, 24. 5. 1932.

${ }^{8}$ ANB, ŽB, S I/c-PVV, Band 38, Sitzung des Exekutivausschusses der ŽB vom 3.2.1931. Band 40, Sitzung des Exekutivaussschusses vom 22.12.1931.

9 SÚA, MF, Karton 63, 762/33, „Information“ über die Verhandlungen, ungezeichnet, vom 22.5.1933.

10 Mitte 1937 gelangte Preiss beim Studium von Liebiegs Bilanzen zu dem Schluß, Liebieg verdiene keinesfalls genug, um die Zinsen bezahlen zu können. Zudem traten immer neue Probleme auf, etwa die Insolvenz der „Oberschlesischen Holzindustrie“, gegen die Liebieg Forderungen hatte, welche in den kommenden zwölf Monaten fällig werden sollten. Vgl. ANB, ŽB, S VII/i-1-I, Preiss an Tille, 18.7.1937. 
fang 1929 war in Prag eine polnisch-tschechische Gesellschaft für den Rohstoffhandel gegründet worden, die, mit der Perspektive einer engeren und dauerhaften wirtschaftlichen Kooperation der beiden Länder, polnische Agrar- gegen tschechische Industrieexporte vermitteln sollte. ${ }^{11}$ In diesem Zusammenhang fanden bald darauf in Gdingen Besprechungen zwischen den polnischen Behörden und tschechischen Handelskammervertretern über die Nutzung des Hafens für den tschechischen Transithandel statt; der Bau eines eigenen Hafenbeckens durch die Tschechoslowakei wurde ins Auge gefaßt. ${ }^{12}$ Am 11. September 1929 reiste Handelsminister Novák mit einer hochkarätigen Delegation von Politikern und Vertretern der Wirtschaft - darunter Śámal, Preiss, der Generaldirektor der Škoda-Werke, Loewenstein, und Hodáč - nach Polen. ${ }^{13}$ Vor diesem Hintergrund richtete Anfang 1930 Hodáč ein Glückwunschtelegramm zum zehnjährigen Jubiläum der Einrichtung des Korridors an den polnischen Handelsminister Kwiatkowski, welches das Versprechen enthielt, eine Umleitung des tschechoslowakischen Transithandels von Hamburg nach Gdingen zu unterstützen. ${ }^{14}$ Diese Aktion des Generalsekretärs, dem man übrigens auf deutscher Seite niemals nachgesehen hatte, daß er nach dem Weltkrieg in der oberschlesischen Frage als Sachverständiger gegen Deutschland aufgetreten war, und der gerade in der tschechischen Öffentlichkeit durch eine chauvinistische Ansprache von sich reden gemacht hatte ${ }^{15}$, erregte auf deutscher Seite böses Blut im Übermaß. Nun handelte es sich hier allerdings um eine eigenmächtige, im Zentralverband nicht ordnungsgemäß beschlossene Eskapade, von der der Hauptverband überhaupt erst durch einen Artikel im „Prager Tagblatt" Wind bekommen hatte. Kislingers Interpretation, der hier sich offenbarende "Grad der nationalpolitischen Erhitzung und Angriffslust“ gebe „zu denken“, seine Drohung mit einem "Nachspiel“ zu dieser „zeitweilig bis zur Schamlosigkeit gesteigerte(n) Beharrlichkeit" Hodáčs, der, gefördert von Preiss, unkontrollierte Machtbefugnisse in seiner Person vereinige $^{16}$, und das auf dem Sprechtag des DHI am 26. Februar 1930 beschlossene Einschreiten veranlaßten am 12. März den Zentralverband zu der beschwichtigenden Erklärung, bei dem Telegramm habe es sich lediglich um einen Akt der Höflichkeit gehandelt; der im „Prager Tagblatt“ publik gemachte Text entspreche zudem nicht dem Original. Eine weitere Erörterung in der Sitzung des engeren Präsidiums des Zentralverbands am 26. März, mündend in die Versicherung, man habe nicht beabsichtigt, Politik zu betreiben, schaffte den Casus belli aus der Welt. ${ }^{17}$

Das Pendant zu diesem Lapsus war auf deutscher Seite die „Ratshesky-Affäre“: Ratshesky, neuer Gesandter der USA in Prag, unternahm nach seinem Amtsantritt drei Reisen mit dem Ziel, Land und Leute kennenzulernen. Die zweite führte ihn im September 1930 nach Nordböhmen, wo die Anknüpfung persönlicher Kontakte zu prominenten Reichenberger und Gablonzer Industriellen auf der Tagesordnung stand. Auf einem Diner mit den Spitzen der deutschen Wirtschaft und Gesellschaft, unter anderem Ginzkey,

11 Deutsches Konsulat Krakau an AA, 14.3.1929, in: BArch-B, AA, 66935.

12 Danziger Neueste Nachrichten vom 7.9.1929.

13 Gesandtschaft Prag an AA, 11. 9. 1929, in: PA, R 89969.

14 Gesandtschaft Prag an AA, 18.3.1930, in: PA, R 73795.

15 So die Rechnung, die die deutsche Gesandtschaft gegen Hodáč aufmachte: Vgl. Gesandtschaft Prag an AA, 18. 3. 1930, in: PA, R 73795.

16 PA, R 73 795, Kislinger an Siegert, 27.2. 1930. - Siegert an AA, 4. 3. 1930.

17 Vgl. den abschließenden Bericht in: MDHI 11 (1930), S. 255. 
Medinger, Liebieg, Riedl und Hartig, begrüßte Ginzkey, in dessen Maffersdorfer Villa der Gesandte untergebracht war, Ratshesky im Namen „des deutschen Teils der tschechischen Republik und bat ihn, in den Vereinigten Staaten von der „Unterdrückung der Deutschen" zu berichten. Der Diplomat vermied eine Parteinahme; auf eine ähnliche Verlautbarung antwortete er, wer den internationalen Frieden wolle, müsse zunächst für den inneren Ausgleich Sorge tragen - eine Spitze, die von allen Anwesenden wohl verstanden wurde. Hatte man den Gesandten als Verbündeten der Irredenta vereinnahmen zu können geglaubt, so lag nach Auffassung des Berichterstatters der Präsidentenkanzlei die Bedeutung der Reise gerade in der diesbezüglichen völligen Ernüchterung der Deutschen. ${ }^{18}$ Waren die deutschen Industriellen auch keinesfalls über einen Kamm zu scheren - Liebieg habe sich, wie Sámal notierte, im Gegensatz zu Ginzkey „sehr ordentlich" benommen -, so zog der Kanzler doch das Fazit, es sei ratsam, ein Auge auf den Gesandten zu behalten und ihn von den deutschen Cliquen, in die er geraten sei, fernzuhalten. ${ }^{19}$

In aktuellen wirtschaftspolitischen Fragen dominierte nach wie vor der Konsens: Der Zentralverband erkannte das 1929 vom DHI ausgearbeitete Wirtschaftsprogramm als Grundlage seiner Unterhandlungen mit dem Handelsministerium an. ${ }^{20}$ Nachdem Anfang 1929 der Hauptverband auf die schnellstmögliche Konstituierung der vereinbarten gemeinsamen Arbeitsausschüsse gedrungen und verlangt hatte, von allen wichtigen Belangen unverzüglich verständigt $\mathrm{zu}$ werden ${ }^{21}$, beteiligte er sich bereits in den folgenden Monaten intensiv an der Arbeit dieser Gremien, zumal seine personellen Erweiterungsvorschläge Billigung gefunden hatten.22 Generalthema blieb die Außenhandelspolitik, die binnenwirtschaftlich mit dem Problem des Ausgleichs zwischen Industrie und Landwirtschaft, mit der Frage der Senkung der Produktionskosten und auf diesem Wege mit der Steuerpolitik verzahnt war. ${ }^{23}$ War auf der Vollversammlung des Zentralverbands im Frühjahr 1929 vor dem Hintergrund der leidlich stabilisierten Verhältnisse Handelsminister Nováks Rede noch auf einen hoffnungsfrohen Ton gestimmt ${ }^{24}$, so rief Preiss unter dem Eindruck der amerikanischen und der reichsdeutschen Terraingewinne auf dem Weltmarkt bereits zu erhöhter Wachsamkeit auf. Die Tschechoslowakei könne ihre Position nur halten, wenn sie die Kostenbelastung der Produktion mildere, die fiskalische Belastung herabsetze und Fusionen sowie Rationalisierungsinvestitionen steuerlich begünstige. Preiss bekannte sich zu Englišs Politik der Reduzierung der Staatsausgaben in Verbindung mit einer den Haushaltsausgleich anvisierenden Steuerreform. ${ }^{25}$ Die auf dem Sprechtag des Hauptverbandes Mitte Juni des Jahres verabschiedete Stellungnahme zum Staatsvoranschlag für 1930 spann dieses Thema mit der Kritik an der geplanten

18 AKPR, T 12/25, Teil V, Karton 135, Bericht vom 30. 10. 1931 (!) für die Präsidentenkanzlei, Verfasser unklar.

19 AKPR, T 12/25, Teil V, Karton 134, Aktenvermerk Šámal vom 1.4.1931.

20 Bericht über die Vollversammlung des DHI am 5.4. 1930, in: MDHI 11 (1930), S. 269.

21 Bericht über die Vollversammlung des DHI am 9. 3. 1929, in: Tagesbote (Brünn) vom 10. 3. 1929.

22 Rede Janovskys, Ausschußsitzung des DHI am 19.6.1929, in: MDHI 10 (1929), S. 519.

23 Rede Schichts, Vollversammlung des Zentralverbands am 22.5.1929, in: MDHI 10 (1929), S. 444-446. - Rede Preiss', Vollversammlung des Zentralverbands am 22.5.1929, in: OB 11 (1929), S. 229-231.

24 Rede Nováks, Vollversammlung des Zentralverbands am 22. 5.1929, in: OB 11 (1929), S. 228.

25 Rede Preiss', Vollversammlung des Zentralverbands am 22. 5. 1929, in: OB 11 (1929), S. 229-231. 
Ausweitung von Ausgaben und Einnahmen weiter. ${ }^{26}$ Der Kampf gegen neue Steuerpläne verschärfte sich mit der Weltwirtschaftskrise und gipfelte 1930 in der Herausgabe einer vielbeachteten Denkschrift des DHI, die zu einererheblichen Milderung der ursprünglich vorgesehenen zusätzlichen Belastungen führte. ${ }^{27}$

Die gravierendste wirtschaftspolitische Hypothek der Tschechoslowakei war und blieb das Exportproblem. Dem gelegentlich, vermehrt in der Krise lautwerdenden Plädoyer für einen Abbau der Exportwirtschaft und ihre Substituierung durch Landwirtschaft bzw. landwirtschaftliche Industrien erteilte der DHI eine scharfe Absage, da solche Deindustrialisierungspläne die Ausfuhrabhängigkeit der ČSR weit unterschätzten: Einer Umfrage des Hauptverbandes bei den Mitgliedsunternehmen zufolge lag sie nicht, wie oft angenommen, bei 25, sondern in wichtigen Industriezweigen zwischen 45 und 95 Prozent. Daß diese exorbitante Exportquote drastisch reduziert und zudem die freigesetzte Arbeitskraft vom Agrarsektor aufgesogen werden könne, sei unrealistisch. Eine solche Umbaustrategie werde zudem die Kaufkraft des Binnenmarktes beschneiden und so die Absatzchancen der Landwirtschaft und allfälliger Ersatzindustrien beeinträchtigen - ganz zu schweigen von den verheerenden Konsequenzen für die Staatseinnahmen. ${ }^{28}$ Nicht zuletzt das niedrige Entwicklungsniveau der östlichen Landesteile, so Mühlig, auf der Vollversammlung des Zentralverbands im Mai 1932 alle Argumente bündelnd, lasse eine auf den Binnenmarkt setzende Autarkiepolitik realitätsfern erscheinen. ${ }^{29}$

Einzig die Förderung des Exports durch eine gemäßigt freihändlerische Außenhandelspolitik war aus dieser Perspektive vernünftig; das im Zeichen der Krise zunehmend in Anwendung kommende Regulierungsinstrumentarium - Devisenbewilligung, Clearing, Kontingentierung und Kompensationen - wurde folglich als kontraproduktiv eingestuft. ${ }^{30} 1932$ forderte der Hauptverband Vorkehrungen gegen die Drosselung der Einfuhr durch das umständliche, oft sogar schikanöse Devisenregime. ${ }^{31}$ Auf der Vollversammlung des Zentralverbands im Frühjahr 1929 hatte Schicht bereits moniert, die Beschlüsse der Genfer Weltwirtschaftskonferenz 1927 zur Beseitigung internationaler Handelshemmnisse seien so gut wie ohne Widerhall geblieben. Schicht wußte sich mit Preiss in der Warnung vor einer Zollabschottung einig: Hohe Inlandspreise trieben die Lebenshaltungskosten und damit die Löhne in die Höhe. ${ }^{32} \mathrm{Daß}$ die Vollversammlung des DHI zum zehnjährigen Verbandsjubiläum im September 1929 - die letzte vor der Weltwirtschaftskrise - trotzdem von einer deutlich optimistischeren Grundstimmung als die des Zentralverbands getragen war, mochte mehr mit diplomatischer

26 Ausschußsitzung des DHI am 19.6. 1929, in: MDHI 10 (1929), S. 519-521 und S. 526-528.

27 Jahresbericht, erstattet auf der Vollversammlung des DHI am 28.2.1931, in: MDHI 12 (1931), S. $139 f$.

28 Dies die Gegendarstellung des DHI zu einer Rede von Minister Viškovský, in der solch abstruse Ideen vorgetragen wurden. Vgl. MDHI 12 (1931), S. $725 \mathrm{f}$.

29 Rede Mühligs auf der Vollversammlung des Zentralverbands am 19. 5. 1932, in: MDHI 13 (1932), S. 259-262.

30 Rede Mühligs, Vollversammlung des Zentralverbands am 19.5.1932, in: MDHI 13 (1932), S. 259-262.

31 Mühlig, Zu dem „Notplane“, S. 562.

32 Rede Schichts, Vollversammlung des Zentralverbands am 22.5.1929, in: MDHI 10 (1929), S. 444-446. - Rede Preiss', Vollversammlung des Zentralverbands am 22.5.1929, in: OB 11 (1929), S. 229-231. 
Zurückhaltung der Deutschen als mit den Fakten zu tun haben. ${ }^{33}$ Die Erwartung, den Regierungsverantwortlichen würden die Leviten gelesen, erfüllte allerdings stellvertretend die harsche Attacke des Gastredners Hodáč gegen die Unentschiedenheit der Handelspolitik; Schicht trug seine behutsame Kritik an der schleppenden Fortentwicklung des Handelsvertragssystems dann in die Worte des Generalsekretärs gekleidet vor. ${ }^{34}$

Die Krise bedeutete auch eine neue Herausforderung für die Verbände. Trotz wachsenden Arbeitsanfalls entließ der Hauptverband 1930 eine Reihe von Angestellten, um Mittel für die nun gebotene stärkere Präsenz in Prag freizumachen. ${ }^{35} \mathrm{Im}$ Chor der deutschen Kritiker der staatlichen Wirtschaftspolitik wurden nun durchaus auch schrillere Töne als die bislang gewohnten laut: Unverblümtes Mißfallen äußerten etwa der Verband der Wollindustriellen Mährens und der Verband der deutschen Industrie in Brünn. Die auf der Sitzung des Zentralverbands am 3. März 1931 vorgetragenen Angriffe des Handelskammersekretärs a.D. Robert Mayer, Wortführer der Brünner deutschen Industrie, gegen das Fortwursteln der Regierung verfehlten ihren Eindruck auch auf die tschechischen Vertreter nicht: Einflußreiche Persönlichkeiten wie der Handelsminister a.D. Hotowetz quittierten solche Husarenritte sogar mit der beifälligen Bemerkung, die Deutschen wehrten sich bei weitem noch nicht genug. Auf der anderen Seite zeigte die besorgte Äußerung eines Brünner Wollindustriellen, die Regierung werde nach dieser frontalen Attacke für die deutsche Wollindustrie wohl gar nichts mehr tun, „wie zaghaft umgekehrt die deutschen beteiligten Kreise vielfach sind “ ${ }^{36}$

War die Schaffung größerer Wirtschaftseinheiten in Mitteleuropa, von denen eine Lösung oder zumindest Milderung der Exportprobleme erwartet werden durfte, seit dem Zerfall der Habsburger Monarchie ein Dauerthema der wirtschaftspolitischen Diskussion gewesen, so rückte mit der Weltwirtschaftskrise die Frage des ökonomischen Nutzens und der politischen Durchsetzbarkeit dieser - in einer Vielzahl von Varianten und Kombinationen erörterten - Integrationspläne auf der Agenda der Industrieverbände in eine zunehmend prominente Position. Bereits die erste, von Mühlig geleitete Sitzung des neugegründeten wirtschaftspolitischen Ausschusses des DHI am 29. Oktober 1930 hatte im Kontext der handelspolitischen Problematik und des Ausgleichs mit der Landwirtschaft diesen Fragenkomplex erörtert. ${ }^{37}$ Im März 1931 herrschte angesichts der deutsch-österreichischen Zollunionspläne in Prag „eine ungeheure Aufregung ... wie noch nie seit dem Bestande der Republik“. Die ökonomische Tragweite des Unternehmens war offenkundig: Deutschland und Österreich, wohin 1930 zusammen 31 Prozent der tschechoslowakischen Ein- und 33 Prozent der Ausfuhren der ČSR gegangen waren, stellten die wichtigsten Import- und Exportpartner des Landes dar; zu befürchten war, daß beim Abschluß eines Zollbündnisses dieses Handelsvolumen zum großen Teil

33 Diese Auffassung vertrat der Kommentar des HR vom 29.9.1929 zu der Veranstaltung.

34 Rede Schichts, Vollversammlung des DHI am 21.9.1929, anläßlich des zehnjährigen Jubiläums, in: MDHI 10 (1929), S. 759-763. - Vgl. auch die Kommentierung im HR vom 26. 9.1929.

35 Jahresbericht, erstattet auf der Vollversammlung des DHI am 28. 2. 1931, Bericht in: MDHI 12 (1931), S. 140.

36 BArch-K, R 2/9953, Deutsches Konsulat Brünn an AA, 12.3.1931.

37 Der Ausschuß war konzipiert als ein ständiges Gremium von Fachleuten. Er bestand im Kern aus dem permanenten Verhandlungskomitee mit der Landwirtschaft, ergänzt durch Vertreter der übrigen Industriezweige. Vorsitzender war Oskar Riethof, als Mitglieder gehörten ihm u. a. Karl Devcic-Siegwardein, Kislinger, Fernegg, Janovsky, Zebisch, Scherb und der Brünner Wollindustrielle Hans Tugendhat an: Vgl. MDHI 12 (1931), S. 676. 
verlorengehen würde. ${ }^{38}$ Schwerer aber wog die vorauszusehende Abhängigkeit von einem neuen wirtschaftlichen und bald wohl auch politischen Machtblock in der Mitte Europas; die tschechoslowakische Presse würdigte die Zollunionspläne denn auch vor allem hinsichtlich ihrer politischen Bedeutung. ${ }^{39}$

Die deutschen politischen Parteien in der ČSR neigten in der Zollunionsfrage aus Gefühlsgründen zur österreichischen Seite und machten von dieser Haltung nur unter dem Druck der öffentlichen Meinung Abstriche. Konnte die deutschnationale Opposition ohne irgendwelche taktische Bedenken Benešs schärfstens ablehnende Linie in der Zollfrage konterkarieren ${ }^{40}$, so sahen sich die aktivistischen Regierungsparteien - der Bund der Landwirte und die deutschen Sozialdemokraten - zumindest aufs Lavieren verwiesen: Sie konnten es sich nicht leisten, die Warnungen Ministerpräsident Udržals und der tschechischen Presse vor einer Parteinahme gegen die "Interessen des Staates" in den Wind zu schlagen. Trotzdem nahmen die deutschen Sozialdemokraten am 7. April 1931 letztendlich eine Entschließung für die Zollunion an; die DAWG, der Koalition lose attachiert, äußerte sich am 12. April im gleichen Sinn. Nur der Bund der Landwirte blieb reserviert. ${ }^{41}$ Bezog die Jahresversammlung des Deutschpolitischen Arbeitsamtes am 6. Mai auch keine klare Position, so zeigte sich die Burg doch zufrieden, daß zumindest die deutschen Minister im Kabinett Benešs Exposé zur Zollfrage letztlich gebilligt hatten, so daß summa summarum eine schweigende Zustimmung der „Regierungsdeutschen “ zu Benešs Politik vorausgesetzt werden konnte. Vermutlich war dies die klügste Lösung: War die Erfolgsbilanz des Aktivismus auch nichts weniger als brillant, so wären bei einem Ausscheiden der Deutschen aus der Regierung aller Voraussicht nach doch alle mühsam errungenen kleinen Erfolge hinfällig geworden; bei einem Verbleib der deutschen Minister im Kabinett hingegen konnte man sich zumindest der Hoffnung hingeben, Beneš von seiner rein "negativistischen " Haltung abbringen zu können. ${ }^{42}$

"Bohemia" und „Prager Tagblatt" als die tonangebenden deutschen Presseorgane der Republik erachteten den Anschluß an die Zollbewegung allerdings als die einzige Option für die Exportindustrie der Republik dem Verlust der bisherigen Absatzgebiete vorzubeugen. Am 24. März sprach sich auch die Arbeitsgemeinschaft der deutschen wirtschaftlichen Verbände für einen mitteleuropäischen Wirtschaftsblock unter Einschluß Deutschlands als einzige Möglichkeit, eine handelspolitische Isolierung der Tschechoslowakei zu verhindern, aus. ${ }^{43}$ Bezeichnenderweise verlief die Front in diesem Konflikt aber nicht etwa zwischen Deutschen und Tschechen, sondern zwischen der Wirtschaft - ohne Ansehen ihrer nationalen Oberservanz - und der offiziellen Außenpolitik. Nahmen die tschechischen Politiker, je nach Parteischattierung mehr oder weniger geräuschvoll, eine ablehnende Stellung zu den Unionsplänen ein, die sich aus dem historisch ge-

38 „L.S.“, Zollunionsplan.

39 Vgl. die Zeitschriftenschau des Národnostní obzor zum Thema, in: NO 1 (1931), S. 275 f.

40 ÖStA, BAA, Gesandtschaft Prag, Zl.110/Pol., Österreichische Gesandtschaft Prag an BAA, 7.5.1931.

41 ÖStA, BAA, Gesandtschaft Prag, Zl.93/Pol., Österreichische Gesandtschaft Prag an BAA, 20.4. 1931.

42 Dies Mareks Interpretation der Motive. Daß Beneš den Einwänden der deutschen Minister Beachtung schenken würde, hielt Marek allerdings für nicht sehr wahrscheinlich: Vgl. ÖStA, BAA, Gesandtschaft Prag, Zl. 110/Pol., Österreichische Gesandtschaft Prag an BAA, 7. 5. 1931.

43 ÖStA, BAA, Gesandtschaft Prag, Zl.74/Pol., Österreichische Gesandtschaft Prag an BAA, 26.3. 1931. 
wachsenen Minderwertigkeitskomplex gegenüber den Deutschen und der - sicherlich nicht unrealistischen - Furcht vor einer großdeutschen Hegemonie erklären mochte, so waren die Praktiker, auch auf tschechischer Seite, „keineswegs so intransigent", daß sie die Vor- und Nachteile eines Anschlusses an die Zollunion nicht zumindest erwogen hätten. ${ }^{44}$ Deutsche wie tschechische Wirtschaftskreise nähmen - so das vom österreichischen Gesandten in Prag, Marek, gezeichnete Stimmungsbild - vor dem Hintergrund des faktischen Bankrotts der Handelspolitik, die nicht imstande gewesen sei, die mitteleuropäische Rolle der Tschechoslowakei zu gestalten, „durchwegs eine sehr zurückhaltende, ja vielfach eine sehr günstige Haltung" ein. Der Schaffung vergrößerter Wirtschaftsgebiete hatte Mühlig bezeichnenderweise ja schon vor dem Ausbruch des Streits um die Zollunion in der Vollversammlung des Hauptverbandes am 28. Februar 1931 das Wort geredet. ${ }^{45}$ Die Zeit der Meistbegünstigung, so der Tenor auch auf der Vollversammlung des Verbandes mährischer Industrieller am 22. April, sei vorbei; der europäische Trend, gegen den die Tschechoslowakei allein sich nicht stemmen könne, bewege sich in Richtung auf Zollbündnisse. Ein Anschluß an eine "Gegen-Union" etwa der südosteuropäischen Agrarstaaten erschien wenig erfolgversprechend. ${ }^{46}$

Auch Rosche als eine der gewichtigsten Stimmen der deutschen Industrie der Republik wies am 27. März im Abgeordnetenhaus das Alternativkonzept einer Kleinen Wirtschaftsentente als wirklichkeitsfern zurück ${ }^{47}$, und Bacher mahnte, im Unterschied zu der "nervösen, stellenweise geradezu hysterisch anmutenden Stellungnahme“ großer Teile der tschechischen Parteipresse müsse die Republik, nachdem die südosteuropäischen Agrarstaaten zu handelspolitischen Konzessionen kaum in der Lage seien, eine Lösung unter Einschluß Deutschlands und Österreichs anstreben. ${ }^{48}$ Auf tschechischer Seite bedeutete das Plädoyer des Prager Handels- und Gewerbekammersekretärs Fafl im Industriellenklub, die Entwicklung zunächst einmal ruhig zu verfolgen, eine Absage an jegliche "negativistische Einstellung " ${ }^{49} \mathrm{Z}$ war prognostizierte Fafl für den Fall des Zustandekommens einer Zollunion neben einer Beeinträchtigung des tschechoslowakischen Absatzes nach Österreich ein unbedingtes und eindeutiges Übergewicht des Reiches in einem „wirtschaftlichen Dreibund“ Deutschland-Österreich-Tschechoslowakei sowie eine Anpassungskrise für die tschechoslowakische Wirtschaft; ungeachtet dessen

44 ÖStA, BAA, Gesandtschaft Prag, Zl. 85/Pol., Österreichische Gesandtschaft Prag an BAA, 9. 4. 1931. - Vgl. zur Einstellung der deutschen Wirtschaft in der ČSR auch: Binder, Zollpakt.

45 Rede Mühligs auf der Vollversammlung des DHI am 28. 2. 1931, in: MDHI 12 (1931), S. 136.

46 "L.S.“, Zollunionsplan.

47 ÖStA, BAA, Gesandtschaft Prag, Zl.78/Pol., Österreichische Gesandtschaft Prag an BAA, 28.3.1931.

48 Bacher nahm von seinem Verdikt ausdrücklich die tschechischen Sozialdemokraten aus. Vgl. F.B. (= Franz Bacher), Konstruktive Politik. Die bereits zahlreich vorliegenden „kleineuropäischen Szenarios" - das Programm der Kleinen Wirtschaftsentente, den Hantos-Plan und den Tugendhat-Plan eines Zollverbandes der Tschechoslowakei, Österreichs, Ungarns, Jugoslawiens und Rumäniens - sowie den "großeuropäischen“ Plan Meißners - das „Maximalprogramm“ eines Zollzusammenschlusses zwischen Deutschland, Polen, Bulgarien, Italien und allen Nachfolgestaaten - tat Bacher nicht einfach ab, sondern insistierte nur auf einem möglichst flexiblen und umfassenden Vorgehen. - Zu weiteren Stimmen aus dem deutschen Lager vgl. die NO 1 (1931), S. 275 f., die eine positive Stellungnahme Liebiegs und einen zustimmenden Artikel Peters' in der Bohemia vom 5. Mai anführt.

49 Nál vom 26. 3. 1931. 
befürwortete er mitteleuropäische Wirtschaftsverhandlungen. ${ }^{50}$ Der Zentralverband wahrte angesichts dieser unterschiedlichen Szenarios Zurückhaltung: Preiss vermied auf der Vollversammmlung am 21. Mai eine Stellungnahme. Schon dieser Umstand erregte Aufsehen und wurde von dem gemeinhin bestens informierten Marek unter Berufung auf eingeweihte industrielle Kreise als wachsende Opposition gegen Beneš ausgelegt. $^{51}$

Angesichts der unbedingten Gegnerschaft des Außenministers gegen die Zollunion sahen sich die Wirtschaftsverbände allerdings zu behutsamem Taktieren genötigt. Daß eine Befürwortung der Zollunion von sinnvollen, unverfänglichen, unpolitischen Motiven bedingt sein könne, lag jenseits des Horizonts der tschechischen Außenpolitik. "Grotesk" sei, so Beneš, daß gerade die mehrheitlich deutsche Textil-, Porzellan- und Papierindustrie und der Kohlenbergbau, die "die Sache bezahlen“, d. h. unter dem Exportrückgang am meisten leiden müßten, für das Projekt votierten. Dies lege den Verdacht nahe, man denke auf deutscher Seite im wesentlichen politisch und lasse es an Loyalität zur Tschechoslowakei fehlen. ${ }^{52}$ Vor diesem Hintergrund übermittelte Mitte April Kislinger an Marek die Befürchtungen deutscher Industriekreise der ČSR, auf der bevorstehenden Tagung des Sudetendeutschen Heimatbundes in Wien könne die sachliche Behandlung der Zollunionsfrage, durch die allein man vor der tschechischen politischen Öffentlichkeit bestehen könne, „durch nationale Schlagworte und Überführung der Angelegenheit auf ein rein politisches und nationalistisches Geleise" gestört werden. Die deutschen industriellen Organisationen könnten sich „nur dann der Mithil$\mathrm{fe}$ der tschechischen Fachvereinigungen im Sinne der deutsch-österreichischen Wirtschaftspolitik versichern..., wenn sie ausschließlich rein sachliche und niemals politische Argumente hiefür ins Treffen führen". Auch die DAWG dürfe jetzt nicht durch eine politische Äußerung, die nur Wasser auf den Mühlen der tschechischen Nationalisten sein könne, desavouiert werden. ${ }^{53}$

Mit dem Scheitern der Zollunionspläne - dessen politische Hintergründe in diesem Zusammenhang nicht interessieren - war die Frage der internationalen ökonomischen Integration keineswegs obsolet, denn der Wiederaufbau der Wirtschaft war, wie Mühlig auf der Vollversammlung des Hauptverbandes im April 1932 ausführte, ein nur auf der übernationalen Ebene lösbares Problem. ${ }^{54}$ Mühlig bescheinigte der Prager Außenpolitik einen neuen Realismus, der begriffen habe, daß internationale Zusammenarbeit nur auf der Grundlage wirtschaftlicher Komplementarität, nicht aber luftiger politischer Loyalitäten stattfinden könne. ${ }^{55}$

50 Mixa, der spätere Generalsekretär des Zentralverbands, plädierte zusammen mit Kislinger für die Billigung des Referats und die Annahme der Empfehlung, man solle in Verhandlungen eintreten. Gegen die beiden stand der Vertreter der deutschen Landwirtschaft, Senator Luksch: Vgl. AMZV, Sektion IV, Karton 746, Protokoll über die Plenarsitzung des Ausschusses für Außenhandel des PSOH am 10.4.1931 mit dem Referat Fafls in der Anlage.

51 ÖStA, BAA, Gesandtschaft Prag, Zl.125/Pol., Österreichische Gesandtschaft Prag an BAA, 22.5.1931.

52 ÖStA, BAA, Gesandtschaft Prag, Zl. 90/Pol., Österreichische Gesandtschaft Prag an BAA, 15.4.1931.

53 ÖStA, BAA, Gesandtschaft Prag, Zl. 88/Pol., Österreichische Gesandtschaft Prag an BAA, 14. 4. 1931.

54 Rede Mühligs, Vollversammlung des DHI am 9.4.1932, in: MDHI 13 (1932), S. 175-181.

55 Rede Mühligs, Vollversammlung des DHI am 9. 4. 1932, in: MDHI 13 (1932), S. 175-181 - Rede Schäfers, ebenda, S. 182. 


\section{Die Politik - ein Keil zwischen den Verbänden? SHF/SdP, Hauptverband und Zentralverband (1933-1934)}

Waren die ersten Jahre nach dem Beitritt des DHI zum Zentralverband vom Gleichklang des politischen Aktivismus und der Kooperation der Wirtschaftsverbände geprägt, so schuf der Aufstieg des Nationalsozialismus in der Gestalt zunächst der DNSAP, dann der Sudetendeutschen Heimatfront (SHF) und ihrer Nachfolgeorganisation, der Sudetendeutschen Partei (SdP), eine prinzipiell neue Situation. Ob die Henlein-Bewegung schon in ihren Anfängen als nationalsozialistisch zu bezeichnen sei, ist in der Forschung kontrovers; sicherlich war die Ideologie der SHF/SdP in manchen Punkten auf die spezifischen Bedürfnisse und Erwartungen der Deutschen im tschechoslowakischen Staat zugeschnitten. Allerdings enthielt sie von Anfang an und in zentraler Position auch die meisten wesentlichen Elemente der nationalsozialistischen Weltanschauung; die Unterschiede reduzieren sich letztlich auf Nuancen. Ebenso waren die Organisation und die politische Praxis der SHF/SdP in mancher Hinsicht zwar von der „Umwelt", der parlamentarischen Demokratie der ČSR, geprägt; auch hier aber sind die Gemeinsamkeiten mit der NSDAP mit Händen zu greifen. ${ }^{1}$

Die im Grundsatz - wenn auch nicht von Anfang an durchwegs offensichtliche - nationalitätenpolitische Intransigenz der SHF/SdP beinhaltete die Forderung an die deutschen Wirtschaftsvereinigungen der Republik, sich aus der Kooperation mit ihren tschechischen Partnern zu lösen und sich unter dem Primat der Partei in eine „sudetendeutsche Volksgemeinschaft“ „einzuordnen“. In der Konsequenz dieser Umorientierung wäre eine von der tschechischen Wirtschaft mehr oder weniger separierte, auf das Reich orientierte Volkswirtschaft gelegen. Der Hauptverband hätte in diesem Fall seine mit dem Zentralverband geteilten gemäßigt liberalen Auffassungen zugunsten des von Grund auf illiberalen nationalsozialistischen Ordnungsmodells aufgeben müssen. Diese Formierung der Wirtschaft fand in den folgenden Jahren tatsächlich, wenn auch langsam, statt. Selbst als im Vorfeld von „München“ unter den länger werdenden


de rapide Fortschritte machte und auch der Druck auf die Wirtschaft wuchs, vollzog der Hauptverband die zugemutete Umorientierung vergleichsweise zögerlich und halbherzig.

Anfang der dreißiger Jahre machte sich der Nationalsozialismus in der Innenpolitik der ČSR gebieterisch geltend. Im April 1932 leiteten auf der Grundlage des Republikschutzgesetzes die Behörden wegen der Bedrohung der Selbständigkeit und Einheit des Staates und der demokratisch-republikanischen Staatsform in drei Fällen Verfahren ein, in denen die Verbindungen verschwörerischer Zirkel zu reichsdeutschen nationalistischen Verbänden verhandelt wurden. ${ }^{2}$ Die tschechische Presse begrüßte die harten Urteile gegen die Angehörigen der nationalsozialistischen Volkssport-Vereinigung im Herbst des Jahres; allerdings setzten diese Verfahren im aktivistischen Lager eine Debatte über die Berechtigung der Regierungsbeteiligung in Gang. Außerdem zog der Staat sich durch diese politischen Prozesse unter der jungen Generation der Deutschen

1 Vgl. zur ausführlichen Begründung dieser Position und zur Kontroverse Boyer/Kučera.

2 Der Gesandte in Prag an AA, 13.4. 1932, in: ADAP, Serie B, Band 20, Dokument Nr. 48, S. 112114. 
eine Irredenta heran und machte es den Aktivisten zunehmend schwer, sich gegen nationalistische Schreihälse zu behaupten. ${ }^{3}$ Erschütterten die „Volkssportprozesse" auch das Vertrauen in den Einfluß der Deutschen in der Regierung grundstürzend, so zogen die aktivistischen Parteien doch den Verbleib dort, wo sie Zugeständnisse für ihre Klientel durchsetzen konnten, einem Ausscheiden vor. ${ }^{4}$ Die im Anschluß an den Volkssportund den Jungsturmprozeß gegen die DNSAP-Abgeordneten Krebs, Jung, Schubert, Knirsch und Kaspar erhobene Anklage, die diese mit mehr oder weniger ernst genommenen Loyalitätskundgebungen zum Staat und Absagen an ein „Drittes Reich“ abzubiegen suchten ${ }^{5}$, machte die Polarisierung des deutschen Milieus ein weiteres Mal offenkundig. Die Stimmenthaltung der deutschen Sozialdemokraten und des Bundes der Landwirte in der Frage der Aufhebung der Immunität dieser Abgeordneten lieferte der deutschen Opposition einen willkommenen Arlaß für Polemik. Zusätzlich nahm nun der Dissens innerhalb des aktivistischen Lagers zu. ${ }^{6}$

Im Banne der Machtergreifung Hitlers war im Frühjahr 1933 in den deutsch besiedelten Gebieten der Republik ein Radikalisierungsschub unverkennbar. Im Grenzgebiet nehme, so das Brünner deutsche Konsulat, „die jüngere Bevölkerung an der nationalen Bewegung in Deutschland außerordentlich starken Anteil“ und verleihe „ihrer Sympathie für die nationalsozialistische Partei und ihrer (!) Führer lebhaften Ausdruck "7 - eine Psychose, die die Gestaltungskraft des Aktivismus zu unterhöhlen drohte. ${ }^{8}$ Daß nach reichsdeutschem Vorbild nun die Idee der Volksgemeinschaft an Boden gewann, zeigte sich am 19. März 1933 anläßlich der Gründung eines „Deutschen Volksrates“ in Reichenberg und der hierbei spürbaren Tendenz zum Ausbau dieses Gremiums zu einer überparteilichen Instanz. ${ }^{9}$ Als Reaktion auf den Vormarsch der DNSAP bei den Gemeindewahlen im Frühjahr stellten die Nationaldemokraten einen Antrag auf Auflösung der Partei und auf die Verlegung von Staatspolizei in alle wichtigen Städte; die Verbote reichsdeutscher Presseimporte nahmen zu. ${ }^{10}$

Mit der Auflösung der DNSAP und dem Verbot der nationalsozialistischen Gewerkschaften zerklüftete sich die deutsche politische Landschaft endgültig in die Aktivisten

3 Der Gesandte in Prag an AA, 25. 9. 1932, in: ADAP, Serie B, Band 21, Dokument Nr. 76, S. 159161. - ÖStA, BAA, Gesandtschaft Prag, Zl. 107/Pol., Österreichische Gesandtschaft Prag an BAA, 7.10.1932.

4 ÖStA, BAA, Gesandtschaft Prag, Zl. 139/Pol., Österreichische Gesandtschaft Prag an BAA, 6.12.1932, auf der Grundlage einer vertraulichen Information aus deutsch-christlichsozialen Kreisen.

5 Jungs Verlautbarung im Budgetausschuß, die DNSAP strebe nur nationale Autonomie, aber kein „Drittes Reich“ an, beurteilte die tschechische Presse als „unwürdigen Schwächeanfall“. Krebs' Versicherung, man betreibe keine Irredenta, sondern kämpfe, auf dem Boden des Staates stehend, lediglich um Selbstverwaltung, nahm die tschechische Offentlichkeit "nicht ohne Ironie“ auf: Vgl. PA, R 73 924, Gesandtschaft Prag an AA, 11.1. und 18.1.1933.

6 ÖStA, BAA, Gesandtschaft Prag, Zl. 44/Pol., Österreichische Gesandtschaft Prag an BAA, 17.3. 1933.

7 PA, R 73 894, Deutsches Konsulat Brünn an AA, 29. 5. 1933.

8 ÖStA, BAA, Gesandtschaft Prag, Zl. 200/Pol., Österreichische Gesandtschaft Prag an BAA, 28. 9. 1933.

9 ÖStA, BAA, Gesandtschaft Prag, Zl. 49/Pol., Österreichische Gesandtschaft Prag an BAA, 24.3. 1933.

10 PA, R 73 894, Gesandtschaft Prag an AA, 11.5. 1933. - Es gab auch Pläne, die „Bohemia“ und andere deutsche Blätter im Land einzustellen: Vgl. OOStA, BAA, Gesandtschaft Prag, Zl. 200/Pol., Österreichische Gesandtschaft Prag an BAA, 28.9.1933. 
in der Regierung (Bund der Landwirte und Sozialdemokraten) bzw. in der Opposition (Christlich-Soziale, Gewerbepartei und DAWG) und die amorphe Anhängerschaft der verbotenen Organisationen. ${ }^{11}$ Die massenhafte Beteiligung der deutschen Bevölkerung an den Feierlichkeiten zum Staatsgründungstag am 28. Oktober mochte auch mit der demonstrativen Zurschaustellung der Staatsmacht zu tun haben, erfolgte zu einem guten Teil aber auch aus der Erkenntnis heraus, daß die chauvinistische Überhitzung und die Vertiefung der Kluft zu den Tschechen den eigenen Interessen nicht förderlich war. ${ }^{12}$

Die im Herbst 1933 gegründete Sudetendeutsche Heimatfront begriff sich, wie die ersten Verlautbarungen und der Auftritt ihres Führers Konrad Henlein vor der Presse am 8. Oktober 1933 dartaten, nicht lediglich als Nachfolgeformation der aufgelösten DNSAP, sondern als „Bewegung“, mit dem Anspruch, den Willen der Deutschen im Lande zu formieren und allen „Parteienzwist“ zu überwinden. Der Weg von der „Parteipolitik“ zur „Volkspolitik“ beinhaltete keine Absage an jedwede Organisation - auch der Wille des Volkes mußte schließlich artikuliert werden. Die aus dem Spannschen Gedankengut übernommenen Idee der "ständischen Durchgliederung“ des "Volkskörpers" implizierte jedoch die unbedingte Absage an den Klassenkampf; sie beinhaltete den Anspruch auf Transzendierung ständischer Sonderinteressen im Monolithen der „Volksgemeinschaft" unter Leitung der Heimatfront.

$\mathrm{Da}$ in dieser Perspektive weniger die Weltwirtschaftskrise für die wirtschaftliche Misere der deutschen Volksgruppe verantwortlich war als vielmehr der Umstand, daß die Deutschen im Lande „einen regellosen Haufen" sich bekämpfender Interessengruppen darstellten, mußte die Krise durch die Integration der großen "Wirtschaftsglieder" in den "Volkskörper" behoben werden. Alle deutschen Arbeiter, Angestellten und Unternehmer waren zu erfassen und in einem gestrafften Wirtschaftsverbandswesen aus einem Guß zu gliedern, das eine „rein sachliche Führung und Betreuung“ unter Ausschaltung aller „kleinliche(n) Gruppeninteressen“ ermöglichte. Die „Wirtschaftsstände“ sollten zwar als separate Gebilde weiterhin in eigener Regie ihre Führung bestimmen, ihre Vertreter bildeten aber den wirtschaftlichen Führungskörper, das oberste Beratungsorgan der politischen Führung in Gestalt der SHF. ${ }^{13}$ Die etwa bei Walter Brand unüberhörbar an nationalsozialistische Vorbilder anklingende Gemeinnutz-Rhetorik ${ }^{14}$ erteilte dem „atomistischen Liberalismus" und „Individualismus“ eine schroffe Absage.

11 BArch-K, R 43/I-153, Gesandtschaft Prag an AA, 30. 11. 1933. - Der Gesandte in Prag, Koch, an AA, 10. 10. 1933, in: ADAP, Serie C, Band I/2, Dokument Nr. 488, S. 889 f.

12 Sogar national eingestellte Deutsche, so der österreichische Gesandte Marek, von dem diese Interpretation stammt, seien deshalb auf den Nationalsozialismus nicht so gut zu sprechen gewesen: Vgl. ÖStA, BAA, Gesandtschaft Prag, Zl. 234/Pol., Österreichische Gesandtschaft Prag an BAA, 3.11.1933.

13 Rede Henleins vor den Vertretern der Presse am 8. 10.1933 in Prag, in: Jahn (Hrsg.), Henlein spricht, S. 11-17. - „Was wir sind und was wir wollen“. Ein Rundbrief an die Mitarbeiter aus den Gründungstagen der Bewegung, in: Ebenda, S. 20. - O.V., Wesen und Werden, S. $28 \mathrm{ff}$. SÚA, SdP, Karton 68, Memorandum Henleins für Spina vom 14.10.1933. - SÚA, SdP, K3KH, 1933-1938. SDH-Schulungspapier "Sudetendeutsche Politik - Lage und Folgerungen“, undatiert (vermutlich 1933).

14 Die geistige Abhängigkeit der SHF, insbesondere Brands, vom reichsdeutschen Nationalsozialismus gerade hinsichtlich der Übernahme der Idee der "Totalität“ bzw. der „Volksgemeinschaft" betont Chmelár, Deutsches Problem, S. $61 \mathrm{ff}$. Die bei Brand noch vergleichsweise behutsam formulierten Inhalte nahmen laut Chmelár̆ in der „Kleinarbeit der Unterführer" und der bezahlten Agitatoren noch weit schärfere Formen an. 
Ihr Leitbild war die „dem Menschen dienende“, im Rahmen der berufsständischen Selbstverwaltung durch fachmännische Hand "geplante" Wirtschaft. Ein national sektioniertes, gegen Parteipolitik immunisiertes „wirtschaftliches Ständehaus“ neben dem Parlament realisierte das Gemeinwohl. Privateigentum war ,ideelles Lehen des ganzen Volkes". ${ }^{15}$

Die SHF betonte die kulturelle Verbundenheit mit den Deutschen jenseits der Grenze, bekundete aus taktischen Gründen jedoch, "grundsätzlich und eindeutig“ auf dem Boden des demokratischen Staates zu stehen; sie bejahte die "positive Mitarbeit“ in diesem, ja sogar die Regierungsbeteiligung als Garantie der Gleichberechtigung und einzig möglichen Rahmen einer Selbstverwaltung. ${ }^{16}$ Der Anspruch auf „Erneuerung des organischen Gehalts" der Demokratie und auf eine Ersetzung der Vollstrecker des anonymen Parteiwillens durch die "verantwortlich handelnde Persönlichkeit" verklausulierte allerdings nur notdürftig das Führerprinzip. ${ }^{17}$ Aus diesem Grund hinterließ die SHF auch allenthalben einen zwiespältigen Eindruck. Im September 1934 bekundete Spina für den Bund der Landwirte, man werde einer Auflösung der Partei nichts in den Weg setzen, da Henlein sein Versprechen, „Hakenkreuzler“ nicht als (Unter-)führer in die Partei aufzunehmen, gebrochen habe. ${ }^{18}$ Henlein lasse eine eindeutige Absage an Hitler vermissen und führe Agitationsmethoden ein, „die von drüben kommen“. Der Parteiführer, persönlich von guten Absichten, aber „ein kindischer Phantast“, sei nicht fähig „den Besen zu nehmen und alles hinauszuwerfen, was sich an Führern und Unterführern in seine Organisation eingeschlichen hat". Die SHF sei eine "amorphe Masse“, von der man die Hälfte über Bord werfen, die bessere Hälfte zu „konstruktiver Mitarbeit" erziehen müsse.

Dieser Auffassung, anstelle einer Auflösung der SHF sollte den in der Partei vorhandenen gutwilligen Elementen Auftrieb verliehen werden ${ }^{19}$, leistete Henlein am 21. Oktober 1934 mit der abwiegelnden Erklärung von Böhmisch-Leipa ${ }^{20}$ geschickt Vorschub. Erinnerten das Massenaufgebot und die Disziplin der Teilnehmer zwar eher an Veranstaltungen der NSDAP als an Parteitage der „alten“ deutschen Parteien, so lagen auf der anderen Waagschale Henleins Genugtuung über Hitlers Erklärung vom 17. Mai, mit allen Nachbarn in Frieden leben zu wollen, und sein Bekenntnis zu einer mitteleuropäischen Ordnung, welche in Rechnung stellte, daß die Siedlungsgebiete im Herzen des Kontinents nicht zu entwirren und reine Nationalstaaten deshalb nicht möglich seien. Henlein erteilte zwar wieder jeglicher Parteipolitik zugunsten der Volksgemeinschaft eine Absage; seine Rede enthielt aber auch, $\mathrm{da}$ "Volkstreue“ "Staatstreue" nicht ausschließe, ein Bekenntnis zur Mitarbeit im Staat. Henlein distanzierte sich von Faschis-

15 Brand, Grundlagen, S. $17 \mathrm{ff}$. - Die polemische Absage dieser "nationalen und sozialen Partei“ an den Klassenkampf und an das „Freibeutertum des Kapitalismus“ illustriert etwa auch die Rede Karl Hermann Franks in der Sitzung des Abgeordnetenhauses am 19.6. 1935: Vgl. SdP im Parlament. Ein Jahresbericht 1935/36, S. 39.

16 Brand, Grundlagen, S. 42 f. - SÚA, SdP, Karton 68, Memorandum Henleins für Spina vom 14. 10. 1933.

17 Rede Henleins vor den Vertretern der Presse am 8. 10.1933 in Prag, in: Jahn (Hrsg.), Henlein spricht, S. 11-17. - O.V., Wesen und Werden, S. $28 \mathrm{ff}$.

18 AMZV, Sektion III, Karton 655, Mappe 10, Aufzeichnung über eine Information des deutschen sozialdemokratischen Abgeordneten Taub vom 27. 9.1934.

19 So exemplarisch etwa HP, 13. 10.1934, S. 771.

20 Vgl. den Text der Rede in: Jahn (Hrsg.), Henlein spricht, S. 22-41. 
mus und vom Nationalsozialismus; zwar verwarf er den "Liberalismus“, bekundete aber unter der Parole der „Liberalität" Achtung vor den Rechten des Individuums, vor der Meinungs- und vor der Koalitionsfreiheit. Zutreffend kommentierte die deutsche Gesandtschaft diesen rhetorischen Spagat unter dem Damoklesschwert des Parteienverbots als Verzicht auf großdeutsche Allüren „im großen und ganzen“, billigte im gleichen Atemzug jedoch der in der tschechischen Presse von ganz rechts bis ganz links argwöhnisch gestellten Frage, inwieweit Henleins Publikum nicht eine reservatio mentalis gehegt habe, einige Berechtigung zu. ${ }^{21}$

Für die Auffassung, zwischen SHF und NSDAP bestünden Verbindungen, wenn diese unter den obwaltenden Umständen auch nicht zugegeben werden dürften ${ }^{22}$, sprach nicht zuletzt die Finanzierung der Partei durch reichsdeutsche Gelder, die ihr auf verschlungenen Wegen über die größte deutsche Bank in der Republik, die Kreditanstalt der Deutschen (KdD), zuflossen. ${ }^{23}$ Auffällig war, daß die SHF den angesichts des großen Propagandaaufwands aufgeworfenen Fragen nach der Herkunft ihrer Mittel auswich. Die Leipaer Kundgebung hatte der örtliche Filialleiter der Kreditanstalt organisiert; der SHF-Hauptgeschäftsführung in Eger stand der ehemalige KdD-Beamte Fritz Köllner vor. Die KdD war auch in Manipulationen zum Schaden der Gegner der SHF verwickelt: So hatte sie der Deutschen Landbank in Tetschen, die dem Bund der Landwirte nahestand, Darlehen gekündigt und dadurch ein Moratorium dieses Geldinstituts provoziert.

Der zumindest kryptonazistische Charakter der Partei, insbesondere aber die Vision der „Volksgemeinschaft“, beinhalteten in der Konsequenz auch die Absage an eine $\mathrm{Zu}$ sammenarbeit von Deutschen und Tschechen in der Wirtschaft. Die von der SHF proklamierte „Verständigung von Volk zu Volk“ sei, so Spina, „eine flache Redensart“, denn faktisch hätten sich über die Nationalitätengrenzen hinweg allenthalben Brücken gebildet - allerdings zwischen Parteien und Interessengruppen identischer Ausrichtung: Der Bund der Landwirte kooperiere mit der tschechischen Agrarpartei, die deutschen Sozialdemokraten kooperierten mit den tschechischen; Kontakte bestünden zwischen den beiden Gewerbeparteien, und auch die Industrie habe "Kollaborationsbrücken" aufgebaut. ${ }^{24}$

Ungeachtet der Anmutungen der SHF bestanden in der Wirtschaft diese Brücken weiter: Im Januar 1934 konstatierte Mühlig mit Genugtuung, es sei ihm gelungen, Preiss „von der Ehrlichkeit meiner Bemühungen, mit vereinten Kräften unserer Wirtschaft

21 PA, R 73 841, Gesandtschaft Prag an AA, 22. 10. 1934.

22 Der Bericht zitiert die Bemerkung eines Mitarbeiters der Prager deutschen Botschaft, eines in der Wolle gefärbten Nationalsozialisten: Die "Kameradschaftsbündler“ in der SHF wie Heinrich, Hönig und Brand seien zwar keine Nazis; der NSDAP könne dies aber gleichgültig sein, „weil das 'Fußvolk' richtig eingestellt sei“'. Vgl. ÖStA, BAA, Zl. 676/Pol., Österreichische Gesandtschaft Prag an BAA, 8.11.1934.

231925 war die Bank durch einen Hundert-Millionen-Kronen-Kredit des Allgemeinen Deutschen Genossenschaftsverbands saniert worden. Der Verband überwachte seitdem das Finanzgebaren der Kreditanstalt, die Direktoren Kiesewetter und Baumann waren ihm gegenüber weisungsgebunden: Vgl. hierzu und zum folgenden: AMZV, Sektion III, Karton 655, Mappe 10, Stellungnahme des Sekretärs Graf (BdL) vom 3.11.1934. - PP vom 22.11.1934.

24 AMZV, Sektion III, Karton 655, Mappe 10, Aufzeichnung über eine Information Spinas vom 29. 9. 1934. 
und damit unserem Staate zu nützen, zu überzeugen ". ${ }^{25}$ Auf einer gemeinsamen Vollversammmlung des Hauptverbands und des Slowakischen Industriellenverbandes im März 1934 in Preßburg hob der Präsident des DHI das konzertierte Vorgehen in Fragen der Sozialgesetzgebung hervor ${ }^{26}$ und zeigte sich Ende Juli vom Ergebnis der Besprechung mit Preiss über Organisationsfragen unbedingt zufrieden. ${ }^{27}$ Jenseits solcher Details erwies sich der Gleichklang in zentralen ordnungspolitischen Fragen, deren Erörterung durch die Wirtschaftskrise angefacht und nun außerdem vom nationalsozialistischen Vorbild autoritärer Wirtschaftsreglementierung angeschoben wurde. Auch in der Tschechoslowakei schob sich nun die Auffassung in den Vordergrund, der Parlamentarismus habe sich überlebt. Angesichts der lauter werdenden Rufe nach einer „Regierung der starken Hand“, welche allein zu einer Belebung der Wirtschaft imstande sei $^{28}$, proklamierte Hodáč im Juni 1933 auf der Vollversammlung des Zentralverbands die Verteidigung des freien Unternehmertums und die Abwehr aller über die Setzung von Rahmenbedingungen - wie sie etwa der Zolltarif darstellte - hinausgehenden Eingriffe des Staates als Linie der Industrie. Den erzwungenen Interessenausgleich durch einen Korporatismus nach italienischem Vorbild lehnte der Generalsekretär zwar nicht ausdrücklich ab, er gab jedoch der Hoffnung Ausdruck, in der Tschechoslowakei würden sich solche autoritäre Methoden erübrigen ${ }^{29}$ - eine Position, die sich vermutlich weniger auf einen standfesten Liberalismus ${ }^{30}$ gründete als auf die Befürchtung, angesichts der Präponderanz agrarischer und sozialistischer Einflüsse in der Regierung werde ein Anwachsen des Staatsinterventionismus zu Lasten der industriellen Interessen gehen. Ende 1933 konstatierte der „Observer", Sprachrohr des Zentralverbands, mit einiger Erleichterung, abgesehen vom ordnungspolitischen Sündenfall des Viehsyndikats sei es im wesentlichen gelungen, die "gelenkte Wirtschaft ${ }^{\alpha}$ abzuwenden; bei den in diesem $\mathrm{Zu}$ sammenhang aufgelisteten, von der Industrie vereitelten Eingriffen handelte es sich, neben Beschränkungen des Außenhandels, durchwegs um solche im Interesse der Linken bzw. der Agrarier. ${ }^{31}$

Die gleiche antiinterventionistische Abwehrhaltung leitete die Industrie in der Kartellfrage. Die Notwendigkeit, die Errichtung von Kartellen - „Kinder der Not“ - gesetzlich zu regeln, wurde nicht von ungefähr gerade in der Krise unabweisbar. Hatte

25 ANB, ŽB, S VII/i-1-I, 576, Mühlig an Preiss, 22. 1. 1934.

26 ANB, ŽB, S VII/i-1-I, 563, Mitteilung Mixa an Preiss, 26.3.1934.

27 ANB, ŽB, S VII/i-1-I, 989, Preiss an Tille, 26.7.1934.

28 Vgl. etwa HP 8 (1934), S. 73.

29 Rede Hodáčs, Vollversammlung des Zentralverbands am 28. 6. 1933, in: OB 15 (1933), S. 201 f. Vgl. auch HR vom 3.7.1933.

30 Von neuerlichen ständischen Anwandlungen zeugt, daß auf seiner Weihnachtsansprache 1933 Preiss und zu dieser Zeit außerdem der Pilsener Kammerpräsident Weissberger sowie der Prager Kammerpräsident Třebický wieder einmal die Forderung nach einem „echten“ Wirtschaftsparlament an Stelle des Senats artikulierten: Vgl. HR vom 5.4.1934.

31 Vorgelegt worden waren auf der Grundlage des Ermächtigungsgesetzes in den letzten Monaten des Jahres 1933 u. a. Pläne zu einer Reglementierung des Holzhandels bzw. der Holzproduktion und des Milchhandels, außerdem das Projekt eines Getreidemonopols. Auf der anderen Seite beinhaltete die "unheilige Allianz" von Agrariern und Linken die Allgemeinverbindlichkeit der Kollektivverträge, die Verpflichtung, jede Produktionsbeschränkung dem Ministerium für soziale Fürsorge zu melden, sofern mehr als ein Viertel der Arbeiter dadurch von Entlassung bedroht war, sowie das Recht des Staates, ein wegen Beschäftigungsmangel eingestelltes Unternehmen durch einen Treuhänder zu leiten: Vgl. OB 16 (1934), S. 1 f. 
der Hauptverband schon 1932 eine grundsätzlich positive Einstellung zur Regulierung von „ruinösem Wettbewerb“, zur Verstetigung von Produktion und Preisbildung und zur Gewährleistung angemessener Gewinne bekundet und nach einem Kartellgesetz gerufen $^{32}$, so wollte er doch alle Initiativen zu einer solchen "gesunden Planwirtschaft" Absprachen der Industrie vorbehalten wissen; ein staatliches Oktroi nach dem Vorbild des reichsdeutschen Zwangskartellgesetzes lehnte er ab. ${ }^{33}$ Der Zentralverband zögerte zwar mit seiner Stellungnahme zu der im April 1934 im Entwurf vorliegenden Kartellverordnung und wollte angesichts divergierender Brancheninteressen die Grundsatzpositionen erst auf einer eigens anberaumten Sitzung des erweiterten Präsidiums geklärt sehen; ungeachtet solcher interner Divergenzen im Detail galt aber auch hier der Passus über die staatliche Kompetenz zur Zwangskartellierung als unannehmbar. ${ }^{34}$

Loyalität bewies der Zentralverband im „Testfall Hodáčc, als dessen Aktivitäten das Einvernehmen mit dem Hauptverband zu beeinträchtigen drohten. Daß der Generalsekretär seit den Vorkriegsjahren eng mit Preiss zusammengearbeitet hatte und diesem auch persönlich nahestand, fiel nicht ins Gewicht. ${ }^{35}$ Hodáčs Stellung geriet 1933 im Zentralverband zunehmend ins Wanken. Dem Vorwurf der Überlastung und der Zersplitterung seiner Arbeitskraft zwischen dem nationaldemokratischen Abgeordnetenmandat und dem Amt des Generalsekretärs leistete das Ausbleiben greifbarer Erfolge beim Ausgleich von Konflikten Vorschub. ${ }^{36}$ Das Fortbestehen des Interessengegensatzes von Industrie und Landwirtschaft wurde ihm nun als persönliches Versagen angerechnet. Daß Hodáč das Sekretariat des Zentralverbands für Parteiaufgaben einsetzte, heizte vor alle im Hauptverband die Stimmung gegen ihn nicht wenig an. Taktisch geschickt zog er sich angesichts dieser Situation im März 1933 auf den weniger exponierten, trotzdem einflußreichen Posten eines Vizepräsidenten des Zentralverbands zurück. ${ }^{37}$

Endgültig von allen Ämtern entbunden wurde Hodáč erst $1935^{38}$, nachdem er durch seine Beteiligung an den Prager Universitätskrawallen den deutschen Mitgliedern gegenüber in eine unhaltbare Lage geraten war. ${ }^{39}$ Die Aufforderung des Schulministeri-

32 Rede Mühligs, Vollversammlung des DHI am 9. 4. 1932, in: MDHI 13 (1932), S. 175-181. - Mühlig, Zu dem „Notplane“.

33 Rede Mühligs, Vollversammlung des DHI am 8.4.1933, in: MDHI 14 (1933), S. 169-176.

34 ANB, ŽB, S VII/i-1-I, 563, Mixa an Preiss, 11.4. 1934. - Aktennotiz Preiss vom 17. 4. 1934 über ein Gespräch mit Beran, von Preiss an Mixa übersandt am 17.4.1934.

35 WI 15 (1933), S. 283.

36 Etwa zwischen Textil und Chemie, zwischen Räucherern und Viehimporteuren, Maschinenbauern und Eisenproduzenten.

37 WI 15 (1933), S. 283. - HR vom 23. 2. 1933. - HA 12 (1933), S. 106f. - Indiz für Hodáčs weiterhin starke Stellung in der Politik war, daß er - allerdings unbestätigten Informationen zufolge Anfang April 1933 im Rahmen einer geplanten Kabinettsrekonstruktion anstelle des bisherigen nationaldemokratischen Handelsministers Matoušek in die Regierung eintreten sollte. Hodáč, als Handelspolitiker eine Autorität, wäre auch der Burg genehm gewesen, die damals, nicht zuletzt im Hinblick auf die Gerüchte um ein Ermächtigungsgesetz, eine Regierung der starken politischen Persönlichkeiten anstrebte. Die in Aussicht genommenen Änderungen wären auch im Sinne des von Beneš geplanten politischen und wirtschaftlichen Abwehrkampfes gegen den $\mathrm{Na}$ tionalsozialismus gewesen: Vgl. ÖStA, BAA, Gesandtschaft Prag, Zl. 58/Pol., Österreichische Gesandtschaft Prag an BAA, 1.4.1933.

38 Vollversammlung des Zentralverbands am 25.6.1935, in: OB 17 (1935), S. 153.

39 WR 8 (1935), S. 811. 
ums an die Prager deutsche Universität, ihre Insignien der tschechischen Universität auszuliefern, hatte den Widerstand der Studenten, der deutschen Presse und der deutschen Politik provoziert; dieser wiederum wurde zum Anlaß antideutscher Ausschreitungen, an deren Spitze sich die tschechischnationale Opposition setzte, zu der die $\mathrm{Na}$ tionaldemokraten nach ihrem Ausscheiden aus der Regierung gehörten. Hodáč selbst führte „einen Trupp johlender junger Leute an", der die Parolen „Deutsche hinaus" und, im gleichen Atemzug, "Juden hinaus" - skandierte. ${ }^{40}$ Die Affäre hatte ein parlamentarisches Nachspiel, in dessen Verlauf Rosche unter Zustimmung aller tschechischer Koalitionsparteien scharfe Angriffe gegen Hodáč vortrug, der gegen die Deutschen auftrete, gleichzeitig aber vom Zentralverband ein zum Großteil aus den Beiträgen der deutschen Industrie finanziertes Gehalt beziehe. Nur die „Národní listy“ und faschistische Blätter nahmen Hodáč halbherzig in Schutz, während die "Lidové Noviny" mit Genugtuung notierte, „der vermeintliche Generalissismus der tschechischen und deutschen Industrie“ sei nun "unter dem Beifall des gesamten Parlaments mit einem Schlage aus dem politischen Leben ausgereiht" worden. ${ }^{41}$

Hodáčs Nachfolger als Generalsekretär, Mixa, war von 1919 bis 1922 im Eisenbahnministerium und dann als - bemerkenswert erfolgreicher - Tarifexperte des Zentralverbands tätig gewesen. Er wurde von einem großen Teil der Industrie nicht zuletzt deshalb begrüßt, weil ihm keine irgendwie spürbare Affinität zu einer Partei nachgesagt werden konnte. ${ }^{42}$ In kurzer Zeit gelang es ihm, den durch Hodáč ramponierten Ruf des Verbands wiederherzustellen, die Geschäftsführung zu entpolitisieren und die Organisation wieder zu einem schlagkräftigen Instrument industrieller Interessenpolitik zu machen. ${ }^{43}$ 1937 wechselte Mixa vom Zentralverband auf einen Direktorenposten in der Živnostenská banka. ${ }^{44}$ Sein Nachfolger František Benda, der im Handelsministerium sechzehn Jahre lang als Sektionschef für Industrieangelegenheiten amtiert hatte, galt als weiterer Garant gegen einen Rückfall in die Politisierung. ${ }^{45}$

Die in diesem Kapitel abgehandelten Entwicklungen bestätigen die Eingangsbehauptung, daß der Aufstieg der SHF/SdP für die Wirtschaft eine vorerst lediglich im Prinzip neue Situation schuf; die Beziehungen zum Zentralverband blieben unberührt.

40 ÖStA, BAA, Gesandtschaft Prag, Zl. 711/Pol., Österreichische Gesandtschaft Prag an BAA, 1.12. 1934 .

41. Als Hodáč sich in der Nationalversammlung zu rechtfertigen versuchte, wurde er niedergeschrien, „sodass ihm nichts anderes übrig blieb (!), als seine Verteidigungsrede dem Stenographen ins Ohr zu diktieren“. Vgl. zu dem ganzen Vorgang ÖStA, BAA, Gesandtschaft Prag, Zl. 714/Pol., Österreichische Gesandtschaft Prag an BAA, 6.12.1934.

42 WI 15 (1933), S. 283.

43 HA 16 (1937), S. 191. - BÖ vom 25. 3. 1937.

44 HA 16 (1937), S. 191.

45 HA 16 (1937), S. 191. - BÖ vom 25. 3. 1937, S. 7. - HR vom 25.3.1937. 


\section{Die Politik - kein Keil zwischen den Verbänden: SdP, Hauptverband und Zentralverband (1935-1937)}

Die Parlamentswahlen vom Mai 1935 waren die Peripetie der SHF. Die Agitation der Partei, die sich kurz vor dem Urnengang in Sudetendeutsche Partei (SdP) umbenannte $^{1}$, legte einen ohnehin nur mehr notdürftig verhüllten Irredentismus bloß. Die Wahlen wurden allgemein als Plebiszit für Deutschland verstanden; die SHF/SdP als „das Sammelbecken und die meßbare Größe des Irredentismus" reduzierte ihre Loyalitätsbekundungen auf das Allernotwendigste und offerierte bereits eine das Deutsche Reich ins Kalkül einbeziehende Lösung der innenpolitischen Probleme. Die deutschen Sozialdemokraten und der Bund der Landwirte erwiesen sich als hilflos angesichts der Erosion des Aktivismus; es gelang ihnen auch nicht, klarzumachen, daß eine Grundsatzentscheidung der deutschen Politik anstand, welche die Unterstützung der Aktivisten durch die Regierung unabdingbar machte. ${ }^{2}$

Näherte sich im Vorfeld der Wahlen die SdP zum ersten Mal Persönlichkeiten des deutschen Wirtschaftslebens der Republik, so resultierten daraus noch keine engeren oder gar auf Dauer verfestigten Beziehungen zum Hauptverband. An der Aussprache über aktuelle Fragen, zu der die Partei für den 16. Januar 1935 Vertreter der deutschen Wirtschaft im Land lud, waren jedenfalls nicht die Spitzen des DHI, sondern lediglich einige Männer der zweiten Garnitur und diese nicht als Repräsentanten des Verbands beteiligt. ${ }^{3}$ Einen nicht unwichtigen Erfolg hatte die Partei zu dieser Zeit allerdings bereits mit der Gewinnung Rosches verbuchen können, den zur SdP herüberzuziehen Henleins Verhandlungen zur SdP seit dem Frühjahr 1934 bezweckt hatten. ${ }^{4}$

Rosche teilte nicht die generationstypischen Erfahrungen der jungen SdP-Mitglieder; er war auch kein SHF-Mann der ersten Stunde. Waren gegen seine Aufnahme in die Partei zunächst erhebliche Widerstände zu verzeichnen gewesen, so dürften die von ihm mitgebrachten Beziehungen zur Industrie den Ausschlag zu seinen Gunsten gegeben haben. Seiner Kandidatur als Industrievertreter auf der SHF-Liste stimmten im Januar und Februar 1935 „infolge seiner durch ein Jahr bewiesenen anständigen Haltung“ jedenfalls die Hauptleitung und alle Kreisleiter „ohne weiteres" zu. ${ }^{5}$ Hatte die „Př́tomnost ${ }^{\star}$ noch Jahre später Rosches substantielle Beiträge zu ökonomischen Fragen, die ihn sogar ministrabel erscheinen hatten lassen, in bester Erinnerung, so registrierte sie um so befremdeter nach dem Schwenk seine bei jeder sich bietenden Gelegenheit abgegebenen

1 Der Anlaß war, daß neuerlichen Verbotsbestrebungen durch die Tilgung des - im Kontext der parlamentarischen Demokratie nicht sonderlich gut klingenden - Begriffs „Front" der Wind aus den Segeln genommen werden sollte.

2 AMZV, Sektion III, Karton 655, Mappe 10, Aufzeichnung über eine Information Spinas vom 31. 1. 1935. - Aufzeichnung über eine Information Taubs vom 14.3.1935.

${ }^{3}$ Auf der Einladungsliste standen Wilhelm Sebekovsky, Enhuber, Max Hibsch (Aussig), Singer (Asch), Spittaler (Reichenberg), Hans Wolf (Eger) und, als Vertreter der Kreditanstalt der Deutschen, deren Direktor Kiesewetter: Vgl. SÚA, SdP, Karton 31, 18 AA/Wa 35-37/2, SHF/Hauptstelle Eger, Wirtschaftsamt an Sebekovsky u.a., 16.1.1935.

${ }^{4}$ Kundt prognostizierte in einem ausführlichen Schreiben über diese Verhandlungen an Henlein, die DAWG werde nach dem Ausscheiden Rosches ohnehin zusammenbrechen: Vgl. SÚA, SdP, Karton 21, Kundt an Henlein, 19.5.1934.

5 SÚA, SdP, Karton 7, 2 K-KH (1934-37)7, Hauptleitungssitzung der SdP am 28. 1. 1935. - Hauptratstagung der $\mathrm{SdP}$ am 10.2.1935. 
Bekenntnisse zu Hitler und gegen die Tschechen, hinter denen das Blatt nur das Motiv vermuten konnte, Rosche suche durch Verbalradikalismus seine Außenseiterposition zu überspielen. ${ }^{6}$ Zur Rosche-Gruppe gehörten mit dem Generaldirektor von Mannesmann-Komotau, Doderer, und mit Mühlig bereits einige wichtige Meinungsführer. Schicht, Kislinger und der DAWG-Mann Kostka hingegen wurden im April vom Bund der Landwirte für seine Kandidatenliste umworben.?

Obwohl die Partei also bereits Fühler zur Industrie ausstreckte, schossen in erster Linie die Fäden zwischen ihr und dem Lager der tschechischen Agrarier hin und her. Stoupal, der Führer des rechten Flügels dieser Partei, suchte die SHF in der ersten Märzhälfte als Gegenleistung für ihre Zulassung zu den Wahlen zur Kooperation zu verpflichten. ${ }^{8}$ In der im Frühjahr verhandelten Frage des Parteienverbots schwang sich die Agrarpartei zum Protektor der SHF auf. ${ }^{9}$ Hintergrund war die deutschlandfreundliche Linie der tschechischen Agrarier: Über den deutschen Gesandten Koch ließ man den Wunsch nach einem Informationsbesuch im Reich und nach Kontakten zum Reichsnährstand durchblicken. ${ }^{10}$ Nachdem das Auswärtige Amt im März die von Reichsbauernführer Darré ausgesprochene Einladung befürwortet hatte, wurde das Unternehmen aufgrund des bereits angelaufenen Wahlkampfs in der ČSR und der Verkündung der deutschen Wehrgesetze, in deren Folge kein tschechischer Politiker einen solchen Besuch hätte wagen können, aufgeschoben. ${ }^{11}$ Unmittelbar vor den Wahlen stellte sich die Agrarpartei dann geschlossen gegen die SdP. ${ }^{12}$ Diese konterte mit dem Angebot einer Verschmelzung an die Adresse des Bundes der Landwirte. ${ }^{13}$

Die SdP suchte Bundesgenossen also vorerst nur in zweiter Linie bei der Industrie. Auch der Hauptverband hielt Abstand und ließ sich von der Welle des Irredentismus im Vorfeld der Wahlen nicht überspülen. War die Vollversammlung am 23. März auch schon äußerlich eine "gewaltige Kundgebung " 14 im Zeichen der großen Politik, so vollzog der DHI doch den „Aufbruch“ nicht mit, sondern zurrte im Gegenteil die Bande zum Zentralverband fester. Für den nordmährisch-schlesischen Industrieverband, wie der Hauptverband seit Jahren unter dem Dach des Zentralverbands, seit jeher aber auch in enger Fühlung mit dem DHI, betonte Generaldirektor Federer, ständiger Informationsaustausch zwischen den industriellen Vereinigungen sei in der Krise mehr denn je vonnöten. ${ }^{15}$ Mühlig würdigte Preiss' Anwesenheit als besonderes Ereignis für den

6 Pर̌ 15 (1938), S. 420.

7 Jedenfalls wurde hierüber verhandelt. Unerwünscht waren im BdL hingegen die ,jüdischen Demokraten“ á la Bacher: Vgl. AMZV, Sektion III, Karton 655, Mappe 10, Aufzeichnung „Graf“ aus dem BdL vom 16.4.1935.

8 PT vom 16.3.1935.

9 ÖStA, BAA, Gesandtschaft Prag, Zl. 158/Pol., Österreichische Gesandtschaft Prag an BAA, 4.4. 1935.

10 PA, R 30497 k, Gesandtschaft Prag an AA, 2.3.1935.

11 PA, R 30 497k, AA/Ritter an Winter, 12.3.1935. - Winter an Ritter, 15. 3. 1935. - Reichsbauernführer an AA/Altenburg, 18. 3. 1935, mit Abschrift der Einladung. - Gesandtschaft Prag an AA, 3.4. 1935 .

12 ÖStA, BAA, Gesandtschaft Prag, Zl. 265/Pol., Österreichische Gesandtschaft Prag an BAA, 23. 5. 1935.

13 PA, R 73 841, Gesandtschaft Prag an AA, 28. 2. 1935.

14 Der Kammerspielsaal des Teplitzer Stadttheaters war überfüllt; obwohl Stühle dazugestellt wurden, reichte der Platz nicht: Vgl. PT vom 24. 3.1935.

15 Rede Federers, Vollversammmlung des DHI am 23. 3. 1935, in: MDHI 16 (1935), S. 111. 
DHI und als „Anerkennung für dessen loyale, korrekte Gesinnung“. ${ }^{16}$ Preiss’ Ansprache, Höhepunkt der Versammlung und - so Mühlig - eine „Programmrede von besonderer Bedeutung ${ }^{\text {“ }}{ }^{7}$, legte mit der Einordnung der tschechischen nationalen Wiedergeburt und der Gründung der Republik in den Zusammenhang der Aufklärung ein Bekenntnis zur Demokratie ab. Die "nationale Komponente“, so Preiss beinahe entschuldigend, habe im wirtschaftlichen Emanzipationskampf der Tschechen eine Rolle spielen müssen. Zwar bekundete der Präsident als Pragmatiker, für den „das richtige Beurteilen der Wirklichkeit und das Aufbauen auf dieser" den Inbegriff des Politischen darstellte, „der großen Bewegung“ im Reich eingedenk zu sein; vor dieser „die Augen zu verschließen" sei schier unmöglich. Die Kooperation der Wirtschaft, Tradition seit den Zeiten der Monarchie, könne jedoch jenseits aller „Politik“ und „unbeschadet dieser Idee im Deutschen Reiche" fortgesetzt werden; die Industrie sei sogar auf die Rolle eines Vorreiters der Zusammenarbeit verpflichtet. ${ }^{18}$

Diese als persönliche Überzeugung deklarierten Überlegungen, denen „speziell in diesem Momente" Ausdruck zu geben er für richtig befunden habe ${ }^{19}$, stießen auf positive Resonanz: Es werde ihm, so Preiss' deutscher Stiefbruder Heinrich Reinl, besondere Genugtuung bereiten, daß die „so versöhnlich gehaltene Rede im deutschen Hauptverbande in Teplitz in deutschen, nationalen Kreisen den denkbar günstigsten Eindruck gemacht hat ${ }^{\prime 2}{ }^{20}$ Zustimmend war das Echo in der Presse beider nationaler und beinahe aller politischen Lager. ${ }^{21}$ Der Präsident habe, so die „Přítomnost“, als höflicher Mann deutsch gesprochen, ohne auf tschechischer Seite hierfür getadelt zu werden - ein Fortschritt, wenn man bedenke, daß vordem ein von Masaryk dem "Prager Tagblatt“ in deutscher Sprache gewährtes Interview in der Redaktion der „Národní listy“ geradezu epileptische Anfälle hervorgerufen habe und man sich wundern müsse, daß das Blatt den Präsidenten aufgrund dieser "landesverräterischen Ausführungen“ nicht aus dem Volk ausgeschlossen habe. ${ }^{22}$ Der Urheber dieser ironischen Spitze gab allerdings auch - sicherlich nicht zu Unrecht - zu bedenken, ob dieses klingende persönlich-politisch-philosophische Bekenntnis zum Liberalismus und zur Privatinitiative in der rauhen Wirklichkeit der Krise Bestand haben könne. ${ }^{23}$

Nicht verwunderlich war, daß die Kommentatoren sich in erster Linie auf Preiss' Äußerungen zu den reichsdeutschen Verhältnissen kaprizierten. Preiss' Sichtweise des Nationalsozialismus barg ja offensichtlich Implikationen für seine Einstellung zur SdP und auf diesem Umweg zum Hauptverband. Vor dem Hintergrund der Deutschlandreise des Präsidenten im Jahr zuvor handelte es sich um ein höchst sensibles Thema. Diese

16 Rede Mühligs, Vollversammlung des DHI am 23.3.1935, in: MDHI 16 (1935), S. 109.

17 Rede Mühligs, Vollversammlung des DHI am 23.3.1935, in: MDHI 16 (1935), S.112. - Auch Preiss selbst war sich der Bedeutung seiner Erklärung bewußt. Er hatte den Text im vorhinein seinem Generalsekretär Mixa zur Beurteilung übermittelt, weil es sich bei der Zusammenarbeit von Tschechen und Deutschen um ein intrikates Thema handle: Vgl. ANB, ŽB, S VII/i-1-I, 563, Preiss an Mixa, 16.3.1935.

18 Rede Preiss', Vollversammlung des DHI am 23.3. 1935, in: MDHI 16 (1935), S. 101-103.

19 ANB, ŽB , S VII/i-1-I, 732, Preiss an Reinl, 29.3.1935.

20 ANB, ŽB, S VII/i-1-I, 732, Reinl an Preiss, 28. 3. 1935.

21 Zum Presseecho vgl. HA 14 (1935), S. 195 f.

22 P ̌̉ 12 (1935), S. 195.

23 Ebenda. 
Visite hatte rein informatorische Ziele verfolgt ${ }^{24}$; Beneš hatte sie ausdrücklich gebilligt ${ }^{25}$, und auch die reichsdeutsche Diplomatie hatte sie als willkommenen Anlaß verstanden, ausländischen Meinungsführern zu demonstrieren, wie "normal“ die Verhältnisse im nationalsozialistischen Deutschland seien. ${ }^{26}$ Preiss hatte einige Tage vor allem in Westfalen und im Rheinland verbringen und sich mit eigenen Augen ein Bild vom Leben dort machen wollen. ${ }^{27}$ Seine Feldforschungen - der Präsident besuchte Industriewerke, diskutierte mit Bankenvertretern und Verbandsmanagern, mit "Hakenkreuzlern“ aus Wirtschaft und Presse, aber auch mit Arbeitern und dem Mann auf der Straße - veränderten Preiss' aus der heimischen Presse gewonnenes Deutschlandbild in positiver Richtung $^{28}$ - was nun allerdings keinesfalls bedeutete, daß er eine Nachahmung für die ČSR empfohlen hätte: Benešs Sorge, der erste Mann der tschechoslowakischen Wirtschaft liebäugle mit einer Diktatur à la Hitler, sei, wie Preiss dem Leiter der Kanzlei des Präsidenten, Šámal, versicherte, unbegründet. ${ }^{29}$ Einige Monate später notierte Šámal ein weiteres Mal, Preiss habe Beneš gegenüber "nicht einmal im Traum“ die Übernahme des „Modells Deutschland“ befürwortet. ${ }^{30}$ Am 5. April 1935 sprach sich Preiss in aller Öffentlichkeit, vor dem Forum der Vollversammlung der slowakischen Industrie in Preßburg, ausdrücklich gegen eine Übernahme der deutschen wie der italienischen, ebenso aber auch der sowjetischen Autokratie aus: „Sozialismus“ bzw. „Faschismus in einem Lande" seien in einem essentiell auf Ausfuhr angewiesenen Staat nämlich undenkbar. Gegenüber dem Anwalt der Deutschen Agrar- und Industriebank, Moritz Weden, hatte der Präsident des Zentralverbands zwar Bewunderung über die im Reich allenthalben spürbare Organisationskraft und den Arbeitswillen der Deutschen geäußert und sich über den liebenswürdigen Empfang bei der IG Farben, bei Krupp und anderen Großunternehmen angetan gezeigt. Das Fazit lautete aber auch privatim lediglich, die deutsche Wirtschaft sei unbesiegbar; Deutschland könne in Europa nicht auf Dauer isoliert werden, und die Tschechoslowakei habe aus dieser Erkenntnis die Folgerungen zu ziehen. ${ }^{31}$

War hinter diesen Äußerungen somit schwerlich mehr als ein Plädoyer für die Verbesserung der politischen und wirtschaftlichen Beziehungen zum Reich zu suchen, so blieb doch ein Schimmer von Verdacht: Preiss' Auftritt in Preßburg, so der österreichische Gesandte Marek, sei „umso bemerkenswerter“, als er in letzter Zeit „seine deutliche Sympathie für das nationalsozialistische Deutschland“ bekundet habe; Beneš sei

24 Preiss hatte vor, dies bei der deutschen Gesandtschaft vorab klarzustellen: Vgl. ANB, ŽB, S VII/i-1-I, 989, Preiss an Tille, 27.7.1934.

25 Er bat Preiss auch um eine Schilderung seiner Eindrücke nach der Rückkehr: Vgl. ANB, ŽB, S VII/i-1-I, 989, Preiss an Tille, 30.7.1934.

26 So der "Hackenkreuzler" (sic!) Baron Stein zu Preiss auf der deutschen Gesandtschaft: Vgl. ANB, ŽB, S VII/i-1-I, 989, Preiss an Tille, 31.7.1934.

27 ANB, ŽB, S VII/i-1-I, 539, Preiss an Mastný, 30. 7.1934.

28 „....und ich habe sehr interessante Kenntnisse und Erfahrungen gewonnen, die das, was wir in unseren Blättern lesen, in einem beträchtlichen Ausmaß korrigieren“: Vgl. ANB, ŽB, S VII/i-1-I, 539, Preiss an Mastný, 1.10.1934. - „Ich habe dieses Jahr selbst eine Reise nach Deutschland unternommen und festgestellt, daß vieles anders aussieht, als man es bei uns schildert“: Vgl. ANB, ŽB, S VII/i-1-I, 295, Preiss an Hotowetz, 1. 10.1934.

29 AKPR, T 421/29, Karton 170, Aktenvermerk Śámal vom 5.12.1934.

30 AKPR, T 421/29, Karton 170, Aktenvermerk Śámal vom 12.2.1935.

31 Gesandtschaft Prag an AA, 8. 10. 1934, in: Deutsche Gesandtschaftsberichte aus Prag, Teil 4, Dokument Nr. 68, S. $147 \mathrm{f}$. 
„äußerst ungehalten“. Die Rede müsse man als „Rückzug seiner Person“ werten - als eine Finte mit dem Ziel, bei den maßgebenden Persönlichkeiten nicht weiter anzuecken. ${ }^{32}$ Ähnliche Unsicherheit hatte auch Preiss' Auftritt vor dem Hauptverband hinterlassen: Hob das „Prager Tagblatt" auf das „unzeitgemäße“ Bekenntnis zu den dem Nationalsozialismus diametral entgegengesetzten Ideen des Liberalismus und der $\mathrm{Hu}-$ manität $\mathrm{ab}^{33}$, so merkte Marek an, Preiss sei „bei den unentwegten Demokraten nicht gerade gut angekommen"; man dürfe annehmen, der Deutschlandaufenthalt habe ihn in seiner "ohnehin recht autokratischen Tendenz" bestärkt. Nicht verbürgt war allerdings die von Marek kolportierte Äußerung des Präsidenten auf einer Gesellschaft, in Deutschland regiere ein Anstreicher - „wir hier haben aber nicht einmal einen solchen Anstreicher" ${ }^{34}$ Offizielle Linie des Präsidenten blieb jedenfalls die Kooperation mit den Deutschen im Lande und ihrer Wirtschaft, jenseits und unbeschadet aller Politik: Er wolle sich, so bekräftigte Preiss diese Haltung auf der Vollversammlung des Zentralverbands am 25. Juni 1935, „von der Politik fernhalten“, nicht „über den Einfluss politischer Ideen des Deutschtums auf diese Wahlen sprechen“ und nur die ökonomische Seite der Problematik, also die Arbeitslosigkeit, reflektieren. Er sei sich dieser Hinsicht „der Loyalität unserer deutschen Mitbürger und Mitarbeiter aus den Kreisen der Industrie bewusst". ${ }^{35}$

Bis zu den Maiwahlen hatte Henlein in erster Linie mit sozialpolitischen Forderungen die Stimmen der Arbeiterschaft zu gewinnen gesucht. Erst nach den Wahlen schielte er nach der Kapitalkraft der Industrie und suchte nach reichsdeutschem Muster die Beziehungen in diese Richtung zu intensivieren. Kislinger wurde an die Partei herangezogen; er, der bald als „Visitenkarte der SdP an der Türe der Industrie ${ }^{\alpha 36}$ galt, wurde am 22. Juli 1935 von der Regierung zum Mitglied der böhmischen Landesvertretung ${ }^{37}$ ernannt und nahm dieses Mandat für die SdP wahr. Neben ihm saß als Wirtschaftsvertreter der Partei der Schluckenauer Fabrikant Wilhelm Weber, ein ehemaliges Mitglied der Rosche-Gruppe. Nicht unrecht hatte die deutsche Gesandtschaft allerdings mit ihrer Einschätzung, die Ernennung der beiden Industrievertreter sei ein Indiz dafür, „daß man tschechischerseits mit einer Nachgiebigkeit gerade von dieser Seite eher rechnen zu können glaubt ${ }^{\star 38}{ }^{38}$ Kislingers Auftreten - er arbeitete in der Budgetkommission der Landes-

32 ÖStA, BAA, Gesandtschaft Prag, Zl.172/Pol, Österreichische Gesandtschaft Prag an BAA, 6.4.1935.

33 Kommentar des PT vom 24.3.1935.

34 ÖStA, BAA, Gesandtschaft Prag, Zl.158/Pol., Österreichische Gesandtschaft Prag an BAA, 4. 4. 1935.

35 Rede Preiss', Vollversammlung des Zentralverbands am 25.6.1935, in: OB 17 (1935), S. 164.

36 HR vom 5. 9.1935.

37 Die Landesvertretung umfaßte 180 Mitglieder, von denen zwei Drittel gewählt wurden. Ein Drittel ernannte die Regierung aus den Kreisen von Wirtschaftsfachleuten, Repräsentanten der Kultur, der nationalen und sozialen Gruppen. Die Ernennungen waren in der dem 22. Juli vorangehenden Kabinettssitzung erfolgt, und zwar - dies die Kritik der deutschen Gesandtschaft - in einer Art und Weise, als hätte der SdP-Wahlerfolg nicht stattgefunden: Von den insgesamt 35 Deutschen in der böhmischen Landesvertretung waren zehn ernannt, davon aber nur zwei SdPVertreter - eben Kislinger und Weber: Vgl. PA, R 73 842, Gesandtschaft Prag an AA, 24. 7. 1935. - Zum Protest der SdP gegen die Modalitäten der Ernennungen anläßlich der Eröffnung der Landesvertretung am 25.10.1935 vgl. SÚA, SdP, Karton 55, 29-L-1936/37-6, Die SdP in der Landesvertretung Böhmens, o.O., o.J., S. $1 / 1$.

38 PA, R 73 842, Gesandtschaft Prag an AA, 24. 7.1935. 
vertretung mit $^{39}$ - war nämlich höchst moderat, durchwegs auf eine sachliche Tonlage und das Leitmotiv, alle Dinge "wirtschaftlich richtig“ anzusehen, gestimmt. Man werde sich in diesem Fall "viel eher finden ", nicht so häufig "aneinander vorbeireden und auch nicht gegeneinander"; sein Ziel sei es, „über das entweder weltanschauliche oder parteipolitische Gezänke hinweg“ das Augenmerk „den streng realen Ziffern“ zuzuwenden. Alle von der Wirtschaftsnot Betroffenen sollten sich „in einem neuen nationalen Ideal“, geprägt von der „Solidarität der Stände und von der Solidarität der Nationen“, vereinigen. ${ }^{40}$

Im Juni 1935 trieb die Hauptleitung der SdP den Ausbau ihrer Wirtschaftsorganisation voran, der durch den Einzug ins Parlament erforderlich geworden war. Beschlossen wurde die Einrichtung einer Industriegliederung unter der Leitung Fritz Köllners ${ }^{41}$; ihm sollte ein Kreis der Partei nahestehender Industrieller zur Hand gehen. Verbindungsmann zum Hauptverband wurde Karl Janovsky, der als Beauftragter der Partei außerdem für die konzeptionellen Grundlagen der Wirtschaftspolitik sowie für die Koordinierung der Zusammenarbeit mit den Hauptleitern für Sozialpolitik, für Landwirtschaft und für Handel und Handwerk zuständig war. ${ }^{42}$ Die Entwicklung der Wirtschaftsorganisation in den folgenden Jahren ist aufgrund der lückenhaften Überlieferung nur ansatzweise zu rekonstruieren. 1938 fungierte Wolfgang Richter als Leiter der Abteilung; er stand in einem nicht ganz spannungsfreien Verhältnis zu Janovsky. ${ }^{43}$ Am 26. März 1936 hatte sich auch ein Fraktionsausschuß für Gewerbe, Handel und Industrie der SdP-Parlamentarier konstituiert, für den der Abgeordnete Peschka die Gesamtverantwortung trug. Rosche, für die SdP in die Nationalversammlung gewählt, war zusammen mit dem Abgeordneten Budig für die Industrie zuständig. ${ }^{44}$

Richtete sich die SdP in personeller und organisatorischer Hinsicht also auch bereits auf eine Annäherung an die Unternehmerschaft ein, so blieb die programmatische Distanz zu dieser doch nach wie vor unverkennbar. Bis etwa Ende 1937 verlief auf diesem Terrain eine deutliche Scheidelinie zwischen dem Hauptverband und dem Zentralverband einerseits, der Partei andererseits - Bruchlinien, die die kontrastierende Analyse der beiden Programmatiken verdeutlicht: Hatte nicht zuletzt das reichsdeutsche Vorbild

39 SÚA, SdP, Karton 55, 29-L-1936/37-6, Die SdP in der Landesvertretung Böhmens, o.O., o.J.,

S. 4/2, Übersicht über die Funktionen der SdP-Mitglieder in der Landesvertretung.

40 SÚA, SdP, Karton 55, 29-L-1936/37-6, Rede Kislingers in der Landesvertretung am 13.6. 1936.

41 Fritz Köllner (1904-1986), Dr. jur., Bankangestellter. Verwurzelt in der Sudetendeutschen Turnerbewegung. Ab 1933 hauptamtlicher Funktionär der SHF. 1933-1938 Organisationsleiter und Hauptleitungsmitglied der SHF/SdP. Parlamentsabgeordneter von 1935 bis 1938: Vgl. Balling, Von Reval bis Bukarest, Band I, S. $356 \mathrm{f}$.

42 SÚA, SdP, Karton 6, 2K-KH 1934-38/3, Hauptleitungssitzung der SdP am 12.6. 1935. - SÚA, SdP, Karton 7, 2K-KH, 1934-37/4, Hauptleitungssitzung am 27.6.1935. - SÚA, SdP, Karton 31, $18 \mathrm{AA} / \mathrm{Wa} 35-37 / 2$, Vollmacht Henleins für den Beauftragten für Wirtschaftspolitik der SdP vom 13. 9. 1937. - SÚA, SdP, Karton 42, Hauptamt für Handwerk und Handel, Aufgabenbeschreibung vom 13.4.1938.

43 So reklamierte Janovsky die Behandlung finanzpolitischer Fragen für sich. Die Kanzlei Henleins vermied es, Partei zu ergreifen: Janovsky hatte eine Generalvollmacht für die Wirtschaftspolitik, Richter andererseits war als Abgeordneter unverzichtbar und außerdem bereits seit 1935 Verbindungsmann zu den sudetendeutschen Banken. Die Kanzlei forderte die beiden zu kollegialer Zusammenarbeit und zur Einreichung von Vorschlägen bzgl. einer präziseren Abgrenzung der Arbeitsgebiete auf: Vgl. SÚA, SdP, Karton 31, 18 AA/Wa 35-37/2, Janovsky an Richter, 24. 6. 1938.

44 SÚA, SdP 31, 18 AA/Wa 35-37/2, SdP/Zentralstelle für Handel und Gewerbe an Arbeitsamt, 27.3. 1936. 
eines massiven Staatsinterventionismus, welcher die extreme Konsequenz aus dem allgegenwärtigen Versagen der „unsichtbaren Hand“ zog, auch in der Tschechoslowakei die Debatte über die "gebundene Wirtschaft" belebt, so herrschte doch in der deutschen wie in der tschechischen Industrieorganisation der Republik nach wie vor offene Skepsis gegen eine weit ausgreifende Regulierung der zentralen ökonomischen Parameter. Sogar in der Landwirtschaft, deren vergleichsweise schwach differenzierte Produktpalette eine Planung eigentlich erleichterte, seien - dies war Liebiegs Fazit auf der Vollversammlung des DHI im März 1935 - die Erfolge administrativer Eingriffe bislang mäßig gewesen. ${ }^{45}$ Vielleicht Kohle, Eisen und Elektrizität, so der Brünner deutsche Industrielle Fritz Jellinek, aber "nicht Kleiderstoffe, Spielwaren, Porzellangeschirr oder Ledergalanterie“ könne man regulieren. ${ }^{46}$ Mühligs geringe Meinung von der Leistungsfähigkeit der tschechoslowakischen Staatsverwaltung hob zum einen auf deren notorische, gut kakanische Entschlußlosigkeit und Trägheit ab; sie basierte aber auch auf einer allgemeinen Theorie des "Staatsversagens": Weil der Staat zwar täglich tiefer in die Wirtschaft interveniere, dabei jedoch keine planvolle Strategie über den Parteiinteressen verfolge, unterblieben Eingriffe dort, wo man ihrer eigentlich bedürfe. Deshalb sei der in der Tschechoslowakei „weitaus überspannte staatliche Aufgabenkreis“ auf ein "gesundes Maß" zurückzuführen. ${ }^{47}$

Die Problematik des Staatsinterventionismus war im Zentralverband bereits seit 1929 in einem hauptsächlich mit Vertretern der tschechischen Industrie besetzten Komitee des Beirates für volkswirtschaftliche Fragen intensiv erörtert worden. Nach dem Hinscheiden dieses Gremiums wurde die Debatte Mitte der dreißiger Jahre auf der Basis der von Engliš - inzwischen Präsident der Nationalbank - ausgearbeiteten Konzepte wieder aufgenommen. ${ }^{48}$ Sprach sich Engliš auch für eine Beschneidung der Auswüchse des freien Wettbewerbs aus, so hielt er doch am Primat der Unternehmerfreiheit gegenüber „Kollektivismus" und Planwirtschaft fest, deren entscheidendes Kriterium er in der Abschaffung des Preises als Knappheitsindikator und Lenkungsinstrument erblikkte. Die dirigierte Wirtschaft sei unvereinbar mit der Demokratie und setze eine der Tschechoslowakei unmögliche, weil die Krise verschärfende Auskopplung aus der Weltwirtschaft voraus. ${ }^{49}$ Auf diesem Fundament nahm der Zentralverband im März 1935 die Arbeit an einem Plan zur Reorganisation der industriellen Erzeugung, des Finanz- und Kreditwesens, zur Ankurbelung des Außenhandels und zur Beseitigung der Arbeitslosigkeit in Angriff, der durchwegs allfällige Regulierungsmaßnahmen der Zuständigkeit der industriellen Selbstverwaltung überantwortete. Behördliche Eingriffe waren nur in Ausnahmefällen und wenn die Industrie dies selbst befürwortete vorgesehen. Private Investitionen seien, wie die wenig ermutigenden Resultate in anderen Ländern zeigten, öffentlichen vorzuziehen und dürften von diesen nicht verdrängt werden. Preis- und

45 Rede Liebiegs (als Präsident der Handelskammer Reichenberg), Vollversammlung des DHI am 23.3. 1935, in: MDHI 16 (1935), S. 109 f. - Rede Liebiegs, Vollversammlung der Reichenberger Kammer am 10.4.1935, im PT vom 11.4. 1935.

46 Jellinek, Landwirtschaft.

47 Mühlig, Pohledy. - ANB, ŽB, S VII/i-1-I, 576, Rede Mühligs auf dem Sprechtag des DHI in Troppau am 16.11.1937.

48 HR vom 7.3. 1935.

49 Rede Englišs, Generalversammlung der Tschechoslowakischen Nationalbank am 1.3. 1935: Vgl. PT vom 1.3. 1935. - Engliš hatte seine Position außerdem in einer Serie von 15 Artikeln in den Lidové Noviny dargelegt: Vgl. PT vom 17.5.1935. 
Steuerpolitik sollten in erster Linie die private Kapitalbildung fördern. ${ }^{50} \mathrm{Als}$ Bekenntnis zu diesem Credo wurde auch Preiss' bereits zitierte Rede Anfang April in Preßburg verstanden. ${ }^{51}$ Die Ansprache des Präsidenten vor der Vollversammlung des Zentralverbands am 25. Juni hob als Vorbild einer "Zweckorganisation“ der Wirtschaftsgruppen mit dem Ziel der „Gleichgewichtsherstellung des Ganzen in der Demokratie“ Großbritannien und die Vereinigten Staaten hervor; hatte dort die Ausbildung korporativer Strukturen in der ersten Phase des New Deal auch einen kräftigen Schub erfahren, so waren diese vom totalitären Staatsinterventionismus im Deutschen Reich doch weit entfernt. Preiss wies dem Staat lediglich die Rolle des Schiedsrichters gegenüber den Syndikaten zu, welche - unter dem Dach des Zentralverbands - autonom die Produktion regulieren sollten. ${ }^{52}$ Das große Programm von 1935, eine Systematisierung der auf der Hauptversammlung vorgebrachten Konzepte, bewegte sich dann in diesem Rahmen und auf dem Boden der politischen Demokratie. ${ }^{53}$

Ein gesamtindustrieller Konsens war besonders zwanglos in sozialpolitischen Fragen herzustellen, etwa hinsichtlich der Ablehnung der Vierzig-Stunden-Woche als krisendämpfender, weil das Arbeitsvolumen breiter verteilender Maßnahme. Die zu ihrer Einführung erforderliche Reorganisation des Produktionsprozesses hätte nach Meinung der Industrie kostentreibend gewirkt, vor allem bei Lohnausgleich. ${ }^{54}$ Der Arbeitgeberschaft des Zentralverbands der deutschen Industrie artikulierte diese Auffassung auch im Namen der deutschen Industrie; im Vorfeld der Wahlen sprach in diesem Sinne eine Delegation unter Preiss' Führung beim Ministerpräsidenten vor. ${ }^{55}$ Die Verhandlungen in dieser Frage schleppten sich durch die folgenden Jahre hin, ohne daß ein Resultat erreicht worden wäre. ${ }^{56}$

Die dringend erwünschte, auch durch eine Ausweitung des inneren Marktes nur unvollkommen zu kompensierende Belebung des Exports ${ }^{57}$ wurde nach wie vor durch die "industriefeindliche Einstellung maßgebender Faktoren in der Gesetzgebung und Verwaltung“ behindert; hier sah sich die Industrie in Opposition zu „einer geschlossenen, fast feindlichen Phalanx ${ }^{\text {“58, }}$, verursacht durch das Übergewicht der Landwirtschaft in der Konstellation, welche die tschechoslowakische Politik seit dem Zusammengehen der Agrarier mit der Linken in der zweiten Hälfte der zwanziger Jahre dominierte.

50 BÖ vom 7.3. 1935, S. 5. - Rede Mixas, Gesamtstaatliche Wirtschaftskonferenz der volkswirtschaftlichen Gebietskörperschaften am 14.4.1935 in Prag, in: OB 17 (1935), S. 99-101. - Eine detaillierte Übersicht auch in dem Vortrag Mixas vor der Tschechischen Volkswirtschaftlichen Gesellschaft in Prag am 14.10.1935, in: OB 17 (1935), S.249f.

51 Rede Preiss, Vollversammlung des Verbands der slowakischen Industrie am 5. 4. 1935, in: OB 17 (1935), S. $83 \mathrm{f}$.

52 Rede Preiss, Vollversammlung des Zentralverbands am 25.6.1935, in: OB 17 (1935), S.161, $162 \mathrm{ff}$.

53 HA 14 (1935), S. 722. - HR vom 28. 11. 1935. - Pimper, Průmysl.

54 „Ein Notschrei der Industrie des Bezirkes Rumburg“, in: MDHI 16 (1935), S. 41-43.

55 PT vom 21.2. und vom 5.3.1935.

56 Eine Arbeitszeitverkürzung, so Preiss Mitte 1937, würde ohne ein Mitziehen Großbritanniens und Deutschlands schwere Schäden verursachen: Vgl. ANB, ŽB, S VII/i-1-I, 770, Preiss an Rükkel, 8.6. 1937.

57 Rede Preiss, Vollversammlung des Zentralverbands am 25.6.1935, in: OB 17 (1935), S. $161 \mathrm{f}$, $164 \mathrm{ff}$.

58 Entschließung der Ortsgruppe Warnsdorf des DHI auf ihrer Jahreshauptversammlung am 18.3.1935, in: MDHI 16 (1935), S. 116. 
An dieser Stelle interessieren weniger die damals und in den folgenden Jahren erörterten Einzelmaßnahmen ${ }^{59}$ als vielmehr die grundlegenden Vorstellungen hinsichtlich der Intensivierung und räumlichen Orientierung des Exports: Die Zeichen der Zeit wiesen nach gesamtindustrieller Auffassung in Richtung einer Beendigung der Autarkiebestrebungen; geboten waren die Schleifung der in der Krise aufgerichteten Handelshemmnisse, die Entbürokratisierung des Ausfuhrverfahrens und die Bildung größerer Wirtschaftsgebiete, innerhalb derer der Austausch, möglichst auch die Produktion, aufeinander abgestimmt werden sollten. ${ }^{60} \mathrm{Da}$ dies in erster Linie handelspolitische Übereinkünfte mit den anderen Nachfolgestaaten und eine Zollregelung für Mitteleuropa voraussetzte $^{61}$, begrüßte das handelspolitische Komitee des Zentralverbands im März 1936 den Hodža-Plan einer mitteleuropäischen Integration. ${ }^{62}$ War die zentraleuropäische Handelspolitik mit dem Kristallisationskern der Kleinen Entente auch erste Priorität, so wurde doch auch die Notwendigkeit einer Steigerung der Exporte in die "großen, freien, entfernten Märkte", insbesondere in Übersee, anerkannt. ${ }^{63}$ Die 60 Prozent der tschechoslowakischen Ausfuhr, die, wie Mixa im Oktober 1935 vorrechnete, zwischen 1929 und 1934 in die entwickelten Industrieländer gegangen seien, könnten nach der Normalisierung der wirtschaftlichen Verhältnisse auf Dauer erhalten bleiben; auch der Anteil der Exporte in die Agrarländer des europäischen Südostens in Höhe von 25 Prozent im Jahr 1929 sei nicht endgültig verloren. Als dritten Orientierungsraum benannte der Generalsekretär die Länder in Übersee und im Fernen Osten. ${ }^{64}$

Das wirtschaftspolitische Programm der SdP hatte im Vorfeld der Wahlen von 1935 Konturen angenommen und konkretisierte sich in der Folgezeit durch die Aktivitäten der Partei in Abgeordnetenhaus und Senat weiter. Die charakteristische Mixtur von traditioneller Mittelstands- und Agrarrhetorik, die Proklamation des „deutschen Sozialismus“, scharfe Ausfälle gegen das „parasitäre Kapital“, in erster Linie aber die autoritäre Option in der Ordnungspolitik markierten die Differenzen zur Industrie deutlich. Gemeinsamkeiten bestanden am ehesten dort, wo sich die positive Einstellung der Partei zur "völkischen" Gewerkschaftsbewegung mit der schroffen Absage an marxistischen Internationalismus und "Klassenhaß" verband und die „deutschbewußten Arbeiter" ih-

59 Eine wichtige Rolle spielte hier insbesondere die Frage einer staatlichen Subventionierung der Ausfuhr durch Exportprämien: Vgl. hierzu Janovsky, Ausfuhrprämien. - ANB, ŽB, S VII/i-1-I, 563, Mixa an Preiss, 10. 7. 1935. - SÚA, MPOZZ, Karton 4007, Auszug aus dem Schreiben des DHI vom 1.7.1936 über die Bekämpfung der Arbeitslosigkeit.

60 Sitzung des handelspolitischen Komitees des Zentralverbands am 17.9.1936, Bericht in: OB 18 (1936), S. 259 f. - Anfang des Jahres hatte Mixa als aktuelle Gefahren die Devisenbewilligung und die sonstigen handelspolitischen Bindungen bezeichnet; sie sollten eher gelockert werden: Vgl. „M“ (= Mixa), Rückkehr. - Rede Janovskys, Vollversammlung des DHI, Kreis Karlsbad, im Juni 1936 (ohne Tag, in: Zeit vom 11.6. 1936). - ANB, ŽB, S VII/i-1-I, 576, Rede Mühligs auf dem Sprechtag des DHI in Troppau am 16.11.1937.

61 Rede Preiss, Vollversammlung des Zentralverbands am 25.6.1935, in: OB 17 (1935), S. $161 \mathrm{f}$,, $164 \mathrm{ff}$.

62 Sitzung des handelspolitischen Komitees des Zentralverbands am 27. 3. 1936, Bericht in: OB 18 (1936), S. $116 \mathrm{f}$.

63 Rede Mixas auf der Gesamtstaatlichen Wirtschaftskonferenz der volkswirtschaftlichen Gebietskörperschaften am 14. 4.1935 in Prag, Bericht in: OB 17 (1935), S. 99-101.- Sitzung des handelspolitischen Komitees des Zentralverbands am 26.10.1936, Bericht in: OB 18 (1936), S. $298 \mathrm{f}$.

64 Vortrag Mixas vor der Tschechischen Volkswirtschaftlichen Gesellschaft in Prag am 14. 10. 1935, in: OB 17 (1935), S. $249 f$. 
re Absicht bekundeten, die "durch den Klassenkampfgedanken verhetzten Schichten des Sudetendeutschtums" ins Volk heimzuführen. ${ }^{65} \mathrm{Da}$ es dem Selbstverständnis der SdP als „Volkspartei des nationalen Protests" entsprach, Widersprüche zwischen „Ständen " und Interessengruppen nicht anzuerkennen, ${ }^{66}$ focht die Partei andererseits allerdings auch gegen das „Freibeutertum des Kapitalismus“ und gegen die „Überfremdung“ durch das "anonyme internationale Finanzkapital", dem sie die Schuld an der Wirtschaftskrise aufbürdete. Private Unternehmerinitiative erkannte Henlein überhaupt nur an, „sofern sich diese den Gesamtinteressen des Volkes einfügen" und sich für ein "gemeinschaftsverpflichtetes Wirtschaften" in der Volksgemeinschaft in die Pflicht nehmen ließ. ${ }^{67}$ Der Antikrisenpolitik der Republik, so im Dezember 1935 der Abgeordnete Tschakert, dürfe es keineswegs darum gehen, ,irgendwelchen Industriebaronen zusätzlich Millionen zu verschaffen“; ihr Ziel müsse es vielmehr sein, „unseren 400000 sudetendeutschen Arbeitslosen Brot und Arbeit zu geben“".68

Billigte die Industrie Wirtschaftsregulierung lediglich dort, wo sie ihrer eigenen Selbstverwaltung überantwortet war, so erachtete die SdP eine "großzügige Planung“ mit dem Ziel der "Abstimmung“ aller Wirtschaftszweige in Produktion und Absatz für erforderlich. Die Absage an die Gewerbefreiheit etwa implizierte eine Regulierung des Marktzugangs mit Errichtungs- und Erweiterungsverboten ähnlich wie im nationalsozialistischen Wirtschaftsrecht. Ein von „Parteipolitik“ freier Senat sollte als national sektioniertes Wirtschaftsparlament und Regulativ des Abgeordnetenhauses fungieren. ${ }^{69}$ Dieses Programm schmückte sich passagenweise mit ständischem Formelzierrat, ging aber faktisch durchwegs von der führenden Rolle der Partei aus. Die Überbrükkung der Gegensätze zwischen den Ständen in der „atomisierten“ Wirtschaft könne, so Janovsky, weder von diesen selbst - also auch keinesfalls von den Industrieverbänden im Widerstreit der Brancheninteressen - noch vom Parteienstaat geleistet werden. $\mathrm{Zu}$ der „über die Opfer entscheidenden Instanz" äußerte sich Janovsky nur unbestimmt; er legte aber nahe, daß die SdP als Sachwalter des „ständischen Interessenausgleich(s)“ anzusehen sei. Voraussetzung für die Herstellung der Ordnung „im eigenen Hause“

65 SÚA, SdP, Karton 54, SHF-Weisung Nr. 92 an die Orts-, Bezirks- und Kreisleitungen vom 19. 4. 1935. - Rede Karl Garliks, Sitzung des Senats am 25. 6. 1935, in: Die SdP im Parlament. Ein Jahresbericht 1935/36, S. 189. - Rede Georg Wollners, Sitzung des Abgeordnetenhauses am 10. 12. 1935, in: Ebenda, S. 190f. - SÚA, SdP, Karton 3, KH 1933-38/6, Text eines Interviews Henleins vom 3. 7. 1935 mit „La Stampa“.

66 Illustrativ für den Spagat zwischen Arbeit und Kapital war der originelle Einfall, auf Wahlveranstaltungen Industrielle für die Forderungen der Arbeiterschaft und vice versa eintreten zu lassen: Vgl. SÚA, SdP, Karton 54, SHF-Weisung Nr. 92 an die Orts-, Bezirks- und Kreisleitungen, 19.4. 1935.

67 SÚA, SdP, Karton 54, SHF-Weisung Nr. 92 an die Orts-, Bezirks- und Kreisleitungen vom 19.4.1935. - Rede K.H. Franks, Sitzung des Abgeordnetenhauses am 19.6.1935, in: Die SdP im Parlament. Ein Jahresbericht 1935/36, S. 39. - SÚA, SdP, Karton 3, KH 1933-38/6, Text eines Interviews Henleins vom 3. 7. 1935 mit "La Stampa“. - SÚA, SdP, Karton 71, Gustav Peters, Die wirtschaftliche Lage vom Standpunkte unserer nationalen Existenz. Rede beim Parteitag in Eger 1936.

68 Rede Robert Tschakerts, Sitzung des Senats am 19. 12. 1935, in: Die SdP im Parlament. Ein Jahresbericht 1935/36, S. $224 \mathrm{f}$.

69 SÚA, SdP, Karton 54, SHF-Weisung Nr. 92 an alle Orts-, Bezirks- und Kreisleitungen vom 19. 4. 1935. - Rede Emil Enhubers, Sitzung des Senats am 20. 12. 1935, in: Die SdP im Parlament. Ein Jahresbericht 1935/36, S. 80. 
seien, auch wenn in einem solchen Fall dann vorübergehend „rustikale Ausdrucksformen und nicht diplomatische Wendungen das Feld beherrschen sollten“, ein „Stillhaltekommando" und „die scharfe Zuchtrute der überparteilichen Vernunft", nach der die Wirtschaft sich eigentlich bereits sehne. ${ }^{70}$

Angesichts der Wirtschaftskrise und der horrenden Exportprobleme befürwortete die SdP die Deindustrialisierung und die Rücksiedlung der Arbeiterschaft aufs Land, wie sie die Industrie seit den frühen dreißiger Jahren des öfteren energisch zurückgewiesen hatte. ${ }^{71}$ Die Partei empfahl in Anknüpfung an die antiindustriellen Ressentiments der Mittelstandsrhetorik verstärkte Förderung von Klein- und Mittelbetrieben und ihren Schutz gegen Proletarisierung. Die „Erneuerung“ und „Anpassung“ der Gewerbeordnung zielte auf die Einführung des Großen Befähigungsnachweises, wie sie die Handwerkspolitik im Reich vorexerziert hatte. Erste Zielscheibe der ebenfalls gut nationalsozialistisch anmutenden Polemik gegen Einheitspreisgeschäfte und Warenhäuser war der tschechoslowakische „Schuhkönig“ Tomáš Bat'a, dessen Unternehmen Schuhhandel und Schusterhandwerk der Republik in die Defensive gedrängt hatten. ${ }^{72}$

Hatten die außenhandelspolitischen Vorstellungen der Industrieverbände durchaus auch die Anbahnung engerer Beziehungen zu Deutschland und die verschiedensten Mitteleuropakombinationen erwogen, mit an erster Stelle aber die Intensivierung des Absatzes nach Übersee in den Blick genommen, so erteilte die SdP jeglicher Westorientierung des Exports eine unbedingte Absage und forderte statt dessen die Umorientierung auf Deutschland "mit ganzem Herzen" nicht nur in der Politik, sondern auch in der Außenwirtschaft. In der Folge des „Tauschabkommens" von 1934, von K. H. Frank wohl kaum in Unkenntnis der Konnotationen als „Novembervertrag" geschmäht, sei die Ausfuhr ins Reich um die Hälfte gesunken. ${ }^{73}$ Die Konjunktur politisch motivierter Europapläne, so Anfang 1936 Janovsky, ignoriere die „natürlichen Raumgesetze“, weil sie die Rechnung ohne Deutschland mache. Der „Wunderglaube" sehe sich nach neuen Bundesgenossen von Österreich bis in den Balkan hinein um - wo die Volkswirtschaften in den letzten Jahren zunehmend ihre Wirtschaftsbeziehungen mit dem Reich intensiviert hätten. ${ }^{74}$

Alle diese Stränge waren in dem vor den Wahlen vorgelegten Arbeitsbeschaffungsplan zum ersten Mal in markanter Weise gebündelt worden. ${ }^{75}$ Dieser setzte nicht auf die Belebung des Exports, sondern auf den Primat des Binnenmarkts. Vorrangiges Ziel war hier die Wiederherstellung des Konsumniveaus vor der Krise. Müsse man aufgrund

70 Janovsky, Ständischer Interessenausgleich. - Ders., Neuzeitliches Wirtschaftsdenken, S. $46 \mathrm{ff}$., Zitat S. 47.

71 SÚA, SdP, Karton 54, SHF-Weisung Nr. 92 an die Orts-, Bezirks- und Kreisleitungen vom 19.4. 1935.

72 SÚA, SdP, Karton 54, SHF-Weisung Nr. 92 an alle Orts-, Bezirks- und Kreisleitungen vom 19. 4. 1935. - Rede Emil Enhubers, Sitzung des Senats am 25.6.1935, in: Die SdP im Parlament. Ein Jahresbericht 1935/36, S. 223. - SÚA, SdP, Karton 71, Gustav Peters, Die wirtschaftliche Lage vom Standpunkte unserer nationalen Existenz. Rede beim Parteitag in Eger 1936.

73 ZT vom 8. 11. 1935. - Rede K.H. Franks, Sitzung des Abgeordnetenhauses am 19.6.1935, in: Die SdP im Parlament. Ein Jahresbericht 1935/36, S. 155. - Rede Wolfgang Richters, Sitzung des Abgeordnetenhauses am 11.12.1935, in: Die SdP im Parlament. Ein Jahresbericht $1935 / 36$, S. $157 \mathrm{f}$.

74 Janovsky, Donaupläne.

75 O.V., Arbeit für 300000 . 
der internationalen Autarkietendenzen und des krisenbedingten unwiederbringlichen Verlustes von Exportmöglichkeiten auch mit einer fortdauernden, jedenfalls durch ein Sofortprogramm nicht zu beseitigenden Restarbeitslosigkeit rechnen, so könnten doch durch eine Kompensation der seit 1929 ausgefallenen Binnennachfrage an die 300000 Arbeitsplätze geschaffen werden. Voraussetzung hierfür war allerdings eine Mobilisierung des "toten Kapitals“, der Differenz von 400 Millionen Kronen zwischen dem realen und einem angenommenen "natürlichen" Notenumlauf, in Kombination mit der Wiedereinspeisung der von den Banken bei der Nationalbank thesaurierten 700 Millionen Kronen in die Zirkulation. Vorrangig seien aus diesem Fond Infrastrukturmaßnahmen - Wohnungsbau, Energieversorgung, landwirtschaftliche Meliorationen - zu finanzieren. Der über die Löhne wirkende Konsumeffekt sollte die Privatwirtschaft ankurbeln. Die Mittel waren ständig im Umlauf zu halten, so daß sich bei den Banken kein neuer "Thesaurierungsniederschlag" bilden konnte.

Nun war das Vorhaben einer durch staatliche Ausgaben finanzierten Konjunkturbelebung keineswegs originell, sondern zehrte von dem in den dreißiger Jahren allgegenwärtigen keynesianischen Ideengut: Schon einige Jahre bevor Keynes 1936 das deficit spending theoretisch fundierte, lag in den Industriestaaten die Idee des „Konjunkturausgleich" durch öffentliche Arbeiten in der Luft. Die deutschen und die tschechischen Verbände der gewerblichen Wirtschaft gleichermaßen waren sich spätestens Anfang der dreißiger Jahre einig gewesen, daß eine Intensivierung der öffentlichen Investitionstätigkeit als wünschenswert anzusehen sei. Der Zentralverband hatte bereits seit 1929 wiederholt einen die Kräfte konzentrierenden längerfristigen staatlichen Ausgabenplan gefordert. ${ }^{76} \mathrm{Im}$ Gegensatz zur SdP waren für die Industrieverbände öffentliche Arbeiten allerdings ein nur subsidiär zur Ankurbelung der Privatwirtschaft einzusetzendes Mittel gegen die Krise, in einer Reihe mit der steuerlichen Entlastung der Unternehmer, der Gewährung von „Erleichterungen“ auf sozialpolitischem Gebiet, der Befreiung von bürokratischen Hemmnissen und der Förderung der privaten Kreditbeschaffung. Gerade für die Vertretung der ausgesprochen ausfuhrabhängigen deutschen Leicht- und Konsumgüterindustrien wie etwa den ADTV spielte vor allem auch die Forderung nach einer staatlich gestützten Wiederbelebung des Außenhandels und nach einer vernünftigen Verkehrs- und Tarifpolitik eine nicht zu unterschätzende Rolle. ${ }^{77}$

Die SdP-typische Polemik gegen das „parasitäre“, „hortende“ Kapital grundierte auch den Arbeitsbeschaffungsplan. Die Neuschöpfung bzw. Erneuerung der Mittel durch den Staat wurde ja durch die „eigensüchtigen“ Thesaurierungsbestrebungen von Banken und Unternehmern geradezu herausgefordert. Deutsch-sozialistisch waren auch die Abschnitte des Programms über die Reorganisierung der Arbeitslosenfürsorge eingefärbt. Weil die Massenarbeitslosigkeit als Folge der privatkapitalistischen Wirtschaftsverfassung aufgefaßt wurde, war das Kapital in die soziale Verantwortung zu ziehen; es hatte seine Opfer für das von diesen unfreiwillig getragene Risiko schadlos zu

76 Zentralverband der tschechoslowakischen Industriellen (Hrsg.), Prúmysl.

77 SÚA, MPOŽ, Karton 2383, 50 315/30, ADTV an MPOŽ, 18.3. 1930. - Ähnlich argumentierten in den dreißiger Jahren durchwegs die Kammern des deutschen Gebiets. Vgl. etwa SÚA, MPOŽ, Karton 387, 17 986/33, Sitzung der Kammer Eger am 24. 10. 1932. - SÚA, MPOŽ, Karton 396, 2203-21, Bericht des Präsidiums der Kammer Reichenberg über die zur Linderung der Arbeitsnot eingeleiteten Aktionen auf der Sitzung der Verwaltungskommission der Kammer am 10.4.1935. 
halten. Bislang war in der Tschechoslowakei die Arbeitslosenunterstützung von Gewerkschaften und Staat zusammen aufgebracht worden. Nun sollte ihre Finanzierung durch eine dem „arbeitslosen Kapitalertrag “ auferlegte Steuer übernommen werden. Die Kontrolle der Mittelverwendung lag beim Staat: Träger der an die Arbeitsbeschaffung gekoppelten Arbeitslosenfürsorge und Arbeitsbeschaffung war ein von der $\mathrm{Be}$ zirksvertretung gewählter „Arbeitspfleger“, der, zugleich öffentlicher Angestellter, Investitionsprojekte ausarbeitete, ihre Durchführung überwachte und je nach Bedürftigkeit hierfür Arbeitslose einstellte.

Auch eine Reihe weiterer von der Parlamentsfraktion der SdP vorgelegter Konzepte ${ }^{78}$ beinhaltete mehr oder weniger offene Kritik an den Unternehmern: So etwa die Absage an das Dumping, d.h. an eine Förderung des Exports um jeden und zu jedem Preis auf der Basis von „Kulilöhnen“. Auch die Forderungen nach Hebung der Kaufkraft durch Preisabbau und Lohnerhöhungen, nach einem Verbot von Überstunden, nach Verkürzung der Arbeitszeit - wenn auch ohne Lohnausgleich -, nach Einführung von Mindestlöhnen, nach Verbindlichkeitserklärung von Kollektivverträgen und Errichtung von Schlichtungsstellen zielten gegen unsoziale Arbeitgeber. Das im Betriebsausschußgesetz vorgesehene formale Mitberatungsrecht sollte zu einem echten Mitentscheidungsrecht erweitert werden.

Diese nicht sonderlich unternehmerfreundliche Einstellung der SdP war auch in den folgenden Jahren zu beobachten. Zwar dürfte die Kritik des Abgeordneten Wollner vom Januar $1937^{79}$ an der gegenüber den deutschen Unternehmern besonders rigorosen, bis zur Existenzvernichtung reichenden Praxis der Steuereintreibung diesen aus der Seele gesprochen haben; im gleichen Atemzug sprach Wollners Denkschrift allerdings auch von einer Korrektur der hohen Belastung der "schaffenden Volksschichten“ und der stärkeren Besteuerung der arbeitslosen Einkommen. Im Frühjahr 1937 veranlaßte eine leichte Wirtschaftsbelebung die Zentralstelle der Arbeiter- und Angestelltenschaft der SdP zu der Forderung an die Arbeitgeber, die Löhne auf ein menschenwürdiges Niveau anzuheben. Nachdem Lohnsenkungen und Rationalisierung, die Verschärfung der Intensität der Arbeit und die im Zuge der Kronenabwertungen verteuerte Lebenshaltung der Arbeiterschaft große Opfer abverlangt hätten, müßten nun die Arbeitgeber ihre Loyalität zum Volkgemeinschaftsgedanken beweisen. „Es kann und darf eben nur jener Unternehmer Mitglied der Sudetendeutschen Partei sein, dessen einwandfreie soziale Haltung nicht anzuzweifeln ist. ${ }^{\text {" } 80}$

Direkte Interventionen in soziale Konflikte lehnte die SdP allerdings ab. Ein Eingreifen sei nur erforderlich bei der Gefährdung deutscher Arbeitsplätze, wenn dies also „volkspolitisch“ geboten sei. Ansonsten seien Arbeitgeber - soweit als Parteimitglieder beeinflußbar - und Arbeitnehmer zur Verständigung anzuhalten. Leben ließ sich auf

78 SÚA, SdP, Karton 38, 23 ZAA/1935-38/2, Memorandum der parlamentarischen Fraktion der $\mathrm{SdP}$ an den Sozialpolitischen Ausschuß des Abgeordnetenhauses, in: Sozial-Mitteilungen der SdP 1 (1935), Folge 1, 2 und 3.

79 SÚA, SdP, Karton 52, 28-Pk (1935-38)/4, Denkschrift des Abgeordneten Georg Wollner vom 15. 1. 1937 für die Minister Nečas (Fürsorge), Kalfus (Finanzen), Černý (Inneres), Dostálek (Arbeit) und Czech (Gesundheit).

80 SÚA, SdP, Karton 38, 23-ZAA/1936-38/1, SdP/Zentralstelle der Arbeiter- und Angestelltenschaft, Mitteilung OG-5/37 vom 22. 4. 1937. - SdP/Zentralstelle der Arbeiter- und Angestelltenschaft, Mitteilung OG-4/37 vom 22.4.1937. 
Unternehmerseite mit derlei Verlautbarungen, zumal die SdP den Streik - als ein das Volksvermögen schädigendes "Mittel des marxistischen Klassenkampfes“ - nur im Sinne einer ultima ratio gegen unsoziale Arbeitgeber billigte. Diese Zurückhaltung galt allerdings nur, solange nicht die "notwendigen" Instrumente nach dem reichsdeutschen Vorbild der Treuhänder der Arbeit zur Verfügung standen. ${ }^{81}$ Die breite Masse, so dekretierte Henlein in Leitmeritz im Herbst 1937, habe sowohl das Spiel der freien Kräfte wie auch die Klassenkämpfe satt. Wirtschaftliche und soziale Gegensätze würden von der SdP nicht geleugnet, jedoch in der Volksgemeinschaft aufgefangen. ${ }^{82}$

Derlei Volksgemeinschaftsrhetorik mag sich objektiv zugunsten der Unternehmer ausgewirkt haben, auf deren Seite die SdP sich übrigens in manchen Streiks durchaus schlug. ${ }^{83} \mathrm{Im}$ Wahlkampf waren auch Spendengelder der Industrie geflossen ${ }^{84}$, ohne daß deren Höhe und Herkunft genauer zu bestimmen wären. Ungeachtet dessen war die SdP keine Industriepartei. Die vom Frühjahr 1937 bis in den Herbst 1938 hinein andauernden Differenzen zwischen Henlein und Kaspar, der das sozialistische Element in der Partei repräsentierte - und die in unserem Zusammenhang nicht weiter interessieren - waren Ausdruck von Macht- und Personalfragen und beruhten nicht auf grundsätzlichen ideologischen Konflikten. ${ }^{85}$ Auf den Parteiversammlungen, etwa auf dem von über 80000 Teilnehmern besuchten „Fahnentreffen“ von Teplitz im Oktober 1936, präsentierte die SdP eine überwiegend aus Arbeitern bestehende Anhängerschaft mit einer starken Beimischung gewerblicher Mittelständler und Bauern. ${ }^{86}$ Dieses Erscheinungsbild war nicht etwa lediglich Kulisse. Die deutsche Industrie der Republik - dies die Bilanz Gustav Hackers, des „Parteiobmanns“ des Bunds der Landwirte für das Jahr 1937 - wünsche seit 1926 unverändert einen Gleichklang von Wirtschaft und Politik unter dem Rubrum des „Wirtschaftsaktivismus“. Es würden „von deutscher industrieller Seite Klagen darüber laut, daß es die deutsche Industrie immer noch nicht verstanden hat, sich in zweckentsprechendem Sinne in eine fortschrittliche, also aktivistische politische Entwicklung einzuschalten " ${ }^{87}$

Für die Sudetendeutsche Partei kam speziell der Hauptverband als Bundesgenosse nicht in Betracht. Abgesehen von der programmatischen Distanz galt dies aufgrund der Kooperation der deutschen Wirtschaftsorganisation mit dem Zentralverband: Der

81 SÚA, SdP, Karton 38, 23-ZAA/1936-38/1, SdP/Zentralstelle der Arbeiter- und Angestelltenschaft, Mitteilung OG-4/37 vom 22.4.1937.

82 Rede Henleins am Erntedankfest in Leitmeritz 1937, in: Tscherne (Hrsg.), Heim ins Reich, S. $41-$ 43, hier S. 41.

83 Dies war insbesondere der Fall bei dem Streik von 30000 Gablonzer Arbeitern, wo die Partei als Streikbrecher auftrat: Vgl. ÖStA, BAA, Gesandtschaft Prag, Zl. 246/Pol., Österreichische Gesandtschaft Prag an BAA, 15.6.1937.

84 Henlein wage, so die deutschen Sozialdemokraten, nicht mehr zu leugnen, daß die von dem „Industriezerstörer Dr. Doderer" gestifteten 800000 Kronen Industriegelder der SdP zugekommen seien: Vgl. SÚA, SdP, Karton 21, Flugschrift der deutschen Sozialdemokraten zu den Maiwahlen 1935.

85 So die korrekte Einschätzung in ÖStA, BAA, Gesandtschaft Prag, Zl. 165/Pol., Österreichische Gesandtschaft Prag an BAA, 8. 4.1937.

86 Der Bericht der österreichischen Gesandtschaft verzeichnet 60 Prozent Arbeiter, 30 Prozent Gewerbler und Kaufleute sowie 10 Prozent Bauern. Diese Angaben hier natürlich mit dem erforderlichen Vorbehalt gegenüber derlei Schätzungen zitiert: Vgl. ÖStA, BAA, 496/Pol., Österreichische Gesandtschaft Prag an BAA, 15.10.1938.

87 Hacker, Kleiner aktivistischer Gewinn. 
DHI, so eine Ausarbeitung der wirtschaftspolitischen Abteilung der Partei vom Dezember 1937, sei in den aktuellen Planungen von sekundärer Bedeutung, da er seinen Einfluß auf die Wirtschaftspolitik an den tschechischen Partner abgegeben habe: „Derzeit kann sich der deutsche Hauptverband der Industrie beim besten Willen nicht erfolgreich behaupten, nachdem er sich selbst entmannte." Da der Rest seiner Bedeutung auf die zahlreichen Fachverbände übergegangen sei, müsse erstes Gebot deren Zusammenlegung und Rückgliederung in einem neuen Hauptverband "mit starker Zügelführung" in der Fach- wie in der Regionalorganisation sein. Das Recht der Zuweisung von Kompetenzen an eine solche De-facto-Neugründung hätte ganz selbstverständlich die Partei in Anspruch genommen. Die - im Rahmen einer allfälligen Wirtschaftsautonomie der Deutschen im Land - ins Auge gefaßte nationale Quotierung der Ein- und Ausfuhrkontingente beispielsweise hätte dann die üblichen Reisen „ein(es) Heer(es) von Intervenienten zwischen Prag und den wichtigsten Industriestädten“ zum Zweck der Aushandlung solcher Anteile erübrigt. „Die auf freiwilliger Grundlage aufgebauten sudetendeutschen Industrieverbände, die zum Teil auf das Niveau von Interventionskanzleien herabsanken, würden zu einem großen Teil arbeitslos werden, was uns mit großer Genugtuung erfüllte, denn sie könnten allmählich auf die ihnen neu zuwachsenden Aufgaben der Verwaltung der autonomen Wirtschaft umgeschult werden. " Hierfür müsse man ihnen "fürs erste klare Leitsätze an die Hand geben“, wie das in der reichsdeutschen Wirtschaftsorganisation der Fall sei. „Es wäre uns durchaus nicht gedient, wenn sich anstatt des Prager Paschalik nunmehr einige autonome Paschaliks auftun würden, die sich bald so räuspern würden, wie ihre Prager Vorbilder zu spucken beliebten. ${ }^{\circ 88}$

88 SÚA, SdP, Karton 31, 18 AA/WA 35-37/2, Ausarbeitung der SdP/Wirtschaftspolitische Abteilung, an Rudolf Schicketanz übersandt am 21.12.1937. 


\section{Die Politik - ein Keil zwischen den Verbänden: SdP, Hauptverband und Zentralverband (1938)}

1937 und verstärkt im Zeichen der Internationalisierung der Sudetenkrise 1938 radikalisierte sich die Henlein-Partei in Programm und Praxis; sie agitierte nun für eine Autonomie der deutschen Volksgruppe, in deren Konsequenz die Sprengung des tschechoslowakischen Staatsverbands gelegen hätte. Voraussetzung, zugleich Komplement einer solchen Abschottung der Deutschen war die „kleine Machtergreifung“, eine Formierung der Volksgruppe unter der Führung der Partei und ihre Transformierung in eine deutsche Volksgemeinschaft en miniature - allerdings bereits unter der Zielperspektive ihrer Eingliederung ins Reich. Dies war der Hintergrund, vor dem sich die Beziehungen zwischen den Industrieverbänden im letzten Lebensabschnitt der Republik entwickelten.

Die Autonomieforderung in unterschiedlich weit reichenden Varianten besaß im Kontext des Nationalitätenkonflikts eine lange Tradition. Jung hatte sie für die DNSAP 1927 in sieben Leitsätzen formuliert, denen zufolge ein eigener Landtag die politische Repräsentation des deutschen Siedlungsgebiets wahrnahm. Deutsch war dort die einzige offizielle Sprache, alle Staatsbediensteten waren Deutsche. Der Volksgruppe, bestehend aus allen tschechoslowakischen Staatsbürgern deutscher Volkszugehörigkeit, oblag die Pflege und Förderung der nationalen und kulturellen Belange. ${ }^{1}$ Auf der Aussiger Haupttagung der SdP am 28. Februar 1937 radikalisierte Henlein diese Konzeption: Er bekannte sich zu „Volkstum“ und „Deutschtum“ als höchsten Werten und forderte die Anerkennung der ethnischen Grenze und die völkische Selbstverwaltung. ${ }^{2} \mathrm{Die} \mathrm{Se}$ parierung der Staatsbürger und ihre Gliederung in Körperschaften des öffentlichen Rechts auf der Grundlage nationaler Kataster und die Eigenregierung im Siedlungsgebiet hätten faktisch die Bildung eines deutschen Staates im Staate bedeutet. ${ }^{3}$ Auch die am 27. April 1937 von der Parlamentsfraktion der SdP vorgestellten, auf den Grundlagen von Aussig fußenden Entwürfe von „Volksschutzgesetzen“ faßten die Volksgruppe als juristische Person, die unter anderem über das Recht verfügen sollte, bestehende freiwillige Organisationen in ihren Dienst zu stellen und deren Statuten zu formulieren. ${ }^{4}$ Die Selbstverwaltungsorganisation der Deutschen sollte unter anderem die Einrichtungen der Sozialversicherung, die nationalen Sektionen der Landeskulturräte und die Handels- und Gewerbekammern umfassen. Die auf freiwilliger Mitgliedschaft beruhenden Unternehmervereinigungen waren in Zwangsverbände mit der Befugnis zur Regulierung von Preisen, Produktion und Absatz umzuwandeln. Eine autonome Wirtschaftskammer als Spitzenvereinigung von Landeskulturräten, Kammern und Be-

1 Krebs, Kampf, 1938, S. $181 \mathrm{ff}$.

2 „Völkische Selbstverwaltung für das Sudetendeutschtum!“, Rede Henleins auf der Haupttagung der SdP in Aussig am 28. 2. 1938, in: Tscherne (Hrsg.), Heim ins Reich, S. 7-21.

3 Aufzeichung des Gesandten von Erdmannsdorff vom 2.3.1937, in: ADAP, Serie C, Band 6/1, Dokument Nr. 240, S. 519.

4 Gesetzesanträge der Sudetendeutschen Partei, 1937. Entwurf am 27.4.1937 überreicht vom Parlamentarischen Klub der SdP i.A. Henleins, gemäß der bei der Haupttagung am 28. 2.1937 in Aussig verkündeten Thesen. - Gmelch, Gesetzesanträge, passim (Die Arbeit war laut Vorwort „im Einvernehmen“ mit der SdP angefertigt und von dieser gebilligt worden). 
zirkswirtschaftsräten verhandelte Wirtschaftsfragen "vom nationalen Standpunkt aus“ und glich "volkspolitisch schädliches" Verhalten einzelner Interessentengruppen aus. ${ }^{5}$

Im Oktober 1937 hatte Peters, der inzwischen zur Partei gestoßen war, in einer Stellungnahme zu Janovskys Entwurf eines Wirtschaftsprogramms von einem solchen Unternehmen abgeraten, $\mathrm{da}$ "keine dringliche Aktualität" bestehe, ein Manifest hingegen zum Handeln verpflichte - dies in einer Situation, in der "wir keine Zwangsmittel besitzen, unseren Willen durchzusetzen “. Peters hatte insbesondere davor gewarnt, den Industriellen zu nahe zu treten: „Ein noch so weit gehendes Bekenntnis zur sozialen Gesinnung ändert praktisch an der sozial- und wirtschaftlichen (!) Lage gar nichts, dagegen eröffnet es Hoffnungen, die wir nicht erfüllen können und die wir nur scheinbar erfüllen könnten, indem wir den Angriff auf die Unternehmerschaft verstärken und damit unleidliche Verhältnisse schaffen “. Janovskys Papier könne die Unternehmer verstimmen; es setze eine nationalsozialistische Großraumwirtschaft voraus, nehme folglich auf „die Winzigkeit dieser Volkswirtschaft zu wenig Rücksicht“. Da die SdP auf die freiwillige Kooperation der Wirtschaft angewiesen sei, der gegenüber ihre Stellung schwächer als etwa gegenüber den Volkstumsverbänden sei, sei Werben besser als Drohen. „Aus meinen Erfahrungen weiß ich, wie zurückhaltend die wirtschaftlichen Kreise sind, auch wenn sie sympathisieren. Durch eine so eindeutige Rede Konrads (gemeint: Henlein, C.B.) können die wenigen Beziehungen zerreißen, die wir zu diesen Kreisen haben, wobei die Gefahr entsteht, daß uns die Wahrung des sozialen Besitzstandes schwerer als bisher wird. ${ }^{* 6}$

Hatte Peters zu diesem Zeitpunkt, zu dem „viele grundlegende Fragen“ noch nicht geklärt waren, eine Verlautbarung noch für ,inoppotun “ (sic!) gehalten”, so änderte die politische Entwicklung bald darauf die Geschäftsgrundlage. Die Zäsur zur letzten Phase der deutsch-tschechischen Beziehungen vor „München“" markierte im November Henleins Brief an Hitler, der offen die „Einverleibung des sudetendeutschen Gebietes, ja des ganzen böhmisch-mährisch-schlesischen Raumes in das Reich" als Ziel formulierte. ${ }^{8}$ Wenig später begann die SdP gegenüber der Wirtschaft fester aufzutreten. Auf der Wirtschaftstagung der Partei am 6. Februar 1938 proklamierte Henleins „Appell“ im Zeichen der Internationalisierung der "Sudetenfrage" den "totalen Verteidigungskampf" der Volksgruppe, welcher die "Ausrichtung" auch der angeblich unpolitischen Bereiche des Volkslebens zwingend mache: „Von der Entscheidung der Wirtschaft wird die Entscheidung des Sudetendeutschtums abhängen." Die "Volkswirtschaft" - im emphatischen Sinne - müsse „auch im Bereich des nationalen Kampfes eine neue Haltung einnehmen“, damit die Lebensgrundlagen gesichert, Überfremdung und „Tschechisierung“ abgewehrt werden könnten. Damit riß Henlein die Kluft zu den Tschechen auf dem ureigensten Terrain des Hauptverbands auf: „Gerade im Wirtschaftsbereich“ gebe es „eine

5 Simon, Selbstverwaltung, S. 107-109.

6 Peters befürwortete eine Veröffentlichung höchstens als „Probeballon“ unter der Verantwortung des Verfassers Janovsky und schlug ansonsten die Überweisung an einen Ausschuß von Vertrauten "Konrads“ bzw. eine parteiinterne Vorklärung unter Einschaltung Richters, Rosches, Kreibichs und Wannemachers vor. Das Elaborat müsse diesen „ohne Geheimnistuerei“ zur Diskussion vorgelegt werden: Vgl. SÚA, SdP, Karton 71, Peters an Henlein, 14.10.1937, und Stellungnahme Peters' vom 14. 10.1937 zum „Wirtschaftsprogramm der SdP“.

7 Ebenda.

8 ADAP, Serie D, Band 2, Dokument Nr. 23, S. 45, 47, Henlein an von Neurath, 19.11. 1937 mit dem „Bericht für den Führer“ in der Anlage. 
unendliche Fülle komplizierter Methoden für die systematische Enteignung eines Besitzes..., mit denen man die tatsächlichen Hintergründe der sich abspielenden Vorgänge sehr wohl zu tarnen versteht". $\mathrm{Zu}$ diesen subtilen Fesselungen rechnete die Rede nicht zuletzt die Vernetzung der deutschen mit der tschechischen Ökonomie. Einer solchen Verbindung wurde folgerichtig eine schroffe Absage erteilt. Die Trennlinien quer durch die Wirtschaft wurden nun in jeder erdenklichen Hinsicht gezogen: Die „Widerstandsfront" gegen den Gegner beginne bei der Zusammensetzung der Belegschaften, über die nicht „die Billigkeit der angebotenen Arbeitskraft, sondern die völkische Zugehörigkeit des um Arbeit Werbenden ... mitentscheiden" müsse. Die deutsche Wirtschaft, welcher kaum verhüllt "Internationalismus“ und Kungeln mit den Tschechen vorgeworfen wurde, müsse zum Nutzen der Volksgenossen investieren und nicht ihr Kapital bei tschechischen Banken anlegen. Mag auf der Wirtschaftstagung Henleins Kampfansage an den Bolschewismus auch angenehm in den Ohren der anwesenden Unternehmer geklungen haben, so scheute der Parteiführer andererseits nicht vor harscher Kritik zurück und mahnte gebieterischer denn je die Umkehr vom Profitdenken zur "Gesinnung" und den „sittliche(n) Wille(n)“ zum Ausgleich in der Volksgemeinschaft an. Die „völkische Bewegung" war als Partner in Tarifverhandlungen und bei der Gestaltung der Arbeitsbeziehungen anzuerkennen. Diese Forderung implizierte konkrete Interventionsrechte auf einem zentralen Betätigungsfeld des Hauptverbands und entsprach der Auffassung vom Primat der Partei über die Ökonomie. ${ }^{9}$

In Anwesenheit wichtiger Exponenten des deutschen Wirtschaftslebens ${ }^{10}$ spannen Henlein und Janovsky zwei Wochen später, auf der Konferenz von Teplitz-Schönau am 20. Februar ${ }^{11}$, das Leitmotiv von der Wirtschaft als dem "nationalpolitischen Schlachtfeld erster Ordnung" und der Notwendigkeit ihrer „Ausrichtung und Neuordnung" im Sinne der „volkspolitischen Entwicklung“ weiter. Da für zwei Jahrzehnte deutsche Wirtschaftsmisere von der Kriegsanleihefrage über die Bodenreform und die Bankensanierung bis zur Handelspolitik, zur Industriekrise und zur Benachteiligung bei der Vergabe von Staatsaufträgen einzig die "Tschechisierung" verantwortlich sei, müßten die „sudetendeutschen Wirtschafter“, deren Sein oder Nichtsein „vom Ausgang der nationalpolitischen Auseinandersetzung“ abhänge, „endgültig erkennen, daß sie beim heutigen Stand der politischen, wirtschaftlichen und nationalen Verhältnisse keine Möglichkeiten der Selbstverteidigung mehr" besäßen; einzige verbleibende Option sei die Eingliederung in die Abwehrfront.

Die "positive" Vision offerierten in Teplitz Janovskys Ausführungen zur Exportpolitik. Sie gründeten auf der seit 1935 propagierten Orientierung der tschechoslowakischen

9 Die ursprüngliche Fassung der Rede war, wie die handschriftlichen Eintragungen in das Manuskript beweisen, noch um einiges schärfer formuliert. Ob die Redaktion des Textes von Henlein selbst stammt, ist unklar. Die wichtigsten Änderungen im folgenden (die Fassung $\mathrm{n}$ a c h Korrektur jeweils in Klammern): 1. Die Wirtschaft sei in eine Haltung abgeglitten, in der nur mehr der Profit maßgebend gewesen sei (die Wirtschaft sei im allgemeinen in eine Haltung abgeglitten...). 2. Die Wirtschaft habe sich widerstandslos gegenüber „entartenden “ Einflüssen gezeigt (...weitgehend widerstandslos...). 3. Nicht die Lohnkosten dürften, sondern die völkische Zugehörigkeit des Bewerbers um Arbeit müsse bei der Einstellung entscheiden (mitentscheiden): Vgl. SÚA, SdP, Karton 2, KH 1937-4/21, „Appell“ Henleins an die sudetendeutsche Wirtschaft auf der Wirtschaftstagung der SdP am 6. 2.1938.

10 HA 17 (1938), S. 134.

11 Leitsätze, S. 1-26 (Henlein) und S. 27-56 (Janovsky). 
Wirtschaft auf das Reich. Besiegelt sei das Schicksal der „schrankenlosen Weltwirtschaft". Mitgedacht als Rahmenbedingung war die Autarkie der großen handelspolitischen Blöcke, welche lediglich subsidiär außenwirtschaftliche Beziehungen unterhielten. Janovsky griff auf sein 1936 formuliertes Konzept ${ }^{12}$ des Handels in geographisch zusammenhängenden Ergänzungsräumen zurück. Vom Donauraum könne Deutschland nicht ferngehalten werden; dort fungiere die reichsdeutsche im Bund mit der deutschen Industrie in Böhmen und Mähren als „natürliche“ Industriewerkstätte des europäischen Südostens. Ein Neubau der Handelsbeziehungen nach dem Grundsatz der nationalwirtschaftlichen Ergänzung setze die Abstimmung der beiden Volkswirtschaften schon nach der Produktionsseite voraus, was einem Teil der tschechoslowakischen Ausfuhr die Grundlage entziehen werde.

Das Konzept einer mitteleuropäischen Volkswirtschaft unter der Hegemonie des Deutschen Reichs ordnete sich in ältere, in die vornationalsozialistische Zeit zurückreichende Denktraditionen ein. 1930 hatte Hans Herdegen das Projekt eines „auslandsdeutschen Wirtschaftskörpers" im Rahmen eines autarken zentraleuropäischen, deutsch dominierten Blocks vorgelegt, das die Auskoppelung der deutschen MinderheitenÖkonomien in Ost- und Ostmitteleuropa aus den dortigen Nationalwirtschaften und ihre engere Verflechtung mit der reichsdeutschen Wirtschaft beinhaltete. Die reichsdeutsche Auslandspropaganda sollte den Absatz deutscher Waren unter den Volksdeutschen steigern; das Reich seinerseits hatte beim Abschluß von Handelsvereinbarungen auf die deutsche Volksgruppe im Land des Vertragspartners Rücksicht zu nehmen. Der auslandsdeutschen Industrie wurde strengste Loyalität abgefordert: Geschäftsgeheimnisse und Patente sollten nur an Unternehmer gleicher Volkszugehörigkeit weitergegeben werden. Die Industrie der Volksgruppe war in Kartelle zusammenzufassen, die im Verbund mit ihren reichsdeutschen Pendants in den Konkurrenzkampf mit der "andersvolkliche(n) Industrie" eintraten. ${ }^{13} 1931$ hatte Krebs den Briand-Plan als Ausfluß französischen Hegemoniestrebens und das Coudenhovesche Paneuropa als Versuch einer Verewigung der „Versailler Verhältnisse“ verworfen und die Zusammengehörigkeit des Wirtschaftsraumes der ehemaligen österreichisch-ungarischen Monarchie mit Deutschland betont. Das deutsche "Lebensraumziel" verortete er im Osten, wo die deutsche Siedlung eine schwammige Grenze besaß und in vorgelagerte Sprachinseln ausfaserte. Dieser Raum sollte durch einen Bund abhängiger Staaten unter deutscher Führung, deren völkische Minderheiten als nationale Selbstverwaltungsgebiete dem „Mutterland“ zugeordnet waren, beherrscht werden. ${ }^{14} 1936$ erklärte Krebs’ „Kampf um Böhmen" unter dem Eindruck der "Macht der Tatsachen“ - gemeint waren die Wirtschaftsbeziehungen zwischen dem Reich und der ČSR - noch unverblümter ein mitteleuropäisches Wirtschaftsgebiet unter Einbeziehung Deutschlands zur „wirtschaftspolitischen Marschrichtung ". ${ }^{15}$

"Teplitz" fand auf tschechischer Seite ein lebhaftes Echo. Die Wirtschaftspresse tat das Programm Janovskys, „nota bene“ eines Mannes des $\mathrm{DHI}^{16}$, als nationalsozialistisch inspiriertes, auf Massenwirkung schielendes, in radikaler Phraseologie schwelgendes,

12 Janovsky, Neuzeitliches Wirtschaftsdenken.

13 Herdegen, Auslandsdeutschtum.

14 Krebs, Paneuropa, passim.

15 Krebs, Kampf (1938), S. 182-184 (unverändert gegenüber der ersten Auflage).

16 Diesen Gesichtspunkt betonte die HP vom 14.5.1938. 
gedanklich dürftiges und naives Produkt ab. ${ }^{17}$ Begeisterung, so die „Hospodářská politika“, habe die Schaustellung von Teplitz nur bei den einfachen Gemütern der ungebildeten SdP-Vertrauensleute erweckt, während sich die deutschen Industriellen verschreckt zurückzëgen. Auch das Volk aber - so verlieh das Blatt dem Vertrauen auf den ökonomischen common sense Ausdruck - werde bald einsehen, daß Janovsky seine Interessen schlecht vertrete. ${ }^{18}$ Englišs scharfsinniger Kommentar spürte die Wurzeln des Elaborats in der Volksgemeinschaftsidee auf. Das Konzept eines mit kollektiven Rechten ausgestatteten „Minderheitsvolkskörpers" umschiffe das unlösbare Problem einer Abgrenzung der in der ČSR unübersichtlich ineinander verzahnten und sich überlappenden Siedlungsgebiete von Tschechen und Deutschen. Engliš arbeitete die Widersprüche einer Konstruktion heraus, welche unter einem „solidaristischen“ Überbau Privateigentum und freies Unternehmertum vorsah; er betonte den wechselseitigen Zusammenhang von "Unternehmersystem" und Demokratie, wies den Hegemonieanspruch der Partei über die Ökonomie zurück und kritisierte die Vagheit der Ausführungen über die Gemeinschaft von Arbeitnehmern und -gebern, über die Festsetzung der Löhne nach Maßgabe von "wirtschaftlicher Tragbarkeit" und Gerechtigkeit. Wolkig seien auch die Strukturen der staatlichen Finanzwirtschaft und die angestrebte Quotierung des Staatsvoranschlags geblieben, obwohl diese einen der wichtigsten Schlüssel zur Lösung des Nationalitätenproblems darstellte. Dynamismus und Vergottung des Volks, der Appell an die Gefühle der Massen anstatt die Vernunft entlarvten, so Englišs Fazit, den trotz traditionalistischer Beimischungen wie der Mittelstandsrhetorik revolutionären Charakter der Bewegung und ihres Programms. ${ }^{19}$

Irritierend nahm sich unter diesen Umständen für die tschechischen Beobachter die Haltung der in Teplitz anwesenden Industriellen aus. Die Industrie der Deutschen im Lande sei, so Engliš, eine ausgesprochene Exportindustrie; die SdP hingegen erteile dem Welthandel eine Absage und heiße die Handelsblöcke willkommen, anstatt die Autarkiepolitik als das eigentliche Übel zu brandmarken..$^{20}$ Auch das „Hospodářský archiv" zeigte sich befremdet von der Teilnahme prominenter Wirtschaftsvertreter, die bislang mit den Tschechen zusammengearbeitet hatten und an einer Beendigung dieser Kooperation eigentlich kein Interesse haben konnten. ${ }^{21}$ Dieser Widerspruch löste sich unter der Prämisse auf, Janovsky könne eine Abkapselung der deutschen von der tschechischen Wirtschaft ins Auge fassen, weil er die politische Autonomie bereits am Horizont zu sehen vermeine. ${ }^{22}$ Der Beobachter der Präsidentenkanzlei sah in Teplitz bereits den Übergang zur unmittelbaren Vorbereitung der Absonderung unter Einbeziehung der Industrie als Träger wie als Rüstkammer des Nationalitätenkampfes vollzogen. Die Kosten der Separierungsstrategie für die Wirtschaft könne eine völlige Autonomie der mehrheitlich deutsch besiedelten Gebiete der Republik unter Führung der Partei keinesfalls aufwiegen. Der Berichterstatter warnte die tschechische Wirtschaft davor, in der Tagung lediglich eine Versammlung unpolitischer Industrieller und Bankiers zu sehen und sich auf die „persönliche Bekanntschaft, gesellschaftlichen und geschäftlichen

17 ONH 43 (1938), S. $407 \mathrm{f}$.

18 HP vom 5.3.1938, S. 168.

19 Engliš, „Deutscher Sozialismus“, passim. - Ders., Průmysl.

20 Ebenda.

21 HA 17 (1938), S. 134.

22 HP vom 5. 3. 1938, S. 168. 
Beziehungen zu den beteiligten Herren“ zu verlassen. Das Verhältnis der deutschen Industriellen zur SdP könne nicht „ausschließlich mit der von dieser Partei freiwillig übernommenen Funktion, soziale Spannungen durch Ableitung in nationale Kanäle privatwirtschaftlich unschädlich zu machen", verstanden werden, denn auf dieser Grundlage allein hätte die SdP kaum erfolgreich zu der Konferenz laden können. Zumindest konnte so nicht die Schroffheit des Teplitzer Auftritts erklärt werden - die Tatsache, daß die „oft mit der SdP verglichene reichsdeutsche NSDAP..., trotzdem sie als eine die totale Macht eines grossen Staates erstrebende Partei im Gegensatz zur SdP in der Lage war, ihren Protégés gewinnverheissende realisierbare Versprechungen zu machen, vor ihrem Machtantritt niemals gewagt (hat), ihnen in einem solchen fordernden Ton gegenüberzutreten“. Hinter den Kulissen müsse es folglich Zusagen der $\mathrm{SdP}$,als bevollmächtigte(r) Expositur einer zahlungsfähigeren Macht" gegeben haben. Im Klartext hieß dies: die Bevorzugung loyaler Unternehmen im Handel mit Deutschland. Die Handelsverträge würden als Instrument der Intervention in die inneren Verhältnisse anderer Staaten, im Dienste einer Expansion der deutschen Wirtschaft und der Gleichberechtigung der Auslandsdeutschen als Glieder einer deutschen Nation eingesetzt. ${ }^{23}$

Sind solche Absprachen in den Akten auch nicht dingfest zu machen, so legen spätestens die Ereignisse vom März nahe, den Schlüssel zu „Teplitz“ in den Wirtschaftsbezie-

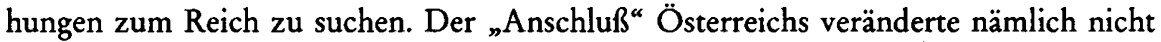
nur die militärische, sondern auch die handelspolitische Lage der ČSR entscheidend zu ihren Ungunsten und machte sie erpreßbar wie nie zuvor. ${ }^{24}$ Dies galt für die tschechoslowakische Volkswirtschaft insgesamt, besonders aber für ihr deutsches Element. Die „Verständigung“ auf dem Obersalzberg hatte in der Republik „erhebliche Beunruhigung" erregt; war diese zunächst noch gemischt mit der Hoffnung auf eine Weitergeltung der Zollpräferenzen, die Österreich wichtigen tschechoslowakischen Exportindustrien eingeräumt hatte, so prognostizierten die Experten doch eine Intensivierung der Handelsbeziehungen zwischen der "Ostmark" und dem "Altreich“ in beiden Richtungen und in deren Folge eine starke Einengung des tschechoslowakischen Exports nach Österreich, das 1937 nach Deutschland, den USA und Großbritannien immerhin der viertgrößte Exportkunde der Tschechoslowakei und ihr sechstgrößter Lieferant - bei einem Handelsbilanzaktivum der ČSR von 422 Millionen - gewesen war. Die deutschösterreichische Zollgrenze wurde bereits am 26. März teilweise aufgehoben; das Reichswirtschaftsministerium war ermächtigt, österreichische Waren vom Zoll zu befreien und die Beschränkungen des Zahlungsverkehrs zu lockern. Die Neufestsetzung des Reichsmarkkurses zum Schilling auf 1:1,5 wertete diesen um mehr als ein Drittel auf und erleichterte zum Schaden der bisherigen Handelspartner Österreichs den reichsdeutschen

23 AKPR, D 13 444/38, Karton 143, Information für den Präsidenten vom 23. 5. 1938. Der Vermerk basiert auf einem Bericht Dr. Nebesářs, ebenda. - Der Verfasser betrachtete die Ruhrhilfe als Analogie. Ein für die Sudetendeutschen psychologisch wichtiger Präzedenzfall sei auch der Handelsvertrag mit Litauen vom August 1936 gewesen, in dem dem Memelland eine bevorzugte Stellung eingeräumt worden sei.

24 Dieses Faktum wurde in der Wirtschaftspresse breit erörtert und kommentiert: Vgl. WR 11 (1938), S. 271f. - MDHI 19 (1938), S.114. - HR vom 17.3.1938. - HP vom 19.3.1938, S. 209. - WI 20 (1938), S. 123 f. - Horna, Splynutí. - Necker, Využití. - Vgl. als Zusammenfassung auch die Analyse der amerikanischen Diplomatie in: NA, State Dept, MPM 218, R 20, Department of State/Adviser on International Economic Affairs, Czechoslovak economy in relation to expansionist policy of Nazi Germany, Teil II, 24.6.1938. 
Absatz in die „Ostmark“. Abzusehen waren die Ausdehnung der Währungs- und Devisenvorschriften des Reiches und die Einbeziehung Österreichs in den Vierjahresplan. Bedroht waren neben den tschechoslowakischen Holz- und den Kohleexporten, deren Ersetzung durch die Ruhrkohle in Aussicht stand, in erster Linie die Metall-, die Textil-, Glas-, Papier- und die Porzellanindustrie - kurz: die deutsche Industrie der Tschechoslowakei. Die durch den „Anschluß“ bewirkte verringerte Diversifizierung der tschechoslowakischen Außenhandelsbeziehungen erhöhte ebenfalls die Abhängigkeit. Unter der - wenig realistischen - Annahme, der Handelsverkehr werde sich nicht reduzieren, hätte die Tschechoslowakei nun mehr als ein Fünftel ihrer Ein- wie ihrer Ausfuhr auf der Basis von 1937 mit "Großdeutschland" abwickeln müssen. Hinzu kam, daß mit der „Eindeutschung“ des Österreichhandels das vergleichsweise liberale österreichische Handelsregime, das keine Deviseninstrumente und kaum Mengenbegrenzungen kannte, von dem illiberalen reichsdeutschen abgelöst wurde. ${ }^{25}$ Deutschland beherrschte sämtliche Transitwege des tschechoslowakischen Exports, auch das „Schlupfloch“ Triest; das Reich war imstande, über die Festsetzung der Frachttarife die Konkurrenzfähigkeit der Tschechoslowakei auf Drittmärkten zu beeinflussen und die Suche nach Ersatz für den verlorengegangenen Österreichabsatz zu behindern. Unsicherheit herrschte auch über das Schicksal des intensiven grenzüberschreitenden Veredelungsverkehrs in Wolle, Leder und Seide, während sich das nordböhmische Bäderdreieck von der in Aussicht stehenden Einschränkung des österreichischen Kurbetriebs beeinträchtigt sah. Unterschiedliche Auswirkungen hatten die Finanzmärkte zu gewärtigen: Zwar war am Finanzplatz Wien lediglich die Živnostenská banka mit einer Filiale vertreten; keine der großen tschechoslowakischen Kapitalgesellschaften wurde nach der in den vorvergangenen Jahren durchgeführten Repatriierung der Aktien mehr von Wien aus beherrscht. Verwundbar waren aber die an der Wiener Börse notierenden tschechoslowakischen Unternehmen, die nie den Weg auf den heimischen Markt gesucht hatten, diejenigen mit Produktionsstätten in beiden Ländern sowie solche, die in der Tschechoslowakei produzierten, den Handel aber von Wien aus betrieben. Hierunter fiel insbesondere eine größere Zahl von Familiengesellschaften der Textilbranche, die trotz der Nostrifikation weiterhin von Wien aus verwaltet worden waren und deren Eigentümer zu einem guten Teil auch in der Zwischenkriegszeit in Österreich gelebt hatten. Die Wiener Gesellschafter intervenierten nach dem „Anschluß“ verstärkt in der Produktion. Wien solle, wie Janovsky im Organ der SdP, der "Zeit", ankündigte, zur Drehscheibe und zum Ausfallstor der deutschen und der österreichischen Wirtschaft nach Südosten werden und in der inneren Zone des großdeutschen Kraftfeldes - Ungarn, Jugoslawien, Rumänien und Bulgarien - die ihm gebührende Stellung einnehmen. ${ }^{26}$

Ein weiteres Druckmittel des Reichs war der Zugriff auf tschechoslowakisches Vermögen in Österreich: Bei der Einsetzung von Kommissaren in die Betriebe oder dem

25 HP vom 19.3.1938, S. $209 \mathrm{f}$.

26 Der Ost-Volkswirt vom 7. Juli 1938 veröffentlichte eine Liste der tschechoslowakischen Beteiligungen an Unternehmen, die auch in Österreich ansässig waren. Erfaßt waren allerdings nur Aktiengesellschaften. Vertreten war Kapital aus der ČSR in den Branchen Textil, Zucker, Bau, Glas, Berg und Hütten, Maschinen und Metall, Chemie, Getränke und Papier. Die Angaben zu der Zahl der Firmen und zum Teil zur Höhe der Beteiligung sind allerdings lückenhaft und lassen sich nicht zu einem aussagekräftigen Gesamtbild addieren. Informationen zu anderen Unternehmen fehlen überhaupt: Hier seien die Besitzverhältnisse aus den Eintragungen im Handelsregister kaum ersichtlich. - Zum Handelsplatz Wien vgl. Janovsky in der ZT vom 17. 3. 1938. 
Verbot der Veräußerung von Fabriken oder Aktienpaketen wurde generell keinerlei Rücksicht auf ausländische Eigentümer genommen. ${ }^{27}$ Der Anordnung vom 26. April über die Anmeldung des Vermögens von Juden ${ }^{28}$ unterlagen, wie die Prager Handelskammer feststellte, für die österreichischen 'Teile ihrer Anlagen in größerer Zahl auch tschechoslowakisch-jüdische Unternehmen vor allem der Textilbranche. Ihre Beschlagnahme und Übertragung auf neue, dem NS-Regime gegenüber willfährige Eigentümer ermöglichte eine Einmischung in die Betriebsabläufe auch in der ČSR. ${ }^{29}$ Als nutzlos erwiesen sich die Proteste der Konsulate gegen die im Zuge der „Arisierung“ geübte Praxis, mit mehr oder weniger sanftem Druck Unterwertverkäufe zu provozieren und die Unternehmen dann auszuschlachten. ${ }^{30}$ Nicht zuletzt gefährdete die "Arisierung" auch die Forderungen tschechoslowakischer Gläubiger. ${ }^{31}$

${ }_{n}$ Es ist vergeblich zu leugnen: Großdeutschland steht mit einem Fuße bereits in der sudetendeutschen Wirtschaft": Daß Janovsky unter dem Eindruck des „Anschlusses“ diese, die über die Wiener Direktionen ohnehin zum Teil bereits in den Vierjahresplan eingebaut war, im Geiste endgültig ins "Großdeutsche Reich" eingliederte, war so unrealistisch nicht. Janovsky machte der Industrie die Rechnung über die ins Haus stehenden Strukturwandlungen und Einbußen auf, stellte andererseits aber auch Vorteile durch den Transfer von Innovationen in Aussicht und legte nahe, in Berlin "den Antrag" auf Eingliederung der Tschechoslowakei in das von der Achse Wien - Berlin aufgespannte Kraftfeld zu stellen sowie direkte, von Prag nur mehr zu ratifizierende Vereinbarungen der deutschen Industriekartelle in der ČSR mit ihren reichsdeutschen Pendants anzubahnen. Die "unter der Fahne Konrad Henleins marschierende Politik" werde ihre Schuldigkeit tun, ihr Gewicht für die Behebung der Clearingprobleme mit dem Reich einsetzen und ihren Beitrag zur Wiedererlangung der Wettbewerbsfähigkeit leisten. Nur eine "grundsätzliche Änderung der politischen Systemeingliederung“, so die Reprise der von Janovsky bereits in den zwanziger Jahren formulierten Auffassung, könne die auf die Produktionskosten drückenden Staats-, insbesondere die Verteidigungsausgaben reduzieren und sie auf die wirtschaftliche und politische Bedeutung eines Kleinstaates abstimmen. In diesem Zusammenhang sei die nach wie vor im liberalistischen Fahrwasser segelnde Organisation der Industrie gut beraten, ihre Einstellung zu überprüfen: „Nach einer ernsthaften Gewissenserforschung im stillen Kämmerlein werden einige Gruppen dahinterkommen, daß man nicht tschechoslowakisch-liberalistische Ausfuhrpolitik machen und gleichzeitig auf das großdeutsche Wirtschaftspferd verstohlenerweise tippen kann. ${ }^{\alpha 32}$

Solche „Hilfe“ à la Österreich wies die tschechische Wirtschaftspresse allerdings entrüstet zurück. Die "Hospodářská politika“ beschuldigte Janovsky, mit manipulierten Zahlen das Fatum einer reichsdeutschen Wirtschaftshegemonie an die Wand zu malen und die durchaus erfolgversprechende Alternative einer Steigerung des Handels in die angelsächsischen Länder zu unterschlagen. Die deutschen Industriellen der Republik

27 HP vom 21.5. 1938, S. $426 \mathrm{f}$.

28 RGBl. I, S. 414 und die Durchführungsverordnung dazu ebenda, S. 415.

29 AMZV, Sektion IV, Karton 675, č.j. 89 425, OŽK v Praze an MZV, 17.6.1938.

30 SÚA, MPOŽ, Karton 1108, 76 825/38, Tschechoslowakisches Generalkonsulat Wien an MPOŽ, 26.6. 1938.

31 SÚA, MPOŽ, Karton 1108, 76 825/38, OŽK Prag an OŽK Eger, 30. 8. 1938.

32 Janovsky in der ZT vom 17.3.1938 . - Ders., Großdeutschland, passim; Zitate S. 34 bzw. S. 38. 
zögen selbst die Ausfuhr in die Devisenländer dem umständlichen und verlustreichen Clearing mit dem Reich vor, dessen Aufrüstungs- und Autarkiepolitik die Struktur des Warenaustausches deformiere, indem es die - zum guten Teil sudetendeutsche - Fertigwareneinfuhr der ČSR auf Rohmaterialimporte umzupolen suche. Eine besonders abgefeimte Zumutung war in den Augen des Kommentators das Projekt einer Integration der deutschen Wirtschaft der Republik in den Vierjahresplan und der Steigerung der Konkurrenzfähigkeit durch eine Senkung des tschechoslowakischen Militärbudgets, wodurch Deutschlands Aufrüstung mitfinanziert werden solle. ${ }^{33}$

Ungeachtet dessen war sich die gesamte Wirtschaft der Republik mit der nordböhmischen Industrie als Avantgarde ${ }^{34}$ und dem Hauptverband sowie dem Zentralverband als Aktionszentren des Ernsts der Lage bewußt. Die Handelskammerzentrale richtete in Zusammenarbeit mit dem Außen- und dem Handelsministerium eine spezielle Informationsabteilung ein. ${ }^{35} \mathrm{Am}$ 26. März bekundete Beran für die Agrarpartei dem deutschen Gesandten Eisenlohr Verständigungswillen. ${ }^{36}$ Am 3. Mai konferierten der ADTV, der tschechische Textilverband und die Sekretäre der Handels- und Gewerbekammern Brünn, Eger und Reichenberg im Außenministerium. ${ }^{37}$ Die Vollversammlung des ADTV am 7. Mai in Reichenberg stand dann unter dem beherrschenden Eindruck, die Politik sei das Schicksal der Wirtschaft. Das Jahr 1937 war insbesondere für die Textilwirtschaft wenig günstig verlaufen: Der von der Kronenabwertung im Oktober 1936 erhoffte Aufschwung des Exports war weitgehend ausgeblieben; der Binnenmarkt war flau. Die Ausfuhr des ersten Quartals 1938 lag unter der des Vergleichszeitraums von 1937 und hatte sich im Rahmen des Gesamtexports unterdurchschnittlich entwickelt, so daß der ADTV einen neuen Krisenschub konstatieren konnte, angesichts dessen in den kommenden Monaten über Sein oder Nichtsein der gesamten Branche befunden werde. Die Verhandlungen mit Deutschland entschieden „die Zukunft der nordböhmischen Textilindustrie für sehr lange Zeit. Wenn die Verhandlungen nicht im Geiste des möglichsten Entgegenkommens an die Wünsche Deutschlands als dem größten Abnehmer tschechoslowakischer Erzeugnisse geführt werden, und wenn sie nicht wenigstens den schon angedeuteten Erfolg der Erhaltung des Status quo heimbringen, dann ist ein

33 "Cato", Velké Německo.

${ }^{34}$ Die Klagen aus der Industrie der böhmischen Randgebiete, wo die Folgen der Weltwirtschaftskrise durch die des „Anschlusses" potenziert wurden, waren besonders laut: Vgl. WI 20 (1938), S. 145-147. - Nicht von ungefähr wurde gerade die mehrheitlich deutsche Reichenberger Kammer von der Kammerzentrale in Prag mit der Ausarbeitung der Verhandlungsgrundlage beauftragt. Das Korreferat verantwortete die Brünner Kammer, in deren Bezirk eine starke deutsche Textilindustrie beheimatet war: Vgl. AMZV, Sektion IV, Karton 970, Mappe 2, Handels- und Gewerbekammer in Reichenberg an MZV, 27.4. 1938, mit den beiden Ausarbeitungen in der Anlage. - Die Nordwestböhmische volkswirtschaftliche Vereinigung mit Sitz in Karlsbad unterbreitete der Regierung für die Verhandlungen mit dem Reich eine nach Branchen gegliederte Wunschliste: Vgl. BO vom 5. 5.1938.

35 Marek, Obchodní jednání. - Bacher hatte am 7. Mai kritisiert, daß die direkte Teilnahme von Industrievertretern an den Verhandlungen nicht vorgesehen war. Das Handelsministerium rechtfertigte dies mit der Ablehnung seitens des Reiches, betonte aber in diesem Zusammenhang noch einmal den engen Kontakt mit Zentralverband, DHI und den Kammern: Vgl. AMZV, Sektion IV, Karton 971, MPOŽ an Bacher, 13.5.1938.

${ }^{36}$ Aufzeichnung Eisenlohrs vom 27.3.1938, in: ADAP, Serie D, Band 2, Dokument Nr. 103, S. 155-157, v.a. S. 155.

${ }^{37}$ AMZV, Sektion IV, Karton 971, 1, ADTV an Tschechoslowakische Gesandtschaft Berlin, 17.5. 1938 . 
erheblicher Teil der tschechoslowakischen Textilindustrie zu einem jahrelangen Siechtum verurteilt. ${ }^{\alpha 38} \mathrm{Nach}$ dem komplikationslosen und vergleichsweise zügigen Abschluß eines Zahlungsabkommens am 16. Mai wurden in Berlin die Verhandlungen über die eigentlich komplizierte und problembefrachtete Materie des Güteraustauschs zwischen der Tschechoslowakei und dem erweiterten Deutschland fortgesetzt. ${ }^{39}$ Auf der Tagesordnung der beiden Regierungsausschüsse stand für die zweite Maihälfte ${ }^{40}$ die Überleitung der tschechoslowakischen Zollpräferenzen im Österreichhandel in eine deutschtschechoslowakische Übereinkunft. Besonderes Anliegen der ČSR war die Aufrechterhaltung des Fertigwarenanteils ihrer Ausfuhr in den von der reichsdeutschen Konkurrenz besonders bedrängten Konsumgüterbranchen Textil, Glas und Porzellan. ${ }^{41}$ Der Zentralverband legte außerdem der Regierung die Wahrung der tschechoslowakischen Verkehrsinteressen ans Herz. ${ }^{42}$

Über die stärkere Verhandlungsposition und die größeren Pressionsmöglichkeiten verfügte zweifellos Deutschland. ${ }^{43}$ Anfang Juni empfahl das Auswärtige Amt angesichts der "chauvinistischen Hetze" der tschechoslowakischen Medien - gemeint war ein Aufruf zum Boykott reichsdeutscher Waren -, in den Unterredungen möge bedeutet werden, daß das Reich die Transitwege der ČSR fast vollständig kontrolliere. ${ }^{44} \mathrm{Z}$ war hätten die Deutschen sich mit einer völligen Drosselung des Handels unter Einschluß der erwünschten oder gar unentbehrlichen Rohmaterialeinfuhren auch ins eigene Fleisch geschnitten; dies galt jedoch kaum für eine Reihe von Posten des tschechoslowakischen Fertigwarenexports wie Bier, Papier, Ton- und Eisenwaren, Autos, Maschinen und Chemikalien. ${ }^{45} \mathrm{Als}$ am 25. Juni die Verhandlungen für zwei Monate unterbrochen wurden, konnte das Auswärtige Amt denn auch feststellen, die tschechoslowakische Delegation habe gegenüber den deutschen sehr weitgehenden Forderungen eine beinahe erstaunlich nachgiebige Haltung " eingenommen - mit dem Ergebnis einer Regelung "völlig im Sinne unserer Wünsche“: Neben einer beträchtlichen Senkung ihrer Kohleexporte in die „Ostmark“ konzedierte die ČSR unter anderem eine erhebliche Erhöhung der deutschen Importe. Ihre eigene Ausfuhr ins ehemalige Österreich sollte sich zwar auf der Höhe des Vorjahres bewegen; dies galt allerdings nur bis Ende 1938 bzw. für die restliche Geltungsdauer des alten österreichischen Zolltarifs. ${ }^{46}$

38 Sitzung des Präsidialauschusses des ADTV am 21.3.1938, in: TR 20 (1938), S. 72 f. - Rede Liebiegs, Vollversammlung des DHI am 2.4.1938, in: TR 20 (1938), S. 83 f. - Rede Liebiegs, Vollversammlung des ADTV am 7.5.1938, in: TR 20 (1938), S. $116 \mathrm{ff}$ - - Ausschußsitzung des ADTV am 2. 4.1938 in Schönau, in: TR 20 (1938), S. 84f. - WI 20 (1938), S. $167 \mathrm{f}$.

39 OVW vom 2.6. 1938. - Woche des Kaufmanns (= Beilage zur WI) vom 18.6.1938, S.1.

40 BArch-B, RMFin, 8754, Clodius an Gesandtschaft Prag, 4. 4.1938.

$41 \mathrm{Vgl}$. zu den Details der Agenda und zu den tschechoslowakischen Interessen: BArch-B, RMFin, 8754, Aktenvermerk Spitta (Vorsitzender des deutschen Regierungsausschusses) vom 30.3.1938. - HR vom 14.4.1938.

42 AMZV, Sektion IV, Karton 970, Mappe 3, Zentralverband an MZV, 2. 5. 1938.

${ }^{43}$ Vgl. im Detail Journée Industrielle vom 23. 5. 1938.

44 PA, Handelspolitik, IVa, Handel 13, Tschechoslowakei, Band 12, Gesandtschaft Prag an AA, 4.6. 1938.

45 IfZ, NG-2951, Aufstellung Wiehl vom 3. 9. 1938, mit der Bitte um Genehmigung durch den Minister.

46 PA, Handelspolitik, IV a, Handel 13, Tschechoslowakei, Band 2, Aktenvermerk Clodius vom 27.6. 1938. - HR vom 29.6. 1938. 
Die geänderte außenhandelspolitische Lage potenzierte insbesondere gegenüber der deutschen Wirtschaft der Tschechoslowakei die Pressionsmöglichkeiten der SdP als "Fünfte Kolonne“ des Reiches. Vordem hatten die deutschen Industriellen in der ČSR über einen „Immediatzugang“ zu den reichsdeutschen Behörden verfügt: 1936 etwa hatte der Unternehmer Schicketanz im Auswärtigen Amt und im Reichswirtschaftsministerium über eine besondere Berücksichtigung im Rahmen der reichsdeutschen Kompensationsgeschäfte mit der ČSR verhandelt, war dort über die unverbindliche $\mathrm{Zu}$ sage einer "wohlwollende(n) Behandlung" allerdings nicht hinausgelangt. ${ }^{47}$ Noch kurz nach dem "Anschluß“ waren andere deutsche Firmen der Republik in Handelsangelegenheiten bei der deutschen Gesandtschaft in Prag vorstellig geworden ${ }^{48}$; im April 1938 verwies die Textilindustrie der Republik darauf, daß 70 bis 80 Prozent ihrer Österreichexporte aus den deutschen Firmen des Landes herrührten und bei einer Anwendung des reichsdeutschen Textilausfuhrregimes mit mehr als 10000 arbeitslosen deutschen Textilarbeitern gerechnet werden müsse. ${ }^{49} \mathrm{Mehr}$ und mehr errang nun aber die SdP die Kontrolle über die Wirtschaftsbeziehungen zum Reich und wurde, wie eine Flut von Anfragen und teilweise anbiedernden Unterstützungsgesuchen demonstriert, zunehmend zum Vermittler und Fürsprecher, zum Hebel, aber auch Filter des bilateralen Handelsverkehrs. Es fanden sich Gesuche um die Öffnung des deutschen Marktes ${ }^{50}$, um Hilfe bei der Erhaltung des Österreichabsatzes ${ }^{51}$ oder um Unterstützung bei der Aufrechterhaltung des Veredlungsverkehrs. ${ }^{52}$ Die Abteilung Wirtschaftspolitik der SdP ersuchte die reichsdeutschen Außenhandelsstellen um Bevorzugung bestimmter Unternehmer ${ }^{53}$ oder um den Einsatz von Devisen für den Einkauf bei deutschen Firmen in der Tschechoslowakei. ${ }^{54}$ Auch für die Landwirtschaft wurde die SdP tätig: Deren Vertreter erhoben wiederholt dringende Vorstellungen, ein Ausfall der Exporte in die „Ostmark" sei für die mehrheitlich deutschen Saazer Hopfenbauern existenzbedrohend. ${ }^{55}$ Für ein fundiertes Urteil über die Ergebnisse dieser Aktivitäten sind die Quellen nicht hinreichend. Wenig plausibel wäre aber die Auffassung, die SdP habe die Macht besessen, in größerem Umfang die Prioritäten der reichsdeutschen Handelspolitik zugunsten der deutschen Wirtschaft in der ČSR „umzubiegen“" ${ }^{56}$ Der Export, so bezeichnender-

47 PA, Handelspolitik, IV a, Handel 11, Nr. 3, Tschechoslowakei, Band 1, Vermerk Clodius vom 22.7.1936.

48 Vgl. etwa zum Fall einer Haidaer Kristallglasschleiferei in: PA, R 111 470, Gesandtschaft Prag an AA, 1.4.1938.

49 PA, Handelspolitik, IVa, Industrie 8, Tschechoslowakei, Band 1, Gesandtschaft Prag an AA, 28.4.1938.

50 „... wo doch Tschechen und Juden nach Deutschland ganz schön arbeiten..." $:$ Vgl. SÚA, SdP, Karton 44, Mappe 22a, Leinwandfabrik NN an SdP/Arbeitsamt, 2.8.1938. - SdP an NN, 4. 8. 1938, und eine ganze Reihe weiterer ähnlicher Vorgänge. - SÚA, SdP, Karton 44, Mappe 37, Schamottefabrik NN an SdP, Juli 1938.

51 SÚA, SdP, Karton 44, Mappe 22a, NN/Fabrik für Haushaltsgeräte an Kanzlei Henleins, 4.7.1938.

52 SÚA, SdP, Karton 44, Mappe 38, mehrere Gesuche aus der Zeit zwischen Juni und August 1938.

53 PA, R 111 470, Gesandtschaft Prag an AA, 25. 2. 1938. Hier handelte es sich um einen Hutproduzenten, der 250 deutsche Arbeitnehmer beschäftigte. Im Spiel waren also sozialpolitische Rücksichten.

54 SÚA, SdP, Karton 44, Mappe 22a, SdP-Kreis VII (Karlsbad) an Richter, 8. 7. 1938. Hier handelte es sich um ein Gesuch an die Berliner Überwachungsstelle für Kleider.

55 PA, Handelspolitik, IVa, Handel 13, Tschechoslowakei, Band 2, RMEL an AA, 29. 9. 1938.

56 Die Prüfungsstelle Chemische Industrie in Berlin gab Anweisung, die Lieferungen von Steril- 
weise die Wirtschaftspolitische Abteilung der Partei im Januar 1938, sei in die Clearingabkommen eingepreßt; jeder Ausfuhrfall müsse einzeln studiert werden, damit man im Rahmen der Verträge die Möglichkeiten ausschöpfen könne. ${ }^{57}$ Hier mögen im einzelnen die Ansatzpunkte zu suchen sein; eine Verschiebung der großen Linien ist nicht ersichtlich.

Nicht nur der Druck von außen machte zwischen dem Frühjahr und dem Herbst 1938 die Wirtschaft und ihre Verbände tendenziell übernahmereif. Hinzu kam eine geradezu revolutionäre Bewegung von unten. Der „Anschluß “ war nämlich auch das $\mathrm{Fa}$ nal für einen neuerlichen Schub der Nazifizierung in den Sudetengebieten, sozusagen für eine Machtergreifung en miniature gewesen. Der rasche Mitgliederzuwachs der SdP war nicht selten Drohungen gegen Leib und Leben geschuldet; an der Tagesordnung waren widergesetzliche Haussuchungen durch SdP-Patrouillen, Verstöße gegen das Verbot öffentlicher Aufmärsche und im Zusammenspiel mit dem Reich organisierte staatsfeindliche Kundgebungen. Die Propaganda der Partei hielt die Öffentlichkeit unter Druck; mit Beflaggung und öffentlich angebrachten nationalsozialistischen Parolen und Emblemen ähnelte das Straßenbild der Städte dem im Reich. Der der SS nachgebildete „Freiwillige Selbstschutz“, eine gut geschulte, auf den Bürgerkrieg trainierte Truppe, provozierte "Zwischenfälle“ und stellte anschließend die „Ordnung wieder her". Die Autorität des Staates wankte, die Staatsgrenze löste sich auf.

Hinzu kamen antisemitische Ausschreitungen und Terror gegen den politischen Gegner wie etwa gegen den DAWG-Senator Kostka nach einem parlamentarischen Auftritt gegen die SdP. In gewittriger Atmosphäre fanden im Mai die Gemeindewahlen statt. Das Ergebnis - über 90 Prozent der deutschen Stimmen für die SdP - kam durch Propagan$\mathrm{da}$, Bedrohung der Kontrahenten und Mißachtung des Wahlgeheimnisses zustande. Behörden und demokratische Parteien waren machtlos, Staatspolizei und Gendarmerie erwiesen sich als zu schwach gegen Rechtsbruch und Gewalt, wenn sie nicht gar, wie die deutschen Sozialdemokraten argwöhnten, eine gegen die Staatsräson verstoßende „Be-

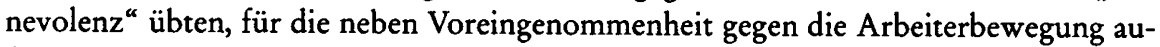
ßenpolitische Rücksichten maßgeblich gewesen sein dürften. Der „von der Propaganda der SdP mitgerissene Teil der Bevölkerung" befinde sich, so das Resümee einer Anfang Juni der Regierung überreichten Denkschrift der deutschen Sozialdemokraten, „psychologisch bereits außerhalb der Grenzen der Republik", und der sozialdemokratische Abgeordnete Taub bescheinigte Anfang Mai der SdP eine "ganz außergewöhnliche $\mathrm{Zu}$ versicht auf den Endsieg, das heißt den Einmarsch der deutschen Truppen“, dem, so die Hoffnung im „einfachen Volk“, bessere Zeiten folgen würden. In SdP-Kreisen herrsche

Katgut in die Tschechoslowakei solle dort mit Rabatt erfolgen, wo man es mit tschechischer oder englischer Konkurrenz zu tun habe. Bei sudetendeutscher Konkurrenz hingegen solle dieses "Dumping“ unterbleiben: Vgl. SOPADE, 5.6.1938, S. 557f. - Eine Ausarbeitung des Auswärtigen Amtes von Anfang September zur Frage weiterer potentieller wirtschaftlicher Druckmittel gegen die ČSR definierte eine Gruppe an sich entbehrlicher sudetendeutscher Exporte ins Reich; diese sollten, obwohl an sich unerwünscht, aber fortgesetzt werden, weil sonst die Sudetendeutschen geschädigt würden, ohne daß dies den tschechoslowakischen Staat besonders beeinträchtige. Wie man sich bei Wegfall dieser Zusatzvoraussetzung entschieden hätte, geht aus dem Exposé bedauerlicherweise nicht hervor: Vgl. IfZ, NG-2951, Aufstellung Wiehl vom 3.9. 1938, mit der Bitte um Genehmigung durch den Minister.

57 SÚA, SdP, Karton 31, 18 AA/Wa 35-37/4, SdP-Wirtschaftspolitische Abteilung/Janovsky an Kreisstandesvertreter Walter Ludwig, 5. 1.1938. 
"nicht nur geflüstert" der Glaube, „daß die Autonomie zur Ausschaltung jedes anderen politischen Einflusses benützt werden soll“ und das Übergangsstadium zur Gleichschaltung mit Deutschland sein werde. ${ }^{58}$ Auf der SdP-Haupttagung am 23. und 24. April 1938 stellte Köllner mit Genugtuung fest, die SdP habe den ihr „aufgezwungenen Parteirahmen gesprengt" und durch die „sudetendeutsche Volksorganisation“ ersetzt. Köllner proklamierte die "Ausrichtung" aller Lebensbereiche des "Sudetendeutschtums“ und das Ende des "Spuks" einer Unterscheidung politischer und unpolitischer Lebenssphären. ${ }^{59}$ In der Folge unterstellte sich eine lange Reihe Verbände aller Art von den Ärzten bis zu den freiwilligen Feuerwehren der Partei. 60

Mit einer Doppelstrategie von Terror und Verlockung brach die SdP auch in die Betriebe und die Arbeiterschaft ein. Der Nazifizierung der Belegschaften leistete Vorschub, daß die Arbeiter angesichts der immensen Arbeitslosigkeit gezwungen waren, die Waffen zu strecken „oder als Judas zu handeln" ${ }^{61}$, wollten sie der Entlassung oder der Aufnahme in dem Vernehmen nach bereits angelegte schwarze Listen begegnen. Attraktiv waren andererseits die Verdienstmöglichkeiten im Reich; hier war beim Beschäftigungsantritt allerdings die SdP-Mitgliedschaft nachzuweisen. Mehr als die Hälfte der Musikinstrumentenhersteller etwa wanderte 1938 nach Sachsen ab, wo die Löhne um die Hälfte über den tschechoslowakischen lagen und zudem zu einem sehr günstigen Umrechnungskurs in Kronen ausgezahlt wurden. Daß die Tschechoslowakei nach dem „Anschluß“ im Einzugsbereich von vier Rundfunksendern des Reichs lag, erhöhte zweifellos die Sogwirkung des „Modells Deutschland“ ".2 Treibende Kraft der Nazifizierung waren in vielen Betrieben, sogar tschechischen oder jüdischen, die oft mit still-

58 IfZ, NG-4381, 386678f., Eisenlohr an AA, 1.4. 1938. - SÚA, MPOŽ, Karton 196, p 2301/37-2, Bericht der Parlamentarierdelegation der Kommunistischen Partei vom 30.4.1938 über eine Fahrt ins Grenzgebiet vom 11. bis zum 15. April 1938. - AKPR, D 13 444/38, Karton 144, von Taub gesammelte Stimmungsberichte, hier aus Tachau, 14.4.1938. - Taub an Sobota, 6. 5. 1938, mit Bericht aus Neudeck vom 3.5.1938 in der Anlage. - Taub an Sobota, 7.5.1938, mit Bericht aus Böhmisch-Leipa vom 3.5. 1938 in der Anlage. - Denkschrift der sozialdemokratischen Arbeiterpartei, auf der Grundlage der Berichte auf einer Tagung der Sozialdemokraten mit anderen Koalitionsparteien, am 9.6.1938 an Minister Mlčoch übersandt. - SOPADE vom 5. 8. 1938, „Nachtrag“, S. $833 \mathrm{ff}$.

59 Rede Fritz Köllners („Die Ausrichtung der Bewegung“), Haupttagung der SdP am 23./24. 4. 1938 in Karlsbad, in: O.V., Lebenswille, S. 55, 60f. - Die Satzungen aus dem Jahre 1934 waren kurz vorher revidiert worden; sie lagen dem Hauptrat am 23. April zur Beschlußfassung vor und sollten am 12. Mai in Kraft treten. Hier waren die - laut Köllner ohnehin obsoleten - Bestimmungen über die ständische Gliederung gestrichen.

60 SÚA, MPOŽ, Karton 196, p 2301/37-2, Denkschrift über den Ausnahmezustand im deutschen Gebiet, am 9. 6. 1938 von Taub an Handelsminister Mlčoch übersandt. - Der Landesverband der freiwilligen Feuerwehren etwa unterstellte sich auf einer Versammlung in Neudeck Ende April/Anfang Mai der Führung Henleins. Hierzu wurde keine Debatte zugelassen; die große Mehrheit begrüßte den Entschluß mit „Sieg Heil“: Vgl. AKPR, D 13 444/38, Karton 144, Taub an Sobota, 6. 5. 1938, mit Bericht aus Neudeck vom 3.5.1938 in der Anlage.

61 AKPR, D 13 444/38, Karton 144, von Taub gesammelte Stimmungsberichte, hier Sonnberg, 6. und 24. 4. 1938.

62 SÚA, PMR, Karton 3945, Mappe "menšiny“ (Minderheiten), Protokoll der Beratung zwischen Hodža, Taub, Jaksch und dem Gewerkschafter Weigelt am 21.3.1938. - AKPR, D 13 444/38, Karton 144, von Taub gesammelte Stimmungsberichte, hier Sonnberg, 6. und 24.4.1938. AKPR, T 12/25, Karton 135, C 6, Aktenvermerk Sobota vom 7.4. 1938. - SÚA, MPOŽ, Karton 196, p 2301/37-2, Sozialdemokratische Denkschrift gegen den Ausnahmezustand. - AKPR, D 13 444/38, Karton 144, Taub an Sobota, 2. 5. 1938. 
schweigendem Einverständnis von Unternehmern und Direktoren agierenden SdP-Mitglieder unter den Angestellten. Die Betriebsleitungen sahen der Eroberung der Betriebsausschüsse tatenlos zu; ein Regierungserlaß gegen "wirtschaftliche Unterdrückung“ vom 13. Mai verpuffte. ${ }^{63}$ Unter den von Unruhen betroffenen Staatslieferanten befanden sich Aufstellungen des Generalstabs von Juni und Juli zufolge so bedeutende Betriebe wie Kunert (Textil), Riedel (Glas), die Neudecker Wollkämmerei und Kammgarnspinnerei, Mannesmann, Schicht, Larisch und die Tefa. ${ }^{64}$ Praktisch alle großen Werke im Grenzland, auch die unter mehrheitlich tschechischem Kapitaleinfluß, waren Anfang Juli Hort staatsfeindlicher Umtriebe. ${ }^{65}$ "Geradezu schlagartig" hatte sozialdemokratischen Berichten zufolge der Terror in Unternehmen eingesetzt, deren Wiener Stammsitze unter reichsdeutsche Botmäßigkeit geraten waren. ${ }^{66}$ Die kombinierte „Machtergreifung von unten und von außen" illustriert der Fall des Textilunternehmens Löry, wo dem Bericht der Union der Textilarbeiter zufolge „die Herren Angestellten“ im Werk bereits den Hitler-Gruß eingeführt hatten und „im März schon im Dritten Reiche zu sein" schienen. Zusätzlichen Schub verlieh dieser Entwicklung am 11. Mai das Auftauchen eines Repräsentanten der inzwischen "arisierten“ Wiener Zentrale der Firma, mit der erklärten Absicht, „Ordnung zu machen“ und die Politik aus dem Betrieb zu verbannen - was bedeutete, daß der Emissär die Mitgliederwerbung der SdP unter der Belegschaft mehr oder weniger "par force" förderte. ${ }^{67}$

Inwieweit die Betriebsleitungen diese Entwicklung duldeten oder gar förderten und inwieweit sie lediglich dem von Partei oder Belegschaften ausgeübten Druck nachgaben, ist nicht zu präzisieren. Daß deutsche Unternehmer, die deutschen Arbeitern Hungerlöhne bezahlten, zum großen Teil den "Gleichschaltungsterror" unterstützten und die SdP die „Profitansprüche der Kapitalisten“ vertrete, war aus den Gewerkschaften zu hören. ${ }^{68}$ Als Schutzbehauptung mag die Rechtfertigung des Direktors der Poldihütte gegenüber der Präsidentenkanzlei zu werten sein, die deutsche Industrie sei mehrheitlich gegen Henlein, die Großunternehmen könnten jedoch, erpreßbar wegen ihrer Filialen in Deutschland, schlecht Position beziehen. ${ }^{69}$ Andererseits bescheinigte sogar die "Př́tomnost" den deutschen Arbeitgebern im Land, wenn sie nicht Mitglieder der Partei seien, könnten sie nicht sicher sein, was ihre Angestellten im Schilde führten. ${ }^{70} \mathrm{Zwar}$

63 SÚA, MPOŽ, Karton 249, p 4126/35-40, PMR an alle Ministerien, 31. 5. 1938. - Einem Erlaß des Innenministeriums vom 29. Juli zufolge waren ungesetzliche, Unruhen in die Betriebe tragende Aktionen auf jeden Fall mit polizeilichen und strafrechtlichen Mitteln zu verhindern: Vgl. SÚA, MPOŽ, Karton 1111, č. 83799/38, Präsidium des Innenministeriums an Präsidium der Politischen Landesbehörde, 29.7.1938.

64 VHA, MNO/HŠ 233, 28/1/5/2, Generalstab an MNO, 7.6.1938. - VHA, MNO/HŠ 233, 28/1/5/4, Generalstab an MNO, 28.7.1938.

65 Der Večerník Práva lidu vom 11.7.1938 erwähnte die Neudecker und die Poldi-Hütte, deren Belegschaft Beziehungen zu NS-Kreisen in Sachsen unterhalte. Sogar die staatliche Tabakmanufaktur Joachimsthal sei von SdP-Einflüssen nicht frei.

66 SÚA, MPOŽ, Karton 196, p 2301/37-2, Sozialdemokratische Denkschrift gegen den Ausnahmezustand.

67 SÚA, MPOŽ, Karton 1107, 73168/38, Stellungnahme der Union der Textilarbeiter vom 19. 5. 1938, von PMR am 27.6.1938 an MPOŽ übersandt.

68 SÚA, SdP, Karton 21, Flugblatt „Schluß mit dem SdP-Terror in den Betrieben“, undatiert, etwa Ende April 1938, hrsg. vom Zentralvorstand der gewerkschaftlichen Industrieverbände.

${ }^{69}$ AKPR, Karton 84, T 182/22, Aktenvermerk Śámal vom 2. 5. 1938.

70 PŘ 15 (1938), S. $519 \mathrm{ff}$. 
sei, so das Blatt Anfang Juli, in einigen Industriellenkreisen die Stimmung "wild“, und man berausche sich an der Parole, lieber im Reich trockenes Brot essen als in der Tschechoslowakei Hunderttausende verdienen zu wollen. Andererseits sei aber auch Nüchternheit zu beobachten. Das Blatt billigte der SdP mehr Macht in der Wirtschaft zu als auf den ersten Blick ersichtlich und ortete eine starke Tendenz der Unternehmer hin zur Partei, sah die Situation aber im Fluß: Die „Sortierung" und Scheidung sei im Gange; niemand wisse derzeit über die Anteile pro und kontra Henlein Bescheid. Dessen Gegnern am ehesten zuzurechnen waren die als deutsch firmierenden jüdischen Unternehmen, die von den 1500 Mitgliedern des Hauptverbandes immerhin 25 bis 30 Prozent ausmachten. ${ }^{71}$

Im Zuge der Machtergreifung in der Wirtschaft begann die SdP, bislang in die Zuständigkeit des Staats bzw. der Verbände fallende Ordnungsfunktionen an sich zu reißen. Zwischen dem Frühjahr und dem Herbst 1938 wurde die Partei zu einer quasi-staatlichen Instanz, die nicht zuletzt der Formierung einer deutschen Separatökonomie Vorschub leistete. Bemühungen um die Katastrierung des wirtschaftlichen Besitzstandes der Volksgruppe blieben angesichts der Komplexität dieser Aufgabe und der kurzen Zeitspanne bis „München“ rudimentär. ${ }^{72}$ Wichtiger waren Initiativen zur Krisenbekämpfung: Die Abteilung für Wirtschaftspolitik befaßte sich mit der Wiederingangsetzung stillgelegter Betriebe. ${ }^{73}$ Kreditersuchen aus der Wirtschaft hatte die Partei seit jeher ihr Augenmerk gewidmet; das Ziel war, volkswirtschaftlich wertvolle Unternehmen zu erhalten „und nicht unüberlegt wieder Volkswerte zu vernichten“ ${ }^{74}$ Die SdP trat allerdings nicht selbst als Geldgeber auf, da ihr Mittel hierzu nicht zur Verfügung standen. ${ }^{75}$ Die Parlamentsfraktion hatte aber bereits 1935 erwogen, der Partei nahestehende Geldinstitute zur Unterstützung einzuspannen, da völlige Ablehnung „bei der Häufigkeit solcher Fälle leicht böses Blut machen “ könne. ${ }^{76}$ Einfluß wurde in erster Linie über Empfehlungen ausgeübt, was in der Regel durch die örtlichen Untergliederungen, in Fällen von allgemeinerer Bedeutung auch durch Fühlungnahme der Parteispitze mit den Bankenzentralen bewerkstelligt wurde. ${ }^{77}$

Erste Ansätze zu einer organisatorischen „Straffung“ der deutschen Wirtschaft der Republik durch die SdP datierten bereits aus dem Jahr 1935, als die Zentralstelle für

$71 \mathrm{PR} 15$ (1938), S. 420.

72 So ersuchte das Wirtschaftsamt der SdP Anfang August die Bezirksstelle Mährisch-Ostrau um Nennung der "deutschen Betriebe“ bzw. derjenigen mit deutscher Belegschaft im Bezirk Mährisch-Ostrau: Vgl. SÚA, SdP, Karton 44, Mappe 49, SdP/Wirtschaftsamt an SdP/Bezirksstelle Mährisch-Ostrau, 3.8.1938.

73 SÚA, SdP, Karton 31, 18 AA/Wa 35-37/4, SdP/Wirtschaftspolitische Abteilung an Ernst Schlinger, 4. 2. 1938.

74 SÚA, SdP, Karton 31, 18 AA/Wa 35-37/2, SdP/Bezirksstelle Schmiedeberg an Georg Wollner, 22. 6. 1936, anläßlich eines Einzelfalls.

75 So - stellvertretend für viele andere Fälle - die Auskunft an einen Antragsteller im März 1938: Vgl. SÚA, SdP, Karton 31, 18AA/Wa 35-37/2, SdP/Wirtschaftspolitische Abteilung an NN/Elektrotechnisches Büro, Teplitz-Schönau, 30.3.1938.

76 Vgl. SÚA, SdP, Karton 31, 18 AA/Wa 35-37/2, Gemeinsamer parlamentarischer Klub der SdP und der Karpathendeutschen Partei u. a. an Neuwirth und Peters, 13.9.1935.

77 So die Schilderung des Procedere anläßlich der Weiterleitung des Gesuches eines Parteimitglieds um einen Existengründungskredit an eine Filiale der Kreditanstalt der Deutschen: Vgl. SÚA, SdP, Karton 31, 18AA/Wa 35-37/2, SdP/Wirtschaftsamt an SdP/Bezirksstelle Winterberg, 8.2. 1936. 
Handel und Gewerbe im Zuge der Anbahnung einer Zusammenarbeit mit dem ADTV eine „Zusammenfassung" der deutschen Textilversandgeschäfte und ihren Anschluß an den Textilverband in die Wege geleitet hatte. ${ }^{78}$ Erst 1938 jedoch forcierte die Partei ihre Bestrebungen zur exklusiven Kartellierung der deutschen Unternehmer; solche Vereinbarungen, zu deren Vorreiter sich die SdP nun aufschwang, waren bis dahin ein wichtiges Operationsgebiet der Verbände gewesen. So bot die Partei dem Verband der Glasindustriellen an, im Parlament die Verbindlichkeitserklärung des Hohlglaskartellierungsvertrags zu betreiben. ${ }^{79}$ In den Verhandlungen über das Weberkartell schwang sich die SdP zum Protektor des ADTV gegenüber dem tschechischen Verband der Textilindustriellen auf. ${ }^{80}$ Der Partei wurde nun auch aus der Wirtschaft heraus die Schiedsrichterrolle in Kartellstreitigkeiten angetragen. Wo Kartelle auf privatrechtlichen Vereinbarungen gründeten, waren solche Interventionen rechtlich eigentlich nicht möglich; politisch waren sie trotzdem durchsetzbar. ${ }^{81}$ Die Überkapazitäten in der Zinkweißproduktion etwa waren durch Betriebseinschränkungen bzw. -stillegungen reguliert worden, bis 1938 ein „Außenseiterunternehmen“ diese Arrangements zu stören drohte. Die SdP, die aus „nationalen Gründen“ ein gütliches Einvernehmen für angebracht hielt, führte hier einen Ausgleich herbei. ${ }^{82}$ Im Zuge der Auseinandersetzungen des deutschen Radiohändlerverbandes mit der tschechischen Radioindustrie über eine Verlängerung des Mitte 1938 ablaufenden Konditionenkartells drängte die Partei auf die Verankerung eines „Schlüssels“ für die Beschäftigung Deutscher in der Geräteproduktion, wo diese bislang unterrepräsentiert waren. ${ }^{83} \mathrm{Daß}$ im Zuge dieser Verhandlungen einige tschechische Hersteller exklusiv den deutschen Kaufleuten, die sich inzwischen in dem SdPorientierten "Verband deutscher Funkhändler" zusammengeschlossen hatten, günstigere Bedingungen als bisher anboten, hatte Irritationen zwischen den deutschen und tschechischen Händlern zur Folge und war wohl als Zeichen für die wachsende Nervosität vor dem Hintergrund der politischen Hochspannung zu werten ${ }^{84}$ Bis Mitte September wurde trotzdem eine Einigung erzielt. ${ }^{85}$

Solche Aktivitäten der SdP begegnen, insgesamt gesehen, allerdings immer noch eher sporadisch als flächendeckend. Wie der Fall der Glasindustrie illustriert, setzten ökono-

78 SÚA, SdP, Karton 31, 18 AA/WA 35-37/4, SdP/Wirtschaftspolitische Abteilung an Verein der Ascher Textilindustriellen, 26. 2.1935.

79 SÚA, SdP, Karton 44, Mappe 32, Richter an Dr. Schmidt im Arbeitgeberverband der Glasindustriellen.

80 SÚA, SdP, Karton 31, 18AA/Wa 35-37/4, SdP/Wirtschaftspolitische Abteilung (Sebekovsky) an Josef Frank, 30. 3.1938.

81 So im Fall einer auf freiem Vertrag basierenden Knocheneinkaufsgesellschaft. Hier fühlte sich ein kleinerer Betrieb durch die "Großen" benachteiligt und bat deshalb die Partei - Eigentümer und Belegschaft waren Mitglieder - um ihr Eingreifen: Vgl. SÚA, SdP, Karton 51, 28-Pk (1935-38)1, Streit und Bergmann an den Parlamentarischen Klub der SdP, 29. 10. 1935, mit Darlegung des Sachverhalts vom 25.10.1935. - SdP, Abteilung Wirtschaftspolitik an den Parlamentarischen Klub, 10.12.1935.

82 Über den inhaltlich allerdings nichts in Erfahrung zu bringen war: Vgl. SÚA, SdP, Karton 51, 28PK (1935-38)1, Exposé der Firma Dudek über die Lage der Zinkweißindustrie in der Tschechoslowakei vom 1.6.1938. - SdP-Abgeordneter Klieber an Wolfgang Richter, 16. 6. 1938.

83 SÚA, SdP, Karton 44, Mappe 35, SdP/Wirtschaftsorganisation an Radiohändler Franz Plaschke, Reichenberg, 24.6. 1938. - WI 20 (1938), S. 177, 240, 306.

84 HR vom 14.7.1938. - Woche des Kaufmanns (= Beilage zur WI) vom 16.7.1938.

85 WI 20 (1938), S. 342. 
mische Erwägungen derlei politisch motivierten „Sonderbündeleien“ Grenzen: Ende Juni etwa betrieb die Partei die Wiederbelebung des zerfallenen Kontingent- und Preiskartells der Stangenglaserzeuger, dem neun deutsche, zwei tschechische und ein jüdischer Betrieb angehört hatten, und zwar in der Form einer "Zentralverkaufsstelle" ausschließlich der deutschen Betriebe. ${ }^{86}$ Dieses Vorhaben sah sich, wie der führende Glasindustrielle Walter Riedel monierte, mit dem "Egoismus“ und dem „mangelnde(n) Gemeinschaftsgeist" der deutschen Unternehmer konfrontiert, denen die Kartellbindung nicht genug Vorteile versprach. Jenseits solcher rhetorischer Pflichtübungen hielt aber sogar das Parteimitglied Riedel, an dessen "nationaler Gesinnung" schwerlich zu rütteln war, ein rein deutsches Kartell, das ja die tschechischen Konkurrenten nicht an der Nutzung ihrer Kapazitäten im vollen Umfang gehindert hätte, für unsinnig. ${ }^{87}$ Die ins Auge gefaßte Einigung, welche „die notwendige Ordnung am Gablonzer Platz durch den Einfluß der Partei“ zustandebringen sollte ${ }^{88}$, ist nicht mehr aktenkundig geworden; vermutlich wurde sie von der Entwicklung überholt.

Die Unterwerfung der Wirtschaft hatte am ehesten dort Erfolg, wo der Export als Druckmittel einzusetzen war. Das Paradebeispiel war die außerordentlich stark - zu Zeiten mehr als 90 Prozent - ausfuhrorientierte Gablonzer Glas- und Bijouterieproduktion $^{89}$, die zudem zum großen Teil auf reichsdeutsche Spediteure und den Transit durch Deutschland angewiesen war. An sich waren die Gablonzer Unternehmer traditionell freihändlerisch eingestellt und hatten sich in Prag für den Abbau von Handelshemmnissen eingesetzt. Ungeachtet manch irredentistischer Anwandlung waren sie in der Republik bald auf eine mehrheitlich staatsloyale Linie eingeschwenkt; sie hatten die demokratischen deutschen Parteien mitfinanziert, verhielten sich ansonsten aber, wenn nicht gerade ihre Exportinteressen auf dem Spiel standen, politisch indifferent. Erst die Weltwirtschaftskrise, die der tschechoslowakischen Wirtschaftspolitik zur Last gelegt wurde, mehrte den Einfluß der DNSAP in Gablonz und verhalf später auch der SdP zum Durchbruch. Dieser erschien die Gablonzer Industrie auch deshalb als ein äuBerst attraktives Werkzeug, weil die ausgedehnten internationalen Verbindungen der Branche sich in den Dienst ihrer Auslandspropaganda stellen ließen. Die Exporteure, unter ihnen viele Reichdeutsche, wurden nun zu Exponenten des völkischen Radikalismus, denen nach 1933 die Hitlersche Politik zur Bekämpfung der Arbeitslosigkeit zunehmend attraktiv erschien.

Dies war der Hintergrund dafür, daß die SdP die Branchenorganisation erobern konnte. Ihre Machtstellung sicherte sie durch die Kontrolle über die Vergabe der Heimarbeiten an die Produzenten. Das Gremium der Exporteure glich nun eher einer Zentrale der Partei als einem Wirtschaftsverband. ${ }^{90}$ Die 27 Mitgliedsfirmen waren zum großen

86 SÚA, SdP, Karton 44, Mappe 45, Richter an Riedel, 29. 6. 1938. - Aufzeichung der SdP, ungez., vom 29.6.1938.

87 SÚA, SdP, Karton 44, Mappe 45, Riedel an Amt für Industrie und Wirtschaftsorganisation der SdP, 5. 7.1938.

88 SÚA, SdP, Karton 44, Mappe 45, Arthur Schick an Hauptamt für Handel und Handwerk der SdP, 21.7.1938. - Schick an Peschka, 23. 7.1938.

89 Die Darstellung der Gablonzer Verhältnisse folgt der ausführlichen Schilderung in den beiden Artikeln von "Certus“, Budoucnost bzw. Politický protektorát. - Vgl. auch HR vom 18.11. 1937.

90 Ein Mitglied des Gremiums war etwa der Fabrikant Simm, dessen Sohn als ein Bindeglied zwischen SdP und NSDAP fungierte. Der Sekretär der Reichenberger Handels- und Gewerbekam- 
Teil, die jüdischen durchwegs, kaltgestellt, denn die zuständige reichsdeutsche Überwachungsstelle konzentrierte die Exportlizenzen auf drei „arische“ Töchter reichsdeutscher Firmen. Bei Licht besehen entsprach das Spiel mit reichsdeutschen Karten allerdings kaum dem Gablonzer Interesse, denn in den Handelsvertragsverhandlungen erwies sich das Reich nichts weniger denn entgegenkommend. Janovskys Konzept einer Integration der deutschen Wirtschaft der ČSR in den Vierjahresplan betrachteten die Exporteure eher mit säuerlicher Miene, denn eine konsequente Durchführung dieser Konzeption hätte den Selbstmord bedeutet.

Im Interesse der „Eindeutschung“ der Gablonzer Wirtschaft rief die Partei nun auch zum Schulterschluß von Exporteuren und Produzenten gegen Arbeitgeber, die Tschechen beschäftigten; als Bat'a über eine Tarnfirma in das Exportgeschäft einzusteigen suchte, stellte sich die SdP an die Spitze einer Gegenkampagne. ${ }^{91} \mathrm{Da}$ Beschwerden der Leidtragenden in Prag erfolglos blieben, fanden sich die tschechischen und die jüdischen Gablonzer Exporteure in andere Länder in einer separaten Organisation, dem Kleineisen-, Zelluloid- und Drechslerverband in Prag, zusammen. ${ }^{92}$ Die noch liberal durchwirkte Vorkriegsgeneration der Exporteure sah, soweit sie nicht ohnehin bereits abgetreten war, dieser Entwicklung apathisch zu oder setzte bereits auf die neue „Ordnungsmacht“. Lediglich die Gefahr des Boykotts Gablonzer Waren in den USA war geeignet, das „Protektorat“ der Partei zu mildern.

Die in Gablonz zu beobachtende Ausgrenzung "rassischer" und nationaler Gegner war kein Einzelfall. Die im SdP-nahen Branchenverband organisierten deutschen Radiohändler etwa hatten im Zuge ihrer Auseinandersetzung mit den tschechischen Produzenten zur Unterstützung der neuen deutsch firmierenden Radiofabrik „Radiophon“ aufgerufen - eine Aktion, die die tschechische Presse nicht zu Unrecht als Schritt auf dem Wege zum Wirtschaftsseparatismus einstufte. ${ }^{93}$ Erste Ansätze zur Absonderung waren bereits 1935 zu beobachten gewesen, als die SdP eine Kampagne für die Warenversorgung der Mitglieder über parteieigene Bezugsstellen ins Auge faßte. Trotz Unterstützung durch die deutsche Gesandtschaft, deren Angehörige über diese Zentralen größere Bestellungen tätigten, gelangte die Aktion über Ansätze im Kohlenhandel nicht hinaus. ${ }^{94}$ Jetzt trieb der Boykott die Keile zwischen dem „sudetendeutschen Wirtschaftskörper" und dem tschechischen tiefer. Er wurde auch auf der tschechischen Seite Anlaß von Abgrenzungsbestrebungen: Eine „nationale Vereinigung zum Schutz des tschechischen Marktes" etwa brandmarkte die deutschen Radiomarken "Telefunken" und "Blaupunkt" als "Geschwür am Körper der tschechischen Volksverteidigung“, Flugblätter warnten im Gegenzug zu Boykott-Aufrufen der SdP vor dem Kauf reichsdeutscher Waren als Beitrag zur Aufrüstung. ${ }^{95}$

mer, Dr. Knoll, war einer der wichtigsten Deutschnationalen, sein Schwiegersohn Dr. Kneisl war der Sekretär der Ausfuhrvereinigung.

91 Der Anlaß war vermutlich Bat' as Bedarf an Devisen für den Rohstoffeinkauf. Vgl. zu den Details, auch den technischen, dieses Vorgangs: SÚA, SdP, Karton 31, 18 AA/Wa35-37/2, $\mathrm{SdP} /$ Wirtschaftspolitische Abteilung an SdP/Kreisstelle Gablonz, 23. 10. 1937. - Atlas Importers Ltd. an „Herrn NN“, 16. 9.1937.

92 HR vom 18.11.1937. - SÚA, MPOŽ, Karton 1107, 68 981/38, PMV an MPOŽ, 10.6.1938.SdP/Kreis Gablonz an SdP/Arbeitsamt, 26. „Gilbhart" (!) 1937.

93 Vgl. Polední list vom 4.8.1938.

94 ÖStA, BAA, Zl. 346/Pol. bzw. Zl. 366/Pol., Gesandtschaft Prag an BAA, 12. 7. und 20. 7. 1935. 95 SÚA, SdP, Karton 44, Mappe 35, Národní sdružení pro ochranu československého trhu, Sektion: 
Die gleiche Stoßrichtung eignete der gegen tschechische Händler und Gewerbetreibende sowie jüdische Kaufleute unter der Hetzparole „Deutsche, kauft nicht beim Juden" in Szene gesetzten Boykottbewegung. Zu den Pressionen, welche die "nichtarische Bevölkerung" zum Verlassen der Grenzgebiete veranlassen sollten, gehörte nun bereits die Ankündigung der physischen Liquidierung der jüdischen „Bankpiraten“ ${ }^{96}{ }^{9}$ Die Ausschaltung der Juden aus dem deutschen Wirtschaftsleben der ČSR bediente sich auch des reichsdeutschen Hebels: Die Kohlenimporte aus den preußischen staatlichen Gruben, bislang in der Hand der jüdischen Firma Hermann Winter, wurden in ,arische Hände“ überführt und der Gesellschaft "Karbo “ übereignet, die zu je einem Drittel von der Kreditanstalt der Deutschen, der preußischen Grubenverwaltung und - dies war ein Kompromiß - der Bank der tschechischen Legion gehörte. Die Führung des Konsortiums lag bei der Kreditanstalt der Deutschen. ${ }^{97}$ Wirtschaftsboykott und Terror hatten zur Folge, daß zwischen März und September 1938 an die 170 tschechische und jüdische Firmen ins tschechische Gebiet der Republik verlagert wurden..$^{98}$ Dem "glajchšaltování" der Wirtschaft widerstrebende Unternehmer wurden gesellschaftlich isoliert; sie wie auch manche Sparer begannen, Einlagen und Wertpapiere von deutschen Kreditinstituten zu Prager Banken zu transferieren. ${ }^{99}$ Boykott provozierte Gegenboykott - auch auf diesem Wege wurden etablierte Beziehungen gekappt. Häuften sich in allen Branchen die Meldungen von der Ablehnung deutscher Produkte, so waren die Betriebe, deren Hauptabsatz ins tschechische Siedlungsgebiet ging, am meisten betroffen. ${ }^{100}$ Die Kommunistische Partei spitzte diesen Sachverhalt auf die Formel zu, die SdP-hörigen Kapitalisten seien der schlimmste Feind, die SdP aber der „Totengräber der sudetendeutschen Wirtschaft". Henlein habe zum ersten Mal im Dezember 1936 das „Kaufen nur bei Deutschen, Druck ausüben auf Kaufleute, daß sie bei deutschen Fabrikanten einkau-

Radio (Nationale Vereinigung zum Schutz des tschechoslowakischen Marktes): Flugblatt, undatiert (1938). Über diese Vereinigung war weiter nichts in Erfahrung zu bringen. - Für Mitte August war wegen des Boykotts ein Gespräch des Telefunkendirektors Horner aus Berlin mit dem Kreissachwalter Handwerk und Handel in der Kreisleitung Gablonz in Aussicht genommen: Vgl. SÚA, SdP, Karton 44, Mappe 35, Kreissachwalter für Handwerk und Handel/Kreis IV (Reichenberg) an SdP/Arbeitsamt, 13.8.1938.

96 SÚA, MPOŽ, Karton 196, p 2301/37-2, Bericht der Parlamentarierdelegation der Kommunistischen Partei vom 30. 4. 1938 über die Fahrt in die Grenzgebiete vom 11.- 15. April 1938. -SÚA, MPOŽ, Karton 196, p 2301/37-2, Denkschrift der deutschen Sozialdemokraten über den Ausnahmezustand im deutschen Gebiet, am 9.6.1938 vom Abgeordneten Taub an Handelsminister Mlčoch übersandt. - Ein Beschwerdeschreiben der tschechischen Gewerbetreibenden von Anfang August beklagte den scharfen Abfall des Umsatzes bei der deutschen Kundschaft: Vgl. AKPR, D 8613, Karton 119, Ortsgruppe Gablonz an der Neisse des Volkstumsvereins für Nordböhmen zusammen mit den örtlichen Parteigruppierungen an Präsidentenkanzlei, 8. 8. 1938.

$97 \mathrm{HP}$ (1938), S. $714 \mathrm{f}$.

98 AMZV, Sektion III, Karton 609, č.j. 122 915/1938, Sbírka propagačního materiálu. Národnostní otázky (Sammlung von Propagandamaterial. Nationalitätenfragen) č. 10 vom 26. 9. 1938.

99 Kř́ž, Henlein. - AMZV, Sektion III, Karton 609, č.j. 127 229, Hubert Ripka, Henleinovská autonomie v praksi (Autonomie à la Henlein in der Praxis), eine vom Außenministerium verantwortete Aufklärungsschrift.

$100 \mathrm{Vgl}$. etwa die Ascher Zeitung vom 2.7. 1938. 
fen" proklamiert - und dies ausgerechnet in Karlsbad, das jetzt zusammen mit den übrigen böhmischen Bädern einen Rückgang der ausländischen Besucher um mehr als die Hälfte zu verzeichnen habe. ${ }^{101}$

Daß andererseits die Gefahr wirtschaftlicher Einbußen als deutsch firmierende, faktisch jedoch internationale Exportunternehmen zu Zurückhaltung zu veranlassen geeignet war, illustriert der Fall Schicht: Die Interessen der Familie waren zu einem wesentlichen Teil durch ihre Auslandsaktivitäten umrissen. Chef des Aussiger Zweigs war der frühere DHI-Präsident Heinrich Schicht, in Wien war die von Werner und Kurt Schicht geleitete Zentrale des Konzerns für das Südosteuropa-Geschäft angesiedelt. War der britische Zweig der Familie mit seinem Oberhaupt Georg Schicht zwar noch in den Verwaltungsräten der mitteleuropäischen Gesellschaften vertreten, so bestimmte seinen Blick doch die Beteiligung an Unilever. Die SdP-Sympathien des Aussiger Zweigs waren in London, wo man auf den Absatz im westlichen Ausland angewiesen war, suspekt. Anläßlich eines Besuchs in Aussig provozierte Georg Schicht im Juli 1935 durch die Anordnung, jeder, der in SdP-Uniform das Werk betrete, sei sofort zu entlassen, einen heftigen Familienstreit mit dem Schwagerzweig. ${ }^{102}$ Die vermutlich von der Konkurrenz ausgestreute Nachricht, das Unternehmen habe Henlein mit acht Millionen Kronen unterstützt, veranlaßten Mitte 1938 Georg Schichts Prager Generalrepräsentanten Jan Diviš gegenüber Kanzler Sámal zu der hastigen Versicherung, Schicht sei unpolitisch; er sei allerdings machtlos dagegen, daß Mitarbeiter seiner Unternehmen der SdP angehörten und jüngere Mitglieder seiner weitverzweigten Familie mit dieser sympathisierten. ${ }^{103}$

Für die allenthalben in Gang befindliche Formierung der Wirtschaft und ihre Unterwerfung unter die Hegemonie der Partei lieferte die am 23. und 24. April auf der Karlsbader Amtswaltertagung vorgelegte Autonomiekonzeption Henleins ${ }^{104}$ eine Blaupause, welche auch das Organisationsmodell einer zukünftigen „sudetendeutschen Wirtschaft “ vorzeichnete. Ausgangspunkte waren die Kritik an den Defiziten der bisherigen Minderheitenpolitik und die schroffe Absage an den Aktivismus, dessen Chancen die Tschechen in den vergangenen zwölf Jahren verspielt hätten. Die Prager Regierung habe die Notwendigkeit einer Neuregelung zwar eingesehen, sich zu einer grundsätzlichen $\mathrm{Re}-$ medur jedoch niemals durchringen können. Die Rolle einer Minorität zu spielen seien die Deutschen im Lande nicht mehr bereit; mit einem "Minderheitenstatut" als einer Kodifizierung des minderen Rechtsstatus würden sie sich nicht abfinden lassen. Es

101 SÚA, SdP, Karton 21, Flugschrift der Kommunistischen Partei der Tschechoslowakei „Die Wahrheit über die Wirtschaftsnot in den Sudeten“. Ein ernstes Wort an die Sudetendeutschen, undatiert, (nach dem Juni 1938).

102 OVW vom 28.7.1938.

103 AKPR, D 7013/38, Karton 116, Aktenvermerk Sámal vom 21.6. 1938. - Vgl. auch PA, R 111 485, Bericht der Gesandtschaft Prag an AA, 19. 8. 1938, mit dem Text eines Artikels aus der Kattowitzer Zeitung „Polonia“ vom 9. Juni 1938, auf den sich das Flugblatt stützte bzw. mit dem Text dieses Flugblatts selbst.

104 AKPR, D 1016, Karton 130, Skizze zur Neuordnung der innerstaatlichen Verhältnisse auf Grundlage (sic!) der 8 Punkte aus der Rede des Vorsitzenden der Sudetendeutschen Partei, Konrad Henlein, in Karlsbad am 24. April 1938, undat., an Hodža überreicht am 7.6. 1938. Rede Henleins ("Wir wollen nur als freie unter Freien leben!“), Haupttagung der SdP am 23./24.4. 1938 in Karlsbad, in: O.V., Lebenswille. - SÚA, SdP, Karton 53, 28-Pk (1938) 8/21, Die bisherige Rechtsentwicklung und unsere grundsätzlichen Forderungen für eine Rechtsordnung. Rechtspolitisches Referat Ernst Kundts in Karlsbad am 23.4.1938. 
folgte ein nunmehr offenes Bekenntnis zum Nationalsozialismus und zur „Wiedergeburt" des deutschen Volkes, als dessen Teil die Deutschen in der Tschechoslowakei ungeachtet der Staatsgrenzen sich verstünden. Die Neuordnung des Staates sollte auf dem Gesamtwillen des souveränen Volkes der Republik fußen, der sich auf der Grundlage der Einzelwillen der im Staat siedelnden gleichberechtigten Völker bildete. Diese konstituierten sich als Rechtspersönlichkeiten mit je eigenen Repräsentationsorganen. Neben den bürgerlichen Rechten und Freiheiten der Individuen existierten auch kollektive Rechte und Freiheiten der „Volkspersönlichkeiten“; diesen standen das Selbstbestimmungsrecht, ein angemessener Anteil an der Leitung des Staates, Schutz gegen „Entnationalisierung " und - im Falle der Deutschen - die Freiheit des Bekenntnisses zur „Weltanschauung“ zu. Auf dieser Grundlage war nun nicht mehr die Regelung der Beziehungen zwischen einer deutschen Minderheit und einem tschechischen Staatsvolk, sondern die Neugestaltung des Verhältnisses zweier gleichberechtigter Völker zueinander angesagt.

Diese Konzeption beinhaltete die territoriale Umgliederung der ČSR in die Wirkungsbereiche der "Volkspersönlichkeiten“, somit die Absonderung des deutschen Siedlungsgebiets und die Aufteilung der legislativen und administrativen Kompetenzen zwischen den Organen des Gesamtstaates und einer völkischen Selbstverwaltung. Außenpolitische Angelegenheiten, beispielsweise der Abschluß von Staatsverträgen, oblagen weiterhin der - in nationale Kurien gegliederten - Nationalversammlung. Die Legislative war zwischen dieser und den Volksvertretungen aufgeteilt. Die Staatsausgaben, insbesondere die öffentlichen Investitionen, waren nach Maßgabe der „nationalen Gerechtigkeit" zu quotieren; zu veranschlagen waren „Wiedergutmachungsleistungen“. In den Etat waren auch die Mittel der Selbstverwaltung eingestellt, die dieser zur Eigenverwendung überlassen waren. Die Handhabung des Schlüssels überwachte ein Kontrollamt bei der obersten Rechnungsbehörde im Verein mit einer parlamentarischen Kontrollkommission.

Kundt kritisierte in Karlsbad eine Mißachtung der Deutschen nicht zuletzt in der Wirtschaft. Die deutschen Verbände seien ständig dem Druck des Zwangszusammenschlusses mit den tschechischen und der Gefahr der "Tschechisierung" ausgesetzt gewesen. Um dem in der Zukunft vorzubeugen, waren Beamtenstellen nach Nationalitätenproporz zu besetzen. Devisen- und Handelspolitik, Finanz- und Steuerwesen waren dem deutschen Einfluß zu öffnen. In einigen Ressorts wie etwa im Handelsministerium waren deshalb nationale Sektionen einzurichten. Auch ins Finanz- und ins Außenministerium, in die zentralen Institutionen des Geldwesens, die Nationalbank und das Reeskompte- und Lombardinstitut, in die Getreidegesellschaft, das Exportinstitut und die Exportkreditversicherung, das Statistische Staatsamt und den Statistischen Staatsrat, die Zentralversicherungsanstalt, den Wirtschafts-, den Investitions-, den Versicherungsund den Elektrizitätsbeirat waren deutsche Vertretungen einzubauen. In den Wirkungsbereich der obersten Selbstverwaltungsbehörde fielen die Aufsicht über Handelskammern und -gremien sowie das Recht zur Errichtung berufsständischer Pflichtverbände. Diesen oblag die Wirtschaftsförderung; sie nahmen auch die Aufsicht über die freien Wirtschaftsverbände wahr.

Die Karlsbader Autonomieforderungen und der weite Weg, den die SdP seit Henleins Rede von Böhmisch Leipa 1934 zurückgelegt hatte, waren das Generalthema der tschechischen Presse. Die Forderung nach einer nationalsozialistischen Exklave im de- 
mokratischen Staat, das Bekenntnis zu Pangermanismus und Rassismus, der Wille zur Revision der in den Pariser Vorortverträgen gezogenen Grenzen und die bloßen Lippenbekenntnisse zum tschechoslowakischen Staat stießen dort auf fast einhellige Ablehnung. ${ }^{105}$ In einer Erklärung des Außenministeriums für die internationale Öffentlichkeit zeigte sich die Tschechoslowakei bereit, den Forderungen in der Beamtenfrage, hinsichtlich eines Entnationalisierungsgesetzes, der Quotierung des Etats und - zu einem großen Teil - hinsichtlich der Selbstverwaltung und eines Entschädigungsgesetzes entgegenzukommen; die Lockerung der Kohäsion des Staates durch ein chaotisches Nebeneinander territorialer und zentraler Verwaltung gedachte man jedoch keinesfalls zuzulassen - einmal abgesehen davon, daß ein solcher Umbau schon an der Streulage der Nationalitäten scheitern müsse. ${ }^{106} \mathrm{Die} \mathrm{SdP}$, so Ministerpräsident Hodža, könne die Lösung der "Sudetenfrage“ allein im Rahmen der Verfassung, nicht aber auf der Grundlage territorialer Autonomie mit Verwaltungsgrenzen zwischen deutschem und tschechischem Gebiet anstreben. ${ }^{107}$

Die Beziehungen zwischen Hauptverband und Zentralverband blieben vom Klimawandel nicht unbehelligt. Allerdings waren auf der Vollversammlung des $\mathrm{DHI}$ in Teplitz-Schönau am 2. April die Töne ungeachtet der Teplitzer Manifestation der SdP, der außenpolitischen und außenwirtschaftlichen Umwälzungen immer noch auffallend moderat gewesen. Obwohl Henlein, der eingeladen war, aber an der Teilnahme verhindert zu sein vorgab, ein Grußwort mit dem Wunsch nach einer "geschlossene(n) Organisation der Arbeitgeber auf nationaler Grundlage“ und nach „volle(m) Verständnis“ für die politische Arbeit des „Sudetendeutschtums“ übermitteln ließ ${ }^{108}$, kreiste Mühligs Rede nicht um die Parteipolitik, sondern um die neuerliche Flaute in der Textil- und der Porzellanindustrie und in den Gablonzer Gewerben. Der Ruf des Präsidenten nach einer den „Anschluß" in Rechnung stellenden Verbesserung der Handelsbeziehungen zu Deutschland und der Schaffung eines mitteleuropäischen Wirtschaftsraumes war somit vorrangig durch die handelspolitische Misere und nicht durch großdeutsche Allüren motiviert. Ansonsten bewegten sich die Kritik an der Steuer- und Finanzpolitik und die Forderung nach einer Fokussierung der Wirtschaftspolitik auf das Kardinalproblem der Arbeitslosigkeit in den gewohnten Bahnen. Mühligs Ruf nach einer „Wiedererstarkung unseres Volkes" und die Bekundung des Willens zur Mitarbeit an der „Schaffung ausreichender Lebensgrundlagen" waren schwerlich als Bereitschaft zur Übernahme der der Wirtschaft von der SdP zugedachten Rolle zu werten, zumal der Präsident sich im gleichen Atemzug ausdrücklich zum „industriellen Gemeinschaftssinn“ bekannte, womit nach Lage der Dinge nur die Mitarbeit der Deutschen im Zentralverband gemeint sein konnte. ${ }^{109}$ In ähnlicher Manier spielte Liebieg zwar auf die politisch außer-

105 Gesandtschaft Prag an AA, 26. 4. 1938, in: ADAP, Serie D, Band II, Dok. Nr. 138, S. 194. - Peroutka, Německá otázka. - Aus der Wirtschaftspresse insbesondere HR vom 28. 4. 1938. - HP 12 (1938), S. $343 \mathrm{f}$.

106 AMZV, Sektion II, karton 619, Mappe 3, Memorandum on the National Policy of the Czechoslovak Republik, undatiert, aber ca. Frühjahr 1938.

107 Aufzeichnung Eisenlohrs über eine Unterhaltung mit Hodža am 23.3.1938, dat. 24. 3. 1938, ADAP, Serie D, Band 2, Dok. 103, S. 151.

108 Vollversammlung des DHI am 2.4.1938, in: MDHI 19 (1938), S. 136.

109 Rede Mühligs, Vollversammlung des DHI am 2.4. 1938, in: MDHI 19 (1938), S. 129-135. 
ordentlich "bewegte Zeit" an; einzige Pflicht des verantwortungsbewußten Industriellen sei in dieser jedoch die Sorge um die Wirtschaft, nicht die um die "notwendige politische Betreuung des Volkes“.110

Im allgemeinen billigten die tschechischen Kommentatoren Mühligs Kritik, betonten deren Übereinstimmung mit der Position des Zentralverbands und bemängelten lediglich ein Auftreten mit zu leiser Sohle. Das „Hospodářský archiv“111 wertete die Ausführungen des Präsidenten über die Notwendigkeit einer Unterordnung der Wirtschaft unter die Politik als taktisch motiviertes Zugeständnis an die „Heil-Hitler-Stimmung“, schrieb ansonsten aber den deutschen Industriellen im allgemeinen genug Nüchternheit und Besonnenheit zu, zu wissen, daß „Politik“ der Industrie nur schade. Tadelte der "Hospodářský rozhled“112 auch "Orientierungsschwierigkeiten“ des Hauptverbandes, eine gewisse Zögerlichkeit seiner Loyalitätsbekundungen zum Staat und eine aus manchen Parolen vermeintlich herauszuhörende, den Markspekulationen deutscher Unternehmer Anfang der zwanziger Jahre vergleichbare "Spekulation mit der deutschen Karte", so sah das Blatt die Unternehmerschaft doch größtenteils noch auf Seiten des Aktivismus. Einzig das volkssozialistische „České slovo"113 beschuldigte Mühlig, die tschechische Politik für alle Wirtschaftsnöte verantwortlich zu machen und zu unterschlagen, daß die tschechischen Unternehmen mit den gleichen Problemen zu kämpfen hätten. Die Klagen über die Bürokratie seien berechtigt; allerdings gehe in Deutschland die Reglementierung der Wirtschaft sehr viel weiter, während in der Tschechoslowakei die gelenkte Wirtschaft ihren Höhepunkt bereits überschritten habe. Zweifellos zu Recht replizierte die „Bohemia “114, Mühligs Ausführungen, die auch den tschechischen Unternehmern aus der Seele gesprochen hätten, seien hier verzerrt wiedergegeben worden.

Im Vorfeld des „Anschlusses“ und im Zeichen der Erosion der Christlich-Sozialen bzw. des Bundes der Landwirte - die Deutschen Sozialdemokraten waren aus plausiblen Gründen keine Stütze der Unternehmerschaft - drohten die aktivistischen Industriellen in der Folgezeit in ein Vakuum zu fallen. Der Kommentator des „Hospodářský rozhled $^{\text {“115, }}$, der dies mit erheblichem Unbehagen beäugte, legte angesichts der alternativen Optionen - Fortsetzung der Zusammenarbeit mit der tschechischen Industrie auf der Basis der bestehenden Gemeinsamkeiten oder Unterwerfung unter den Primat der Politik und wirtschaftspolitischer Stichwortgeber für die SdP - den deutschen Industriellen die Besinnung auf das abschreckende Beispiel der Aushöhlung der Unternehmerfreiheit im nationalsozialistischen Deutschland ans Herz und riet zu einer positiven Einstellung zu demjenigen Staat, von dem man die Erfüllung der industriellen Forderungen reklamiere.

Dissonanzen mit dem Zentralverband waren in Teplitz keine erkennbar. Preiss, am Besuch der Versammlung verhindert, ließ ein Plädoyer für den deutsch-tschechischen Ausgleich verlesen. ${ }^{16}$ Mühlig hatte ihm, da es seit jeher Usus gewesen war, die Texte

110 PA, Gesandtschaft Prag I/1c, Band 1. - Rede Liebiegs, Vollversammlung des DHI am 2. 4. 1938, in: MDHI 19 (1938), S. 137 f. und TR 20 (1938), S. 83 f.

111 Marek, Průmysl.

112 HR vom 7.4. 1938.

113 ČS vom 8.4.1938.

$114 \mathrm{BO}$ vom 10.4. 1938.

115 HR vom 7.4. 1938.

116 Vollversammlung des DHI am 2.4.1938, in: MDHI 19 (1938), S. 136. - Mühlig hatte schon einige Tage vorher begrüßt, daß Preiss in etlichen Punkten anderer Ansicht als die offizielle Poli- 
der großen Kundgebungen im vorhinein auszutauschen, Ende März sein Manuskript übersandt und sich für die „,in Anbetracht der Zeiten“ vergleichsweise temperamentvolle Fassung entschuldigt ${ }^{117}$, was Preiss post festum brieflich ausdrücklich billigte. ${ }^{118}$ Anfang April diskutierten die beiden Präsidenten, am zwölften des Monats auch die tschechischen Mitglieder des engeren Präsidialausschusses im Zentralverband Mühligs Teplitzer Forderungen, beide Male mit dem Ergebnis fast bruchloser Übereinstimmung. ${ }^{119}$ Preiss regte die Bildung einer paritätischen Kommission als Forum der Aussprache zwischen beiden Organisationen an; der Präsidialausschuß entsprach dem Wunsch des DHI nach Entsendung zweier zusätzlicher deutscher Repräsentanten ins Präsidium des Gesamtverbandes. ${ }^{120}$ Nach einer Unterredung mit Hodža konnte Preiss „mit absoluter Satisfaktion konstatieren“, der Ministerpräsident begrüße die Zusammenarbeit der Wirtschaftsverbände „mit Genugtuung“, er suche über Preiss' Vermittlung das Gespräch mit Mühlig und wünsche dessen Verbleib im Präsidium des Zentralverbands. ${ }^{121}$

Blieben kontrapunktisch zur "hohen Politik“ in den folgenden Wochen die Weichen vorerst auch auf Kooperation gestellt, so bahnten sich im Hauptverband doch gewisse Tendenzen zum Austritt aus dem Zentralverband an - in Preiss' Augen „in der heutigen Lage national-politisch vielleicht begreiflich", wirtschaftlich aber kontraproduktiv. Preiss regte ein "wenigstens in der Industrie“ geschlossenes Vorgehen mit Unterstützung der industriefreundlichen Parteien sowie den Besuch Mühligs in Prag an, „damit wir die Angelegenheit, wie unter uns üblich, offen besprechen und uns an dem gemeinsamen Vorgehen (!) einigen können“. ${ }^{122}$

Die Wende im Hauptverband ist nach Aktenlage nicht exakt zu datieren; auf einer für den 2. Juni anberaumten außerordentlichen Hauptversammlung wurde sie dann jedenfalls in aller Öffentlichkeit besiegelt. Atmosphärisches Indiz für die seit dem 2. April hinter den Kulissen stattgehabten Verschiebungen war der besondere Beifall für Wolfgang Richter, den Hauptleiter der SdP für Wirtschaftsorganisation und Industriefragen. ${ }^{123}$ Mühlig - der der Sitzung selbst gar nicht mehr beiwohnte - verzichtete nun „aus Gesundheitsrücksichten“ zugunsten des SdP-Mitglieds Theodor Liebieg auf das Präsidentenamt und wurde „unter lebhaften Sympathiekundgebungen“ zum Ehrenvor-

tik sei und im Sinne einer Verständigung zu wirken gedenke: Vgl. ANB, ŽB, S VII/i-1-I, 576, Mühlig an Preiss, 30.3.1938.

117 Vgl. ANB, ŽB, S VII/i-1-I, 576, Mühlig an Preiss, 30. 3. 1938.

118 Er gehe nicht konform mit etlichen Ansichten der tschechischen offiziellen Kreise und werde dies in der Generalversammlung des Zentralverbands offen zum Ausdruck bringen: Vgl. ANB, ŽB, S VII/i-1-I, 576, Preiss an Mühlig, Konzept vom 5.4.1938. - Mühlig seinerseits pflichtete einer Rede von Preiss zur wirtschaftlichen Lage von Anfang April bei: Sie stimme mit dem Inhalt der Erklärung auf der Teplitzer Kundgebung des DHI überein: Vgl. ANB, ŽB, S VII/i-1-I, 576, Mühlig an Preiss, 11.4. 1938.

119 Tschechische Eingaben sollten auf tschechisch, deutsche auf deutsch erledigt werden, d. h. die Nationalität des Ansuchers war in jedem Fall zu respektieren.

120 Vgl. zu den Details: ANB, ŽB, VII/i-1-I, 576, Preiss an Mühlig, 12.4.1938. - ANB, ŽB, VII/i-1-I, 906, Bericht Sádeks für Preiss vom 12.4.1938.

121 ANB, ŽB, VII/i-1-I, 576, Preiss an Mühlig, 12.4. 1938.

122 ANB, ŽB, VII/i-1-I, 576, Preiss an Mühlig, undatiertes Konzept. Der Text stammt aus dem Zeitraum zwischen der Vollversammlung vom 2. April (vorher ist von Austrittstendenzen nichts bekannt) und dem 2. Juni, d. h. dem Datum von Mühligs Rücktritt als Präsident des DHI.

123 Außerordentliche Vollversammlung des DHI am 2.6.1938, in: MDHI 19 (1938), S. 233. - ZT vom 3.6. 1938. 
sitzenden befördert. ${ }^{124} \mathrm{Daß}$ man in Nadelstreifen-Kreisen den Comment zu wahren verstand, zeigte auch die Laudatio, die Mühligs Wirken für den „Gemeinschaftsgeist“ in der Wirtschaft rühmte. ${ }^{125}$

Zweifellos korrekt verortete die Presse die Hintergründe von Mühligs Absetzung dem bescheinigt wurde, durch seine guten Beziehungen zu Preiss und zur Regierung viel für die deutsche Industrie erreicht zu haben - im Kontext der Machtergreifung der SdP im Verbandswesen, welcher der DHI angesichts der Nachgiebigkeit seiner führenden Kreise wenig entgegenzusetzen hatte. Mühlig hatte in der Folge von Henleins Karlsbader Rede resigniert - dies war Anlaß für die Einberufung des außerordentlichen Treffens gewesen. Da der Präsident kein Hehl daraus gemacht hatte, daß er das Teplitzer Programm nicht in allen Punkten unterstützte und eher auf die Kooperation mit den Tschechen baute, war der Konflikt mit Janovsky, dem unnachgiebigsten Vertreter der Gleichschaltung der deutschen Industrie, unüberbrückbar geworden. Dieser hatte gegen Mühlig sogar dessen mehrjährige Zugehörigkeit zur Freimaurerei ins Feld geführt. ${ }^{126}$ Mit dem Präsidenten schied eine Reihe seiner Gefolgsleute aus der Spitze des Hauptverbandes aus. ${ }^{127}$ Das Präsidium demissionierte in toto; neuer stellvertretender Vorsitzender wurde das SdP-Mitglied Emil Kreibich. ${ }^{128}$ Auch die übrigen Neubesetzungen zeugten vom Vorrücken der Partei. ${ }^{129}$ „Im Zuge der Veränderungen“" wurde nun auch der Sekretär des wirtschaftspolitischen Referates, Reinhard Schmidt, Janovskys Nachfolger, verabschiedet. Zum Geschäftsführer bestellte das Präsidium den Syndikus des Kreises Trautenau und der Fachgruppe Leinenweber/Trautenau im ADTV, Ernst Stade. Zugleich mit einer Vereinheitlichung der Organisation und weil der neue Verbandspräsident in Reichenberg ansässig war, wurde die Übersiedlung des Teplitzer Zentralbüros und des Finanzreferats dorthin beschlossen. ${ }^{130}$

Liebiegs programmatische Rede vor der außerordentlichen Vollversammmlung vom 2. Juni, deren Konzept die SdP dem neuen Präsidenten praktisch in die Feder diktiert hatte ${ }^{131}$, definierte das Selbstverständnis des Hauptverbands neu. Dieser firmierte nun

124 BO vom 3.6. 1938. - Gerüchte, Liebieg sei nur als Interimsvorsitzender für den Glasindustriellen Walter Riedel gedacht, dementierte Riedel energisch: Vgl. WI 20 (1938), S. 230.

125 Außerordentliche Vollversammlung des DHI am 2.6.1938, in: MDHI 19 (1938), S. 233.

126 ONH 43 (1938), S. 553. - HR vom 9.6. 1938.- Montagsblatt vom 6.6. 1938.

127 Es handelte sich um Grohmann (Teplitz), Bechert (Saaz) und, aus der Finanzverwaltung, Riethof (Teplitz).

128 Dr. Emil Kreibich, Gesellschafter der Firma Rudolf Webers Erben, Macospinnerei in Schlukkenau, Mitinhaber der Firma Friedrich Mattausch und Sohn in Franzenthal. Vorstandsmitglied des ADTV. Nach der Annexion des Sudetenlandes Leiter der Spinnerfachgruppe Sudetengau in Reichenberg und Nachfolger Liebiegs als Präsident der Reichenberger Kammer, damit Leiter der Wirtschaftskammer Sudetenland: Vgl. TR 21 (1939), S. 31.

129 In das Präsidium rückten ein: Walter Dudek, Karl Hielle, Hermann Klaubert, Franz Kluge, Walter Riedel, Adolf Steinecke, Wilhelm Weber und Hermann Wolfrum. Zumindest die SdPMitgliedschaft Riedels ist bezeugt, Weber vertrat die Partei schon seit längerem in der böhmischen Landesvertretung. Neue Mitglieder des Präsidialausschusses waren Friedrich HerringFrankensdorf und Hermann Larisch: Vgl. BO vom 3.6. 1938 und Bericht über die außerordentliche Vollversammlung, in: MDHI 19 (1938), S. 236.

130 WI 20 (1938), S. 195, 259, 263f., 274, 283. - MDHI 19 (1938), S. 308. - BO vom 3.6. 1938.

131 Kreibich hatte Richter das Konzept der Rede überbracht, die - so Richter dann an Liebieg „Sie, sehr geehrter Herr Baron, am 2. Juni halten werden“. Richter übermittelte am 28. Mai Liebieg den überarbeiteten Text: Vgl. SÚA, SdP, Karton 44, Mappe 48, Richter an Liebieg, 28. 5. 1938, . 
nicht mehr als „irgendeine Vereinigung von Industriellen zum Schutz privater Interessen“, sondern als ein der "Volksgemeinschaft" verpflichteter Verband der Deutschen Industrie, der aus diesem Grund an den jüngsten Entwicklungen hin zur Einheit der Deutschen in der Republik nicht vorübergehen könne. Liebieg machte sich die Auffassung von der Wirtschaft als "Volkswirtschaft“ im emphatischen Sinn zu eigen, in der die Sorge um die Erhaltung des deutschen Arbeitsplatzes erste Priorität genieße und die Unternehmer die „echte Werksgemeinschaft“ mit den „Gefolgschaften“ suchen müßten. Zwar bekannte er sich unverbindlich weiterhin zur Meinungsfreiheit und zur „Natürlichkeit“ permanenter Interessenkonflikte innerhalb der Wirtschaft, mahnte in den entscheidenden Fragen aber „Einheitlichkeit“ an und forderte die Eingliederung aller noch „beiseitestehenden" deutschen Unternehmen in den Hauptverband, dessen organisatorische Straffung sowie ein Ende der „unfruchtbaren“ Ausschußberatungen, an deren Stelle so wurde kaum verhüllt das Führerprinzip eingeführt - „wenige“ Männer „verantwortungsbewußt" zu handeln hätten. Zweideutig und zwiespältig nahm sich die Neubestimmung des Verhältnisses zum Zentralverband aus: Hier stellte Liebieg eine Überprüfung der "bisher bestehenden Bindungen“ in Aussicht, kündigte die Zusammenarbeit allerdings nicht schlichtweg auf, sondern insistierte lediglich auf einer weitaus nachdrücklicheren Repräsentation der deutschen industriellen Interessen und wirklich wirksamen Hilfe seitens der Regierung. ${ }^{132}$

In Deutschland wurden Liebiegs Ausführungen nicht zu Unrecht als Zeichen dafür aufgenommen, „daß der Geist der Autorität und des Führerprinzips seinen Einzug halten will in die Leitung der sudetendeutschen Industrie “. ${ }^{133}$ Ebenso korrekt verortete die tschechische Wirtschaftspresse ${ }^{134}$ das tendenzielle Abrücken vom Zentralverband im Prozeß einer „Vervolksgemeinschaftung“ der Deutschen mit „preußischer" Systematik; die SdP suche zu demonstrieren, daß Autonomie in allen Lebensbereichen realisierbar sei - nicht zuletzt in der Wirtschaft, wo die Dissoziation der Organisationen als Pendant zur parallel verlaufenden Lösung der Bande zwischen der deutschen und der tschechischen Wirtschaft im Alltag aufzufassen sei. Allerdings erschien auch dem „Hospodářský rozhled“ der Umstand bemerkenswert, daß der Hauptverband sich, trotz allem, keineswegs mit fliegenden Fahnen ergeben habe: Mühligs Rede im April, obwohl radikaler als gewohnt, habe überhaupt noch keine neue Qualität gezeigt, Liebieg habe am 2. Juni immerhin noch deutliche Spuren der Unsicherheit zu erkennen gegeben und sich anmerken lassen, daß er die Orientierung an Böhmisch-Leipa 1934 der an Karlsbad 1938 vorgezogen hätte. Der alte Industrielle, taktierend zwischen den zum Radikalismus tendierenden Unternehmern und einer immer noch aktivistischen Mehrheit, habe der Regierung in nationalsozialistischer Terminologie letztlich doch Kooperation angeboten. Ähnliche Halbherzigkeit bescheinigte der Kommentator der Organisationsreform: Liebieg habe das Führerprinzip nach dem Motto „fortiter in modo, suaviter in re“ eingeführt. Dem Präsidenten assistierte nun zwar anstelle der bisherigen „großen Ausschüsse“ ein Gremium dreier starker Männer, ansonsten aber war die Führungsspitze nicht verschlankt worden, sondern umfaßte weiterhin nicht weniger als zehn Vizepräsidenten und drei Kassenwarte. In den steigenden Schlammfluten des Antisemitismus

132 Rede Liebiegs, außerordentliche Vollversammlung des DHI am 2.6. 1938, in: MDHI 19 (1938),

S. 233-236. - BO vom 3.6. 1938.

133 WR 11 (1938), S. 700.

134 HR vom 9.6. 1938. 
stehend, hatte der Hauptverband zwar seine beiden jüdischen Vizepräsidenten zum Rücktritt genötigt, diese dann aber in den Präsidialausschuß aufgenommen; auch in anderen Ausschüssen saßen weiterhin Juden.

Daß die Brautwerbung so zögerlich verlief und der Hauptverband sich mit der in den Raum gestellten „Änderung der Statuten“ offensichtlich zurückhielt, brachte der „Hospodáŕský rozhled" nicht zu Unrecht mit den vitalen Interessen der deutschen Industrie in Verbindung. Wie 1918, als die deutschböhmische Wirtschaft vor dem Anschluß ans Reich zurückscheute, hätte die Realisierung von Janovskys Konzept jetzt, mehr denn zuvor, Glas, Porzellan und Textil einer technisch und ökonomisch weit überlegenen Konkurrenz ausgesetzt - einmal abgesehen von den Engpässen bei der Rohstoffversorgung, mit denen im Zeichen des Vierjahresplans zu rechnen war. Eine Autonomie à la Karlsbad aber hätte eine separate, vom innerböhmischen Markt ausgesperrte deutsche Wirtschaft zur Folge gehabt und deren vielfältige sonstige Komplementärbeziehungen zu den tschechischen Gebieten durchtrennt. Fatal hätte sich insbesondere die Abschneidung der Lebensmittelzufuhr aus Innerböhmen ausgewirkt, auf die die Grenzgebiete essentiell angewiesen waren. Soweit im Hauptverband trotzdem Nazifizierungstendenzen wirksam geworden waren, konnte man sich diese auf tschechischer Seite nur vor dem Hintergrund von Hysterie oder Terror erklären; immerhin habe die Kooperation unter dem Dach des Zentralverbands über Jahre hinweg ohne nennenswerte Divergenzen funktioniert und dem Hauptverband politische Wirksamkeit ermöglicht. ${ }^{135}$

Ungeachtet aller Turbulenzen waren die beiden Verbände nach wie vor auch personell eng verzahnt. Die Schnittmenge zwischen den 52 bzw. 24 Mitgliedern der Führungsgremien des Zentral- bzw. des Hauptverbands - Präsident, Vizepräsidenten und Präsidium bzw. Präsidialausschußmitglieder - wurde von acht Personen gebildet; ein Drittel der Führungsmannschaft des Hauptverbandes war also auch im Zentralverband in leitender Position vertreten. ${ }^{136}$ Ebenso ins Auge fielen die organisatorische Verklammerung sowie die Präsenz der Deutschen in den Fachgruppen des Zentralverbands und deren zahlreichen Untergliederungen. Als Fachgruppe Glasindustrie etwa fungierte der Wirtschaftsverband der Glasindustriellen der Tschechoslowakischen Republik mit Mühlig und Riedel als stellvertretenden Vorsitzenden; Ehrenvorsitzender des Arbeitgeberverbands der Glasbranche war Mühlig, erster Vorsitzender wiederum Riedel. Auch die deutschen und die tschechischen Arbeitgeberverbände waren weitgehend integriert: Der Konföderation Tschechoslowakischer Arbeitgeberorganisationen gehörten neben der Arbeitgeberhauptstelle des DHI der Verband der Deutschen Großgrundbesitzer, die Geschäftsstelle der Deutschen Land- und Forstwirtschaft in Prag, der Hauptverband des Deutschen Gewerbes und der Reichsverband der Deutschen Kaufmannschaft an. Im Verwaltungsausschuß der Konföderation saßen unter anderen Hans Tichi und Rudolf Fernegg als stellvertretende Vorsitzende, Kislinger und Doderer als Mitglieder. ${ }^{137}$

135 In den Ausschüssen hatte während dieser Jahre ein einziges Mal eine Kampfabstimmung stattgefunden, und zwar über die Frage, ob ein Industriellenball veranstaltet werden solle.

136 Nämlich Mühlig, Karl Hielle, Antonín Hödl, Fr. Kluge, Walter Riedel, Willy (Vilém) Weber, Felix Richter und Paul Bechert.

137 SÚA, ÚSČP, Karton 1, Přehled organisace ústředního svazu československých průmyslníků 1937/38 (Überblick über die Organisation des Zentralverbands der tschechoslowakischen Industriellen 1937/38). 
Preiss hatte Mitte Mai Mühlig nach Bekanntwerden von dessen Demissionsabsichten postwendend sein Bedauern ausgedrückt, im gleichen Atemzug aber auch dem Nachfolger Liebieg, der ihm noch im April zu seinen "mannhaften Worten“ und „außerordentlich verständnisvollen Darlegungen“ anläßlich der Hauptversammlung der Živnostenská banka gratuliert hatte, eine Aussprache über die Fortsetzung der Zusammenarbeit angeboten. ${ }^{138}$ Er wisse sich mit Liebieg einig in der Pflicht, ,in diesen Tagen offen zu bekennen, wie es nötig ist (!) mit den Deutschen zu einer Verständigung auf einer Basis, die beide Seiten befriedigen würde, und die zur Aufblühen (!) unseres gemeinsamen Vaterlandes führte, zu arbeiten " ${ }^{139}$ Liebiegs Beziehungen zur SdP waren offensichtlich fragiler: Mitte Juni versprach der neue Präsident zwar, die ihm übersandten Karlsbader Reden Henleins und Kundts eifrig zu studieren. ${ }^{140}$ Bezeichnenderweise wurde ein erster Termin für eine Zusammenkunft mit Henlein aber erst Mitte Juli vereinbart. ${ }^{141}$

Daß Liebieg ein unsicherer Kantonist war, erwies sich in aller Deutlichkeit auf der Vollversammlung des Zentralverbands am 14. Juni. Diese war im Zeichen der politischen Spannungen stärker besucht als sonst und stand in ganz besonderem Maße im Zentrum der öffentlichen Aufmerksamkeit. Anwesend waren die wichtigsten Persönlichkeiten des wirtschaftlichen und politischen Lebens der Republik. Als Symbol des Zusammenrückens angesichts der lebensgefährlichen Bedrohung des Staates wertete die Presse den minutenlangen Beifall für den Ministerpräsidenten; präsent war die Tagespolitik aber auch im großen Applaus der tschechischen Seite für Liebieg. Hellhörige Beobachter notierten die Zweisprachigkeit der Versammlung sowie die kleinen Symbole wie Liebiegs kräftigen Beifall für die Rede Bat'as und vice versa. ${ }^{122}$ Den Ton gab der Gastredner, Handelsminister Mlčoch, vor: Die Wirtschaft kenne keine Nationalitätenprobleme; angesichts der engen ökonomischen Verflechtung gebe es nur ein einziges wirtschaftspolitisches Programm. ${ }^{143}$ Liebieg spielte im Kernstück seiner Rede seine gerade zwei Wochen alten Äußerungen vor dem Hauptverband mit der Beteuerung herunter, man verstehe sich nach wie vor als unpolitisch und betreibe die Straffung der Organisation aus rein sachlichen Gründen. Die Betonung des "deutschen Charakters" des DHI hebe auf einige strukturbedingte Sonderbelange der deutschen Wirtschaft im Land ab, sei aber keinesfalls als Aufkündigung der Kooperation zu lesen, da trotz der „turmhohen Hindernisse" alle Ziele nur gemeinsam mit dem Zentralverband und in Loyalität zur Republik verfolgt werden könnten.

Dies bedeutete nun nicht, daß Liebieg mit seiner Kritik an der Prager Wirtschaftspolitik hinter dem Berg gehalten hätte: Es existierten zwar Pläne und Projekte, jedoch immer noch nicht der auf das Grenzland gemünzte große Wurf einer Antikrisenstrategie,

138 ANB, ŽB, S VII/i-1-I, 576, Preiss an Mühlig, Konzept vom 14. 5. 1938. - ANB, ŽB, S VII/i-1-I, 491, Liebieg an Preiss, 11.4.1938. - Preiss an Liebieg, 16. und 23. 5. 1938. - Liebieg an Preiss, 2.6. 1938 .

139 ANB, ŽB, S VII/i-1-I, 491, Konzept des Schreibens von Preiss an Liebieg, undat.

140 SÚA, SdP, Karton 44, Mappe 48, Richter an Liebieg, 16.6.1938. - Liebieg an Richter, 18.6. 1938.

141 Vgl. die Bestätigung des Termins für den 23. des Monats: SÚA, SdP, Karton 44, Mappe 48, SdP an Liebieg, 16.7.1938.

142 ONH 43 (1938), S. 550-557. - WI 20 (1938), S. 242.

143 SÚA, MPOŽ, Karton 242, P-3751, Rede Mlčochs auf der Vollversammlung des Zentralverbands am 14.6. 1938. 
keine die "natürlichen Räume" anpeilende Exportpolitik und keine ausreichende Unterstützung der Ausfuhr. Nach wie vor ungelöst seien die Probleme des Clearings, der hohen Steuerbelastung und der Behinderung der Wirtschaft in den Grenzgebieten durch die jüngsten Mobilmachungsanstrengungen. Liebieg rechnete den Regierungen vor, den Ausgleich der natürlichen Nachteile versäumt zu haben - schwächte diesen Vorwurf im gleichen Atemzug allerdings ab durch den Zusatz, die Deutschen machten letztlich niemanden für die Misere verantwortlich: Man wisse, daß es sich teilweise um „Schicksal" handle. ${ }^{144}$

Für die SdP lag der Skandal in ebendieser auf den ersten Blick unscheinbaren Floskel. Die Partei hatte wegen der verspäteten Konzipierung von Liebiegs Text zwar keinen Einblick mehr in diesen nehmen können; auf einer Vorbesprechung mit Richter am 10. Juni waren als Generallinie für den Auftritt des Präsidenten aber dessen Verlautbarung vom 2. Juni sowie kompromißlos scharfe Schuldzuweisungen an die Adresse der Regierung wegen ihrer wirtschaftspolitischen Versäumnisse festgelegt worden. ${ }^{145}$ Die Rede von den „natürlichen “ Problemen, so Richter, sei „in jeder Hinsicht katastrophal“. Liebieg sei von der in Aussicht gestellten Revision der Bindung an den Zentralverband abgerückt, er habe die Organisationsreform von einer prinzipiellen zu einer technischen Angelegenheit heruntergestuft und sich durch Mlčochs "seid nur unpolitisch, damit wir euch leichter fressen können " einwickeln lassen. "In Anbetracht des wohl beiderseits bestehenden Wunsches nach aufrichtiger Zusammenarbeit" gab Richter mit unverkennbar drohendem Unterton der Hoffnung Ausdruck, die "Pannen“ seien lediglich auf Zeitknappheit bzw. organisatorische Probleme zurückzuführen, und mahnte eine personelle Auffrischung durch die schnellstmögliche Bestellung eines geschäftsführenden Sekretärs zum Ghostwriter Liebiegs an. ${ }^{146}$

Setzte der Zentralverband gerade im Zeichen der Krise programmatisch nach wie vor auf die Demokratie als das die Unternehmerfreiheit ehestens gewährleistende System ${ }^{147}$, so erwies sich Preiss am 14. Juni einmal mehr als Politiker von feiner Witterung und als Virtuose der diplomatischen Absicherung nach allen Seiten: Zwar bekundete er Verständnis für die deutsche „Wiedergeburt" und Achtung vor Hitlers Gespür für den „kleinen Mann"; er selbst aber habe sich trotz seiner viel angefeindeten Suche nach einem modus vivendi mit dem "neuen Deutschland“ dessen Ziele nie zu eigen gemacht, sondern pflege lediglich den Realismus eines Landes in europäischer Mittellage, das auf gute Beziehungen zu allen Staaten von Deutschland über Italien bis zu den Westal-

144 SÚA, MPOŽ, Karton 242, P-3751, Rede Liebiegs auf der Vollversammlung des Zentralverbands am 14.6.1938.

$145 \mathrm{Vgl}$. das Konzept der Rede in überarbeiteter Fassung, die die Schlechterstellung der deutschen im Vergleich mit der tschechischen Industrie hervorhob: SÚA, SdP, Karton 44, Mappe 48.

146 Er meinte dabei den bereits als Kandidaten ins Auge gefaßten Dr. Stade. Vier Leute seien mit der Konzipierung der Rede beauftragt gewesen, von denen der Schlußredakteur die politische Bedeutung des Textes am wenigsten verstanden habe. Vgl. SÚA, SdP, Karton 44, Mappe 48, Felix Richter, SdP/Amt für Industrie- und Wirtschaftsorganisation an Liebieg, 16.6. 1938.

147 Rede Ś́deks, Vollversammlung des Zentralverbands am 14.6. 1938, in: OB 20 (1938), S. 168. Der Preiss nahestehende Dvořáček resümierte im Frühjahr 1938 eine Diskussion - unklar, wo und in welchem Rahmen - über die Frage der Reglementierung der Industrie mit den Worten, die Demokratie sei, wenn auch nicht das Bequemste, so doch dezidiert das Günstigste für die Unternehmer, weil sie ihm die vergleichsweise größte Bewegungsfreiheit ermögliche: Vgl. ANB, ŽB, S VII/i-1-I, Hejda an Preiss, 3.3.1938. 
liierten existentiell so sehr angewiesen sei, daß es sich ideologische Vorbehalte nicht leisten könne. ${ }^{148}$ Im Interesse der Wirtschaft wie des Exports und angesichts der welt- wie der innenpolitischen Spannungen bekundete Preiss den Willen zum Frieden nach außen wie zum Ausgleich nach innen, er dementierte eine aktuelle Kriegsgefahr, reklamierte gleichzeitig jedoch das Recht der Tschechoslowakei auf Notwehr bis zum letzten Atemzug. ${ }^{149}$

Die Ansprachen der Präsidenten hatten eine über die Belange der Wirtschaft weit hinausreichende Bedeutung; sie wurden in Presse und Öffentlichkeit, welche die Hauptversammlungen seit jeher, vor allem aber seit dem Beitritt des DHI zum Zentralverband, als ökonomisches und politisches Konjunkturbarometer aufgefaßt hatten, auch so aufgenommen: Die Veranstaltung verleihe jenseits aller Schattierungen und Nuancierungen der Ansichten einer grundlegenden Gemeinsamkeit der Interessen Ausdruck, welche der „Hospodářský rozhled “ ${ }^{150}$ nicht einmal in erster Linie auf der materiellen Seite, sondern im Ruf nach Anerkennung der Unternehmerfreiheit und in dem Kampf gegen seine „moralische Deklassifizierung“ erblickte. Preiss habe die nationalen Spannungen als wesentliche Krisenursache anerkannt, Liebieg hingegen demonstriere, daß es im Konkreten zwischen tschechischen und deutschen Industriellen - wie überhaupt zwischen deutschen und tschechischen Bürgern - keinen Dissens geben müsse. Auch nach Auffassung der deutschen Gesandtschaft hatte Preiss, obgleich ein nationalbewußter Tscheche, ein Manifest des Versöhnungswillens vorgetragen ${ }^{151}$, und sogar die „Zeit“, das Sprachrohr der SdP, apostrophierte Preiss als einen zur Vernunft mahnenden „Rufer in der Wüste“. ${ }^{152}$ Hätte sich mancher auch deutlichere Anstrengungen der Deutschen zur Zerstreuung der tschechischen Befürchtungen gewünscht, so anerkannte man doch die weitgehende Übereinstimmung in der Sache und hoffte auf die Autorität der Industriellen zur Wiederherstellung geordneter Verhältnisse. ${ }^{153}$ Die der Burg nahestehende "Přítomnost“ goutierte das öffentliche Schauspiel eines Dissenses zwischen Liebieg und Kislinger, dessen Rede der Auffassung der SdP viel eher entsprochen hatte ${ }^{154}$, be-

$148 \mathrm{Ob}$ nun, im Jahre 1938, dahinter mehr, d. h. auch aus dem Herzen kommende Sympathien für das Modell Deutschland standen, bleibt unklar. Kanzler Sámal jedenfalls hatte wenige Wochen zuvor deutlich verschreckt eine Mitteilung seiner Tochter notiert, Preiss habe sich ihr gegenüber lobend über Deutschland und Hitler, besonders aber über die deutsche Industrie ausgesprochen. Man könne sich sofort verständigen. Die Politik Benešs und Masaryks sei falsch gewesen; er habe immer recht gehabt: Vgl. AKPR, T 421/29, Karton 170, Präsidentenkanzlei, Aktenvermerke Śámal über eine Unterhaltung seiner Tochter mit Preiss vom 10.4. und 13.4.1938.

149 SÚA, MPOŽ, Karton 242, P 3751, Rede Preiss', Vollversammlung des Zentralverbands am 14. 6. 1938. - Ergänzend herangezogen der Abdruck in: OB 20 (1938), S. 166, und der zur selben Zeit veröffentlichte Aufsatz $O$ předpokladech.

$150 \mathrm{HR}$ vom 16.6.1938.

151 PA, R 111 569, Gesandtschaft Prag an AA, 15. 6. 1938, Übersicht über die öffentliche Resonanz. - Vgl. an Pressestimmen etwa: OVW vom 16.6.1938. - HA 17 (1938), S. 385 f.

152 ZT vom 17.6.1938.

153 ONH 43 (1938), S. 550-557.

154 Der „Hospodářský rozhled“ mutmaßte, auch Kislingers Rede sei sicher nicht im DHI redigiert worden: Vgl. HR vom 16.6. 1938. - Eine der Quellen des industriellen Niedergangs, so Kislinger, sei die Politik. Ein "gewisser Systemzwang, durch eine verfehlte Ideologie erzeugt “, führe zu Kampfaktionen gegen ökonomische Interessen und füge Verluste im wirtschaftlichen Besitzstand zu, vermindere das Kapital, verschärfe den Kampf um den Arbeitsplatz und beuge die staatliche Wirtschaftslenkung „zu unseren Ungunsten“. Aber sogar diese Rede vollführte abschließend einen versöhnlichen Schwenk: Außerhalb der deutschen Bezirke leide die Wirtschaft 
trachtete aber nicht einmal dessen Verlautbarungen als solide Basis einer Prognose über den zukünftigen Kurs des DHI. ${ }^{155}$ Hauptsächliche deutsch-tschechische Gemeinsantkeit seien die Rat- und Konzeptlosigkeit in der Wirtschaftspolitik und das Bedürfnis $\mathrm{zu}$ „überwintern“. Das Blatt ermutigte die deutschen Industriellen, sich nicht unter dem Druck des lärmenden Pöbels von der SdP an die Leine nehmen zu lassen und ermunterte zu einem Ausgleich mit dem Herzstück einer gemeinsam verantworteten industriepolitischen Konzeption. ${ }^{156}$

Die Verhandlungen, die dann im Sommer über eine Neugestaltung des Verhältnisses der Verbände stattfanden, bleiben aufgrund der spärlichen Quellen fast völlig im dunklen. Möglicherweise wurde eine völlige Gleichstellung mit der Konsequenz der Beendigung der Mitgliedschaft des DHI im Zentralverband ins Auge gefaßt. ${ }^{157} \mathrm{Da}$ sich die Unterhandlungen zwischen der Regierung und der SdP über ein Nationalitätenstatut dahinschleppten, die künftige Stellung der Deutschen im Staat und somit dessen politische und administrative Struktur unklar blieben, kamen die Gespräche jedoch kaum voran. ${ }^{158}$ In der Praxis wurde die Zusammenarbeit fortgesetzt; zumindest dementierte der Zentralverband anderslautende Gerüchte ausdrücklich. ${ }^{159}$ Dies galt ungeachtet des sich verschärfenden Zugriffs der SdP auf den Hauptverband: Die im Juni bei der Partei in großer Zahl eingehenden Anfragen aus der Industrie, ob eine Beteiligung an der Jubiläumsspende zu dem für Ende Oktober ins Haus stehenden zwanzigsten Geburtstag der Republik angeraten sei, veranlaßten die SdP, den DHI zur offiziellen Ablehnung aufzufordern. ${ }^{160}$

Erst am 25. Juli erörterten bei Riedel in Unterpolaun führende Persönlichkeiten des deutschen Bankwesens der Republik und der SdP angehörende und nahestehende Unternehmer - vertreten waren etwa der Direktor der Kreditanstalt der Deutschen, Kiesewetter, Theodor Liebieg und sein Sohn Wolfgang sowie die Textilunternehmer Richter und Kreibich ${ }^{161}$ - den Ausbau der Beziehungen zwischen Industrie und Par-

zum großen Teil unter den gleichen Problemen: Vgl. Rede Kislingers, Vollversammlung des

Zentralverbands am 14.6.1938, in: OB 20 (1938), S. 169.

155 P̌̌ 15 (1938), S. $387 \mathrm{f}$.

156 Vaník, Řeč Liebiega.

157 WI 20 (1938), S. 239.

158 WI 20 (1938), S. 259. - Ende August etwa übersandte Sádek Preiss Informationen über den „Dritten Plan" und verband dies mit der Frage nach den zukünftigen Kompetenzen der dort vorgesehenen „Gaue“ in wirtschaftlicher Hinsicht: Vgl. ANB, ŽB, S VII/i-1-I, 906, Sádek an Preiss, 30. 8.1938.

159 Dies in einer von zweideutigen Zwischentönen nicht freien Meldung in der "Wirtschaft“ : Das Verhältnis der Verbände, so hieß es hier, sei durch einen Vertrag geregelt, um dessen Aufhebung oder Änderung anzusuchen beiden Seiten freistehe. Diese Formulierung konnte als Versuch einer Abkoppelung der Verhandlungen von ihrem politischen Hintergrund interpretiert werden. Im gleichen Atemzug gab der Zentralverband allerdings zu, möglicherweise seien die Auseinandersetzungen zwischen SdP und Regierung in diesem Zusammenhang doch von Belang. Daß die Redaktion des Blattes diese Meldung ausdrücklich als offizielle Stellungnahme des Zentralverbands kennzeichnete, darf wohl als Distanzierung aufgefaßt werden: Vgl. WI 20 (1938), S. 264.

160 SƯA, SdP, Karton 44, Mappe 48, SdP/Amt für Industrie- und Wirtschaftsorganisation an Liebieg, 16.6.1938.

161 Neben den genannten waren dies Walter Riedels Bruder Arbo Riedel und Freddy Mahlmann, der Generaldirektor der Textilfirma Ginzkey. Aus Finanzkreisen kamen Freiherr von Lüdinghausen, Fürst Rohan, der Präsident des Verwaltungsrats der Böhmischen Escompte-Bank, Max 
tei. ${ }^{162} \mathrm{Da}$ die seit längerem geplante Aussprache mit Henlein aufgrund der nicht ausgeräumten Spannungen bezeichnenderweise immer noch nicht stattgefunden hatte, sollten in einem ersten Schritt wenigstens die Kontakte zu Richter intensiviert werden. Auf der Tagesordnung standen in Unterpolaun auch die weitere Formierung der deutschen Wirtschaft im Land sowie ihre Abkoppelung von der tschechischen. Als Hausbank, die den Einfluß jüdischen und tschechischen Kapitals auf die deutschen Unternehmen zurückdämmen sollte, wurde vorrangig die Böhmische Escompte-Bank, in deren Verwaltungsrat Riedel saß, ins Auge gefaßt. Befand sich ihr Kapital auch zu einem großen Teil im Besitz der Živnostenská banka, so war sie doch bereits teilweise „entjudet“ und hatte ihr Geschäft in den Grenzgebieten forciert. Der Vertrauensmann der SdP in der Bank, Novotný, wurde als Kandidat für den Direktorenposten gehandelt. Andere Banken sollten unter die Botmäßigkeit der Böhmischen Escompte-Bank gebracht werden, indem man ihnen unter tätiger Mithilfe der SdP die Kundschaft abspenstig machte. Die Böhmische Union-Bank etwa, die ebenfalls ihre Geschäfte zum großen Teil im deutschen Gebiet betrieb, galt als „verjudet“ und stand unter der indirekten Kontrolle der Živnostenská banka, die bei ihr nahestehenden Gesellschaften jeweils kleinere Pakete von Aktien der Bank untergebracht hatte. Ein weiteres Anliegen der Runde war es, den Verkauf des jüdischen Weinmann-Konzerns an die Živnostenská banka zu verhindern. Große Sorge bereitete die Schwächung der deutschen Wirtschaft durch die Abwanderung deutscher, von den höheren Gehältern im Reich angelockter Fachkräfte, die durch Tschechen ersetzt wurden.

Die seit dem April geringer gewordene Distanz des Hauptverbands zur SdP hatte auf der anderen Seite die Sezession des Vereins der mährischen Wollindustriellen zur Folge. ${ }^{163}$ Die Brünner, schon zu Zeiten der Monarchie als Individualisten bekannt, hatten auch nach 1918 eine Aversion gegen Reichenberg gehegt; zudem war hier die Zusammenarbeit zwischen Deutschen und Tschechen besonders ausgeprägt. Das Vertrauen in die Liebiegschen Friedensschalmeien verlor man in Brünn endgültig, als der DHI am Gängelband der SdP den Beschluß faßte, die Spende der Wirtschaft zu Verteidigungszwecken nicht mitzutragen, womit er sich - zum ersten $\mathrm{Mal}$ - einer von Tschechen und Deutschen gemeinsam getragenen Loyalitätsbekundung gegenüber dem Staat verweigerte. Eine wichtige Rolle spielte auch, daß 29 von 30 Mitgliedern des Verbandes Juden waren. Nur der einzige Nichtjude vollzog den Austritt nicht mit. Intensiver als anderswo waren somit im Brünner Einzugsbereich für die Unternehmer die Störungen spürbar, die die von Liebieg, mehr aber noch von Kislinger initiierte Politik mit Janovsky im Hintergrund hervorrief. ${ }^{164}$

Die Prognose des „Hospodářský rozhled“, für den Fall der endgültigen Unterordnung des Hauptverbands unter die SdP sei mit weiteren Austritten und Abspaltungen und mit dem Herabsinken zur Bedeutungslosigkeit zu rechnen, klang plausibel. Ihr Eintreffen wurde allerdings durch „München“ verhindert. Schließlich waren - gerechnet nach Kapital und Lohnsumme - 25 bis 30 Prozent der als deutsch firmierenden Unter-

von Richter, Verwaltungsrat der Böhmischen Union-Bank und Direktor Kiesewetter von der Kreditanstalt der Deutschen.

162 SÚA, SdP, Karton 44, Mappe 48, Protokoll des Treffens vom 25. 7.1938.

$163 \mathrm{Vgl}$. zu diesem Vorgang den HR vom 23.6.1938.

164 PR 15 (1938), S. $387 f$. 
nehmen im Hauptverband (deutsch-) jüdische; wären diese aus dem DHI ausgetreten, hätte sich die Mitgliederzahl von 1500 auf 800 bis 900 reduziert. Anders als in Böhmen und Schlesien wo die deutsche Industrieorganisation im Sommer noch relativ geschlossen war, näherte sich zu dieser Zeit in Mähren der Hauptverband bereits dem Zerfall. Die Mehrheit der nordmährischen Unternehmen war über den Mährisch-Schlesischen Industrieverband ohnehin dem Zentralverband angegliedert. Die Mitglieder des Verbands mährischer Industrieller waren zum großen Teil Juden; auch hier bestand die Gefahr des Überwechselns zum Zentralverband, wo viele Firmen ohnehin eine Zweitmitgliedschaft besaßen. Im Verband der mährischen Textilindustriellen, wo einer Schätzung zufolge ein Drittel der Spindelkapazität in deutschem, 27 Prozent in deutsch-jüdischem, 28 Prozent in tschechischem und 6 Prozent in tschechisch-jüdischem Besitz - Zugehörigkeit des Rests unklar - waren, wären die jüdisch-deutschen Betriebe in der Austrittsfrage zum Zünglein an der Waage geworden. ${ }^{165}$

Konkurrenz entstand dem DHI nun zudem in Gestalt des Deutschen Wirtschaftsverbands, auch wenn dessen Aktivitäten schwerpunktmäßig außerhalb des industriellen Sektors lagen und in der Leitung überwiegend Landwirte und Gewerbetreibende vertreten waren. ${ }^{166}$ Der Aufruf zur Gründung dieser Vereinigung war am 10. April ergangen; nach der Genehmigung der Statuten am 10. August erfolgte tags darauf die offizielle Konstituierung. Die 45 Mitglieder machten sich sogleich an die Vorbereitung einer „Deutschen Wirtschafts-Tagung ${ }^{\text {. }}{ }^{167}$ Geschäftssprache des Verbandes war das Deutsche. Er verstand sich als überparteiliche, ja unpolitische Interessenorganisation der gesamten deutschen Wirtschaft der Republik, zu deren demokratischer Verfassung er sich ausdrücklich bekannte und bekundete, auch und gerade in der Wirtschaft Brücken zu den anderen Nationalitäten bauen zu wollen. ${ }^{168}$ Die Organisation, die auf Anweisung des Staatspräsidenten mit 10000 Kronen unterstützt wurde ${ }^{169}$, erteilte in einem Appell Anfang September allen unverantwortlichen, Verwirrung stiftenden Elementen eine Absage und warb für die Erhaltung des tschechoslowakischen Staates sowie für die Verständigung zwischen Deutschen und Tschechen in Wirtschaft und Verwaltung, in der Sprachen- und der Kulturpolitik. ${ }^{170}$ Gegen diese Konkurrenz richteten sich unverzüglich sämtliche Geschütze der SdP: Sie diffamierte den Verband als ein von Pfründenjägern in Szene gesetztes Vorhaben mit gefährlichen "spalterischen Tendenzen“ und Verbindungen zum tschechischen HUS. ${ }^{171}$ Die Drahtzieher mit ihren „durchwegs übel beleumdeten Hintermännern" glaubte man in der volkssozialistischen Partei, bei Klerikalen, Juden und den tschechischen Volkstumsorganisationen aufspüren zu können.

$165 \mathrm{HR}$ vom 23.6.1938.

166 AKPR, T 12/25, Karton 135, C 6, Übersicht „Die Leitung des Deutschen Wirtschafts-Verbandes", undatiert.

167 AKPR, D 13 444/38, Karton 142, Deutscher Wirtschaftsverband, Arbeitsbericht Nr. 1 vom 26. 8. 1938 .

168 Mährisches Tagblatt vom 15.7.1938. - AKPR, T 12/ 25, Karton 135, C 6, Einladung zu einer deutschen Wirtschaftstagung, undatiert. - AKPR, D 13 444/38, Karton 142, Statuten des Deutschen Wirtschaftsverbandes, undatiert.

169 AKPR, T 12/25, Karton 135, C 6, Aktenvermerk Schieszl vom 27.7.1938.

170 AKPR, D 13 444/38, Karton 142, Aufruf des Deutschen Wirtschaftsverbandes vom 5. 9.1938.

171 Hospodářské ústřední středostavovské, d. h. Mittelständische Wirtschaftszentrale. 
Unter der Devise „unpolitisch“ sollten, wie die Prager Gesandtschaft dem Reichswirtschaftsministerium warnend mitteilte, über „arische“ Mittelsmänner Geschäfte mit dem Reich angebahnt werden. ${ }^{172}$

Wann die Spitzen des Zentralverbands die Möglichkeit einer Abtrennung der mehrheitlich deutschen Gebiete vom tschechoslowakischen Staat konkret ins Auge zu fassen begannen, geht aus den Akten nicht hervor. Am 20. September lag Preiss ein Überblick über die Verbandsmitglieder in den überwiegend deutsch besiedelten Bezirken vor. Über die Bedeutung dieser Unternehmen, über die Rohstofflagerstätten, die Verkehrswege und den Im- und Export des deutschen Gebietes wurden nun Studien angefertigt man stellte sich auf die neuen Rahmenbedingungen ein. ${ }^{173}$ Hinsichtlich der desaströsen ökonomischen Konsequenzen einer Zerteilung der Republik jedenfalls herrschten keine Illusionen: Die Amputation der deutschen Industrie, so die Prognose, werde im Rumpfstaat das Gewicht des Agrarsektors, nicht zuletzt auch das politische, weiter anwachsen lassen - eine Deindustrialisierung mit fatalen gesamtwirtschaftlichen und politischen Konsequenzen, da in erster Linie die Industrie bislang den Staatshaushalt und die Sozialversicherung, überhaupt den Lebensstandard finanziert hatte. Die dann zum Agrarexportland mutierte Tschecho-Slowakei werde auf den Absatz ihrer Überschüsse nach Deutschland angewiesen sein und müsse zur Bezahlung dieser landwirtschaftlichen Ausfuhren erhöhte Fertigwarenimporte von dort zulassen. In der Konsequenz werde sich das Regime ökonomischer und damit auch politischer Abhängigkeit etablieren, das bereits die Beziehungen des Reiches zu den Staaten Südosteuropas charakterisierte. Der zu erwartende Bevölkerungszustrom aus den abgetretenen Gebieten, insbesondere die vielen Staatsangestellten, belasteten den Arbeitsmarkt und die Sozialversicherung, was politische Krisen und ein Anwachsen des Extremismus provozieren werde. ${ }^{174}$

172 PA, R 111 572, Gesandtschaft Prag an AA, 19.8. 1938.

173 ANB, ŽB, S VII/i-1-1, 906, Sádek an Preiss, 20. 9. 1938. In den Kreisen mit mehr als achtzig Prozent deutscher Bevölkerung hatte der Zentralverband diesem Bericht zufolge direkt oder über die Fachgruppen 513 Mitgliedsfirmen, in den Kreisen mit 50-80 Prozent deutscher Bevölkerung gehörten dem Verband 318, insgesamt also 831 Unternehmen an. Für Mähren lauteten die Zahlen 60 bzw. 108, also insgesamt 168.

174 ANB, ŽB, S VII/i-1-I, 906, Aufzeichnung des Zentralverbands, ungezeichnet, undatiert. - Aufstellung über Industrie-Verluste, dito. - Aufstellung über Steuer-Verluste, dito. 


\section{Der Hauptverband nach der Annexion des Sudetenlandes}

$(1938 / 39)$

Nicht einmal im unmittelbaren Vorfeld von „München“ trennten sich die Wege der deutschen und der tschechischen Industrieorganisation endgültig. Zwar erwog in der zweiten Septemberhälfte die tschechische Spitze des Zentralverbands, nach der Annexion der Grenzgebiete die Repräsentanten des DHI im Präsidium des Zentralverbands nicht mehr zu dessen Sitzungen zu laden. ${ }^{1}$ Erst nach dem Münchner Abkommen aber verlor der DHI den Status einer regionalen Organisation des Zentralverbands. ${ }^{2}$

Als Präsident der Reichenberger Handelskammer, des Deutschen Hauptverbandes der Industrie und des Allgemeinen Deutschen Textilverbandes entbot Theodor Liebieg „im Bann des wunderbaren Befreiungswerkes“ Hitler und der einmarschierenden Wehrmacht einen hymnischen Willkommensgruß, der die Topoi des „Volkstumskampfs" nun in unverkennbar nationalsozialistischen Jargon rahmte. Sich mit dem Wind drehend, dementierte der Präsident rundweg die vorangegangenen zwei Dekaden nicht immer reibungsloser, aufs Ganze gesehen aber leidlich funktionierender übernationaler Zusammenarbeit der Industrie: „Ein Siegerdiktat“ habe 1918 geglaubt, „trennen zu können, was durch Blut, Sprache und Kultur Einheit ist. Gerechtigkeit und die ewigen Gesetze der Natur erwiesen sich als stärker." Nachdem in der Folge des Ersten Weltkriegs die Siegerstaaten Deutschböhmen gegen "feierlichen Protest" von Österreich losgerissen hätten, habe man sich "trotz stärksten inneren Widerstrebens“ zum Zusammenleben mit den Tschechen entschließen und sich "wohl oder übel" mit diesem Zustand abfinden müssen, obwohl die Prager Politik ein „durchtriebenes und niederträchtiges Spiel mit unserer Geduld und ein Sich-weiden an unserer Not und unserem Elend“, gipfelnd im „Tscheka-Terror" der jüngstvergangenen Wochen, gewesen sei. ${ }^{3}$ Liebieg gab der Hoffnung Ausdruck, nach der Beendigung der „Kampfjahre ${ }^{\alpha 4}$ des Hauptverbandes werde das Reich auf eine großzügige Ankurbelung der Industrie nach dem Vorbild Österreichs und auf eine Überwindung der Anfangsschwierigkeiten mittels Steuerung der Wirtschaft "autoritär von oben " hinarbeiten. ${ }^{5}$

Am 14. Oktober setzte der Oberbefehlshaber des Heeres den Stillhaltekommissar Albert Hoffmann ein, dem die "Ausrichtung" und Führung aller deutschen Organisationen der annektierten Gebiete, ihre allfällige Auflösung oder Neuordnung, die Überführung oder Eingliederung in andere Vereinigungen, die Abberufung bzw. Neubestellung der leitenden Organe und die Überprüfung ihres Gebarens oblag. Alle Verbandstätig-

1 ANB, ŽB, S VII/i-1-I, 906, Sádek an Preiss, 20. 9. 1938. - In diesem Schreiben findet sich noch einmal ein Beispiel dafür, wie diffus die Grenze zwischen den beiden Verbänden war: Šádek fragte nämlich Preiss, ob auch mit den Präsidialmitgliedern Spiro, Epsten, Heller und Hödl in diesem Sinne verfahren werden solle; er war sich über deren nationale Zurechnung also offensichtlich nicht im klaren.

2 ANB, ŽB, S VII/i-1-I, 906, Rundschreiben Nr. 13 an die Mitgliedsfirmen vom 21.10.1938.

3 Bei der Rede vom "tschekistischen Terror" dürfte Liebieg im Auge gehabt haben, daß er aufgrund des Gesetzes Nr. 125 vom 10. Juli 1933 zu Hausarrest verurteilt worden war: Vgl. den Abdruck der Verfügung unter dem Titel "Ein tschechisches Kulturdokument" in TR 20 (1938), S. 267.

4 Dies Liebiegs Charakterisierung der Jahre bis 1938 anläßlich seines Abtritts im Jahre 1939. Vgl. TR 21 (1939), S. 27.

5 Von Liebieg verfaßter "Willkommensgruß der Werktätigen an die Abordnung der Wehrmacht“, den „Sendboten“ Hitlers, in: TR 20 (1938), S. 266 f. - Verlautbarung des ADTV ebenda, S. 265. Vgl. auch MDHI 19 (1938), S. 389 f. 
keit und jegliche Veränderung des Status quo waren von der Genehmigung des Kommissars abhängig; seine Verfügungen ergingen ohne Begründung und waren nicht anfechtbar. ${ }^{6}$ Liebiegs Angebot an Henlein, die von ihm geleiteten Organisationen für den "wirtschaftlichen Wiederaufbau" in den Dienst zu nehmen, erübrigte sich damit. Die Verordnungen vom 24. September und vom 29. Oktober $1938^{7}$ führten die grundlegenden Bestimmungen über den „organischen Aufbau“ der deutschen Wirtschaft auch in der "Ostmark" und im Sudetenland ein. ${ }^{8}$ In der "Selbstverwaltung" galten damit Führerprinzip und Zwangsmitgliedschaft; vom Hauptverband erging der Aufruf zum "Anschluß" an alle noch nicht organisierten Firmen."

Von einer unmittelbaren „Erfassung“ der Betriebe vom Reich aus wurde allerdings vorerst abgesehen; nur die Verbände sollten an sie herantreten. Ob diese hierfür geeignet waren, mußte im Einzelfall mit Wolfgang Richter, den der Reichskommissar für den "Sudetengau" zu seinem Wirtschaftsbeauftragten ernannt hatte, geklärt werden. ${ }^{10}$ Richter betraute den vormaligen Hauptverband, nun "Sudetendeutscher Hauptverband der Industrie" (SDHI), mit der "Selbstverwaltung" nach dem Vorbild der reichsdeutschen Wirtschaftsverfassung. Alle industriellen Fachverbände waren ihm eingegliedert, alle Hauptverbandsmitglieder waren zwangsweise auch Fachverbandsmitglieder. Da die Branchenorganisation des Hauptverbandes nicht lückenlos gewesen war, wurde ein Reihe von Fachvereinen neu gegründet. Die bisher zweisprachigen Wirtschaftsvereinigungen wurden, soweit sie ihren Sitz im annektierten Gebiet hatten, zu rein deutschen Verbänden. Wo dies nicht der Fall war, wurden sie durch Neugründungen ersetzt. Richter ernannte die Leiter der Fachverbände bzw. -gruppen; sie waren weisungsgebunden. Arbeitgeberangelegenheiten ging auf die DAF über. ${ }^{11}$ Im Zuge der vom Reichswirtschaftsministerium via Reichskommissar verfügten Überführung der deutschen Wirtschaftsverbände der annektierten Gebiete in die entsprechenden reichsdeutschen Gliederungen wurde Anfang 1939 der Allgemeine Deutsche Textilverband durch eine Bezirksgruppe Sudetenland der Wirtschaftsgruppe Textilindustrie mit Sitz in Reichenberg ersetzt. ${ }^{12}$ Die Wirtschaftsorganisation der besetzten Gebiete wurde zentral-einheitlich behandelt, die eigenmächtige Anbahnung von Verbindungen mit den Wirtschaftsorganisationen des "Altreichs" war vom Reichskommissar untersagt. ${ }^{13}$

Die Eingliederung der Wirtschaft in den annektierten Gebieten und die Ausdehnung der reichsdeutschen Mechanismen der Wirtschaftslenkung hatten erhebliche Umstellungsprobleme zur Folge, die den Aufgabenbereich und die Regulierungsmacht der nunmehrigen Zwangsorganisation beträchtlich ausweiteten. ${ }^{14}$ Angesichts der Verunsi-

6 Verordnung vom 22. 10. 1938 über die Auflösung, Überleitung und Eingliederung von Organisationen in den sudetendeutschen Gebieten, in: VOSG 1938, S. 35f. - TR 20 (1938), S. 277 f.

7 RGBl. I, S. 1201 bzw. S. 1547 f.

${ }^{8}$ Nach dem Gesetz zur Vorbereitung des organischen Aufbaus der deutschen Wirtschaft vom 27.2.1934, in: RGBl. I, S. 185.

9 Vgl. etwa die Aufforderung zum Eintritt in den ebenfalls zum Zwangsverband gewordenen ADTV in: TR 20 (1938), S. 277.

10 Hahn, Eingliederung.

11 TR 20 (1938), S. 268. - Hahn, Eingliederung.

12 Leiter war Rudolf Wannenmacher, sein Stellvertreter war Max Richter, Dr. Karl Devcic war Hauptgeschäftsführer. Personal und Kanzlei wurden übernommen. Kontinuitätsbrüche gab es also zumindest in diesem Falle nicht: Vgl. TR 21 (1939), S. 27, 43 und 65.

13 TR 20 (1938), S. 283.

14 TR 20 (1938), S. 268. 
cherung vieler Firmen durch die neuen Rahmenbedingungen wurde die Beratungstätigkeit intensiviert. In der Textilindustrie, wo die Auslastung der Kapazitäten in der Folge der Eingliederung in die Kriegsvorbereitungswirtschaft weit über dem langjährigen Durchschnitt lag, war die Organisation durch die vielfältigen administrativen Probleme im Zuge des Wiederanlaufs krisenbedingt stillgelegter Betriebe, der Beschaffung von Rohstoffen und der Ersetzung der ausgefallenen alten Lieferanten stark in Anspruch genommen. Hinzu kamen neue Aufgaben in der Bewirtschaftung und bei der Bearbeitung der nun stark zunehmenden Staats-, insbesondere der Wehrmachtsaufträge. ${ }^{15}$ Ein Problem stellte insbesondere die Modernisierung der Betriebe dar. Weil die Wirtschaftskrise die Kapitalakkumulation weitgehend verhindert hatte, waren viele Betriebe tief verschuldet und technisch veraltet, so daß nicht nur die Fachgruppe Textilindustrie für eine Erleichterung der Kapitalbildung und die bevorzugte Lieferung von Maschinen in das annektierte Gebiet Sorge zu tragen hatte. ${ }^{16}$ Kredite vergab zu einem Zinssatz von fünf Prozent der Reichskommissar im Einvernehmen mit dem Reichsfinanzministerium und der Reichsbank auf dem "bewährten Weg“ von der Deutschen Zentral-Genossenschaftskasse in Berlin über die Kreditanstalt der Deutschen an die Hausbank des Unternehmens. ${ }^{17}$ Mit dem Gesetz zur Sicherung der Kreditversorgung in den sudetendeutschen Gebieten vom 31. Oktober 1938 übernahm die Reichsregierung Bürgschaften in Höhe von 150 Millionen Mark für Kredite, die in erster Linie für die Wiederinbetriebnahme stillgelegter Unternehmen, für Umstellungen und Neuerrichtungen im Rahmen des Vierjahresplans, aber auch für „Arisierungen “ verwendet werden sollten. Über die Anträge entschieden Kreditausschüsse beim Reichskommissariat in Reichenberg bzw. bei den Regierungen in Karlsbad, Troppau und Aussig; auch hier war die Beteiligung der Wirtschaftsorganisation vorgesehen. ${ }^{18}$

$\mathrm{Da}$ der Wirtschaftsbeauftragte des Reichskommissars von den Unterorganisationen bei der Förderung des Exports zu unterstützen war ${ }^{19}$, sah sich der Sudetendeutsche Hauptverband auch in diesen Bereich „eingeschaltet". Hierzu wurden ihm Beauftragte der im Reich für die Überwachung der Ausfuhr zuständigen Prüfungsstellen beigegeben. ${ }^{20}$ Das Spektrum der Aufgaben läßt sich anhand der Nachfolgeorganisation des ADTV illustrieren, deren Hauptgeschäftsführer nach der „Münchner Deklaration“ (sic!) im Reichswirtschaftsministerium um finanzielle Unterstützung des Exports ansuchte: Angesichts der Sperrung der Tschecho-Slowakei für Importe aus den von Deutschland annektierten Gebieten drang die Organisation auf Öffnung des „Alt-

15 Tätigkeitsbericht der Bezirksgruppe Sudetenland der Wirtschaftsgruppe Textilindustrie vom 11.7. 1939, in: TR 21 (1939), S. 205-208.

16 Erste Sitzung des Beirates der Bezirksgruppe Sudetenland der Wirtschaftsgruppe Textilindustrie am 11.7.1939, in: TR 21 (1939), S. 194.

17 TR 20 (1938), S. 271.

18 TR 20 (1938), S. 309.

19 TR 20 (1938), S. 272. - Schon in der ersten Oktoberhälfte stellte der Hauptgeschäftsführer des DHI, Stade, eine Denkschrift zur Lage des sudetendeutschen Exports in Aussicht: Vgl. BArch-K, R 7/3452, Vermerk RMWi/Dr. Bockmeyer vom 8. 10. 1938.

20 BArch-K, R 7/3452, RMWi an den Reichskommissar für die sudetendeutschen Gebiete, 6. 10.1938. - Bestätigung durch den Wirtschaftskommissar des Reichskommissars, 7. 10. 1938. - Einer der Beauftragten sollte der Kreiskanzlei des SDHI in Karlsbad für die keramische Industrie beigegeben werden, in Reichenberg saßen die Beauftragten für die Glasindustrie und für die Gablonz Industrie, für die Branchen Papier, Metall und Chemie: Vgl. BArch-K, R 7/3452, Vermerk RMWi/Dr. Bockmeyer vom 8.10.1938. 
reichs", auf die Befreiung der Einfuhren von Zöllen bzw. Umsatzsteuern und die Abschaffung der Devisenvorschriften, sie kümmerte sich um die aus der Sperrung der Brünner und Prager Postscheckkonten und dem Abreißen der Bankverbindungen entstandenen Probleme, betrieb die Bezahlung von Lieferungen an den tschechoslowakischen Staat, erarbeitete statistische Unterlagen zum Waren- bzw. Zahlungsverkehr aus den annektierten Gebieten in die alten Handelsgebiete und konnte Erfolge bei der Flüssigmachung eingefrorener Forderungen in Jugoslawien, Rumänien und in der Türkei verzeichnen. ${ }^{21}$

Der Sudetendeutsche Hauptverband wirkte auch in Fragen der Marktregelung mit: Er verfügte zunächst die Lösung der Kartellvereinbarungen deutscher Unternehmen in den annektierten Gebieten mit solchen in der Zweiten Tschechoslowakischen Republik und den eventuellen Anschluß an die zuständigen Kartelle des "Altreiches“. ${ }^{22}$ Marktregelnde Vereinbarungen, die sich auf die Wirtschaft in den annektierten Gebieten erstreckten, waren in der Folge des Erlasses des Reichswirtschaftsministeriums vom 12. Oktober 1938 von diesem zu genehmigen; die Anträge wurden über die Reichsgruppen der Wirtschaft geleitet, die zusammen mit dem Sudetendeutschen Hauptverband der Industrie Durchführungsrichtlinien ausgearbeitet hatten. ${ }^{23}$ Der ADTV etwa bzw. später die Wirtschaftsgruppe Textil führten Verhandlungen über ein Gebietsschutzabkommen mit dem Ziel, eine Überschwemmung der annektierten Gebiete mit Waren aus dem "Altreich" zu verhindern. ${ }^{24}$

Die Resultate dieser „fürsorglichen Betreuung" enttäuschten trotzdem binnen kurzem die Hoffnungen der "sudetendeutschen " Unternehmer; diese Entwicklungen liegen jedoch jenseits der zeitlichen Grenzen der Untersuchung. Auch in der Zweiten Tschechoslowakischen Republik bildete sich eine deutsche industrielle Organisation: Am 11. März 1939 beschloß die Vollversammlung des Verbandes mährischer Industrieller ihre Umwandlung in den „Verband der deutschen Industrie in der Tschecho-Slowakei“. Der Einfluß des Nationalsozialismus war unverkennbar: Der Verband verstand sich als Einheitsorganisation der deutschen Industrie unter dem Kommando des „Volksgruppenführers" Kundt, als dessen Wirtschaftsbeauftragter Kislinger fungierte. Hauptsächliche Aufgabe war die Pflege der Beziehungen zur Wirtschaft im Reich bzw. im "Sudetengau" sowie die "Einschaltung" in den sprunghaft angestiegenen Deutschlandhandel. Der unter dem Banner des Volksgemeinschaftsgedankens angestrebte Zusammenschluß von Unternehmern und Arbeiterschaft unter einem organisatorischen Dach dürfte mit der wenige Tage später durchgeführten Unterwerfung der Tschecho-Slowakei gegenstandslos geworden sein. ${ }^{25}$

21 Tätigkeitsbericht der Bezirksgruppe Sudetenland der Wirtschaftsgruppe Textilindustrie vom 11.7.1939, in: TR 21 (1939), S. 205-208.

22 Erst auf diesem Umweg bestand die Möglichkeit des Abschlusses eines neuen zwischenstaatlichen Kartells mit der Zweiten Tschechoslowakischen Republik: Vgl. MSDHI 19 (1938), S. 400 und Frankfurter Zeitung vom 26. 10.1938.

23 BayA 84/31, Übersicht über die Maßnahmen zur Angleichung der Wirtschaft des sudetendeutschen Gebietes an die des Deutschen Reiches, undatiert.

24 Tätigkeitsbericht der Bezirksgruppe Sudetenland der Wirtschaftsgruppe Textilindustrie vom 11.7.1939, in: TR 21 (1939), S. 205-208.

25 Die Kundgebung Kundts am 11. März trug dessen Wirtschaftsbeauftragter Kislinger vor. - Vgl. Sonntag vom 12.3.1939. 